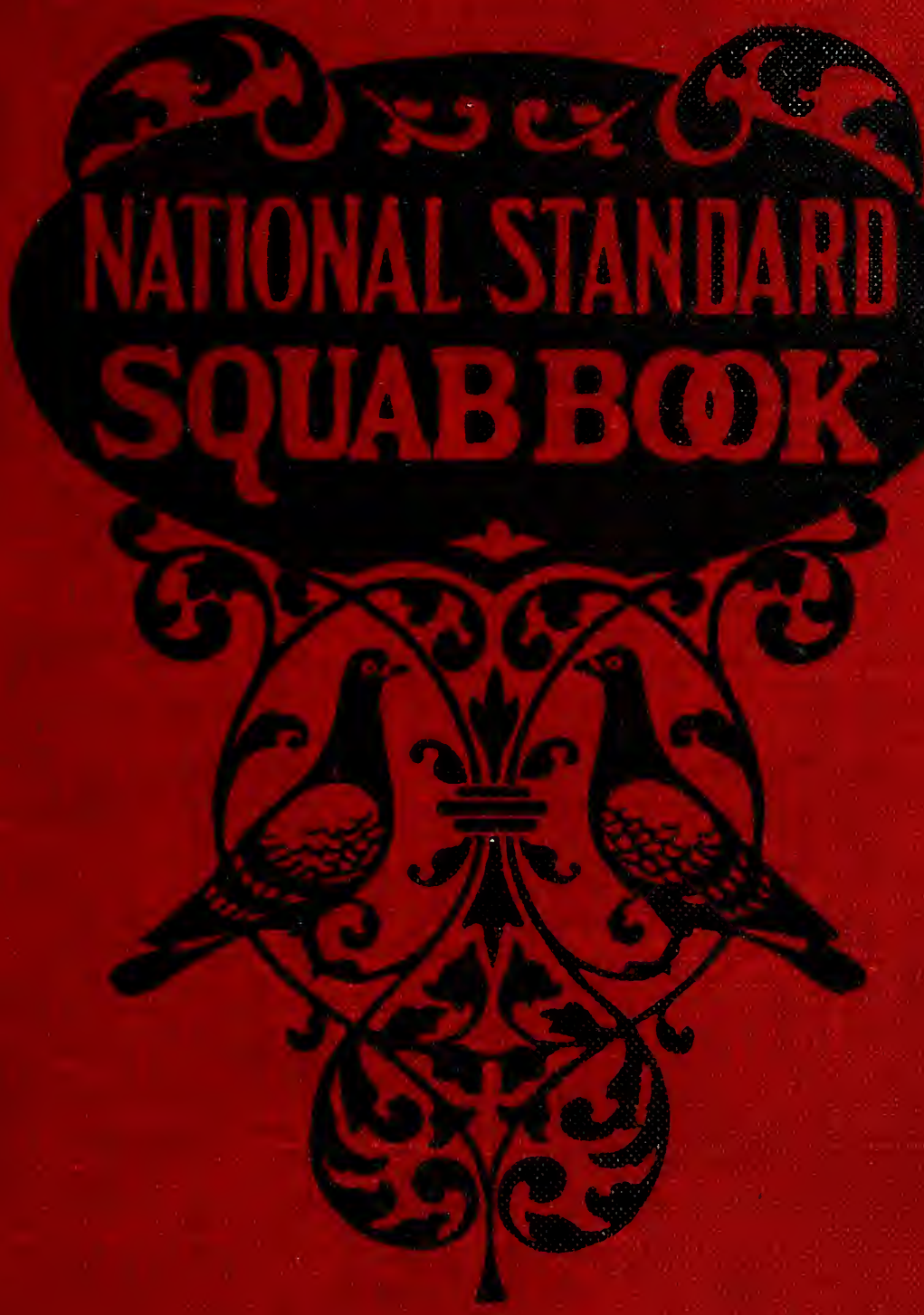

ELMER C.RICE. 


$$
\text { \% }
$$





\section{.}





\section{The National}

Standard Squab Book 




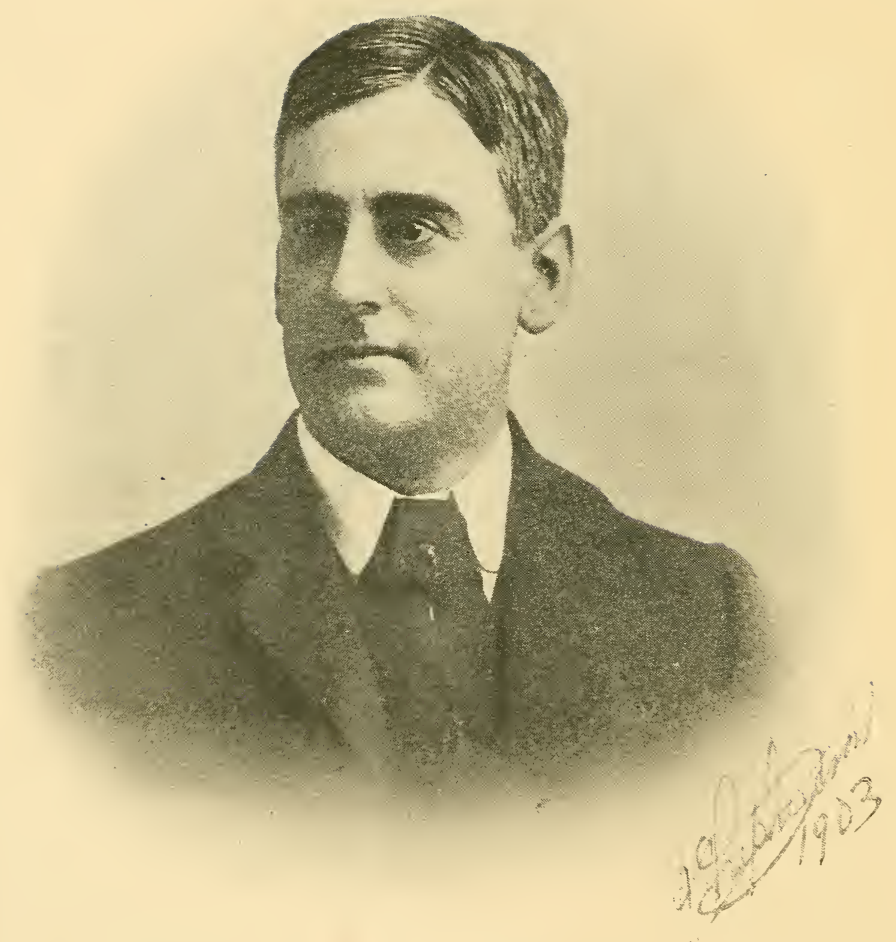

ELMER C. RICE. 


\section{The National \\ Standard Squab Book}

By Elmer C. Rice

A PRACTICAL MANUAL GIVING COMPLETE AND PRECISE DIRECTIONS FOR THE INSTALLATION AND MANAGEMENT OF A SUCCESSFUL SQUAB PLANT. FACTS FROM EXPERIENCES OF MANY

HOW TO MAKE A PIGEON AND SQUAB BUSINESS PAY, DETAILS OF BUILDING, BUYING, HABITS OF BIRDS, MATING, WATERING, FEEDING, KILLING, COOLING, MARKETING, SHIPPING, CURING AILMENTS, AND OTHER INFORMATION

Illustrated with New Sketches and Half Tone Plates from Photographs Specially Made for this Work 


\begin{tabular}{|c|}
\hline LIBRARY of CONGRESS \\
\hline $\begin{array}{l}\text { Two Coples Recelved } \\
\text { FEB \& } 1907\end{array}$ \\
\hline 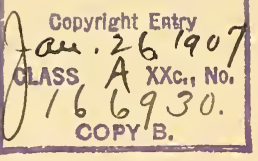 \\
\hline
\end{tabular}

Copyright 1901, by Elmer C, Rice Copyright, 1902, by Elmer C. Rice Copyright, 1903, by E.mer G. Rice Copyright, 1904, by Elfiter C. Rice Copyright, 1905 , by Elmer C. Rice Copyright, 1906, by Elmer C. Rice Copyright, 1907, by Elmer C. Rice

All rights reserved.

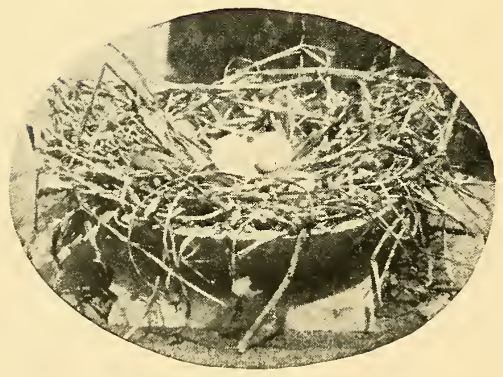

A WELL-BUILT NEST. 
Preface

Chapter I. Squabs Pay . . . . . . . 15

Chapter II. An Easy Start . • . • . . 21

Chapter III. The Unit House . . . • . 37

Chapter IV. Nest Bowls and Nests . . . . . 45

Chapter V. Water and Feed . . . . . . 51

Chapter VI. Laying and Hatching • • • • $\quad 63$

Chapter VII. Increase of Flock • . • • • . 75

Chapter VIII. Killing and Cooling . $\quad$ • $\quad$. 79

Chapter IX. The Markets . . . . . . 83

Chapter X. Pigeons' Ailments • • • . . . 89

Chapter XI. Getting Ahead . . . . . . 93

Chapter XII. Questions and Answers . . . . . 101

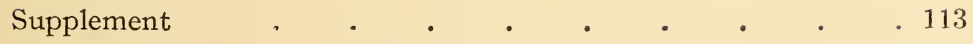

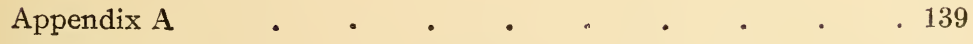

Appendix B $\quad . \quad$. $\quad . \quad$. . 153 


\section{ILLUSTRATIONS.}

Page

Portrait of the Author (Frontispiece)

A Well-Built Nest .

Thoroughbreds

How a Back Yard may be Fixed for Pigeons . . . . 18

Cheap but Practical Nest Boxes . . . . . . 22

How City Dwellers without Land may Breed Squabs _ . . 24

Unit Squab House (with Passageway) and Flying Pen . . 26

Nest Boxes Built of Lumber . . . . . . . 28

Best Nest Box Construction . . . . . . . 30

Interior of Squab House Showing Perches . . . . 32

A Pretty Squab House and Flying Pen . . . . . . 36

Multiple Unit House . $\quad . \quad$. $\quad . \quad$. $\quad . \quad$. $\quad .38$

Interior of Multiple Unit House . . . . . . . $\quad .40$

Multiple Unit House, Ten Units, Built according to Our Plans . 42

Nest Bowl, Bath Pan, Drinking Fountain, etc. . . . . 46

Berry Crate to Hold Nesting Material . . . . . . 50

Scenes on the $\$ 200,000$ Farm of One of Our Customers . . 58

Eggs in the Nest, Squabs Just Hatched . . . . . $\quad 64$

Squabs Ore Week Old, Squabs Two Weeks Old _ . . 66

Squabs Three weeks Old, Squabs Four weeks Old . $\quad . \quad 68$

The Mating Coop . . . . . . . 70

Pigeons in St. Mark's Square, Venice . . . . . . 74

Killing Squabs with the Hands . $\quad$. $\quad$. $\quad$. $\quad . \quad$. 80

Killed Squabs Hung to Cool . $\quad$. $\quad$. $\quad$. $\quad$. $\quad$. $\quad .82$

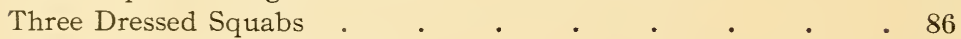

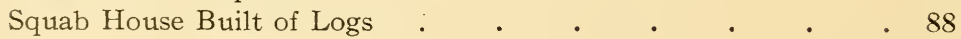

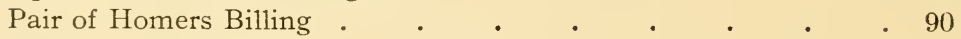

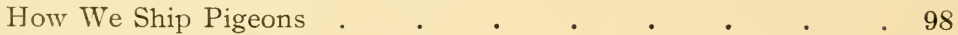

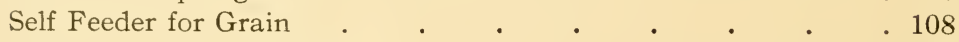

Machine for Killing Squabs . . . . . . . . . 114

Sprayer

Nest Boxes

Mating Coops in Mating House

Pigeons in Corner of Flying Pen 138

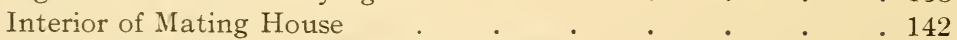

Part of South Side of One of Our Houses . . . . . 146

Dowel System of Feeding and Watering . . . . . 150

Pigeons Bathing . . . . . . . . . 152 


\section{PREFACE.}

This Manual or Handbook on Squabs is written to teach people, beginners mostly, not merely how to raise squabs, but how to conduct a squab and pigeon business successfully. We have found breeders of squabs who knew how to raise them fairly well and took pleasure in doing so, but were weak on the business end of the industry. The fancier, who raises animals because he likes their looks or their actions, or because he hopes to beat some other fancier at an exhibition, is not the man for whom we have written this book. We have developed Homer pigeons and the Homer pigeon industry solely because they are staples, and the squabs they produce are staples, salable in any market at a remunerative price. The success of squabs as we exploit them depends on their earning capacity. They are a matter of business. Our development of squabs is based on the fact that they are good eating, that people now are in the habit of asking for and eating them, that there is a large traffic in them which may be pushed to an enormous extent without weakening either the market or the price. If, as happens in this case, pigeons are a beautiful pet stock as well as money makers, so much the better, but we never would breed anything not useful, salable merely as pets. It is just as easy to pet a practical animal as an impractical animal, and much more satisfying.

This Manual is the latest and most comprehensive work we have done, giving the results of our experience as fully and accurately as we can present the subject. It is intended as an answer to the hundreds of letters we receive, and we have tried to cover every point which a beginner or an expert needs to know. It is a fault of writers of most guide books like this to leave out points which they think are too trivial, or " which everybody ought to know." It has been our experience in handling this subject and bringing it home to people that the little points are the ones on which they most quickly go astray, and on which they wish the fullest information. After they have a fair start, they are able to think out their operations for themselves. Accordingly we have covered 
every point in this book in simple language and if the details in some places appear too commonplace, remember that we have erred on the side of plainness.

The customers to whom we have sold breeding stock have been of great help to us in arranging and presenting these facts. We asked them to tell us just the points they wished covered, or covered more fully, or just where our writings were weak. They replied in a most kindly way, nearly every letter thanking us heartily, and brimming over with enthusiasm for the squab industry.

It has surprised a great many people to learn that Homer pigeons are such a staple and workable article. They have been handled by the old methods for years without their great utility being made plain. When we first learned about squabs, we were struck by the impressive fact that here was something which grew to market size in the incredible time of four weeks and then was marketed readily at a good profit. The spread of that knowledge will make money for you. Show your neighbors the birds you buy of us, tell them the facts, and perhaps give them a squab to eat, then you will find a quick call for all the live breeders you can supply.

The procedure which we advise in this National Standard Squab Book is safe and sound, demonstrated to be successful by hundreds of our customers, many of whom started with no knowledge except what we were able to give them by letter or word of mouth. We have abandoned all instruction which does not stand the test of time and locality, and give only facts of proven value, of real, practical experience.

Boston, August, 1902.

ELMER C. RICE.

\section{POSTSCRIPT.}

This work has met with so much favor during the past year, and has sold so largely in excess of expectations, that we wish to thank our friends everywhere for their cordial support. The Appendix A which appears at the back of this edition was added last February, and it is our intention to keep the work up to date by revisions and additions at least twice yearly, The proof of the pudding is in the eating, and the 
proof of these squab teachings is shown in the successes made by our thousands of customers with no other knowledge of squabs than this as a guide. Our correspondence, now having extended over a long period, shows conclusively that beginners find all questions answered in this book, and go forward confidently and surely to success.

Boston, August, 1903.

E. C. R.

\section{EDITION.}

The old plates of this book have been fairly worn out by much printing, so great has been the demand for it, especially during the past five years. The sales have been larger than for any other work on birds or animals ever written. For this 1907 edition, the whole book has been reset in new type, and new plates made.

The outlook for the squab industry during 1907 and the years to come is of high promise. More people are eating squabs than ever before and more people are raising them. At no time within our memory has the market been overstocked with squabs, and prices have kept up all along the line. Only yesterday we were visited by a gentleman and his niece from New York City who stated that they had priced squabs there December 31 and found them seven dollars and fifty cents a dozen. The dealers who offered them at this price had paid the breeders for them from four dollars to six dollars a dozen, according to their postal card quotations sent out in December.

We shall be pleased to hear from our friends after they have read this book, and welcome any suggestions for its improvement, or for the betterment of the squab industry. The author will gladly answer all such letters and advise fully as to location and construction of buildings, and management of breeding stock.

Boston, January, 1907. 


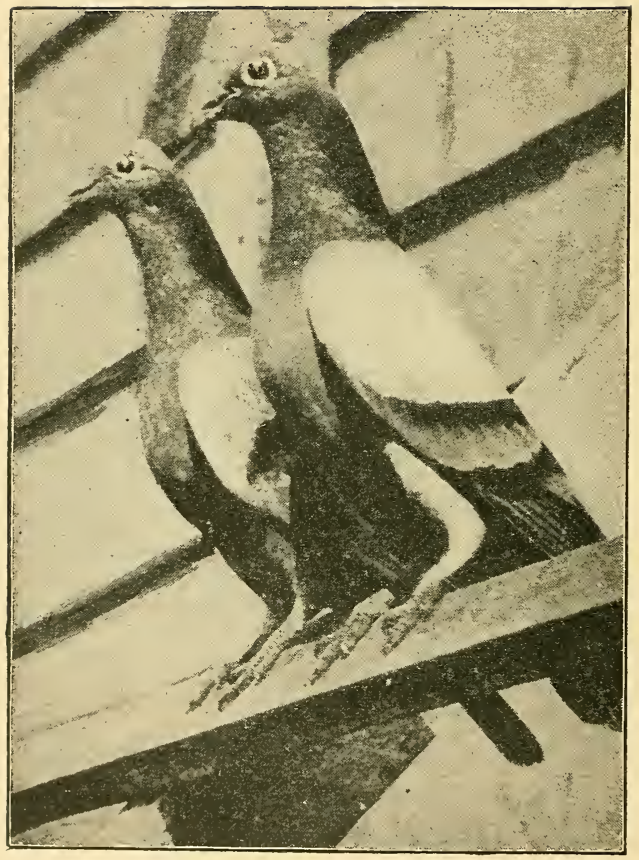

THOROUGHBREDS. 
SQUABS PAY.

Experience of a Customer who Started in January, 1902, Erected a Plant Worth Three Thousand Dollars and Made Money Almost from the Start-Settlements of Squab Breeders in Iowa, California, New Jersey and PennsylvaniaLarge Incomes Made from Pigeons-Squab Plants Known to be Making Money-The Hard-Working Farmer and the Easy-Working Squab Raiser-No Occupation for a DroneNo Exaggeration.

"Will it pay me to raise squabs?" is the first question which the beginner asks. We take the case of a man who bought a Manual in January, 1902. His boys had kept a few pigeons but had never handled them in a commercial way, nor tried to make any money with them. The reading of the book gave him the first real light on the squab industry. Possibly he was more ready to believe because he knew from his own personal experience that a squab grows to market size in four weeks and is then readily marketable. He started at once to build a squab house according to the directions given. The ground was too hard for him to get a pickaxe into, so he laid the foundation timbers on bricks, rushed the work ahead with the help of good carpenters and sent on his order for breeding stock. In the course of a few weeks he ordered a second lot of breeders, followed by a third and a fourth, and he kept adding new buildings. When spring came and the ground softened, he jacked up his first squab house, took out the bricks at the four corners and put in cedar posts. By the middle of July he had five handsome squab houses and flying pens, all built by skilled labor in the best possible style at a cost of at least three hundred dollars apiece. With his buildings and their fittings and his birds, his plant represented an expenditure of between two thousand and three thousand dollars.

This gentleman lives in a locality where he had to put up nicelooking buildings, or the neighbors would have complained. He spent probably three times more money on his buildings 
than the average beginner would spend. $\mathrm{He}$ is a superintendent of a large manufacturing plant, a man of push and energy, and he has four young boys in his family who have helped with the wife and grandfather to make the venture successful. It was a paying venture almost from the very start. Everything that we wrote about squabs as money makers came true in his case. One of the sons, a lad of nineteen, came on to see us the first summer and told us the story of their success. He was after more breeding stock. He said he had many calls from people who wished to buy stock of him, and he was unable to supply all of them, but he did not intend to have money offered him very long without being able to pass out the birds. In other words, they were going into squabs for all they were worth. They had not done any advertising, and had not sold live breeders to any extent, but figured their profits solely on the sale of squabs to commission houses, and they were getting for them just what we said the commission men would pay.

We have a great many visitors, some coming from remote points of the United States. One of our visitors in the summer of 1902 was Mr. A. L. Furlong, from a little town in Iowa. Mr. Furlong said to us: "Iowa is quite a squab breeding State. There are plants in Ruthven, Osage, Wallake and Estherville. The owner of a plant in Ruthven I know very well. He showed me his account books; he was shipping from seven hundred to eight hundred dollars worth of squabs last month. He is making a profit of three thousand to five thousand dollars a year. He ships to the Chicago market, as do nearly all the Iowa breeders. He never gets less than two dollars and fifty cents a dozen for his squabs. I am going to start raising squabs myself.'

Mr. Furlong left an order for one of our Manuals, having given his first one to his friend. He said that his friend was breeding common pigeons and would like to know our methods. We discarded common pigeons some time ago. If our Iowa friends will use Homer pigeons instead of common ones, they will produce a much better squab and make more money.

We had a curious confirmation of the above in August, 1902, when Mr. E. H. Grice, who lives in the northern part of Vermont, visited us. Mr. Grice had just returned from a visit to the West, and stopped for a while at Ruthven, Iowa, where 
he saw the plant above noted. The proprietor referred Mr. Grice to us and advised him to start with Homer pigeons, saying that, if he were to stock up again, it would be with Homer instead of the common pigeons. Before leaving, Mr. Grice gave us an order for one hundred pairs of our Homers. The number of orders for breeding stock which we have received from Iowa is out of proportion to any State near it, showing that these squab plants are known throughout Iowa to be making money. The same is true of California. We visited many squab breeders in eastern States in June, 1902, noting the buildings and methods and finding out from them if they were satisfied with the financial returns. All were enthusiastic and said it was easy work, that squabs beat hens easily and were much less care. The methods of some of these breeders were extremely crude, the birds nesting in old boxes of all sizes nailed to the walls of the squab houses, and apparently never being cleaned. The Homers were small, not being able to raise squabs weighing over seven pounds to the dozen.

Somebody has said that a squab plant of one thousand pairs of birds will pay better than a farm. The contrast between the hard, grinding toil of the man who works a large farm and the "standing around " of the owner of a squab plant is indeed a striking one. However, we do not speak of this to give you the idea that money is going to flow into your lap just because you buy some squab breeders of us. It is no work for a drone or a " get-rich-quick" person whose enthusiasm runs riot for two weeks and then cools off. Our class of trade is men and women of experience and reliable common sense who have a knowledge of the world and understand that things come by work and not for the asking. The people who are able and willing to pay us from fifty to five hundred dollars for a breeding outfit, as hundreds do, are not caught by glittering promises, but have money laid by through exercise of the qualities of ability and shrewdness. The naturally careless, improvident person, who is generally in debt, should not start squab raising. It is a sensible industry for sensible people.

The profits to be made with squabs vary with the individual and with the management of the birds, exactly as with poultry. It is important to have only mated or even pairs in the pens and all birds not producing should be kept in a separate 


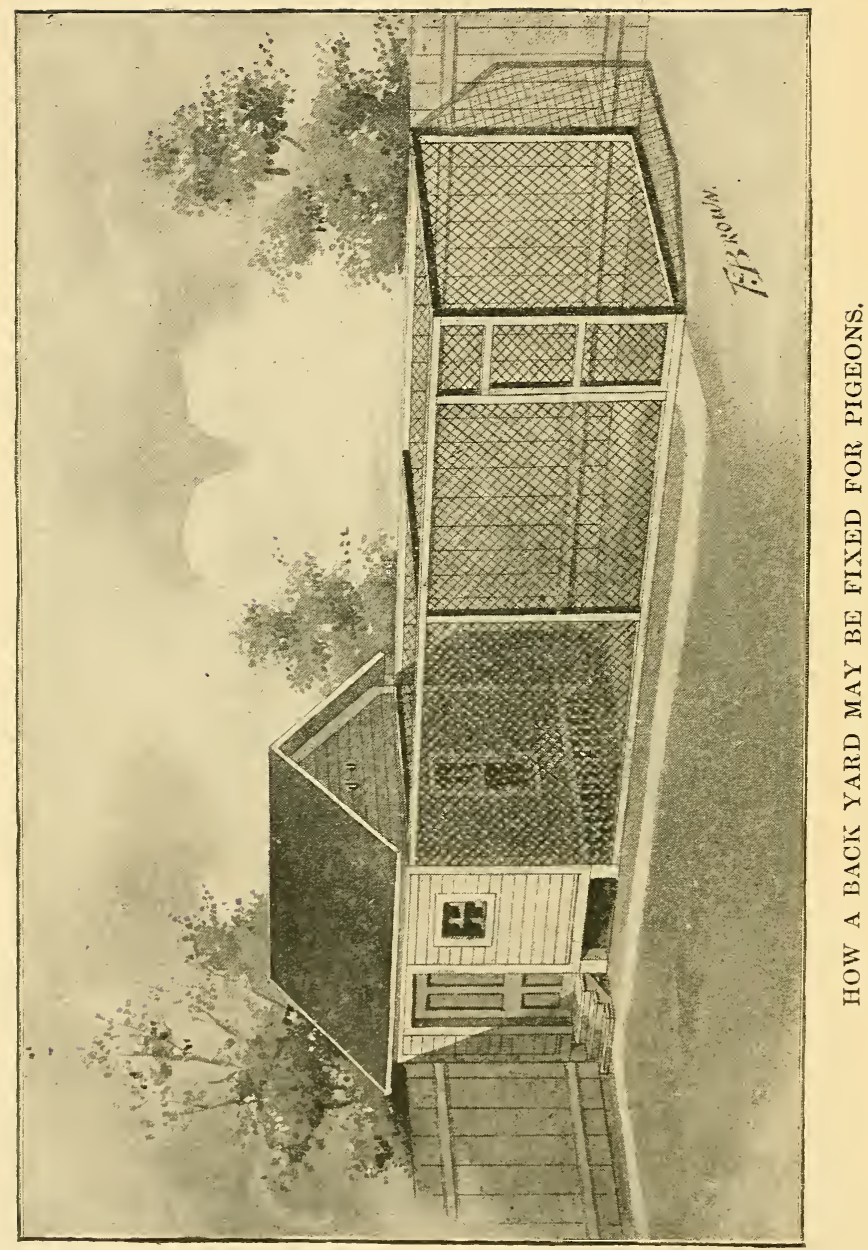


pen and removed to breeding quarters only after they have gone to work. The chief difficulty with a beginner is the matter of sex. The male and the female pigeon have no marks to distinguish them, and the beginner must determine their sex by observation. He must study his birds and come to know them. Some beginners will not equip themselves by study and observation to make a success and may breed in a hap-hazard fashion for a year or more without knowing the sex of the birds they raise. Birds which you raise will go to work more quickly, look better and breed better than any birds you can buy, because that is the temperament of the Homer, to be attached to his home, to love it, and to try to reach it if he can. Anybody who has doubts as to his ability to raise squabs should start with a small flock and breed up until he has acquired skill and experience.

As part of this Manual, in the supplement and appendices, we print many letters from customers who started with small flocks and won striking successes. It is not necessary to get a fancy price for the squabs to make the business a success. In confirmation of this we have in mind the work of two of our customers, young men named Lunn, who have received only two dollars to three dollars a dozen for their squabs, selling to dealers who retail them for four dollars to six dollars a dozen. These brothers have told their story in one of the poultry papers as follows:

"In February, 1905, we got the idea of going into the squab business. We spent some time looking around and in March, 1905 , we bought what we thought was the best stock, namely, the Extra Plymouth Rock Homers. We bought twelve pairs. The birds arrived on March 22, 1905, and were as fine a looking lot of birds as we had seen anywhere. We now (December, 1906) have three hundred pairs. One hundred and fifty pairs are well mated and working. The other one hundred and fifty pairs are all young birds. We raised all our young birds up until September, 1906, and since then have been selling squabs weighing from nine and one-quarter to ten and one-half pounds and receive twenty-three and twenty-five cents each. We feed the best of grain, using cracked corn, kaffir corn, red wheat, buckwheat and peas and a little hemp. We also give a little rice once or twice a week. During the moulting season we added barley to regular 
rations, which was a great help to the birds all that time. We use the self-feeder as described by Mr. Rice in his Manual and we find with it the grain is always clean. We have made the feeding question one of the most important of all and find that the best results are obtained by keeping plenty of grain and good clean drinking water before the birds at all times. The drinking fountains used are automatic and are scalded once each week. About once a week we give a teaspoonful of gentian to a gallon of water. We keep fresh water in the flying pens for bathing purpose at all times during the summer, and in the winter we allow our birds to bathe twice a week at noontime. One thing that is very essential with pigeons is to be kept clean. Our houses and nests are cleaned every week and we also spray the floors, nests and walk with a liquid disinfectant. We have never been troubled with lice, vermin or any disease of any kind. For nesting material we use tobacco stems, cutting them into pieces of about six inches, which we consider the best material for the purpose, and also a safeguard against lice. We feel satisfied with what our birds are doing and have done in the past, so well satisfied, in fact, that we have now under construction buildings that will accommodate nearly one thousand pairs of birds. And the cost of keeping or feeding will not exceed one dollar. a year per pair, so that squabs selling from two dollars to. three dollars per dozen are sure to leave a good profit."

Looking at the financial showing of the Lunn boys, made in twenty-two months, we find that starting with twelve pairs, for which they paid us thirty dollars, they raised three hundred pairs, worth at the same rate seven hundred and fifty dollars. From this must be deducted the grain which they bought in that period. They start the new year with a fine plant capable of earning a big percentage of profit on its valuation. 


\section{CHAPTER II.}

\section{AN EASY START.}

No Special Form of Building Necessary-Points to Remember - Shelter Adapted to the Climate-How to Use a Building which you Now Have-Squab House and Flying PenLining the Squab House with Nests-Use of Egg CratesHow to Put up the Perches-Difference between the Nest Box, Nest Pan and Nest-How to Tell How Many Pigeons can Occupy a Certain Building-A Large Flock of Pigeons is Easily Cared for when Split up into Small FlocksHow to Use Your Time to Best Advantage.

Do not get the idea that any special form of building is necessary to raise squabs. We will tell you how to put up a structure that will make your work easier for you, and enable you to handle a big flock fast and accurately, but pigeons will work in almost any place, if it is free from rats, darkness and the musty dampness which goes with darkness. Any building, whether a woodshed, a corn crib, a barn, an outhouse of any description, or even a hog pen, can be made a successful home for pigeons with a little work.

The points to remember are these, first, that the building be on fairly level, sunny ground; second, that it be raised from the ground so that rats cannot breed under it out of sight and reach; third, that it ought to be fairly tight, so as to keep out rain and excessive cold. Pigeons ought to have sunlight and fresh air, like any other animal, and need protection from the elements.

In practice, therefore, most squab houses are found raised on posts a foot or two feet off the ground; they face the south (here in New England) because most of our bitter weather comes from the north and east. If you live in a State, territory or foreign country where conditions are different, adapt your squab houses to those conditions. In some localities, the fierce weather comes from the south and west, in which case your squab house should face the north or east.

Here in New England we build a tight house to withstand 


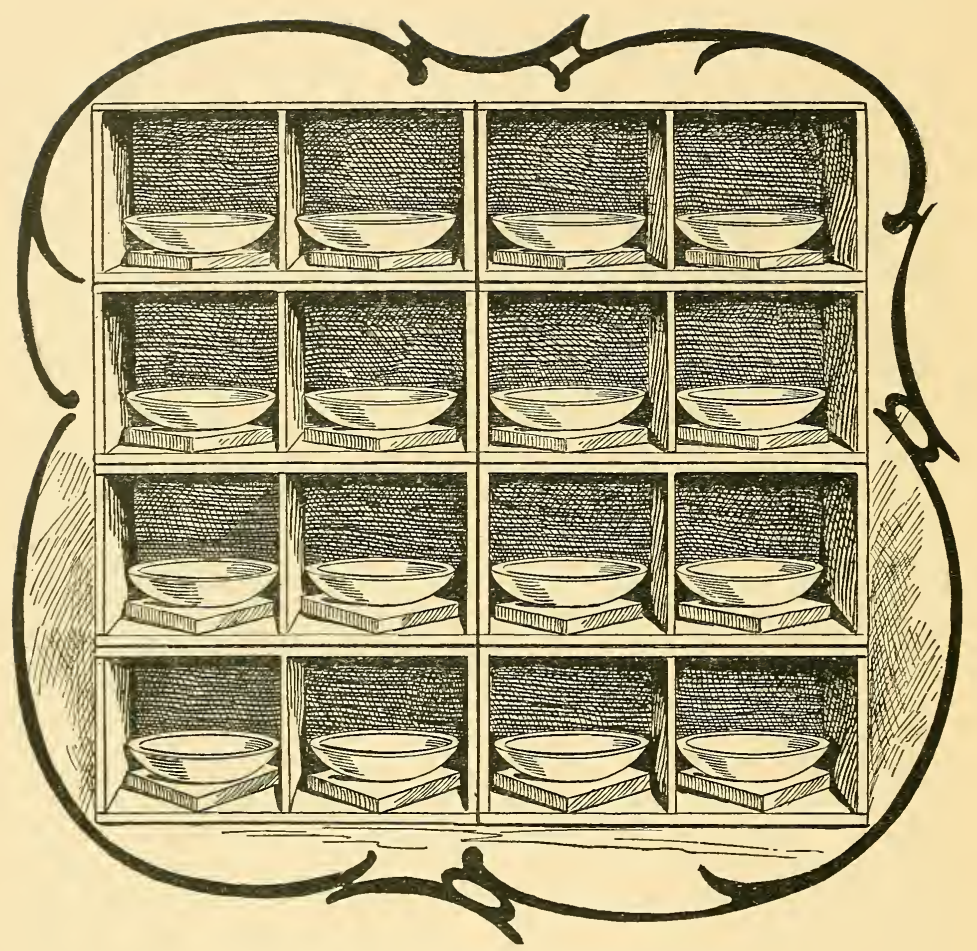

CHEAP BUT PRACTICAL NEST BOXES.

These are empty egg crates piled one atop another from floor to roof of squab house. Each egg crate is two feet long, one foot wide and one foot deep. The partition in the middle makes two nest boxes, each one foot square. Into each of these nest boxes a wood nest bowl is placed. The birds build their nests in these wood nest bowls. 
the cold winters, but in the South the buildings are more open. Be guided by what you see around you in the place where you live. If the houses used by your friends and neighbors for hens and chickens are tight and warm, make your squab house tight and warm. It would be foolish for you, for example, if you live in Texas, to build a strong, tight, close squab house, for in that latitude, in a henhouse built tight and close, vermin would swarm and harass the chicks, and they would harass the squabs just as fast.

Some of our customers write from places like Oregon and Idaho, where there is a wet and a dry season, and are puzzled to know what to do. In such cases we say, arrange your buildings as you see poultry houses arranged. The pigeons will do as well under the same conditions as hens and chickens.

Suppose you have a vacant building or shack of any kind in which you wish to raise squabs. We will take for granted that it has either a flat roof or a ridgepole with sloping roof, and that it is built in rectangular form. Never mind what the dimensions are; our advice will apply to either the large or the small structure.

First raise it off the ground, or build a new floor off the ground, so that rats cannot breed out of your sight in the darkness and get up into the squab house. If there is an old floor, patch up all the holes in it. Now you need one door, to get yourself in and out of the squab house, and you need at least one window through which the pigeons can fly from the squab house into the flying pen and back from the flying pen into the house. You will shut this window on cold nights, or on cold winter days. You must cover the whole window with wire netting so that the birds cannot break the panes of glass by flying against them. If you have no wire netting over the window, some of the birds, when it is closed, will not figure out for themselves that the glass stops their progress, but will bang against the panes at full speed, sometimes hurting their heads and dazing them and at other times breaking the glass.

The flying pen which you will build on the window side of the squab house may be as small or as large as you have room. The idea of it is not to give the birds an opportunity for long flight, but simply to get them out into the open air and sunlight. They enjoy the sun very much, it does them good 


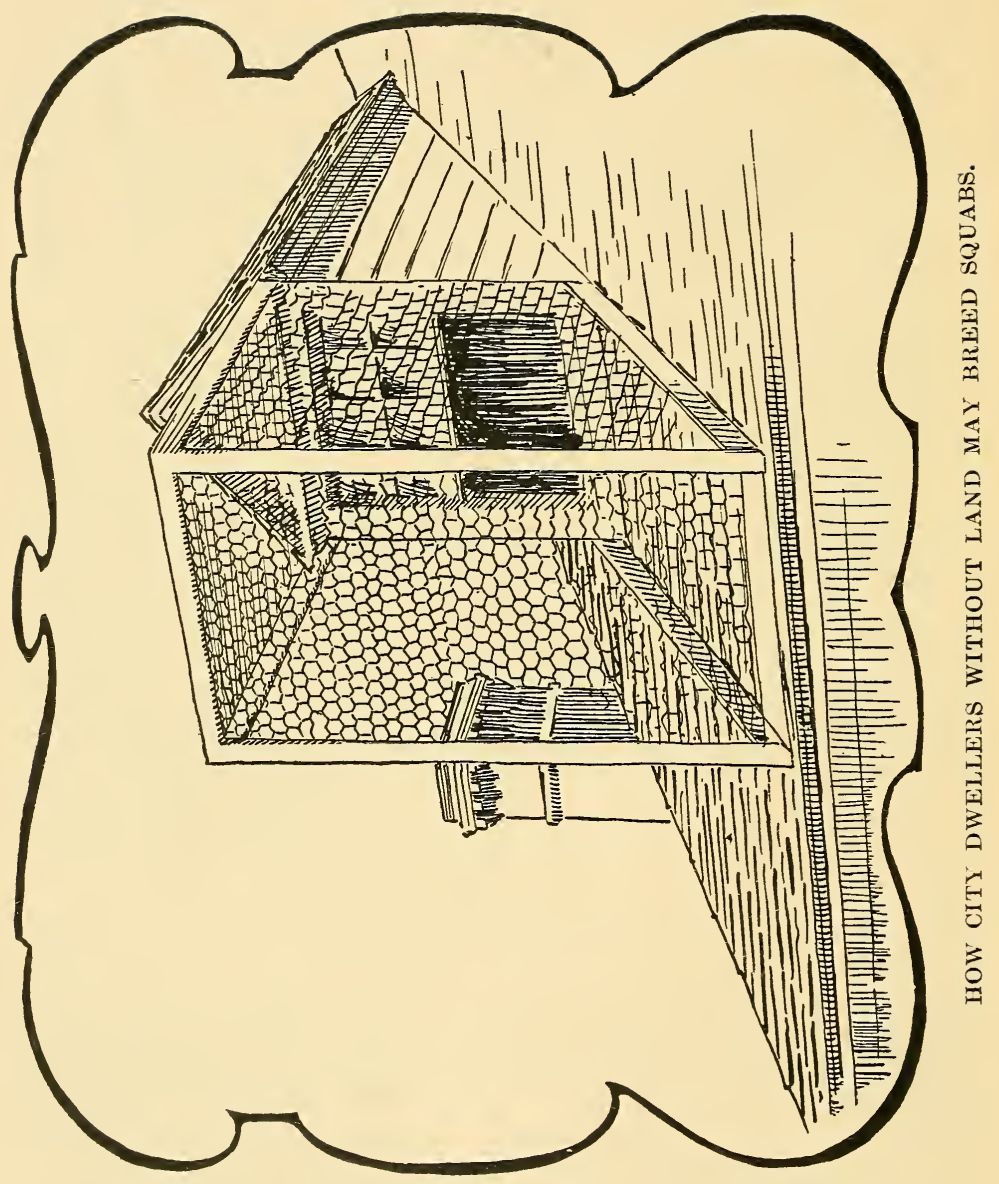


and they court its direct rays all the time. Build the flying pen, if you choose, up over the roof, so the birds may sun themselves there. If that side of the roof which faces the flying pen is too steep for the pigeons to get a foothold, nail footholds along the roof, same as carpenters use when they are shingling a roof, and the pigeons will rest on these to sun themselves. For the flying pen you want the ordinary poultry netting, either of one-inch or two-inch mesh. The two-inch mesh is almost invariably used by squab raisers, because it is very much cheaper than the one-inch mesh. The one-inch mesh is used only by squab raisers who are afraid that small birds (the English sparrows here in New England) will steal through the large meshes of the two-inch netting and eat the grain which you have bought for the pigeons. You can buy this wire netting in rolls of any width from one foot up to six feet. If your flying pen is twelve feet high, you should use rolls of the six-foot wire. If it is ten feet high, rolls which are five feet wide are what you want. If your flying pen is to be eight feet high, buy rolls which are four feet wide. In joining one width of wire netting to its neighbor, in constructing your flying pen, do not cut small pieces of tie wire and tie them together, for that takes too much time and is a bungling job, but buy a coil of No. 18 or 20 iron wire and weave this from one selvage to another of your wire netting in and out of the meshes, and you have the best joint.

You can line the three walls of the interior of your squab house with nest boxes if you choose. The fourth wall is the one in which the window or windows are. On this fourth wall you should not have nest boxes, but perches. These perches, or roosts, should be tacked up about fifteen inches apart, so as to give the birds room without interfering with one another. The advantage of the $\mathrm{V}$-shaped roost which we advise is that a bird perched on it cannot soil the bird underneath. Do not buy the patent pigeon roosts which you see advertised, for a pigeon roosting on one will soil the pigeon roosting on the one immediately below.

Please note particularly at this point the following terms which we use, and do not become confused. The nest box is something in which rests the nest bowl in which the nest is built. Do not speak or think of nests when you mean nest boxes. 


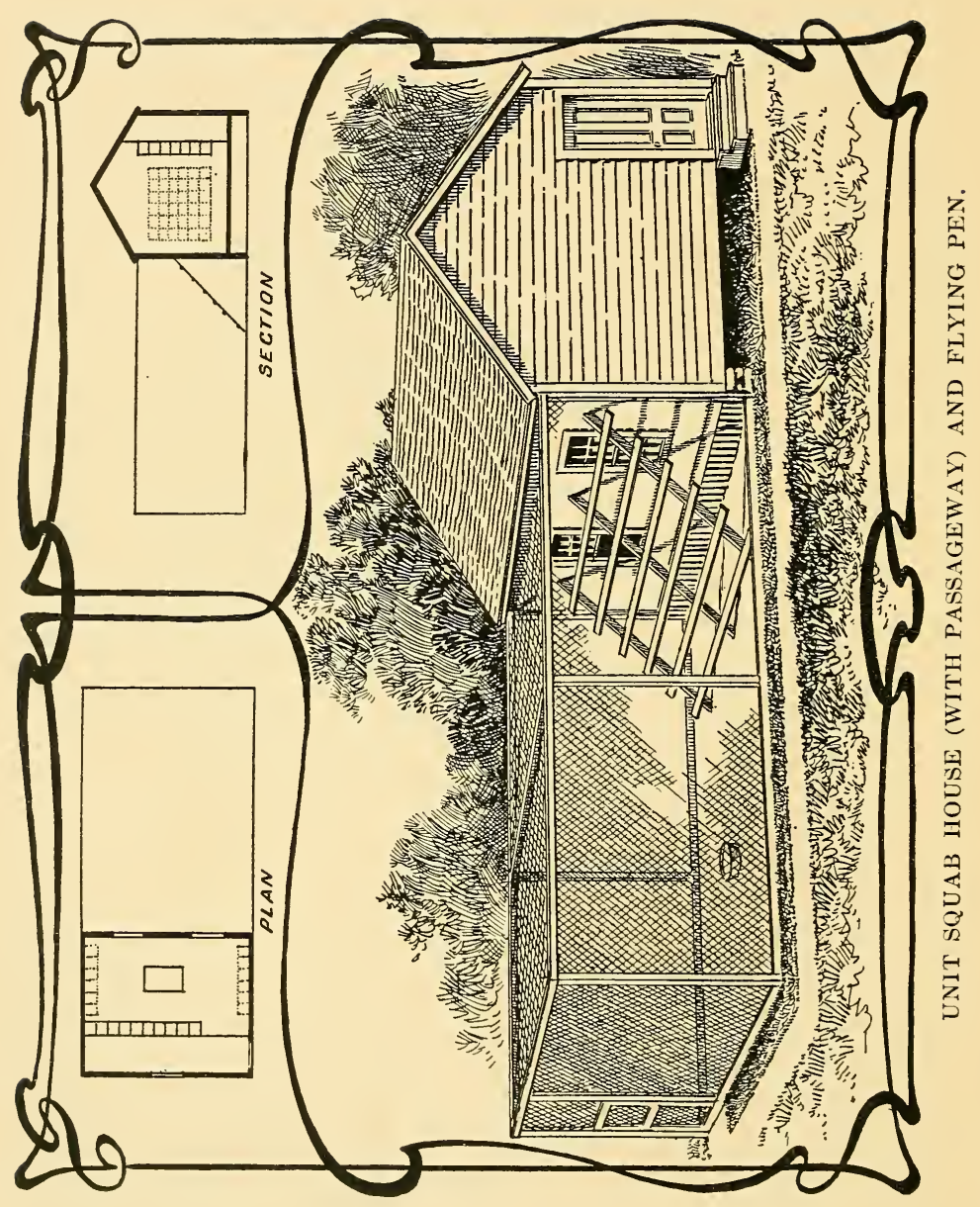


The nest boxes, when done, should look like the pigeon-holes of a desk, and should be about one foot high, one foot wide and one foot deep. A variation either way of an inch or two will not matter.

One way to get these pigeon-holes is to build them of nice pine lumber, in the form of boxing one-half or five-eighths of an inch thick. Another way is to use hemlock or spruce boards one inch thick. The third way (which we think is the best for the beginner who wishes to start most cheaply and quickly) is to use egg crates, or orange boxes. These egg crates are two feet long, one foot wide and one foot deep, but they are divided in the middle by a partition, giving two spaces, each of a cubic foot, and this is just what the squab raiser wants. They are procurable almost anywhere in the United States and Canada new for ten or fifteen cents each, and if you buy them after the egg shippers are through with them, you can get them for three to five cents apiece. Some grocers will be glad to have you carry them away and will charge you nothing for them. The crates are built of thin, tough wood and usually are neat and solid. Take off the covers and throw the covers away,-you do not need them. Then put one egg crate on its side, open top out, place another egg crate on top of that, and so on until you have covered the three walls of your squab house from the floor to the roof. Do not use any nails, they are not necessary: the crates will keep in position by their weight. It is an advantage, also, to have them loose, for when you clean the nests, you can step up on a chair or box, take down the crates, commencing with the top, and clean each one with your feet on the floor. If you build a substantial set of nest boxes of boxing or hemlock lumber, you will have to stand on a chair and strain your arms in order to clean the top nest boxes, so you see there are points in the low-priced arrangement not possessed by the fancy kind. It is on the same principle by which a humble small boy with bent pin and worms and an old pole catches more fish than the city angler with a twentyfive dollar assortment of hooks, lines and artificial flies. It is the pigeons and the intelligence behind them which do the trick, every time. A fancy pigeon house with fancy trimmings cannot produce any better squabs than the home-made affair, provided the birds are the same in both cases. 


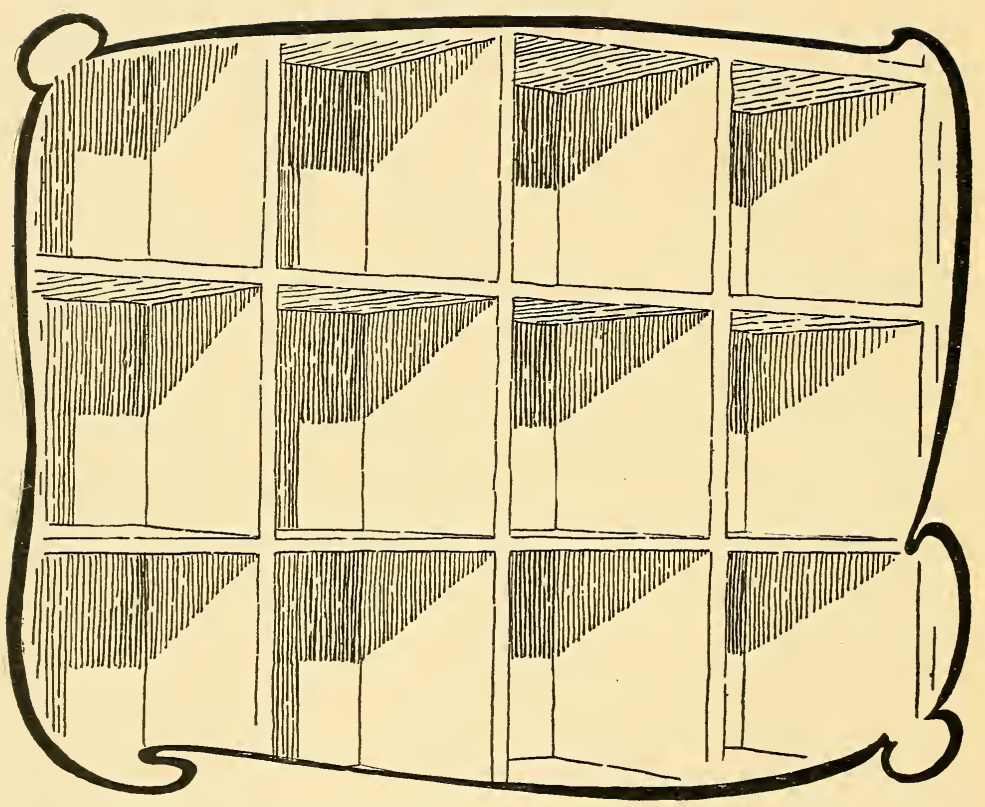

NEST BOXES BUILT OF LUMBER. This shows the front of the nest boxes as they face the interior of the squab
house. They are from ten to twelve inches square, and the same distance deep. A slight variation does not matter. The fronts of the nest boxes are perfectly plain. falling out. It not necessary to nail up pieces of board to keep the squabs from 
You should have a pair of nest boxes for a pair of pigeons. By a pair of pigeons we mean two pigeons, a male and a female. By a pair of nest boxes we mean two nest boxes. We find that the word pair has a different meaning to people in different parts of the country, perhaps on the same principle that a pair of scissors or a pair of suspenders is one object, while a pair of something else, as in this case, means two objects. A pair of pigeons attend to a pair of squabs in one nest box, nevertheless for each pair of pigeons you need two nest boxes, for when the squabs are about two weeks old in one nest, the old birds will go to the adjoining nest box, or to a nest box in a distant part of the squab house, and begin housekeeping again, laying eggs and dividing their attention between the two families.

Count your nest boxes and you will know how many pigeons your house will accommodate. If your count shows ninety-six nest boxes (in other words, forty-eight pairs of nest boxes), you can accommodate (in theory) forty-eight pairs of pigeons. It is important to remember this: Never. fill a house with pigeons to the uttermost limit of its capacity, as shown by count of nest boxes. If you have, for example, forty-eight pairs of nest boxes, do not put into that house more than thirty to forty pairs of pigeons. That will leave plenty of nest boxes for the birds to choose from. We have found by experience that thirty or thirty-five pairs in a ninety-six nest-box house will accomplish more than more pairs in the same space.

Do not write us and tell us that you have a house of a certain size and ask us to tell you how many pairs of pigeons it will accommodate. Put in your nest boxes as we have described and then count them, and you will know. Or you may figure it out for yourself on paper, allowing two nest boxes, each one cubic foot in size, for each pair of birds. To put it in another way, you should allow one cubic foot of nest box space for each breeding pigeon. Surely we have made this so plain now that you cannot go astray.

Perhaps your start will be made with so small a number of birds that you will not have to cover more than one wall of your squab house with nest boxes. Cover one wall, or two walls, or three walls, whichever the occasion demands. Have a lot of spare boxes, and let the breeding pairs choose where 


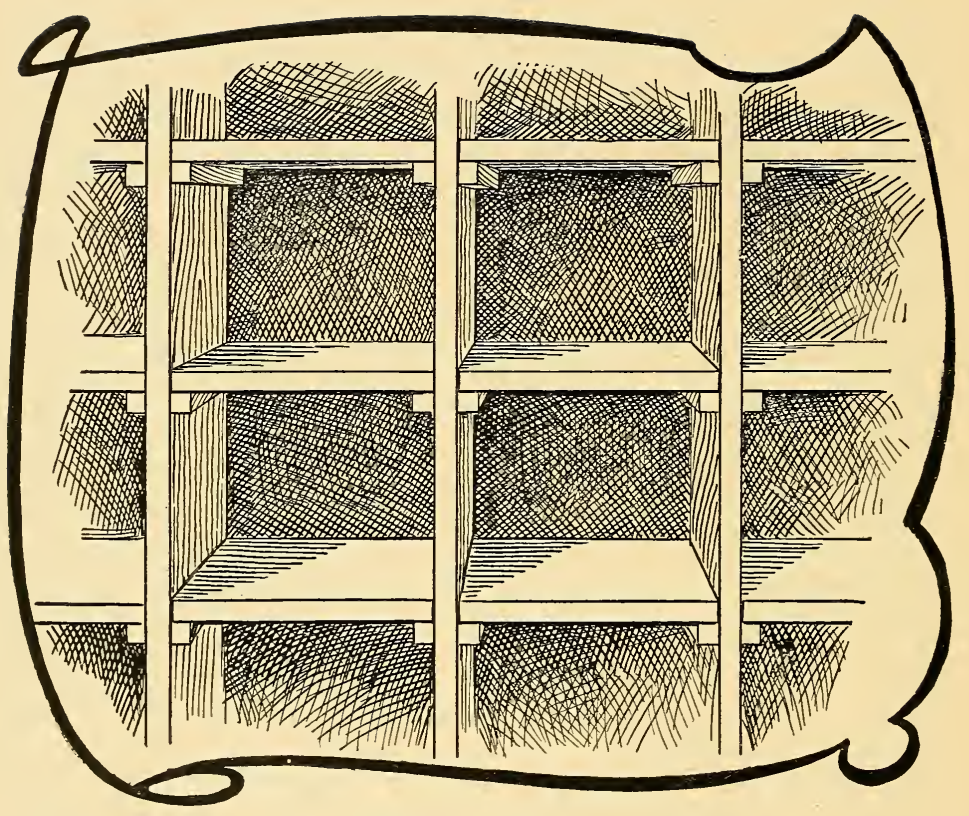

BEST NEST BOX CONSTRUCTION.

When the nest boxes are built of lumber (one-half an inch or five-eighths of an inch thick) the above construction should be employed. The bottoms are not nailed, but slide in on cleats. as shown. The result is a sliding shelf. This shelf may be pulled out at cleaning time and a better and quicker job of cleaning done.

The nest bowls may be screwed directly to the bottoms of the above nest boxes. If that is done. it will not be necessary to screw the nest bowls to blocks of wood, to give them stability.

The nest boxes should be from ten inches to twelve inches square. 
they will. An extra number of nest boxes may be useful to you to accommodate the young birds raised to breeding age from the old birds which you buy of us, if you intend to raise your squabs to breeding age.

An expenditure of not over five dollars, and a couple of days' time, will transform the average old building into a habitation for squabs. Put on the finishing touches and add to the expense to suit your fancy. You may cover the outside of the building with building paper, and shingle or clapboard it. You may put a skylight in the roof for ventilation, Improve it all you wish. Use your own judgment.

To get at your pigeons in such a house, you walk in through the door and find yourself directly among them, the nest boxes all pointing at you. Go to the nest which you wish to investigate or from which you wish to take out the squabs and put your hand in the opening. The old birds will fly by your head, perhaps, and may strike you with their wings, but they will not fly into your face and eyes,- they are good dodgers. Don't be afraid that if you enter the house when the housekeeping is going on you will frighten the birds so they never will come back to the eggs or the squabs. They will seem timid at first, but they will get accustomed to you.

In the course of a few weeks, only a few will make a great hustle to get away from you. Many of them will continue to sit contentedly on the eggs and if you put up your hand to them they will not fly off in fear but will slap you with their wings, telling you in their language not to bother them. Carry some hempseed in with you and you will teach the birds to come and eat it out of your hand. You can tame them and teach them to love you as any animal is taught. The pigeon, particularly the Homer, the king of them all, is a knowing bird.

Tack up a few perches where you have room on that wall or those walls of the squab house which have no nest boxes. You do not need a perch for every pigeon, because while some are on perches, others are in the nests, or out in the flying pen, or on the roof, or on the floor of the squab house. If you have forty-eight pigeons, twenty perches will be enough, and you can get along with a dozen. Make each perch of two pieces of board, one six inches square, the other six inches by five, and toe-nail the perch to the wall of the squab house 


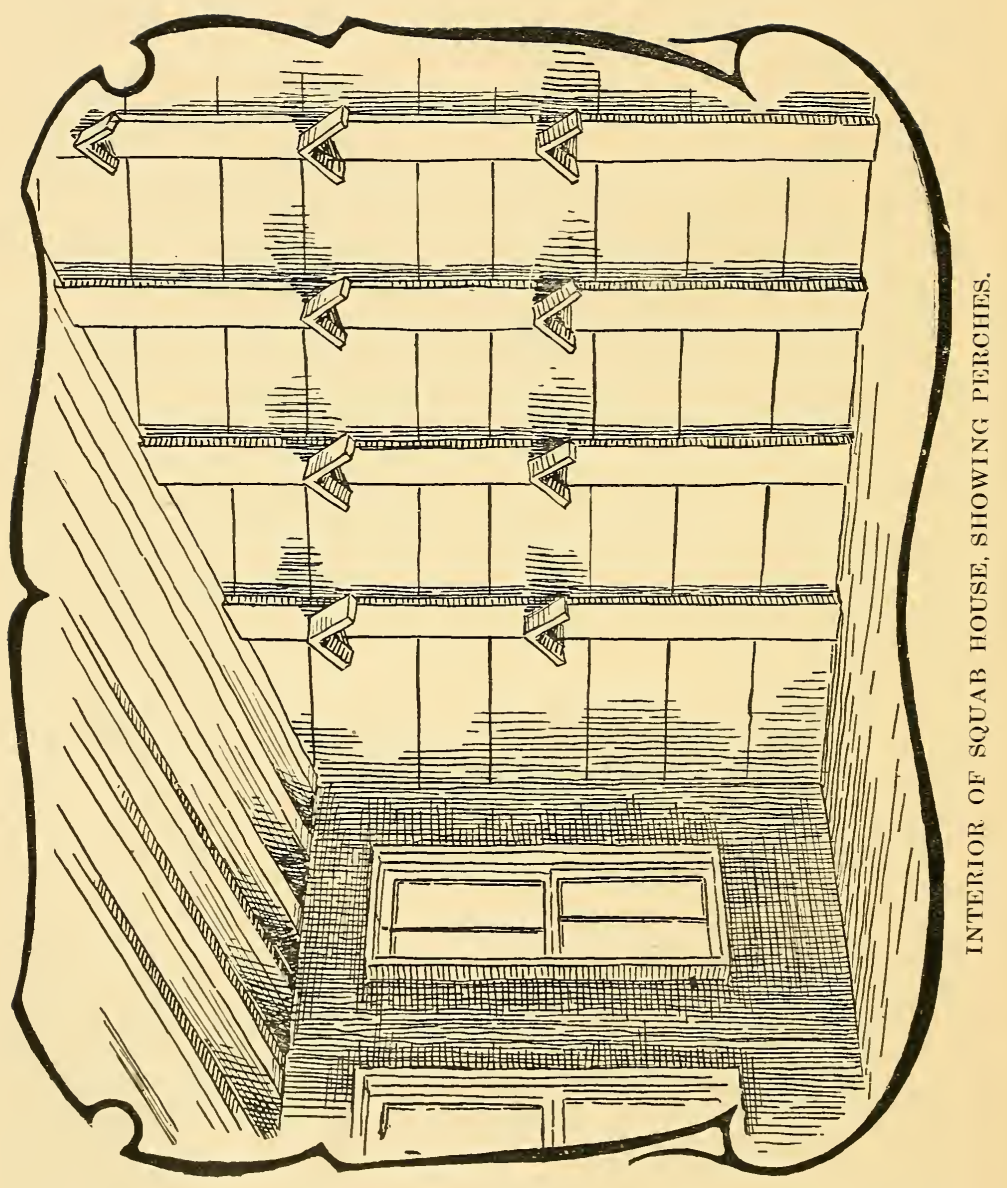


as shown in the illustration. You cannot have one long pole inside the squab house for a pigeon perch. If you had such a pole, and your pigeons were perched on it, or some of them were, a bully cock would saunter down the line and push off all the others.

In the centre of the squab house you place an empty crate or overturned box. The object of this is to break the force of the wind made by the pigeons' wings as they fly in and out of the squab house. Otherwise the floor of the squab house would be swept clean by the force of the wind. It also forms a roosting-place for the birds, and, finally, it is a convenient resting-place for the straw, hay, grass or pine needles out of which the pigeons build their nests.

The floor of the squab house should be kept clean. We formerly advised that a layer of sand or sawdust half an inch thick be kept on the floor of the squab house, to absorb the droppings, but we have found a steady and profitable demand for pigeon manure, and this manure is worth scraping up and carefully saving, for its sale will pay from one-quarter to one-third of the grain bill. Use an ice chisel to scrape the droppings from the floor, and pack the manure away in barrels or bags. Clean the floor about once in three weeks, or oftener, depending on the size of your flock. Pigeon manure is in active demand all the time by tanneries. We send the manure from our pigeons by freight to tanneries in Lowell, Lynn, Peabody and Danvers, and are paid for it at the rate of sixty cents a bushel.

We have a building eighty feet long built especially for the drying and storing of the manure. During the years we have been in the squab business, we have sold enough pigeon man ure to pay for nearly all the pigeon buildings on our farm. Some pigeon raisers with crude methods know nothing of the value of the manure and lose this by-product. They either ruin it by putting sand or sawdust on the floor of the squab house, or else waste it on their gardens. The pure manure is too valuable for home use. To fertilize our flower and vegetable gardens, and hay field, we scrape up from the flying pens, outdoors, the gravel which has become saturated with manure. It is surprising what an increase in vegetation this manure-soaked gravel will cause. Fresh gravel is put down in the flying pens. 
A peculiarity about pigeon manure is that it is not foulsmelling like hen manure, and when it is mixed with water you get a kind of crude soap. In washing the old-style earthenware nest bowls, no soap was necessary. We used warm water in washing them and the manure caked to them formed a cleansing soap in conjunction with the water. If you have a basket in which you have transported pigeons, and whose bottom is caked with the hard droppings, lay the basket face down and sprinkle water liberally on the underside. The manure will drop off in large pieces from the inside and the basket will become perfectly clean.

In raising live-stock of any kind, arrange matters so the animals will look after themselves as much as possible. Aim to cut down the factor of personal drudgery, so as to leave your time clear to observe, plan, and execute intelligently. Beginners who load themselves down with a daily round of exacting duties soon lose heart, their patience gives out and they become disgusted. We have known breeders of rabbits to fail simply because they raised them in hutches. Each hutch had a door and two dishes, one for feed, the other for water. Every day, the door of the hutch had to be opened, the hutch cleaned, the dishes refilled (and often cleaned), and the door closed. It took fifteen or twenty motions to do this for each hutch. Multiply this by twenty to thirty (the number of the hutches), and the burden grew unbearable. It was not surprising that in three or four months the breeder's patience was worn out. The factor of personal drudgery had become greater than the rabbits. The thoughtful breeder would have turned his rabbits into two or three enclosures on the ground and let them shift for themselves. Then one set of motions in feeding would have answered for all, and there would have been no dirt to clean up. Infinite patience as well as skill is required to make a success of animals given individual attention. The aim of every breeder should be to make one minute of his time serve the greatest possible number of animals. When you think and reason for yourself, you understand how much more practical it is to give sixty animals one minute of your time than one animal one minute. Time is money and if you are too particular, and too fussy. and thoughtless about these details, it is a clear case of the chances being sixty to one against you. 
At the start, the problem of breeding squabs for market is in your favor, because one hundred pairs of breeding pigeons may be handled as easily and as rapidly as one pair. Try to keep this numerical advantage in your favor all the time. Discard every plan that cuts down the efficiency of your own labor, and adopt every device that will give you control in the same time over a greater number of pigeons.

It takes brains and skilled labor to run a poultry plant successfully. Every poultryman knows that he cannot entrust the regulation of temperatures of incubators and brooders to an ignorant hired man, but even a boy or girl, or under-the-average farm hand, knows enough to fill up the bath pans and feeding troughs for squab-breeders, leaving the time of the owner free for correspondence and the more skilful work.

The primary object is to breed squabs for market as cheaply, as easily and as fast as possible, without the expenditure of a dollar for fanciful or impractical appurtenances.

Do not think it is necessary to heat your squab house. A squab house which has the chill of dampness taken off it by hot water or steam pipes will raise more squabs than a house not heated, but a flock of pigeons in a small house throw off considerable heat from their bodies and will breed in cold weather all right. After you have developed your plant and have a large business which you wish to keep at the highest state of efficiency, you may heat your squab house. The idea of heat in winter time is to keep the birds more contented and get more squabs out of them, and not at all to keep them alive. Do not be afraid that your pigeons will freeze to death. We have many customers in Canada. In coldest weather, the old birds hover the squabs more carefully.

City people can keep pigeons in the garret of a house, or the loft of a barn, without a foot of ground being needed. In such a case the flying pen, or place to which the pigeons go for sun and air, can be built out on a platform. The illustration (page 24) shows how to utilize a window of a garret. If you think that rats will trouble you in either a garret or barn loft, cover the floor inside, especially the corners, with fine wire netting through which it will be impossible for the rats to gnaw from below.

One of our customers in Illinois, a rich horse breeder having 
a barn some two hundred feet long, turned the whole upper story into a loft for pigeons. The flying pen takes in the whole back of the barn. There are windows and no doors on this side of the barn, the horses using doors on the other side, so this leaves the upper story of the barn, and its whole back-yard, free for the pigeons.

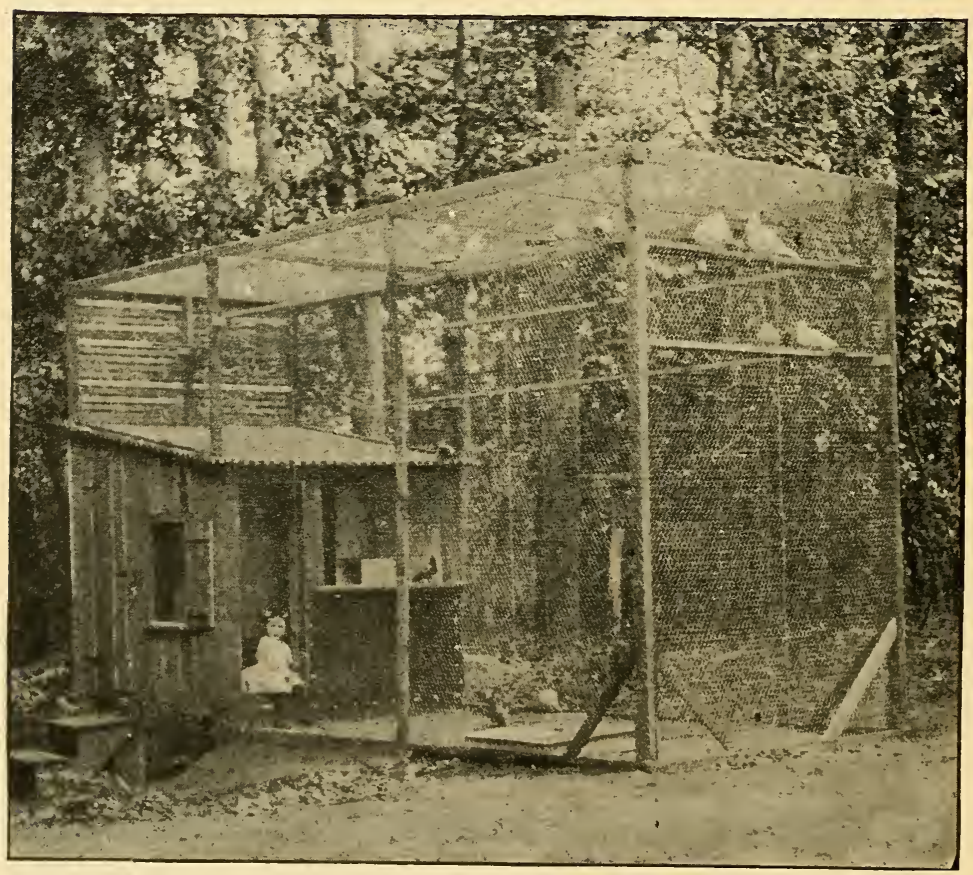

A PRETTY SQUAB HOUSE AND FLYING PEN. 


\section{CHAPTER III.}

\section{THE UNIT HOUSE.}

Best Possible Construction for a Squab Plant-The WindBreak Formation of Roof - Dimensions of the Unit Multiplying the Unit to Increase the Capacity of Your Plant - A Passageway behind the Nest Boxes - Numbering the Nest Boxes, and the Management of a Card Index to Correspond-Cost of the Unit Construction is from Three Dollars to Five Doilars a Running Foot - Working Drawings - The Nest Bowls.

If you have no building already standing which you can fix over for pigeons, you may erect a simple rectangular structure and line it with nest boxes as we have described in the last chapter. We will tell you in this chapter how to put up the finest kind of a pigeon structure. It is at the same time the most expensive. It is the best, the most workmanlike. In saying that it is expensive, we do not mean that money is thrown away on its construction, for that is not so. It is a fit habitation for a money-making investment.

This best method of construction results in what we call the unit house. You can multiply this unit as many times as you please and get as large a house as you wish, or you may add a unit from time to time, just as you add unit bookcases to accommodate the growth of the modern library shelves. You can erect these units separately, or attach one unit to the other so that you have one long building.

The nest boxes are built of boxing and set in a vertical row at the back of the house, forming a wall between which and the north side of the house is a three-foot passageway. You can buy this boxing at a saw-mill all cut, ten by eleven inches, the dimensions of the nest, and if you get it in this shape you can put the boxes together with as much ease as a child builds a doll's house. You will have no doubts as to the squareness and plumbness of the structure when you have it up. Take long lengths of boxing eleven inches wide for the shelving which should form the top and bottom of the nest boxes, then set the ten-inch by eleven-inch pieces the proper distance 


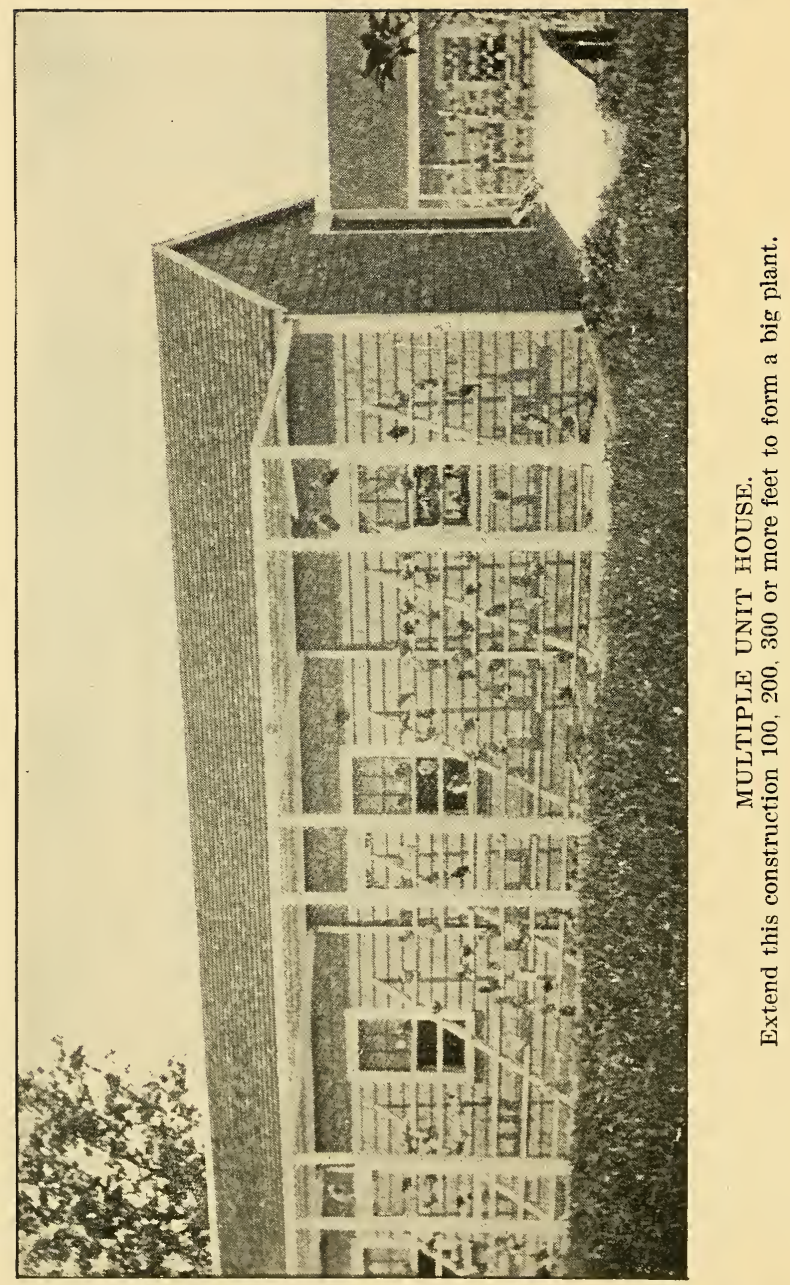


apart. The finished nest will be eleven inches from front to back, ten inches from top to bottom, and about ten inches from one partition to the other (or whatever distance the proper distribution of your nests in pairs permits).

We have found five-eighths-inch boxing to be the best suited. Build the nest boxes up from floor to roof perfectly plain, just as the pigeon-holes of a desk run.

The nest boxes should be perfectly plain, made of simple boxing in the manner described. Do not build up a piece of boxing at the front part of the nest to prevent the nest bowl from being pushed out. Early in our experience we built nests in this way, but soon changed them over to the simpler form, on account of the difficulty of keeping them clean. The droppings bank up at the front of such a nest box.

Pigeons, especially a new flock in a new home, breed best in a house which is somewhat dark, and not too glaring with light. If your window is situated so as to let in a flood of light, you will get better and quicker results by shading it so that the interior will be dim. Some breeders advocate that the nest boxes have fronts of wood (removable) so that the nest box will be darkened. The same result will be accomplished if the window of the house is shaded so as to temper the light and prevent it from streaming into the nest boxes.

The dimensions of this unit squab house are as follows: Length, sixteen feet; width, twelve feet; length of flying pen from end of house to end of yard, twenty feet; distance from floor of squab house to ridgepole, twelve feet; two windows in south wall of squab house, each two feet two inches wide and three feet ten inches high. One window in north wall of squab house, two feet two inches wide and three feet ten inches high. There is a passageway on the north side of the squab house three feet wide, separating the north wall from the vertical row of nest boxes. The door of the squab house opens into this passageway so that you can enter the house without being seen by the birds, and without disturbing them.

If you wish, you can set up rows of nest boxes on the east and west walls of the squab house and accommodate more pairs. You cannot have a passageway behind these nest boxes on the east and west walls, but will approach them from the front by entering the interior of the squab house through a wire door which leads from the passageway. 


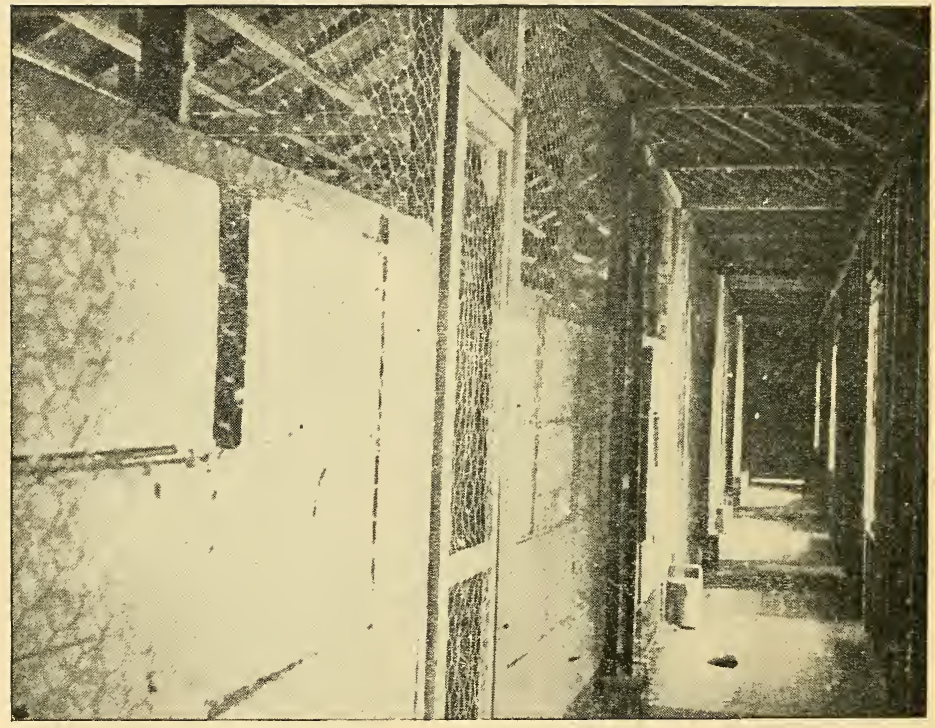

\section{INTERIOR OF MULTIPLE UNIT HOUSE.}

This is one of our houses. The drinking fountains stand in the passageway and their fronts project through the wire netting under the first row of nest boxes. 'The nest boxes are empty egg crates. The feed troughs are inside of each pen. In other houses, we set the feed troughs alongside the drinkers in the alleyway and cut away the netting so the birds can feed from them. We like the last arrangement best because the troughs can be filled more quickly from the passageway, and the time of opening and closing doors and going into pens is saved. 
Build the first unit so that you can extend it either to the east or west (as your land lies) to increase your accommodations. Your squab house will always remain sixteen feet from north to south, but it may be either twelve feet from east to west, for one unit, or twenty-four feet for two units, or thirty-six feet for three units, and so on. Of course you can build one long house sixteen feet wide and in length any multiple of twelve, and keep all the birds you wish in it, but we do not advise such an arrangement. You can keep track of your pairs better if you split a big flock up into unit flocks.

Fanciers breeding flying Homers from our birds, or squabraisers who wish to keep track of every pair of birds, can provide a card index (the cards being perfectly blank and three by five inches in size), number the cards to correspond with the nest boxes, and on these cards keep a record of what the birds in the nest boxes do. These cards, which are blank except for the numbers they bear, can be kept in a tray such as the manufacturers of card indexes advertise in the back pages of the magazines and you can pick out any card you wish, or turn to it, at once. It is much better than keeping a record in a book, for you cannot tear out the leaves of a book, as you can throw away a card, nor can you shift one page from one location to another, as you can a card in a tray.

The floor of the squab house rests on cedar posts and is two feet from the ground. The floor is built of two thicknesses of board, with building paper between. The walls of the squab house are built of boards which are covered with building paper and shingled. The roof is shingled. You can use clapboards on the sides, or common boards.

The cost of such a squab house, complete with flying pen and all inside fittings, built in the best possible manner, will be from three dollars to five dollars a running foot. That is to say, a unit plant twelve feet long will cost from thirty-six to sixty dollars. A plant consisting of three units, thirty-six feet long, will cost from one hundred and eight to one hundred and fifty dollars. We publish and sell for ten cents working drawings showing just how to build a unit in every detail. On the same sheet are working drawings for building a simple squab house (without passageway) to cost from fifteen to twenty-five dollars. Also on the same sheet we give data showing how one of our friends built a 


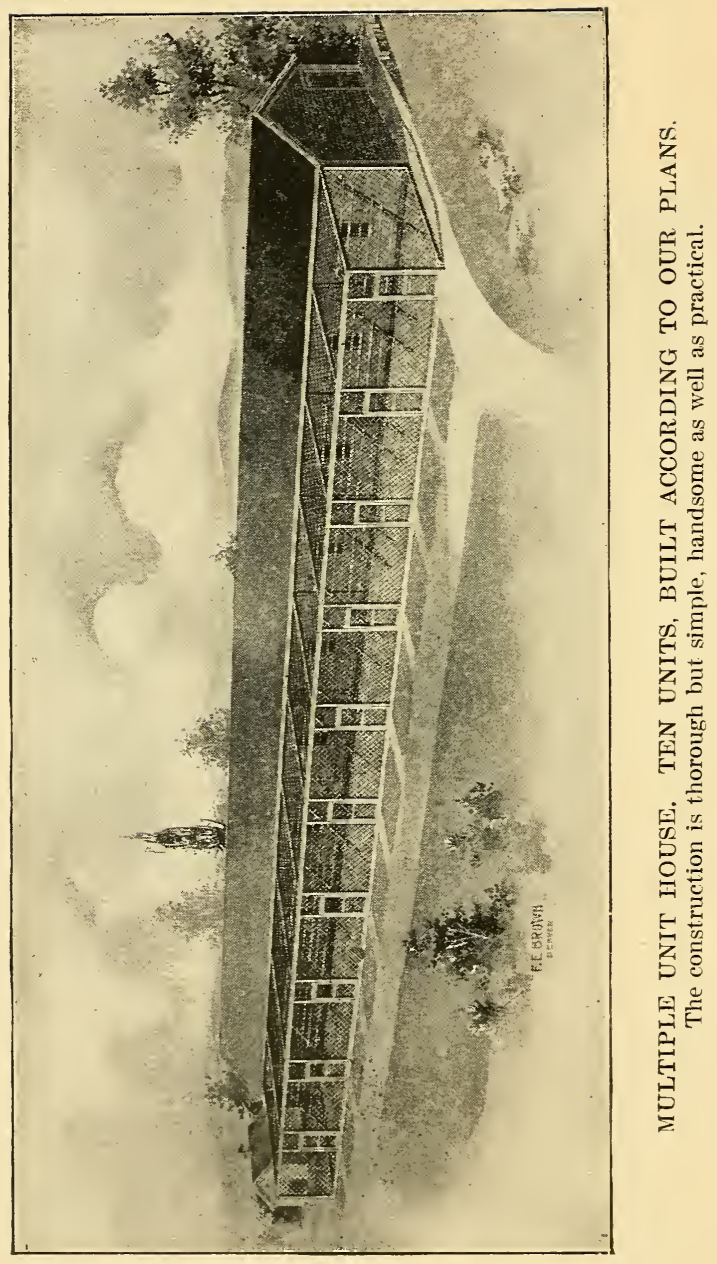


squab house and pen capable of accommodating two hundred and twenty pairs of breeders at a cost of one hundred and thirty dollars. In ordering, simply say you wish plans and specifications for squab houses.

Some beginners with plenty of means and anxious for the best construction write us to ask if a cement floor is not better than a wood floor. A cement floor is positively wrong, for this reason: when it is freshly laid, it is good, but the first winter causes the dirt foundation to shrink and swell, then come cracks in the cement. Rats and mice burrow in the dirt up to the cement and find their way through the cracks to the squabs. In a short time, they are a nuisance. We have seen a squab house built with cement floor which cracked as described and every time the owner and his doy took a walk down the alleyway, they found rats to kill. Finally the whole lot of cement had to be pounded to pieces, shoveled up and carted off. The way to stop rats and mice is to erect the building on posts as we have described. Rats and mice live in the dirt and they cannot get up into the squab house. Let your dog or cat every day under such a house, between the flooring and the ground, and they will keep down the vermin as fast as they show themselves, and your squabs never will be troubled.

In our early plans for the unit squab house, we provided for a building with a "jog" in the roof, making a long, low slope for the south side of the roof, and on this slope the birds would sun themselves and make love. This "jog" construction is more expensive than is needed, and now we have a better way. We have an ordinary pitch roof, sloping equally from the ridgepole to both north and south. We run the flying pen out on the south side, not from the ridgepole, but from the eaves, and then out in the tiving pen we erect perches as shown in the picture. The fact that the birds rest easily on these perches (as the photograph in Appendix A shows) is proof that they are contented and pleased by such an arrangement. We have found, too, that they can hear the squeaks of their young for food better than if they are up on the roof, and better attention to the squabs is the result. It was formerly thought unsafe to erect perching poles in the flying pen directly in front of the windows, the fear being that birds darting suddenly out of the windows 
would strike the perching poles and become injured. Such a fear goes on the assumption that a pigeon cannot take care of itself in flight. They are quick of eye and quick of wing, and are intelligent to a high degree, and we never knew a bird to be injured by flying against horizontal perches in the flying pen. They never strike them but always fly between them or alight on them.

Please note particularly that if you erect one ${ }^{1}$ ong building which will be a multiple of units, you separate these units, both inside and outside of the squab house, not by board partitions, but by wire partitions. For instance, if you have a building one hundred feet long, ten units, you will separate the units by nine wire partitions, these partitions being erected both inside and outside the house. 


\section{CHAPTER IV.}

\section{NEST BOWLS AND NESTS.}

Do Not Use the Old-Fashioned Nest. Pans-Obvious Faults of the Earthenware Nappy-The Wood-Fibre Nest Bowl - How the Pigeons Choose Nest Boxes-What to Use for Nesting Material-How the Birds Manage their Nests.

For nest pans, do not use the heavy, deep, red clay, unglazed dishes which you may see offered for sale as pigeon nests. They are a relic of the past.

In our early experience we used for a pigeon nest bowl che common kitchen yellow earthenware nappy. We employed two sizes, the six-inch and the seven-inch, changing from the large one to the small one when the squabs were two weeks old. These earthenware nappies filled the bill in being cheap and shallow, and the pigeons deposited their manure in a circle outside and not inside the nest, but they have faults which are obvious. They are flat and not rounding on the bottom. When the female pigeon turns the eggs (as she does daily, same as a hen, in order to give the heat of her body to the whole shell and to give fresh albumen to the germ) the eggs are liable to roll apart, making it necessary for the bird to gather them together again, and after two or three mishaps like this she is liable to desert them. The earthenware is cold, breakable and can be kept clean only with water. The washing of the nappies becomes a tedious -task and is often negleeted. "In winter weather, the earthẻnware dishes become so cold that one's fingers are numbed by handling them-and the squabs which sit in them are numbed, even frozen.

Later we perfected a nest bowl made of wood which met every objection raised against earthenware. We sold thousands of them during the two years we had them on the market and they gave good satisfaction except when some were made of improperly seasoned lumber, in which case they would crack and split after a few months' use. After study and experiment to remove this objection, we had expensive patterns and moulds made and began the manufacture of 


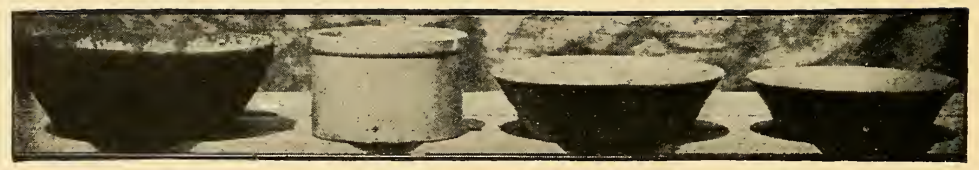

OLD-STYLE NEST PAN. WATER DISH. LARGE NAPPY. SMALL NAPPY. Do not use either the old-style pigeon nest pan or open water dish.

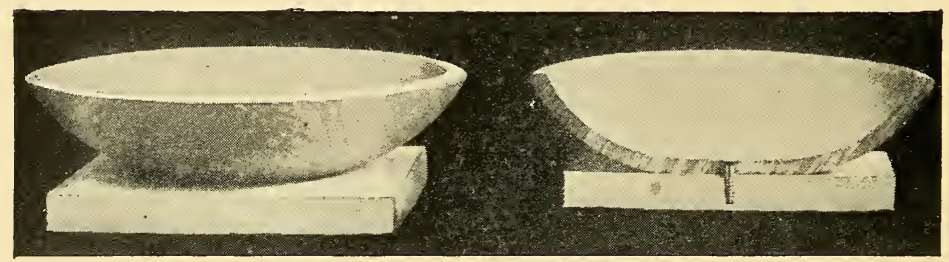

THE WOOD-FIBRE NEST BOWL.

This is made in one size (nine inches diameter of bowl). To give stability, the bowl may be fastened to a base by one screw. The first picture shows the perspective view; the second picture shows one-half cut away. This is the most practical nest pan for squab raising and is having an enormous sale. The bowl may be screwed directly to the bottom of the nest box. (See page 48.)

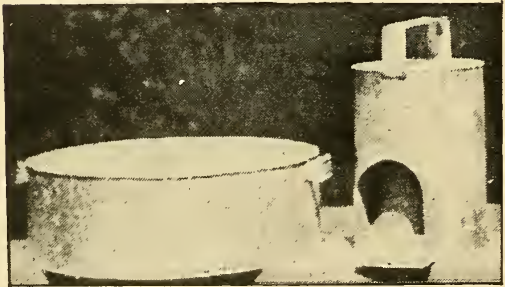

BATH PAN AND DRINKER.

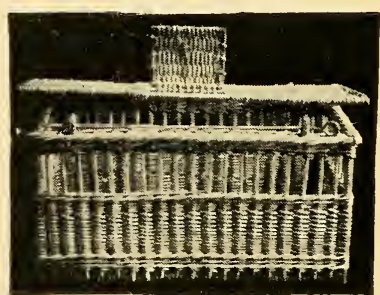

HAND BASKET.

One bath pan to every twelve pairs of birds is necessary. The hand basket (price $\$ 3.50$ ) is used in large plants to carry the squabs from the nests to the killing place. The squabs should not be killed in sight of the parent birds. 
these bowls out of wood fibre. Their success was quickly demonstrated and now we sell nothing else. These woodfibre nest bowls have all the advantages of the wood bowls and at the same time are practically indestructible, cannot warp or split. The wood fibre of which they are made is thick and exceedingly tough, being solidified under many tons' pressure. After making they are treated with an odorless, anti-moisture compound and then baked to flintlike hardness. We sell these wood fibre nest bowls in one size only, nine inches in diameter. Price, eight cents each, ninety-six cents per dozen, eleven dollars and fifty-two cents per gross. We make prompt shipment from Boston same day order is received, in any quantity. No order is filled for less than one dozen. We have the exclusive manufacture and sale of these goods and they cannot be obtained elsewhere.

The advantages of this nest pan are these: (1) The eggs roll to the centre and are always close together under the birds. (2) It is warmer than earthenware and eggs are not chilled. (3) It is cleaned without water by means of a trowel, and may then be whitewashed, if desired. (4) The claws of the old birds and squabs do not sprawl, and no cases of deformed legs in the squabs are found. (5) It is unbreakable. When shipped either short or long distances, no packing is necessary, they are lighter and the freight bill is smaller. (7) And finally the birds " take" to them more readily than to earthenware, getting to work more quickly and producing more squabs.

We make this wood fibre nest bowl in only one size as specified and illustrated (two sizes are not necessary because the feet of the squabs do not sprawl as in the case of the earthenware nappies). You will need one pair of nest bowls for every pair of pigeons (in other words, one nest bowl to every pigeon). If you order twenty-four pairs of breeders you will need forty-eight nest bowls. If you order ninety-six pairs of breeders you will need one hundred and ninety-two nest bowls.

We know our birds will breed more successfully in these nest bowls than in earthenware, and to make it an object for you to buy them, you may deduct the freight charges on nest bowls from your order for birds. First order your nest bowls sent by freight, then when you order your breeders, 
send us your freight receipt and count the amount as cash. Or you may order your birds at the same time you do the nest bowls (and other supplies) and when you get your freight receipt send it to us. Orders for one dozen to four dozen bowls should go by express with the birds (tied to the basket), unless it is desired to have the bowls go with grain, grit, shells, etc., by freight.

Place one nest bowl in each one of your nest boxes. Let the pairs choose to suit themselves. At the end of the month, when you take out the squabs, take out the nest bowl, clean it and put it back.

Many customers who do not use egg crates or orange boxes, but build their nest boxes of half-inch or five-eighths lumber, have written us that they used the construction which we illustrate on page 30 , and which is good, because cleaning can be better done. The bottoms of the nest boxes are removable and rest on cleats, as the picture shows. The cleats are seven-eighths or one inch square and are nailed to the uprights. When this construction is employed, it is not necessary that you have a block or base screwed to our wood-fibre nest bowl. The nest bowl may be screwed directly onto this removable bottom. If you use egg crates or solid-built nest boxes, you will have to give the wood-fibre nest bowl stability by screwing it to a base of wood seven inches square and about three-quarters of an inch thick.

When the squab house is ready for the birds, each of the nest boxes has one of these nest bowls. The pigeons build their own nests in them, taking the nesting material and flying to the nest bowl with it. The average nest has from one to two inches of straw compactly and prettily laid by the birds. Some birds use more nesting material than others. After the squabs are hatched, they quickly show that Nature never intended them to have a dirty nest. When they wish to make manure, they back up to the edge of the nest and "shoot" outward and over the edge of the nest bowl into the nest box, which is just where the breeder wants to find it. In a week or two there will be a circle of solid manure in the nest box, but it is out of the nest, and off and away from the feet of the squabs. As the squabs grow older, their claws tread and throw out the straw on which they were hatched, and the nest bowl gets bare again as it was in the first place. The small 
amount of manure which then sticks to it is removed with a trowel.

The use of this wood-fibre nest bowl has lightened the work a great deal for they never have to be washed. They should not be washed, for water weakens them, particularly at the bottom, where the screw hole is. A washer should be put under the screw head to hold the bowl tight and to prevent its turning while being cleaned. We ship these washers and screws with the bowls.

The pigeons will not take with mathematical regularity pair by pair the nest boxes which you have provided. Some of them will take them in pairs, one adjoining the other. This makes it convenient for you in keeping track of them. Others will take one nest box in one part of the squab house but go to another part of the squab house for their second nest. Some will not take a nest box at all, but will build a rough nest on the floor of the squab house and rear their family there. Let them choose for themselves.

The nests are built by the birds of straw, grass, hay or pine needles. The birds fly to the pile, select what wisps they want, then fly to the nest boxes and arrange the wisps in a nest bowl to suit themselves. Tobacco stems are recommended for nesting material, because the odor from them will have a tendency to drive away lice, but they are not necessary if the nest bowls are used and ordinary cleanliness observed. The tanners do not want manure mixed with tobacco stems which have dropped down from the nests. The stems, when wet in the vat, stain the hides. When tobacco stems are used for nesting material, it is impossible to prevent many of them from dropping to the floor, where they are tramped by the birds into the manure. The tanners do not care if some straw and hay are in the manure. Before cleaning out the squab house, the loose straw and feathers should be swept out with a broom.

The best thing to keep the nesting material in is a berry crate. Fill it with straw and hay (use the fine oat, not rye straw, cut into six-inch lengths)-and shut down the cover. Then when the birds want nesting material they will fly to the vertical openings in the sides of the berry crates, stick their bills in and make their selection. The cover of the berry crate prevents the birds from soiling the nesting material. 
They will not build nests with dirty nesting material. It must be first-class, clean, dry and sweet or they will not use it.

Some of our customers use pine needles successfully for nesting material. We have never tried them because they are not plentiful around our farm. Where they are in abundance, we recommend that they be tried.

When a new lot of pigeons are placed in a squab house, they will cause annoyance, while they are learning their new home and getting ready to go to work, by making manure in the nest bowls, where they roost. This cannot be prevented. The remedy is, to clean once a week.

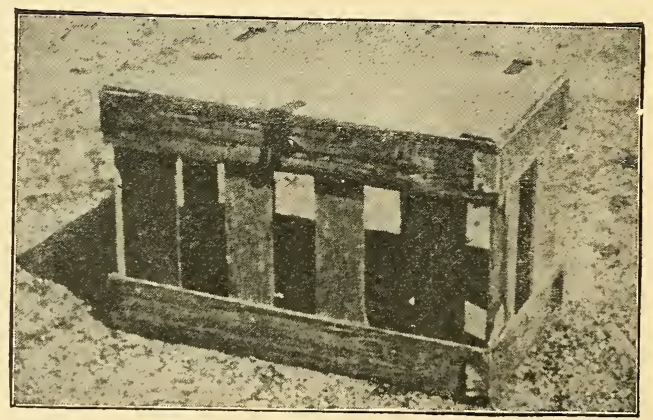

Fill this berry crate with nesting material (straw cut into six-inch lengths, and hay, mixed about equally) and place it in centre of squab house. The cover prevents the birds from fouling the nesting material. They stick their bills through the slats, select the wisps they want, and fiy to nests. 


\section{WATER AND FEED.}

Necessity of Pure Water and Plenty of it-The Kind of Drinking Dish to Use and the Kind Not to Use-Management of the Drinking Fountain and Bath Pan-The Feed Trough and Self-Feeder-Feeding Habits-What Grains to Use-How to Mix Red Wheat and Cracked Corn-Use of Grit, Oyster Shell and Salt-How to Feed the Dainties -Keep Feed before Your Flock All the Time.

Pure water and plenty of it is good for pigeons. When the weather is not too cold, it is the custom of pigeons to get into water, wherever it is. When they cannot bathe in it, they will stick their dirty feet into it. When they cannot get in their feet, they will douse their heads. They are after water all the time. When feeding the squabs, the old bird will fill up its crop with grain, then fly to the water and take a drink, then return and dole out to the squabs the watery and milky mixture on which they fatten.

The source of drinking water should be separate from the bath pan. They will drink from the bath pan, to be sure, while the water remains comparatively clean, but after a few have bathed in it, it is unfit for any bird to drink, and inside of twenty minutes the pan is not only covered with a whitish, greasy scum, but is dyed greenish from the manure which has washed off their feet.

There should be drinking water inside the squab house, provided you have not a running stream or some such clean water device in the flying pen.

The kind of water dish you do not want in the squab house is the kind with the open top, into which the birds can wade, and which they can foul with their droppings. The best device we have found is the self-feeding fountain, such as we illustrate on page 46 . This fountain is made either of crockery or galvanized steel, or iron. Galvanized i1 on or steel is better than crockery, because if water freezes in such a dish the dish will not be cracked. It will be seen by examination of the self-drinker that it is impossible for the pigeons to foul 
the water. The reservoir holds quite a supply of water, which feeds down as fast as it is drunk by the pigeons. We have seen beginners puzzled by these self-drinking dishes; they cannot imagine why the water does not all run out at once by the bottom hole. It is a simple principle in hydraulics which you may demonstrate to your own satisfaction by fill ng an ordinary tumbler with water and then inverting it in a saucer of water. There is no way for the air to get to the inside of the tumbler except by passing under the rim at the points where it touches the saucer, consequently it does not flow down unless the water is removed from the saucer, and then it ceases as soon as the water in the saucer rises over the rim of the tumbler again. In fact, some self-drinkers for poultry are made of two pieces of pottery exactly on the principle of the tumbler and saucer. These fountains are not so practical as the fountain which we illustrate, because a pigeon can roost on the top of it and foul the saucer with its droppings. In the fountain which we picture it is impossible for droppings to reach the mouth containing the water, even if the pigeon is perched directly on top of the fountain. The barrel shape of the fountain makes it hard for more than one pigeon to perch at the same time on its top, but one pigeon usually is found there. He gets there, for the special purpose, it seems, of fouling the water, but the fountain beats him and he can't do it. Neither can he put his feet into the water unless he is an extraordinary gymnast capable of holding his body out at an angle to the perpendicular. The result is, that in actual practice the water keeps clean, and there is a supply of it ready about all the time. A fountain of a gallon capacity will keep two or three dozen pairs of breeders supplied all day. The fountain is filled by turning it on end and pouring water down into the opening. If you fill the fountain at the same time you fill the bath pan in the morning, you will have done your duty by the pigeons for the day.

Cleanse these fountains at least once every two weeks with scalding hot water containing squab-fe-nol (pigeon disinfectant; see our price-list for description).

The best place for the bath pan is out in the yard of the flying pen. A pan fifteen inches in diameter is right for a flock up to twelve pairs of birds. The pan should be from four to six inches deep, not over six inches, for a pigeon will 
not bathe in water where it would be likely to drown if pushed or sat on by its mates. Having the bath pan in position on the ground of the flying pen, you take to it once each day, in the morning, a bucket of water, and pour the water into the pan Then you can go away to business, if you wish. The pigeons will fly to the pan from the interior of the house, or from the roof, wherever they happen to be. Some will splash right in. Others will perch on the rim and drink before they bathe. When the water gets dirty, they know enough not to drink, unless they are very sorely pressed indeed for water. The water gets quite dirty from the bathing. A thick, greasy, white scum forms. The pigeons do not rustle in the dirt, as a hen does, but rely on the water to keep them clean and dainty. They flap their wings in the water and enjoy it thoroughly. A pigeon will never run away from water, as you will discover if when you are watering your lawn you turn the hose on them.

Let the dirty water stand in the bath pan all day if you choose, or you may go to it an hour or two after you have filled the pan, and empty the water. One bath a day is enough.

If there is a stream of water running through your property handy to your squab house, build, your flying pen out over it and you need never trouble with bath pans or drinking water. If it is a deep stream, you will have to contrive a shallow bath tub at the shore, or divert part of the stream into a shallow run. The squab raiser with a stream of water handy should by all means make use of it and save himself the work of carrying water in pails.

The bath pan may rest in a basin, if you choose, and the overflow caused by the splashing of the wings may be conducted to a sewer and drained away. You may conduct water in pipes and have a faucet opening out over the bath pan, which faucet you may control either directly or from a central station. An easy home-made arrangement to be used in conjunction with the bath pan consists of a wet sink in which the bath pan sits, and out of which the splashed water runs. In the winter it may be advisable to give your pigeons their bath in the squab house instead of in the yard of the flying pen, in which case you should have some device on the wet-sink principle to prevent the floor of the squab house from getting damp. 
In northern latitudes it is not necessary nor desirable for the pigeons to bathe on cold winter days. Wait until a warm and sunny day comes. It will do the birds no harm to go for weeks in the winter without bathing. Many of our customers write us that they allow their birds to bathe in the winter seldom or not at all.

Feed may be given to pigeons in a less guarded way, for they do not soil the feed dish so freely as they do the drinking dishes. You may put the feed in open troughs (or on a flat board with a rim around it) in the squab house. If you observe them when eating, you will notice that they stand up to the feed in a somewhat orderly manner and peck at its contents. They do not sit in the dish and roll around in the feed as they do in the water. But they have one fault when eating and that is, to scatter the grains. They will push in their bills and toss them around in a search after tidbits, and scatter out on the floor kernel after kernel, and it will make your bump of economy ache to see this grain scattered around. There do not seem to be any neat, saving pigeons which go to the floor in the wake of their prodigal brethren and eat the crumbs. They all have a fancy for the first table and they get right at it and scatter the grain like the rest of their fellows, and apparently the pigeon who scatters the most grain is the one which struts around with the biggest front. The way to fool them is to provide in the squab house a covered trough, that is, covered except at the slit or points where they stick in their bills for food. With a little ingenuity you can cover an ordinary $\mathrm{v}$-shaped trough so that it will be hard for the pigeons to waste the grain. You may have a self-feeder made as big or as small as you choose and in which the grain will drop down as it is eaten.

We will try to present the matter of feed as clearly and fully as it seems to us to be possible. A woman in Santa Cruz, California, said she would like to raise squabs, and would begin by ordering her feed of us, exactly as we recommended, to be sent to her by freight from Boston via the Southern Pacific. A man in Cleveland ordered a quantity of red wheat and cracked corn to be sent by freight from us, when there were thousands of bushels of both staples in elevators in his city, in fact most of the Boston supply had passed through his city. We did not like to run the chance of 
losing the order for breeding stock either of the woman in Santa Cruz or of the gentleman in Cleveland, but we wrote to both that they ought not to go into the squab-raising business if they were to be dependent on us for grain, that it was too far to send and that if they would look around home they could get what they wanted.

Here in New England we feed to pigeons cracked corn, red wheat, hemp-seed, Canada peas, kaffir corn, - the foregoing as a rule, and sometimes, when cheap, buckwheat, millet and barley.

It was formerly thought that whole corn was not a good food for pigeons, on the theory that the old pigeons would eat the large kernels and then, perhaps, feed them to squabs, choking them. In practice, not one case in one hundred like that will be found. Whole corn is much relished by pigeons. They will eat it before they will eat anything else, except hempseed, and there is no danger in using it. In many sections of the country, we find, good cracked corn is not so easy to procure as good whole corn. The grain dealers take their poor whole corn, sometimes, and work it over into cracked corn. Guod whole corn speaks for itself and when you buy it there is no doubt about it.

All the time people write to us and say they never heard of red wheat. More write and say they don't know what kaffir corn is. Others are puzzled by hemp-seed, they have never seen any. That is surprising to us here in New England, but no doubt we would be just as surprised if we were in our customers' places.

Let us see if we cannot level up the whole country on this question of feed for pigeons. As a rule, we say, feed the grains which are nearest you. This country has its corn belt, its wheat belt, its section where millet is raised. Buckwheat is plentiful in another section. For your leading grain, your staple, feed corn. The point to remember is to feed a variety of grains. Keep this word variety in your mind all the time in dealing with your pigeons. Their appetites do not grow keen on a monotonous diet, they will not lay the eggs they should, and their health will not be good on it. Vary the diet.

In order to find out what grains are convenient to you, go to your nearest grain dealer or country general store. The 
dealer in nine cases out of ten knows nothing about pigeons and their feed and if you give him the name of a strange grain, he will be liable to shy and say he never heard of it. The trouble with him is that he sells horse feed and is accustomed to handling only the grains which horses need. He can get the grains you wish by writing to his nearest port or railroad junction. There is nothing odd or out of the way about the grains. They are going from one point to another all the time. Sometimes they are scarce at certain periods of the year. For instance, nearly every fall there is no kaffir corn at a reasonable price obtainable in Boston, so we do not feed it to our pigeons then, but cut it out altogether in favor of the grains selling at a lower price. Most of the kaffir corn which we get in Boston comes from Kansas. It is a splendid feed for pigeons. It is small and comparatively soft, and their crops make easy work of it. It is nourishing and they like it. Maybe your grain man sells a mixture for pigeons. If you will look in this mixture you will find probably kaffir corn, as well as buckwheat (in black kernels), also red wheat and Canada peas.

A liberal supply of Canada peas and hemp-seed is necessary for a good egg production.

Do not feed a great excess of corn, in the summer time. (By corn, we mean common Indian corn, not kaffir corn. Kaffir corn is harmless, even when forced on the birds.) The effect of corn is to heat the blood. This is what you want in the winter time, but not in the summer.

Red wheat is better than white wheat to feed to pigeons because it is not so likely to cause diarrhœa. (See supplement of this book.)

Beware of feeding too much wheat. Pigeons fed on an excess of wheat are constantly out of condition with continual diarrhœa and will lay no eggs while in that state. We recall vividly cases of pigeons doing poorly caused by the owner's stupidity in feeding too much wheat. One customer in Kansas fed nothing but wheat and got his birds so weak that they could not fly off the ground. Another in California with a flock of over one hundred pairs had not been able in six months' time to get more than one quarter of his birds at work. He complained bitterly that his birds were "not mated," were all cocks, and so on, but after further correspondence 
disclosed that he was feeding nothing but wheat, with the exception of a handful of peas in the middle of the week and a handful of hemp-seed on Sunday!

A properly balanced ration is necessary to egg production in the case of pigeons, same as poultry.

Wheat is a good regulator for pigeons but corn is the great fattener and the main staple.

When anybody fails with pigeons, if you pick up and handle the birds you will find in nine cases out of ten that they have sharp breastbones, which means that they are improperly nourished, out of condition, and of course cannot produce eggs because, they have not the blood and fat to do it.

All the grains which you feed should be old, hard, dry and sweet. If they smell sour or taste bad to your own tongue, don't feed them to your pigeons. Above all, keep your grain dry. If you have the grain stored in bins which are damp from ground water, or which catch the drippings from the eaves, or through holes in the roof, first you will get sour grain and then some of the grain will sprout, and this sprouted grain will derange the bowels of your birds and bring on dysentery. Do not let rank little growths spring up in a dirty squab house or in the yard of your flying pen. Pigeons will peck at green leaves and grass and will not be harmed, but do not give them a chance to peck up sprouted grain and eat the sprout, grain and all, for if they do they will have diarrhœa. A pigeon in good condition and busy with a nest ordinarily will not touch a nasty little green sprout, but in the moulting season, when pigeons are in the dumps generally, and feeling like having a stimulant, they will experiment with these sprouts. Keep the floor of your squab house clean and the yard of the flying pen raked up and you need not worry about this matter.

Ground oyster shell should be placed in a box handy for the pigeons to get at. The purpose of this oyster shell is to provide the constituents of the eggshell. The female pigeon needs it in order to form the egg.

Grit is needed by the pigeons to enable them to reduce to powder the feed which they take into their crops The muscles of the crop work the grit on the grains and reduce the grains so that they mix with the digestive fluids. Cart two or three bushels of gravel or sharp sand into your flying pen and cover the ground with it. It is not necessary to 


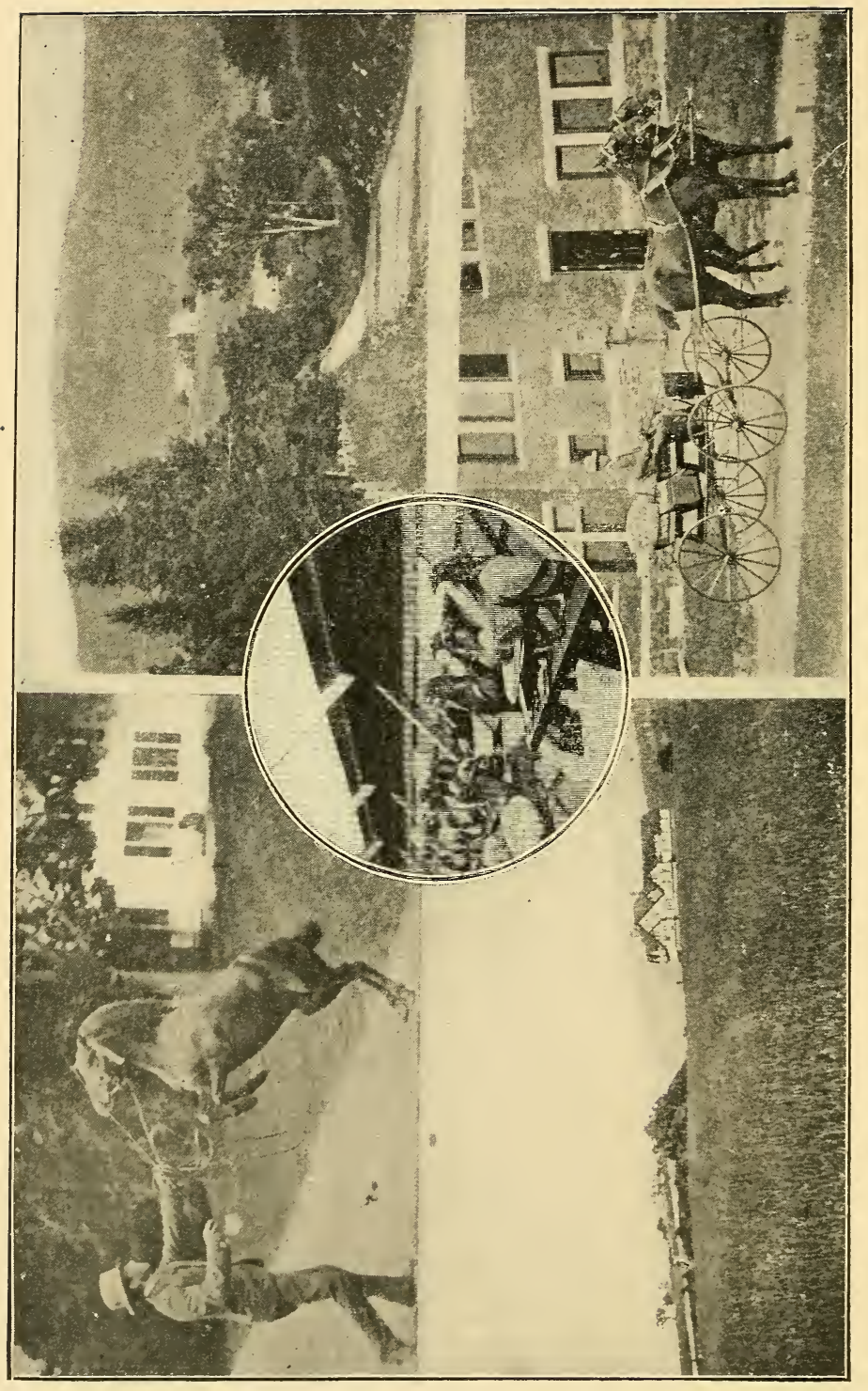

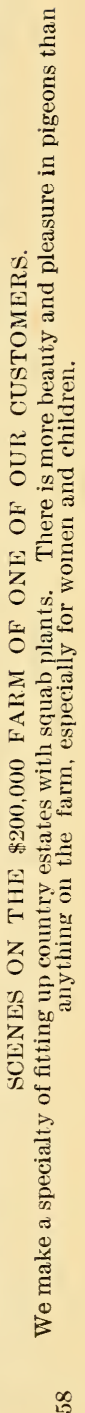


cover the whole space of the ground of the flying pen. For fuller discussion of shells and grit, see supplement.

It is poor policy to mix anything but wheat and corn together. If you make a mixture of peas and hempseed with cracked corn and wheat, you will find that the pigeons. will dig down after the peas and hemp-seed and toss the other grain around and waste it. The only mixture, therefore, which we feed is a mixture of wheat and corn. Fill the self-feeder with whole corn and wheat, in the proportion of three parts of the corn to one of wheat.

We call the wheat and corn staples, because with us in New England they form the major part of the diet, and are the cheapest. The hemp-seed, buckwheat, Canada peas, kaffir corn, millet and barley we call dainties. We do not feed much millet, because we have the other grains, which are cheapest, but some of our customers in the millet sections of the country feed a good deal of millet. In such cases they look on millet as one of their staples, and the hard-to-get grains are classed by them as dainties. The staple grains of which you will feed the most to your pigeons are the ones which are the cheapest for you. The more expensive grains will be classed by you as dainties.

A good way to feed the dainties is to throw them out on the floor of the squab house by hand. You will see the pigeons make a rush for them and eat them with as much relish as a child eats candy. You should feed the dainties about three times a week, throwing handfuls on the floor until you see that the pigeons are satisfied and do not care for any more.

Do not throw any feed on the ground of the flying pen, for the earth is liable to be damp, and this dampness will sour the grain, especially cracked corn, and if the pigeons eat it, they will get sour crops, and the fluids from the sour crops of the parent pigeons will make the squabs sick and perhaps kill them. Do all your feeding in the squab house and your pigeons will not have sour crops.

Do not lay in a big stock of cracked corn at a time, for cracked corn exposed to sudden changes of the weather is liable to take up dampness, and sour. Smell and taste it once a week or so and determine to your own satisfaction that it is not sour. 
Some squab breeders feed twice a day, as much as the birds will eat up clean, but we do not believe in that system of feeding. Our own success, and the success of our customers in squab raising, is based largely on the fact that we insist on a continuous supply of food for the pigeons, when they are breeding. Use the self-feeder only with birds that are producing squabs. A new flock should be fed by hand twice daily what they will eat up clean in ten minutes. Keep them eager, active and racy. Do not let them get too fat, for if you do they will not start laying. Some beginners will use up weeks trying to get their birds started, others get all their pairs going in a few days. It is a matter of skillful feeding, exactly as in the case of hens. The best of mated pairs will not produce eggs unless nourished, because the act of copulation, as in the case of hens and roosters, has nothing to do with the volume of egg production, but only with the fertility of eggs.

Food should be at hand in the self-feeder for birds which are breeding. They do not gorge, as a horse will if an unlimited supply of food is set before him. They are not gluttons, like pigs. They do not lose their racy shape. A squab when hungry will squeak loudly to inform its parents of that fact and if you observe a squab house where the two meals a day are in vogue, you will note quite a chorus of squeaks. In a house where there is feed always at hand, you will not hear many hungry squeaks. It is greatly to your interest that the crops of your young birds be filled with food. The more their crops are stuffed with food, the quicker they will fatten and the fatter they will get. The parent birds should at all times be able to fill up their crops with feed and water and then fly to the nest to disgorge for the benefit of the squabs.

Squab breeders differ concerning self-feeders, same as mothers differ about ways of bringing up babies. Each squab breeder thinks his method of feeding is the best. We speak not wholly from our own experience, but the experiences of thousands of customers extending over many years. There was formerly the same prejudice against self-feeders for poultry, until a man in Ohio, raising poultry with striking success by the aid of self-feeders, made his brethren sit up and take notice. In our stories of success printed at the back of 
this book and elsewhere, are many cases of small flocks increased enormously, and the writers take pains to state that they are using the self-feeder. That is talk that means something. The loudest advocate of no self-feeder is the man who is trying hard to sell his Homers by some kind of a story different from what we tell. It does not matter to him what he says, so long as he combats us. It is the game of such chaps to contradict all others and pose as the only real, simon-pure know-it-alls on pigeons.

Some small parent Homers are such good feeders, such good fathers and mothers, that they stuff their squabs with grain and bring them up to a surprising fatness. We have had pairs of squabs which actually at four weeks of age were bigger than their parents. This is not surprising when you think that the squabs sit in their nest hour after hour doing nothing but accumulate fat, and taking no exercise to train off this fat. The old birds are flying around and do not have much fat on them; they are trim and muscular, and hard fleshed. You can tell an old pigeon after it is cooked when you put your teeth into it, just as you can tell an old fowl.

Provide salt for your pigeons to keep them strong and healthy. The safest kind of salt for you to use is rock salt, such as is sold for horses. Put a couple of big lumps of it in the squab house and let the pigeons peck at it when they wish. Put two more lumps out in the flying pen. When rain comes the water will wash some salt off the lumps into the gravel. (Empty the bath pans upon the lumps of salt.) The pigeons will eat this salt-impregnated gravel all around the lumps for an inch or so down into the ground.

Do not feed powdered salt, for if you do the birds may eat too much of it and it will kill them. Coarse ground salt may be used, but the rock salt is best.

Some green stuff is much relished by pigeons. It is good for them and will increase the egg, and, consequently, squab production. They are very fond of cabbage now and then, which should be chopped fine before being fed. (We mean raw, not cooked, cabbage.) When vines grow over the flying pen, they will be seen pecking at the green leaves. Green clover may be cut up and fed to them in conjunction with grain. It should be remembered that green stuff, as enumerated in this paragraph, is fed only as a relish. 
Table scraps, or what is commonly known as swill, should not be fed to pigeons.

Rice may be fed, if plentiful and cheap. It has a tendency to correct diarrhœa caused by too much wheat.

Some of our customers have been influenced by adverse criticism of our self-feeder to abandon it and feed in open troughs, but they have gone back to the self-feeder. One of these customers was Mr. Tyson, who started with several hundred pairs of our birds three years ago and now (1907) has the largest and best plant in the State of New Hampshire. His wife and son, with himself, have attained a high degree of skill and proficiency in the handling of their pigeons. The squabs they are breeding weigh at least nine pounds to the dozen. They ship to New York City, where they get very high prices. Mr. Tyson started by using the self-feeder for grain, as we advise, but being influenced by something seen in print, abandoned it and gave the open-trough method of feeding, twice or three times a day, a thorough trial. Immediately the birds kegan to fall off in production, and the squabs fell off in weight, some lots getting so skinny as to lose nearly two pounds to the dozen. That experience was enough. The Tysons went back to the self-feeder and now their squabs are plump, as they were in the first place, the old birds are in better condition, and breeding better.

Do not put into the self-feeder a great lot of grain, but only enough to last about two days. A great quantity is liable to take up moisture in a spell of rainy weather and go stale, and is not relished by the birds as if it were supplied fresh every two or three days. 


\section{LAYING AND HATCHING.}

Laying an Egg is under the Control of the Pigeon's MindFertile and Infertile Eggs - How the Cock Drives the HenOne Day between Eggs - Hatch after Seventeen Days - How Squabs are Fed by the Paren' Birds-Mating Males and Females - Use of the Mating Coop-Determination of Sex-Color of Feathers Has No Effect on Color of Flesh-Pigeons Left to Themselves Will Not Inbreed-No Inbreeding Necessary even if you Start with a Small Flock.

The hen pigeon builds the nest. When the nest is built, the cock begins to "drive" the hen around the house and pen. In a flock of breeding pigeons you always will see one or two cocks "driving" their mates, pecking at them and nagging them with the purpose of forcing them onto the nest to lay the eggs. The cock seems to take more interest in the coming family than the hen.

The hen lays one egg in the nest, then skips a day and lays the second egg on the third day. Seventeen days after being laid the eggs hatch. The egg first laid hatches a day before the second, sometimes, but usually the parents do not sit close on the first egg, but stand over it, and do not incubate it. Sometimes one squab may get more than its share of food, and the younger one will weaken and die. This seldom happens but if you see one squab considerably larger than the other, the thing to do is to exchange with a squab from another nest that is nearer the size of the remaining squab. The old birds will not notice the change but will continue feeding the foster squab.

The process of laying an egg is a mental operation. We mean by this that it is not a process which goes on regularly in spite of all conditions. The hen forms the egg in her body and lays it when she is in condition to, and wherl she wants to, not when she is forced to. In other words, the hen lays when conditions are satisfactory to her. That she forms the egg at will is proven by many things, principally by the fact that she allows one day to come in between the first and 
THE QUICK GROWTH OF SQUABS FROM EGGS TO KILLING AGE IN FOUR WEEKS IS ILLUSTRATED ON THIS PAGE, PAGE 66 AND PAGE 68.

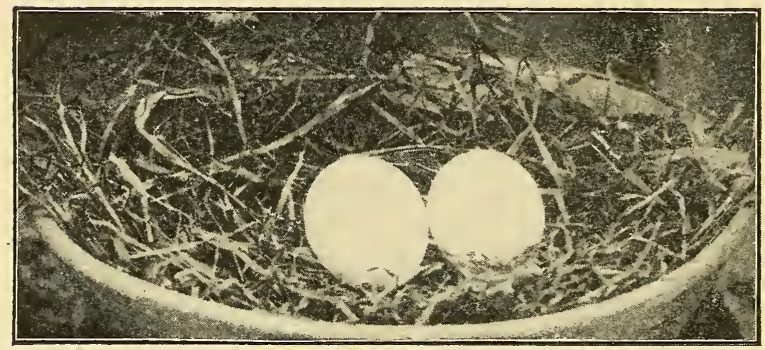

EGGS IN THE NEST.

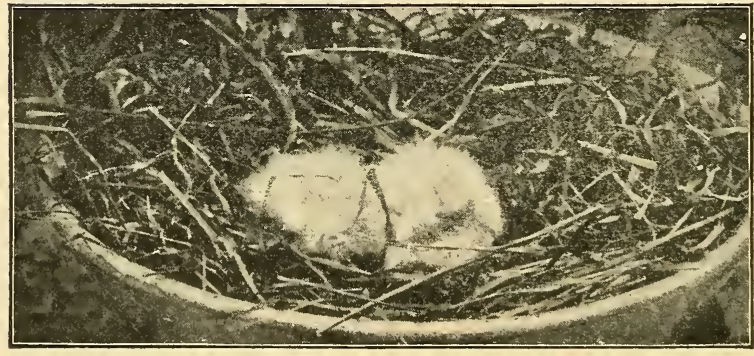

SQUABS JUST HATCHED. 
the second eggs. No doubt, after she has laid the first egg, she hurries the other along and lays it as soon after the first as she can, and it takes forty-eight hours for the egg, complete in its wonderful construction, to form. Hen pigeons in a shipping crate or close coop do not lay eggs, because they know that there are no facilities there for raising young. Once in a while you will find an egg in a shipping crate when the birds are taken out, but it is a comparatively rare occurrence.

Of course, in order to lay a fertile egg, the hen pigeon must have received the attention of the cock bird. It is common for a hen pigeon at five months, and sometimes four, to lay an egg, but as a rule those first eggs from a young hen are not fertile because she has not yet mated with the cock bird. After a hen pigeon has reached six months of age, and is paired with a male, it is safe to assume as an almost invariable rule that the eggs she lays will be fertile. When the male bird gets to be six to ten years old, he may lose his vitality, and the eggs laid by his mate will not be fertile. Then it is necessary to provide the female with a new mate. The breeders we sell are of prime breeding age, from eight months to eighteen months old, and the eggs laid by hens of that age will be fertile and of full size, and the squabs bred from them will not be scrawny and lacking in vitality.

From the day of its hatching to market time the squab is fed by its parents. The first food is a liquid secreted in the crop of both cock and hen, and called pigeons' milk. The parent pigeons open their bills and the squabs thrust their bills within to get sustenance. This supply of pigeons' milk lasts from five to six days. It gradually grows thicker and in a week is found to be mixed with corn and wheat in small particles. When about ten days old, the squabs are eating hard grain from the crops of the mature cock and hen. They fill up at the trough, then take a drink of water and fly to the nest to minister to the little ones. You see how important it is to have food available at all times.

In fourteen, fifteen or sixteen days after the first pair of squabs have been hatched, the cock begins " driving" the hen again. This shows the necessity of a second nest for the pair. In this second nest the hen lays two more eggs, and the care of the first pair of squabs, now between two and three weeks old, devolves upon the cock. When this pair is four 


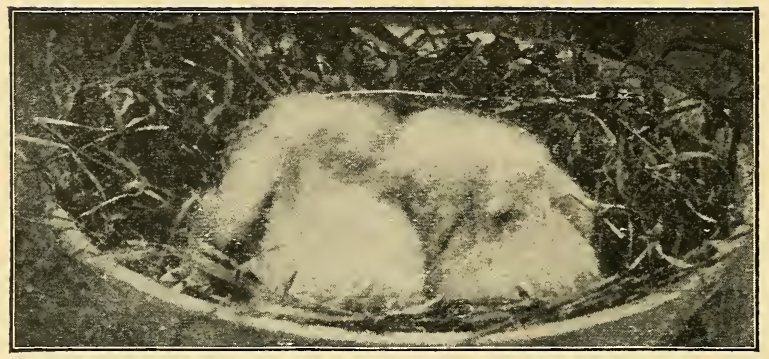

SQUABS ONE WEEK OLD.

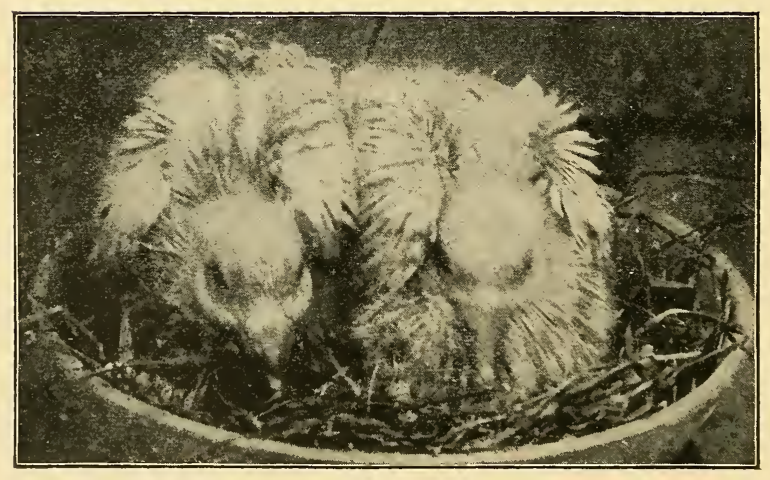

SQUABS TWO WEEKS OLD. 
weeks old, it is taken out of the nest and killed and both the mature birds are concerned then only with the new hatch. This sequence of eggs and hatches goes on all the time.

If there are not two nests, the two new eggs will be laid in the nest where are the growing squabs. The parents in their eagerness to sit on the new eggs will push the squabs out of the nest and they will die for lack of sustenance.

The hen lays the eggs about four o'clock in the afternoon. The cock and hen take turns at covering the eggs, the hen sitting during the night until about ten o'clock in the morning, when the cock relieves her, remaining on until the latter part of the afternoon.

When the squabs are taken out for market at the end of four weeks, the nest bowl and nest box should be cleaned. If this cleaning is done once a week, no trouble from parasites will result. In the summer it is well to add a little carbolic acid to the whitewash as an extra precaution. Sprinkle unslaked lime on the floor of the squab house and in the nest boxes, and spray squab-fe-nol freely.

One way of mating or pairing pigeons is to turn males and females in equal number into the same pen. They will seek their own mates and settle down to steady reproduction. Another method is to place the male and female which you wish to pair in a mating coop or hutch. In the course of a few days they will mate or pair and then you may turn them loose in the big pen with the others. The latter method is necessary when improving your flock by the addition of new blood, or when keeping a positive record of the ancestry of each pair. By studying your matings, you may improve the efficiency of your flock.

In the case of a new flock of pigeons shipped to a new home, all do not go to work at the same time. Those pairs which get to work first are bothered by the slower pairs. To judge from the advertisements of some breeders, anxious to claim everything for their birds and their wonderful matings, the beginner would think that all the birds he buys from them will go to work immediately when released in their new home. This is far from the truth. The pairs will go to work to suit themselves as to time. Some will be quick, others slow. As fast as each pair goes to work, it should be caught and placed in the breeding pen. The first pen, into which the birds 


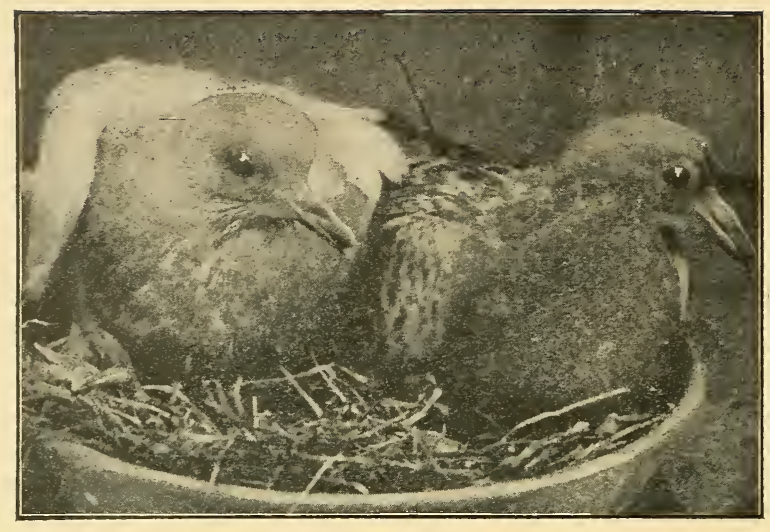

SQUABS THREE WEEKS OLD.

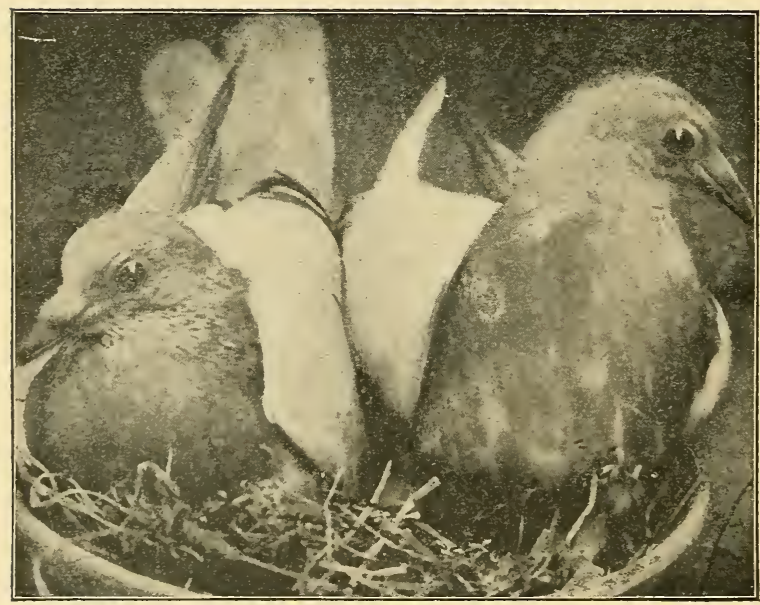

SQUABS FOUR WEEKS OLD.

Ready to be killed for Market. 
were put on arrival, then can be used for the rearing pen for youngsters raised in the breeding pen.

In case a pigeon loses its mate by death or accident, the sex of the dead one must be ascertained. The live one should be removed from the pen and placed in the mating coop with a pigeon of the opposite sex.

The mating coop should have a partition of lattice work or wire. Place the cock in one side, the hen in the other, and leave them thus for two or three days to flirt and tease each other, then remove the central lattice work or wire and they usually will pair, or mate. If they show no disposition to pair but on the contrary fight, replace the partition and try them for two or three days longer. If they refuse to pair after two or three thorough trials, do not experiment any more with them, but select other mates.

The determination of the sex of pigeons is difficult. The bones at the vent of a female are as a rule wider apart than of a male. If you hold the beak of a pigeon in one hand and the feet in the other, stretching them out, the male bird usually will hug his tail close to its body - the female will throw her tail. The best way to determine the sex is to watch the birds. The male is more lively than the female, and does more cooing, and in flirting with her usually turns around several times, while the female seldom turns more than half way around. The male may be seen pecking at the female and driving her to nest. When one pigeon is seen chasing another inside and outside the squab house, the driven one is the female and the driver her mate.

Neither the squab breeder nor the flying-Homer breeder is much concerned about the color of feathers. There are blue checkers, red checkers, black checkers, silver, blue, brown, red, in fact about all the colors of the rainbow. Color has no relation to the ability of a pair to breed a large pair of squabs. We wish specially to emphasize the fact that the color of the feathers has no influence on the color of the skin of the squab. A white feathered bird does not mean a whiteskinned squab. The feed affects the color of the meat a ittle. A corn-fed pigeon will be yellower than one fed on a mixture. Squabs with dark skins (almost black in some cases) are the product of blood matings. The trouble with a dark-colored squab is in the blood and the only remedy is to get rid of them 


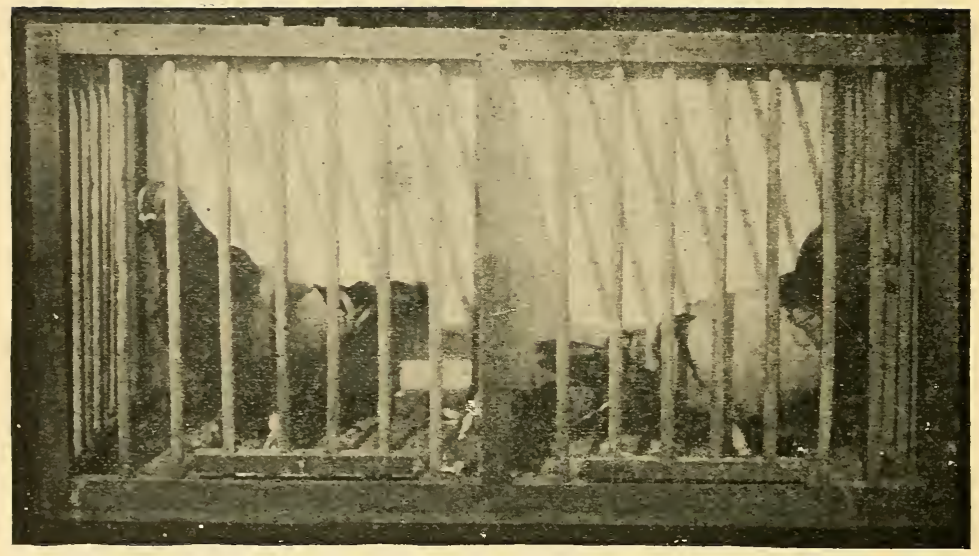

THE MATING COOP.

One way of mating squab breeders is to turn cocks and hens in equal numbers into the same nen. The $\mathrm{m}$ iting coon is used when the breerier wishes to pair a certain male with a certain female. The above mating coop is divided by a partition. The cock is placed on one side of the partition, the hen on the other. as pictured. They are left thus for a day or two to tease each other. Then raise the partition. or take it out, and allow them to approach each other when ther psisally will be found to have formed an attachment. This being the case. ther mar be put into the large pen with the other birds. where ther will find a nest hox and go to housekeeping. If they fight when the partition is remored, try again, or try other mates. The coop pictured above is two feet long, one foot wide and one foot deep. 
either by killing the parents or by remating. Usually the trouble comes from one parent bird, which you find by turning up the feathers and examining the skin. Having found the bird which is at fault, kill it. This point has come up continually in our correspondence. The erroneous belief that white-feathered birds produce the whitest-skinned squabs seems to be widespread and we are asked sometimes for a flock of breeders " all white." Our experience with all white Homers is that they are smaller and have less stamina than the colored ones. The marketmen will take two or three pairs of dark-skinned squabs in a bunch without comment, but an excess of dark ones will provoke a cut in price. Breeders who are shipping only the undressed squabs should pluck feathers now and then to see just what color of squabs they are getting. The dark-colored squabs are just as good eating as the light-colored ones, but buyers for the hotels and clubs, and those who visit the stalls, generally pick out the plump white-skinned squabs in preference to the plump dark-skinned ones. As a rule, squabs from Homer pigeons are whiteskinned-the dark-colored squab is an exception.

Many beginners wish to know if it will be all right for them to buy a flock and keep it in one house for six months or a year, paying no attention to the mating or pairing of the young birds, but leaving that to themselves, so as to get without much trouble a large flock before the killing of the squabs for market begins. Certainly, you may do this, providing extra nest boxes from time to time until your squab house has been filled with nests; then you will have to provide overflow quarters. We are asked if the flock will not become weakened by inbreeding, that is, a brother bird mating up to a sister, by chance. According to the law of chances, such matings would take place not very often. Pigeons in a wild state, on the face of a cliff, or in an abandoned building, would pair by natural selection. The stronger bird gets the object of its affection, the weaker one is killed off or gets a weaker mate, whose young are shorter-lived, so the inevitable result is more strength and larger size. Nature works slowly, if surely. A lot of pigeons in one pen mating or pairing as they please when old enough is the natural way, and if you follow this, you cannot go very far wrong. We advocate matings by the breeder because it hurries Nature 
along the path which makes most money for the breeder. We all know how Darwin studied natural and forced selection of pigeons. He took one pigeon with a certain peculiarity, say a full breast, and mated it to another pigeon with a full breast. The squabs from these birds, when grown, had breasts fuller than their parents. Then these in turn were mated to full-breasted pigeons from other parents, and the grandchildren had even larger breasts. Darwin's experiments covered a period of over twenty years and in this time he developed little faults and peculiarities to an amazing degree. Every intelligent, careful pigeon breeder is striving by his forced matings to push along the path of progress the peculiarity in pigeons which is his specialty. The breeder who selects most carefully and keeps at it the longest wins over the others. By selecting from your best and most prolific breeders the biggest and fattest squabs, keeping them for breeders and mating so as to get something larger and plumper, you are all the time getting bigger squabs. Every breeder of squabs has it in his power to increase the efficiency of his flock by studying his matings. There is commerical satisfaction in breeding for size and plumpness because it pays at once, and at the same time the breeder has the satisfaction of increasing the stamina and variety of pigeons.

To be master of the matings, the breeder should band his squabs. As scon as they are weaned (that is, as soon as the breeder sees them flying to the feed and eating it) they should be taken and put into one of the rearing pens. When about six months old, the breeder should begin mating them by selection, using the mating coop, then when they are mated turn the pair into a working pen with other adult birds. By looking at the number on the band of each bird, then on your record card, you know how to aroid mating up brother and sister.

When the young birds are just over four weeks old, or between four and six weeks, they are able to fly a little, and if they do not hop out of the nest (or are not pushed out by the parents) you may push them out yourself. They are now able to feed themselves. If these young birds are left in the squab house, they will bother the old birds by begging for food, and this infantile nagging will hinder the regular breeders in their next hatch, so the very best thing to do is 
to put the young birds by themselves into a rearing pen, where they cannot bother anybody.

Of course there is likely to be a little inbreeding when you leave the birds to choose for themselves, but not much. If the breeder has not the time to make forced matings, then he may not care to make them. Remember in mating that like begets like. The parent bird that feeds its young the most, and most often, will raise the biggest squab. Sometimes a parent bird will have fine nursing abilities and will stuff its offspring with food. These good-feeding qualities are transmitted from one generation to another and are as much under the control of the breeder as size and flesh-color. Your biggest squabs will be found to have an extra-attentive father or mother, or both. A pigeon with a dark skin, if mated to a white-skinned bird will produce a mulatto-like squab. It is the large, fat, white-fleshed squab which you are after. Disregard the color of the feathers when mating. If when plucking your squabs you come across a " nigger," that is, a squab with a dark skin, find out what pair of breeders it came from and whether the cock or the hen is at fault, and get rid of the faulty one. It is important to start with adult birds that are not related, then you will not begin inbreeding. That is why we make a special effort with our adult birds to have them unrelated.

Some letters from customers make plain to us that a clear knowledge of what inbreeding means is not possessed by everybody. Several have written to this effect: "If I buy two or three dozen pairs from you to start, how can I increase the size of my flock without inbreeding?" When (1) a brother is mated to sister or (2) a father to a daughter, or (3) a mother to a son, or (4) a grandson to his grandmother, etc. that is inbreeding. We know it is forbidden by law for human beings to mate in that manner, because $(a)$ God in the Scriptures has forbidden it, and $(b)$ because the State does not wish to have to care for the puny, weak-minded offspring that would result from such unions. We all know that the marriages of cousins often result in demented, diseased children. Now suppose you buy two dozen pairs of pigeons of us, and number them pairs one to twenty-four. If you mate the offspring of pair two (or any other pair) to the offspring of pair one (or any other pair) that is outbreeding or cross- 
breeding. What you do not do, and what you try to prevent, is the mating of the offspring of pair number one (or any other pair) to each other. So, you see, if you have a dozen or two pairs, you need never inbreed, for there is an infinite variety of matings possible. Breeders of animals sometimes inbreed purposely in order to get better color of fur or plumage, or finer bones, etc. There are no brothers and sisters in the flocks we sell. If you buy one dozen or twenty dozen pairs of breeders of us, the pairs will be unrelated, and you need never inbreed. We never heard a real pigeon breeder worry much about inbreeding, because the likelihood of it in a flock of even a dozen pairs is extremely remote, as we have demonstrated above.
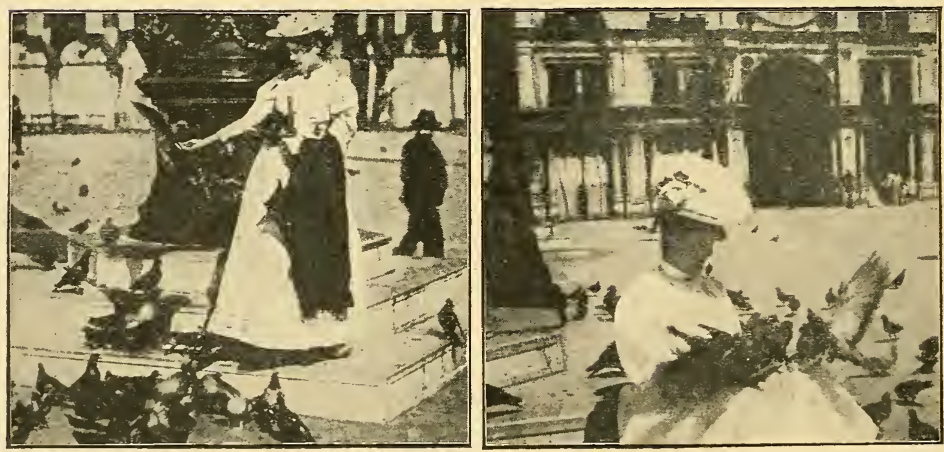

PIGEONS IN ST. MARK'S SQUARE, VENICE.

Get acquainted with the pigeons which you buy of us, and let them get acquainted with you. They will work all the better for being tame and docile. These pigeons in Venice are fed by tourists on corn only. A peddler selling whole corn for two cents a package sits all day long on the steps at the base of the monument. Several photographers in the square make a specialty of taking pictures of tourists feeding the pigeons; snap shots by amateurs are constantly being made. In this city of canals, these pigeons get no grit, in fact nothing but the corn, and they would die if obliged to pick up a living for themselves. They are healthy, proving the incorrectness of the assertion that a feed of nothing but corn will cause canker. They are small, however, of stunted growth. They are so tame that they will perch on your hand and eat grains of corn held in your lips. 


\section{CHAPTER VII.}

\section{INCREASE OF FLOCK.}

It is Possible to Breed One Pair of Squabs Each Month, but in Actual Practice this is Seldom Attained-The Squab Raiser with Pure Thoroughbred Homers should Count on Six to Nine Pairs of Squabs a Year-The Common Pigeon Breeds Only Four or Five Pairs of Squabs a Year, but Eats as Much or More than the Homer-Differences between the Homer and the Common Pigeon-Good Homers Scarce and the Market for them Firm and Steady.

It is theoretically possible for a pair of pigeons to breed twelve pairs of squabs a year, for it takes only seventeen days for the eggs to hatch, and the hen goes to laying again when the hatch is only two weeks old. So, if you start with twelve pairs of Homer pigeons, and they should breed one pair of squabs a month, at the end of the first month you would have twenty-four squabs; at the end of the second month, forty-eight squabs; at the end of the third month, seventy-two squabs; at the end of the fourth month, ninetysix squabs; at the end of the fifth month, one hundred and twenty squabs. Now the first lot of squabs which your birds hatched will be ready to mate and lay eggs, so at the end of the sixth month you should have one hundred and sixtyeight squabs; at the end of the seventh month, two hundred and forty squabs; at the end of the eighth month, three hundred and thirty-six squabs; at the end of the ninth month, four hundred and fifty-six squabs; at the end of the tenth month, six hundred squabs; at the end of the eleventh month, seven hundred and sixty-eight squabs, and at the end of the twelfth month, nine hundred and sixty squabs. Such figures are purely theoretical and are seldom attained in actual practice. You will have some pairs in your flock which will raise ten and eleven pairs of squabs a year, but the average will be seven to nine pairs of squabs a year. If you get less, your flock is not pure thoroughbred Homers, or your feeding and nesting arrangements are wrong. In our visit to squab breeders in 1902 , we asked every one with whom 
we talked how many pairs a year he was getting from his birds, and about all of them said seven to nine. This experience corresponds with ours. We remember particularly an old gentleman, Preacher Hubbell, in Vineland, who had been in the squab business for years but was just going out of it, having sold his place, pigeons and all, to a Swede farmer. He told us he had always made squabs pay him and that his birds, of which he kept a careful record, raised him nine pairs to the year right along.

It is a well-known fact that the common pigeon will breed only four or five pairs of squabs a year, and if handlers of big flocks of common pigeons, like Johnson of California, can make a net profit of one dollar per pair a year from such low breeders, we think anybody of no experience is justified in believing our statement that our Homers are capable of earning a net profit of from two to three dollars per pair a year, taking into account not only their fast breeding qualities, but the superior size of the squabs. Here in New England we consider the common pigeons inconstant and happy-go-lucky breeders. They are not in the same class at all with the Homer pigeon.

The common pigeon, the pigeon which flies the streets of our cities and towns, is a mixture of all kinds of pigeons, and it partakes of the faults of each, and not of the virtues. Its outward appearance is large, but it is an effect of feathers and not of flesh. Its feathers are loose and fluffy and its muscles soft and flabby. Its head is smaller than that of a Homer, the deficiency being marked in the curve of the skull which covers the brain. The Homer has a white flesh ring around the eye, but the common pigeon has none. The Homer has the largest brain of any variety of pigeon, and discloses this fact by its behavior. It has more sense and behaves with more intelligence. Its wonderful homing instinct marks it above and beyond all classes of pigeons and it is this quality which gives it a commercial value all over the world. The feathers of the Homer are laid close like a woman's glove and the muscles under it feel as hard and firm as a piece of wood. Its breast is firm and well protected, with just the right amount of fullness. Its chest is large, indicating good lung power and staying qualities. Its wings are trim and shapely, in flight the poetry of motion. The poise of its body and head reminds one of a race-horse listening for the signal to speed over the 
course. The lines from the neck to the body descend in a long, graceful sweep. Put a thoroughbred Homer into a flock of common pigeons and even a novice, if told to pick out the bird which would fiy the fastest and furthest, would pick out the Homer. The Homer has a long bill (but not so long as the Draguon pigeon). The bill of the common pigeon is short. Its bill is more hooked and is sharper pointed. Its head is shorter and more rounding on top.

The common pigeon is seldom bred in captivity, because it does not pay for the grain which it consumes. If bred in a wild state, it picks up a living in the neighborhood, the owner not keeping it wired in. It is the cheapest kind of a pigeon, and thousands of pairs are used by trap shooters. Undertakers sometimes buy the white common pigeons in order to liberate them at graves, to signify the ascent of the soul to heaven. Common pigeons will live anywhere, do not get attached to any home, but a Homer never forgets the place where it was bred and will search out its home in long flights. Common pigeons will alight on any building and will drink from different springs and wells, fouling them and making themselves a nuisance in a neighborhood. The Homer will alight only on its own squab house and drink only at its own home. Common pigeons sell for fifty cents a pair and are frequently offered as Homers. Do not start with common pigeons and think to learn the habits of squab breeders with them. If you cross a common with a Homer pigeon you will take away the good qualities of the Homer and add nothing. There is not one element in a common pigeon which if added to a Homer would improve the offspring. It is hard to convince some people that there is any difference in pigeons whose feathers are the same color. The result is they buy the cheapest they can get. After feeding them for a time and getting no profitable results, they are compelled to sell them to the first trap shooter who comes along, and they go among their townspeople declaring that the pigeon business is no good. Remember this point, that if you are going to buy grain and feed it to anything so as to get a profit, it is the best policy to feed it to that grade of animal which will show the largest profit. Very few people are satisfied with shoddy suits nowadays, even if they look almost as well as the allwool garments. It is the wear which the customer is after. 
Beware of shoddy pigeons. Buy the best Homers you can get, they will wear best and give you the most pride. Experienced poultrymen do not go here and there looking for fowls at cut prices. They buy breeding stock of a reliable breeder which is reliable and sold at a price which will enable the seller to deliver a high quality article. We can tell when an order for our breeding stock comes from an old poultryman, for they all write: "I want the best stock you can give me."

Good Homers do not glut the markets. They are always fairly scarce, and the price for them has always been well kept up. Beware of cheap Homers for sale at cut prices. There is always something the matter with such birds. They have been worked too long and are played out, or if a flock is offered " at a bargain," the birds do not produce the large, plump, No. 1 squab, but only culls. If a squab breeder is going to quit the business and offers you his flock of birds on the bargain counter, make him give a good reason to you for selling. If he has been unable to make the flock pay, you may be sure that you will be unable to make them pay. If he offers them to you without a good reason for selling, the chances are that it is a poor flock and he has got tired of buying grain for them, and wishes to saddle the burden upon you. We are always selling breeders and it is very much to our interest to protect our reputation by sending out only good Homers that will make money for their owners. This is what we do, and our large business has been built up by square dealing, and knowing the business thoroughly.

A pair of Homers capable of earning a pair of squabs in one month which will sell for at least fifty cents is worth more than one dollar or one dollar and twenty-five cents a pair. A pair of birds capable of earning only a ten-cent or twenty-cent pair of squabs once in two or three months is worth only fifty cents a pair. Jersey cows are worth more than common cows because they earn more. Good Homer pigeons, bred skilfully, are worth more than poor Homers because they earn more. 


\section{CHAPTER VIII.}

\section{KILLING AND COOLING.}

Kill the Squabs in the Morning when their Crops are Empty - Not Necessary to Use a Knife, their Necks may be Tweaked - Drive the Animal Heai out of their Bodies by. Hanging them from Nails - The Ideal Squab when Shipped has an Empty Crop, its Feet have been Washed Clean, and No Blood Shows-Sorting Squabs so as to Get the Highest Price from the Dealer.

The time to kill the squabs is in the morning, when the crops are empty. In killing them it is not necessary to use a knife. Hold each squab in the manner shown in the illustration and break the neck with a sudden pull and push. Do not pull too hard or you will sever the neck from the body. Some of our customers have hard work to get this knack of tweaking the necks and prefer to wring the necks, or to use a knife. To wring the neck, hold the squab by the head in the right hand and throw the body around in a complete circle, this act twisting and breaking the neck.

After the squabs are killed they must be cooled. In other words the animal heat must be driven out of their bodies. Provide a piece of board or studding eight or ten feet long and every four inches along this studding drive a couple of nine penny wire finish nails close together, but not so close that you cannot squeeze in the legs of the squabs. A finish wire nail has no large head like an ordinary wire nail. Suspend the studding from the ceiling by means of wire adjusted at both ends of the studding. This method of hanging it up is to prevent rats and cats from climbing up onto the studding, walking along it and eating the squabs. Place the feet of the squabs between the wire nails and let them hang downwards over night. In the morning the heat will be all out of their bodies and you can pack and ship them. If you are delivering plucked squabs to market, you do not need such an arrangement, but will throw the bodies into a tub of ice water (or cold spring water) after you have plucked them.

When plucking the feathers from the killed squabs, the 


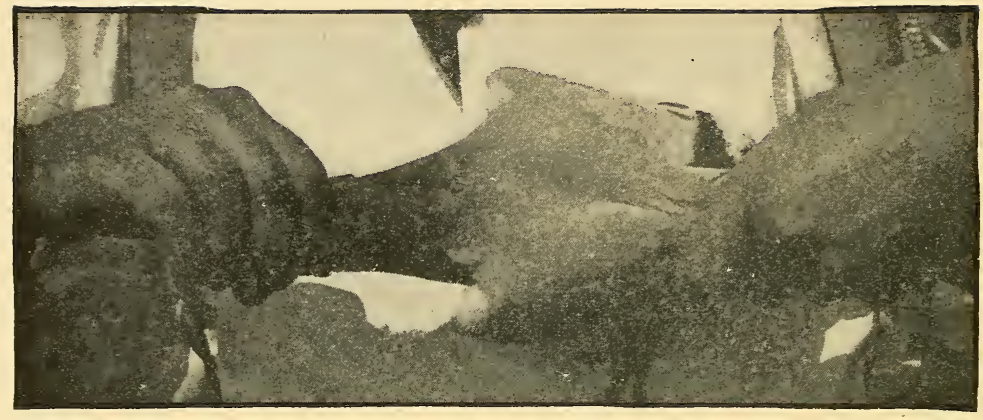

INCORRECT POSITION OF HANDS.

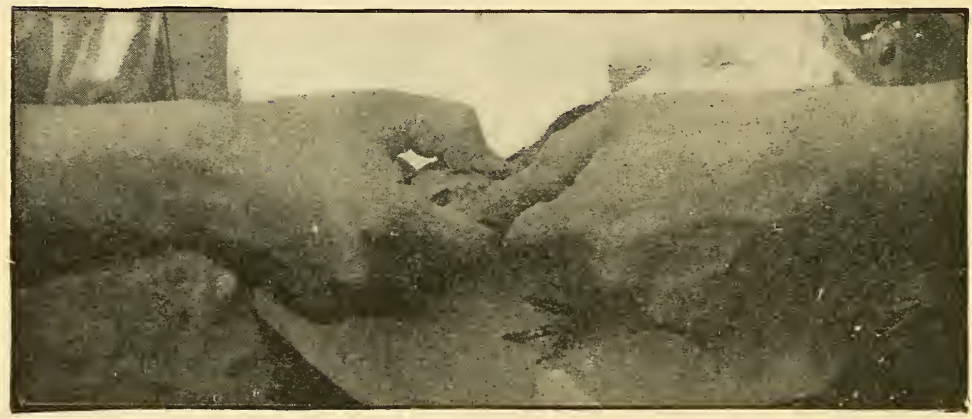

CORRECT POSITION OF HANDS.

A squab is killed for market when it is plump and well feathered, usually when four weeks old, although many are ready for market when a day or two over three weeks old. Hold the hands close together on the neck, as shown in the bottom picture and break the spine of the bird by pulling firmily and then pushing back. Do not put so much strength into the operation that you pull the head from the body. This method of killing is faster and neater than using a knife. 
operator should moisten his thumb and forefinger in a basin of water, to give him a grip on the feathers. They come off easily and an experienced picker will work very rapidly. A sharp pen-knife, or knife such as shoemakers use, is necessary to remove some of the pin feathers. They should be shaved off.

Ignorance of how to cool the killed squabs properly has discouraged many a squab raiser. If you throw the squabs in a pile on the floor after you have tweaked their necks, you will have a fermenting mass and the following morning, when you are ready to ship, many of the bodies will be darkcolored at the place of contact with the floor, or with other squabs, and decay will start from such discolored places. Hang the bodies from the studding, as we have described, and you w 11 cool them just right and you will be surprised that this part of the business ever could have discouraged anybody.

If you number the nails which you have driven into the studding you will know just how many squabs you hang up, and you will not have to handle the squabs a second time to count them.

The ideal squab which brings the highest price in the market is not only large and plump, but has a clean crop, so that no food will be left in it to sour. No blood shows anywhere on the body and its feet are clean. Ship in small quantities, especially in the summer. Do not pack in an enormous box, or the bottom layers will suffer.

A squab should be killed, as we have stated, when from three to four weeks old, most generally at four weeks. Do not wait until it is five or six weeks old, when it may have left the nest. As soon as a squab is old enough to get out of the nest and walk around on the floor of the squab house, it quickly trains off its fat and grows lean and slender. Its flesh also loses its pure white co or and takes on a darker shade. You do not want either of these two conditions.

If you tie up your killed squabs by the feet when shipping to market, do not tie a lean with a fat squab, for if you do the dealer probably will give you the price of the lean one. Put the fat squabs in one bunch and the lean squabs in another bunch. If you are shipping to two dealers, you can very often get the top price from both by giving one your best squabs and the other your second best. 


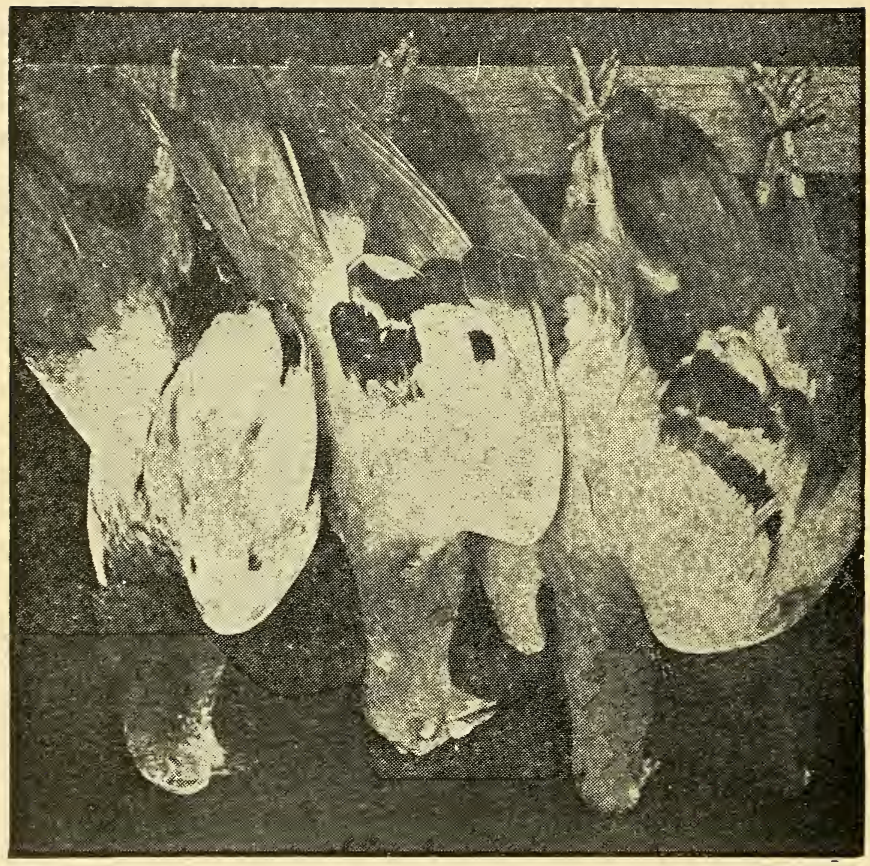

KILLED SQUABS HUNG TO COOL.

After the squabs have been killed they should be hung as this picture shows to cool. The wooden scantling or studding is several feet long and is suspended from the ceiling at its ends by wire, so that cats and rats cannot climb to the squabs. A pair of nails are driven in four inches apart and the squabs' legs set in between them 


\section{CHAPTER IX.}

THE MARKETS.

Squabs with the Feathers on Taken by the Boston and Some Other City Markets - The New York Market Wants Them Plucked and Pays the Highest Price of Any Northern City -Interpretation of Quotations of Squabs as Seen in the Newspapers-White-Fleshed Squabs are Wanted, Not DarkFleshed.

The Boston market, and the markets in some other cities, will take squabs with feathers on. It is only necessary for you to tweak the necks of the squabs and send them to the train, after they have cooled over night. Some shippers do not take the trouble to box the killed squabs, but tie their legs together with string and send them along to market. In the baggage cars of the trains running into Boston you will sometimes see strings of squabs going in to the dealers in this way.

The New York market demands squabs plucked. The squab breeders who have large plants and who ship to the New York market employ pluckers and pay them by the piece. A skillful plucker will strip feathers from squabs at the rate of ten to twenty squabs an hour. The proper time to pluck the killed squab is immediately after killing. When picked clean, throw the squab into cold water and leave it there over night to plump out and harden the flesh. In the summer use ice water.

The squab puts on more feathers than flesh during the last few days of its growth and if you see squabs which are only three weeks old, but which are of good size, you may save a week on feed by killing the squab at that age and plucking it. When the feathers are off of it, it looks like the four weeks squabs which have not matured so rapidly.

If you are shipping to the New York market, you should pack your squabs in a neat white wood box, printed if you please. Do not use a pine box for if you do the odor of the pine will penetrate the squabs.

The New York market for squabs is the best in the North. 
Squabs delivered by our customers there invariably bring from one to one dollar and fifty per dozen more than the Boston market. This is because there are more rich people in New York than there are in Boston, and they are more free with their money in providing luxuries for their table than Boston folks. We do not mean to disparage the Boston market for squabs, which is always good, averaging three dollars a dozen, but we wish to emphasize the fact that the New York market is a phenomenal one. Anybody living near New York can make a fortune raising squabs. Our largest orders have come from customers who are shipping to New York.

Not all the New York newspapers print market quotation of squabs. The New York Evening Sun is an exception. All through the winter squabs are quoted in the Evening Sun at five dollars a dozen. This means that a squab breeder shipping to New York should have got six dollars and seven dollars for a choice product, from private customers.

A correspondent in New York State sends a clipping from the New York Tribune's market columns and asks for an interpretation. We quote from it as follows:

"Pigeons, 20c.; squabs, prime, large, white, per doz., $\$ 3.50$ and $\$ 3.75$; ditto, mixed, $\$ 2.75$ and $\$ 3$; ditto, dark, $\$ 1.75$ and $\$ 2 . "$

The quotation, "Pigeons, 20 cents," means twenty cents a pair for common old killed pigeons. These tough old birds are occasionally found in the markets and are worth only ten or fifteen cents apiece. They are neither squabs nor the old Homer pigeons, but are common pigeons such as fly in the streets. A small boy might get a pair of these street pigeons and kill them and give them to a butcher who would pay him fifteen or twenty cents a pair. These cheap pigeons come into the eastern markets largely from the West in barrels and are sold to Boston commission men for five cents apiece, or fifty cents a dozen. They are retailed at from one dollar to one dollar and twenty cents a dozen. They are in the Chicago market masquerading as squabs. They have been killed with guns and have shot in their bodies. If you ask for pigeon pie at one of the cheap Boston restaurants, you will get a shot or two against your teeth with mouthfuls. After every trap-shooting contest some skulker goes over the 
field and gathers up all the killed and mained birds he can find, and sells them for two and three cents apiece, or for any thing he can get, and these find their way into the markets. The cruel practice of pigeon shooting by miscalled "sportsmen " on Long Island is quite common, and the presence of these birds in the New York butcher shops accounts for the above quotation in the Tribune. It is unnecessary to add that such birds do not compete with squabs. They can be made palatable only by stewing for hours in a pie, which takes out a little of their toughness. There is now a law in New York forbidding pigeon shooting.

As to squabs, the quotation, "Prime, large, white, per dozen $\$ 3.50$ and $\$ 3.75$," is for the kind of squabs that are raised from our Homers, namely, No. 1 grade.

By the quotation, "Mixed, $\$ 2.75$ and $\$ 3.00$," is meant that these amounts are paid for lots of birds composed of No. 1 and No. 2 grades, mixed. If you sort up your birds carefully you will be able to get the No. 1 prices for all. Some people do not know how to sort them, and they have to be satisfied with the price of a mixed lot.

By the quotation, "Dark, $\$ 1.75$ and $\$ 2.00$," is meant the dark-fleshed squabs, as you have learned by reading our Manual. Squabs whose flesh is dark do not sell for as much as the white-fleshed squabs.

Pigeons are of all colors, i.e., as you see their feathers, and the squabs likewise, but when you pluck the feathers off the flesh is either a pure white with a tinge of yellow, or dark like a negro's skin.

Quotations for squabs as found in the market reports in the newspapers are always lower than they really are. The writers of the market columns in the daily papers see only the commission men and cater only to them; they smoke the commission men's cigars and believe what the commission men tell them. They do not see the producer at all. The object of the commission men is to get the squabs as cheaply as they can. When you are breeding squabs make up your mind to get from twenty-five cents to one dollar or more per dozen than you see quoted in the market reports. The only way to find out the truth about the squab markets is to go into them and offer to buy squabs, not to sell them. Then you will learn the true prices. 

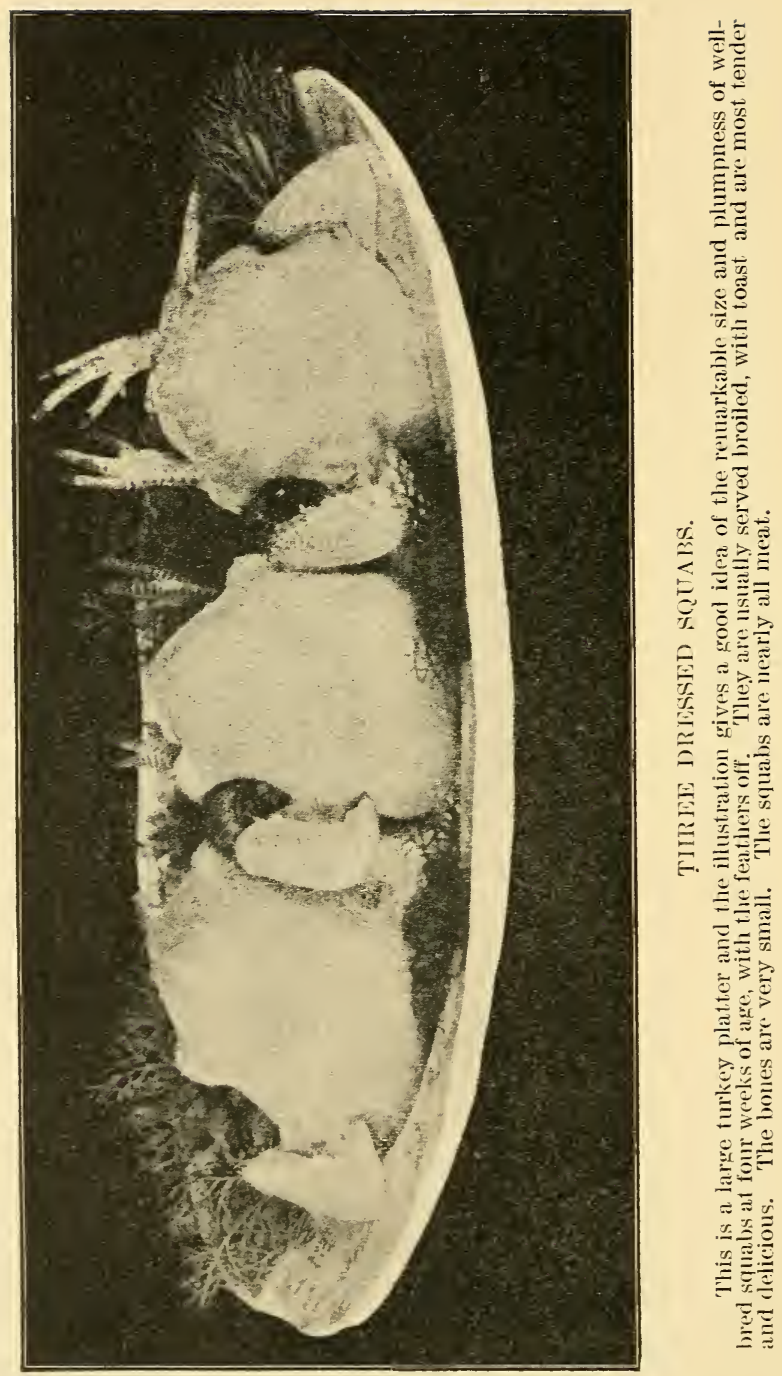
At the same time the report quoted above was printed in the New York Tribune a breeder in Mauricetown, N. J., was getting from four dollars and twenty-five cents to four dollars and fifty cents a dozen for his squabs. (This was the last week in January, 1902.) You see, it does not pay to trust wholly to the market reports in the newspapers. The motive of the city men is to get their goods as cheaply as they can. It is your motive to get as much as you can, and don't be fooled by second-hand information. Go direct to headquarters yourself in person and learn the truth. If the middleman tries to hold down the price to you, go to a consumer and make your bargain with him at top prices.

A breeder in New Jersey writes that there are several squab breeders in his town, all of whom give their regular time to other businesses. He continues: "I am now (February, 1902), getting thirty-two cents each as they run, no sorting, for what few squabs I am now raising, and they are sold to a man who calls every Tuesday for them. When I have enough, I ship direct to New York by express. They sort them in New York."

This is doing extremely well for unsorted squabs. It is only another bit of evidence which proves the money-making condition of the New York market. (The above correspondent's breeders are not first-class, he admits, saying he has been breeding for seven years and his flock has run down.)

The Kansas City market does not yet know what a fat squab is. The only things obtainable there are the squabs of common pigeons, which are quoted low, as they are all over the country. A correspondent in Atchison writes: "I wrote to the Kansas City dealer again, telling him I thought his prices were pretty low for Homer squabs. He replied that they had so few Homers offered that they did not quote them, and they would be worth from two dollars to two dollars and fifty cents per dozen. He quoted common pigeon squabs at one dollar and twenty-five cents to one dollar and seventy-five per dozen, as I wrote you before. That is better, and I want to try raising them as soon as I can get into a place where I can handle them."

Fact is, the squabs that bring from three to five dollars a dozen east of the Mississippi will bring that (and more) as soon as the wealthy trade of Kansas City gets a taste of them. 
Find out for yourself whether your market wants squabs with the feathers on or off. We do not know such details about the squab market in every city in the country and cannot advise you accurately on this point if you write to us from a distant town or city.

The best way to find out the facts concerning the squab market is to go from place to place, or to write, offering not to sell squabs but to buy them. The squab sellers are much more interested in a possible buyer than a possible seller. They receive letters from many inquirers about markets but as a rule pay scant attention to them unless the writer is really producing squabs and has them for sale.

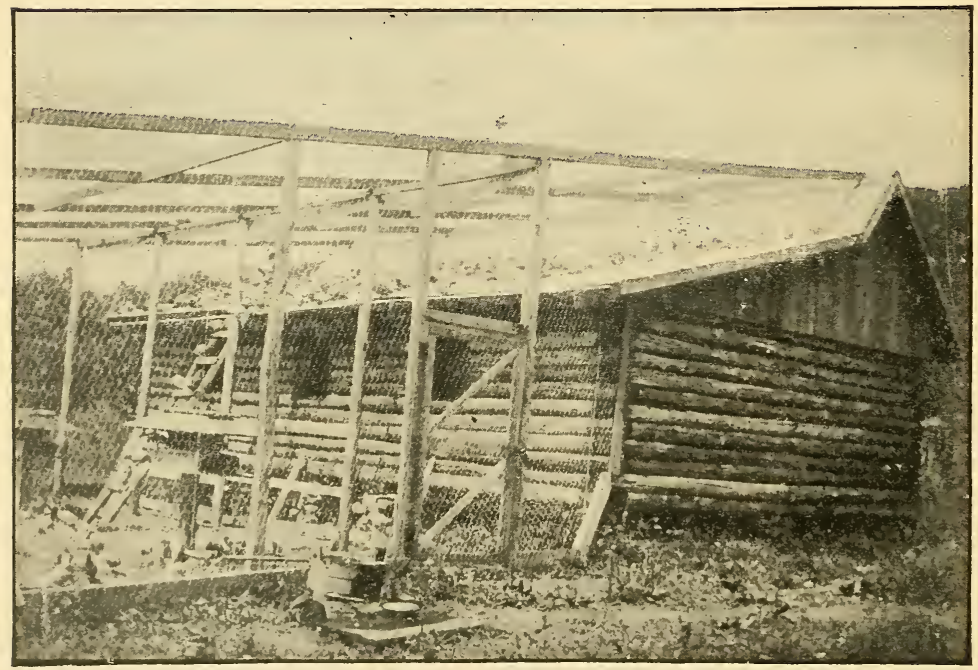

SQUAB IIOUSE BUILT OF LOGS 


\section{CHAPTER X.}

\section{PIGEONS' AILMENTS.}

Canker a Filth Disease which Makes its Appearance in Nasty, Cramped and Crowded Quarters - It is a Captivity Disease and a Sure Cure for it is to Turn the Bird Loose to Get a Change of Food and Plenty of Exercise - A Flock Supplied with Pure Food and Clean Water Never will be SickCanker is Not Epidemic - It does Not Pay to Dose a Sick Pigeon, Better Turn it Out to Get Well.

The principal ailment met with by the squab breeder is canker. This ailment is a puzzle to some breeders and they are alarmed when it makes an appearance in their flock, as it does if the feed is poor or sour, the water dirty, or the squab house filthy. The advice which they give when they find a cankered bird is, "Kill it." That is the advice we used to give at first, but now we know better. First, what is canker? It is a disease of which you know the cause (filth, poor feed or dirty water) and whose symptoms you see in the form of a cheesy-like deposit in the mouth of the pigeon, and breaking out around the bill. Catch the pigeon, hold it in your lap and force open its bill and you will see a yellowish patch or patches in the.mouth, and the mouth will usually be filled with a yellowish deposit which smells bad. The disease is not serious. The trouble lies with the feed and the filth and that is what spreads the same symptoms from one pigeon to another. A case of canker in your flock should be a warning to you that the feed or water is wrong, or that you have a filthy house. Do not get alarmed and kill the bird. Catch the affected pigeon, carry it out of your flying pen and squab house and throw it into the air. The bird may fly away and lose itself, and if it does you are out one pigeon just as if you had killed it. The chances are, however, as in the case of any sick animal, that it will linger around home. Now you will be surprised to see how quickly that pigeon's health will improve. Not having a steady supply of food before it, it will have to hustle for a living, and this exercise and the change of living, and the scanty living, will effect the 


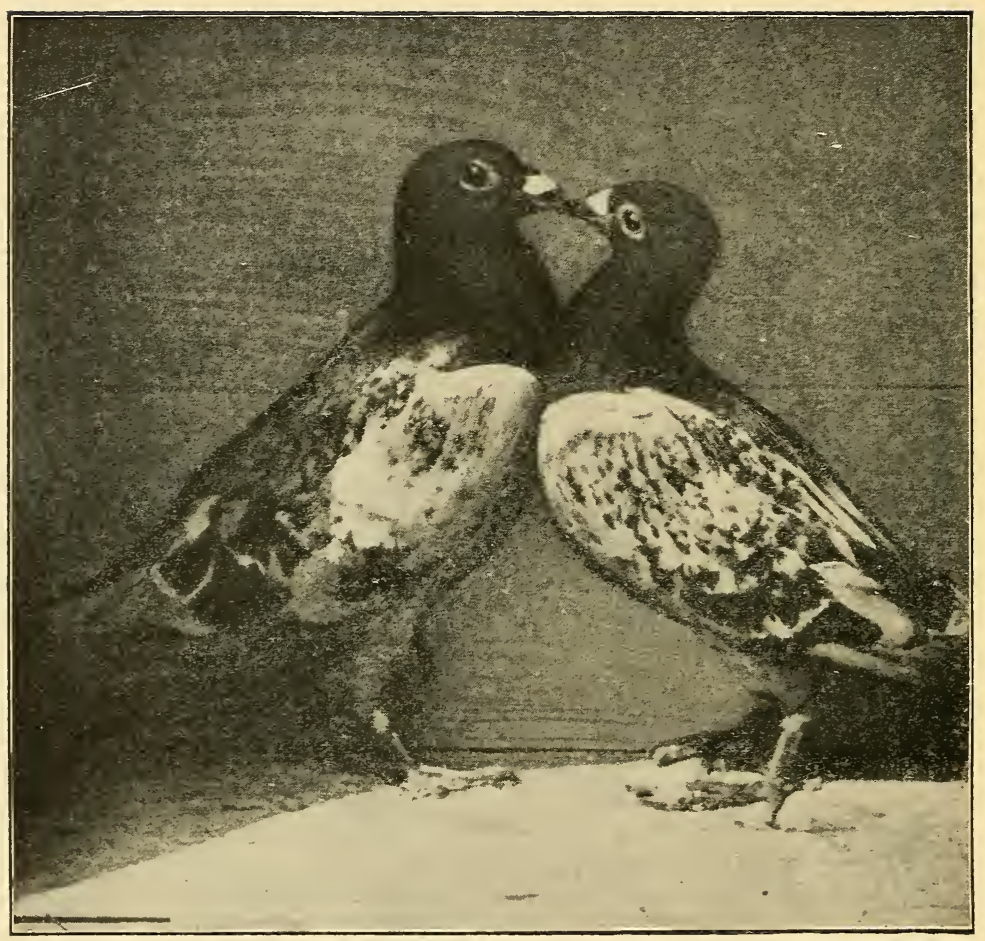

PAIR OF HOMERS BILLING.

This illustration is made from a photograph of a pair of our pigeons caught in the act of billing. or kissing. The pigeon on the left is the male and on the right the female. Billing is one of the acts of love making. Mounting and treading generally follow immediately after billing. 
cure. It will get more fresh air, and a great deal more exercise, and more sun, than it would get if lett in company with the other birds. In about a week you will notice that it will hold its bill tighter, and if there is a sore on the outside of the bill you will see this sore dry up. In two weeks the chances are that the yellowish deposit on the interior of the mouth will be entirely gone. The pigeon will hover around the other pigeons. It will fly to the outside of the netting and look at its fellows. Place a dish on the ground now and then with a little feed and you will attract it. Catch it when you have a favorable opportunity either with a net on the end of a pole, or with a broom, pinning it into a corner. You may have to try several times, but you will get it after a while. Its eye will be brighter and signs of disease will be gone, and you can put it back into the squab house with the others. The exercise, sunlight, change of food, and scanty food, have made the cure. There are few pigeons so bad with canker that they cannot be cured in this way. For that reason we have not much hesitation in saying that canker is a captivity disease, caused by lack of exercise as well as unavoidable filth and too much of the wrong kind of feed. We have observed wild pigeons in the streets and we never saw a case of canker among them. You may say to yourself that it is quite a risk to throw out into the open air a pigeon which has cost you from seventy-five cents to a dollar, but it is better to do this than to take the advice of all other breeders and books and kill it.

If you do not wish to throw a sick pigeon out into the air to get well, construct a box with wire netting over the front, and put the pigeon in there for special feeding and watering until it gets well.

Powdered alum sprinkled.in the drinking water now and then will tend to ward off canker from a flock.

It does not pay to dose sick pigeons, because a cure seldom is obtained by dosing, and you are out your time.

The squab breeder who follows the advice as to feed and water, and cleanliness of squab house, given in this Manual, will not have any sick pigeons. It is so very easy to keep a pigeon in perfect health that the fear of disease is a bugbear not worth taking into account. The element of disease is a constant source of worry to the chicken breeder, and a source of heavy loss to the best of thein. We wish to assure all who 
contemplate starting in the squab breeding business that the pigeon naturally is a healthier and more rugged bird than the domestic hen and that positively you will not be fussing with remedies and cure-alls, in handling them.

" Going light," or wasting away, is an ailment of pigeons occasionally met with. The cause of it is an absence of grit and salt. If your staples of feed are provided as we tell, and you give a variety of feed, and you provide grit and oyster shells, you will have no cases of " going light." The disease is known by a steady wasting away of the pigeon. Catch it and you feel a prominent breastbone, and scanty flesh, showing that some element in the feed is lacking. 


\section{CHAPTER XI.}

\section{GETTING AHEAD.}

Make your Birds Pay for themselves as they Go Along, unless you Wish to Wait Patiently until a Small Flock Increases to a Large One.-Better to Take the Money Made from Sale of Squabs and Buy More Adult Birds than to Raise the Squabs, Because it is a Long Jump from Four Weeks (the Killing Age) to Six Months, at which Age the Birds Begin Breeding - Shipping Points.

It is the birds and not the buildings which count in squab raising and if you have fifty dollars to start, put thirty-five dollars or forty dollars into your birds and the balance into your building. We have had customers start with a hundreddollar building and put a ten-dollar lot of birds into it, continuing to buy ten-dollar lots of us about once a month until they had their flock to a good size, but we believe it is best to let the buildings follow the birds, and not the birds the buildings. In other words, let your birds earn buildings as they go along. It is quite a drag on a small flock to weigh it down with an expensive building much too large for it.

Put this down in your mind solid, where you will not forget it: Make your pigeons pay for themselves as they go.

We sell to a great many poultrymen, and we like to get their orders, for they have been through the mill of raising feathered animals and are practical, and they are quick to see the money in squabs, and when their order for breeding stock comes along, it is in nine cases out of ten a large order, even if they have had no previous experience. They know that in order to sell squabs they have got to have birds enough to breed squabs and it is just as easy for them to spend fifty dollars or one hundred dollars at the start as it is for them to spend ten dollars or fifteen dollars and use up one hundred dollars' worth of time while waiting a year to begin selling squabs.

Many beginners are so skeptical that they do not believe squabs grow to market size in one month, or they have no confidence in their ability to feed the mature birds so as to keep them alive. They wish to make a start with a few pairs 
and actually convince themselves. We do not believe in untried hands plunging into something of which they know nothing, and we commend the caution of the beginner with squabs who wishes to feel his way and " make haste slowly" as the saying is, nevertheless we know it to be a fact that our customers who started with large flocks are making splendid successes, and we are not so cautious as we were in former books in advising a small purchase, at the start. The rules for breeding we have given have stood the test of time; we have not had it said to us that they are misleading or erroneous; on the contrary, our customers write and tell us that their experience corresponds with ours, that the books are all right, and our business has increased right along. When a customer orders two hundred dollars' worth of breeding stock of us and two months later two hundred dollars' worth more (we sell to some customers month after month steadily, as their means or their inclination permit them to buy) we are given a large measure of confidence, first, that people (many of whom we never see and who are not experts) can start with our writings and our breeding stock and make a success; second, that all we have advised about the industry is of general and convincing application; and third, that it does not take extraordinary skill to make a success with squabs.

There are failures with squabs, even by college professors, because some beginners are unsuited to the business. Many are lured into it by get-rich-quick stories. It would amaze you to read the letters that some beginners write. You never can tell a man's pigeon and poultry ability by his orthography and grammar. Letters in crude spelling and crooked writing frequently come from the most successful squab raisers. The knack of caring for animals successfully cannot be acquired by some. Given two women, with cooking materials and the same cook books, one cooks splendidly, and the other miserably. Why? Well, it is the same with pigeons. Some can and some can't. However, the failures at squab or poultry raising seldom blame themselves.

There are many of the naturally careless, improvident persons who have turned to squabs to help them out of financial holes, and they have made a failure of squab raising. Many of us remember the furore over raising chicken broilers for market, which started a score of years ago. The fact that 
some were making money at it started a burning hen fever in hundreds of young and old people anxious to make a lot of money quick. Clerks and society women from New York moved into the suburbs on small farms and began to try to make realities of their dreams. Not accustomed to manual labor, they made a sorry mess of it. Writers of that period tell of chicken gentlemen and ladies who went about their daily round of duties with their delicate hands carefully protected by kid gloves. It did not take long for the end for such experimenters to arrive. They returned to the great city sadder, but wiser. The squab industry has suffered also the past five years from such treatment. Many have played with it as a child would with a new toy, giving up their pigeons in a few months at the slightest discouragement.

The past six years are strewn with the wrecks of imitation squab advertisers and their guarantees. Every spring, when demand for breeders is greatest, some of these come to life again, or new ones crop up, and they get what harvest they can, many of them selling what they can pick up in the way of culls, such as we ourselves sell to Faneuil Hall marketmen to be killed. These advertisers start advertising in January and by June they have quit.

The following, from the pen of an old poultry writer, appeared in a farm periodical of large circulation in January, 1907: "So far, every attempt made in this country to establish a large poultry (chicken) farm has been met by failure. The extensive and successful plants of today are the outcome of a small beginning and a gradual growth. True, the main cause for failure has been the lack of experience; men have undertaken work for which they were not qualified."

So it is the rule with squab and poultry failures, especially women, to blame everybody but themselves. Such persons learn bitterly that experience is indeed a factor.

The place and flock of the one who fails with squabs tell their own story. The drinking fountains are seldom washed, the pen is seldom cleaned and the place has a run-down look generally, sometimes being positively filthy. The grain is bought and fed on the catch-as-catch-can principle with no provision for variety. The cheapest grain is bought, or it is ignorantly bought, and may be full of weevils, or sour. The owner of such a place generally matches the place. 
Some advertisers selling breeding stock try to give the impression in their advertising that they control the matings and love affairs of the pigeons they sell, to the uttermost degree. "We are the ones who can start you right," they say, "with our guaranteed mated pairs." Their pigeons, however, behave just the same as all pigeons. You have just as much control over the minds of your pigeons as anybody. We have the finest equipment for mating in America, as it is the largest, a thousand mating coops being in constant use. One of the buildings is heated by a hot-water plant so as to get quick results in mating in the winter. It is natural for pigeons to breed, same as all animals. Do not believe that the man who offers to sell you pigeons has it in his power to control them after they have left his hands. The control of your pigeons is in your hands absolutely. If you raise an excess of cocks, or if you have an excess of either sex, for any reason, you should procure enough of the opposite sex to match up evenly. You should have some mating coops (ordinary boxes with wire fronts will do) and in them you should pair up birds to suit yourself as to color of plumage, or size, or special characteristics, as you raise them.

We fill all orders, large or small, with equal care and thoroughness, for it is just as much to our interest to please the customer and get more orders in the one case as in the other.

There is not much choice as to what time of year a start in squab breeding should be made. Our customers who start in the winter have been exceptionally successful because then prices for squabs are at the top notch, and it takes only a few sales to make a new breeder thoroughly convinced to go ahead to success. We ship breeders all the year round. A pigeon will not break down under either stifling heat or bitter cold, being different from other animals.

We fill orders in rotation and treat customers alike, and ship promptly. Frequently we get orders to ship by first returning express, and it is very difficult to do this. One customer in Chicago planned to start for Alaska with twelve pairs of our birds, but he held back his letter so that we got it with only two hours to fill crates and get birds to him before his departure. We filled his order as a matter of accommodation. 
In ordering supplies to be sent by freight, remember that it takes a freight shipment some time to get to destination, especially when traffic is congested in the spring or in the harvest season. Give us your order for nest bowls and supplies before your house is ready.

The live breeders are shipped by us either in specially made pine crates or wicker coops. The wicker coops remain our property and are returned to us at our expense by the express companies after the customer has released the pigeons. These baskets are expensive and are fitted with large tin feed and water dishes. It is impossible to break them open with the roughest handling. The birds have plenty of room in them and arrive at their destination in fine condition.

The usual fault of inexperienced shippers is that the box or crate is too high, and too large, giving an opportunity for one bird to pass another by flying over its head. If there is too much room between the top and bottom of the crate feathers will be rumpled and pulled out, and the birds by crowding will suffocate one or two. A large, heavy crate also adds enormously to the express charges. It is not pleasant to buy pigeons and receive them in a cumbrous box weighing from twenty-five to seventy-five pounds, on which the express charges are more than double what they would be were the birds crated properly.

If the birds are going to a point only a day or a day and a night distant, they need no feed nor water. For a long journey, a bag of grain should be tied to the crate. It is the duty of the express messengers to feed and water the birds en route, and they are so instructed by their companies.

Do you know that pigeons are transported by the express companies at the rate charged for ordinary merchandise under the classification in force for 1907 on? The rate is found in every express book (ask your agent to show it to you if there is any dispute over charges) now as follows: "Pigeons, homing, merchandise rate." Tell the agent to look in the P's for Pigeons and he will find it there.

For carrying most live-stock short distances, the animal rate (which is double the merchandise rate) is charged. This is a peculiar rule when it was formerly applied to pigeons, and it worked so that the buyer at a remote point got his shipment cheaper than the buyer nearer us. For instance, we 


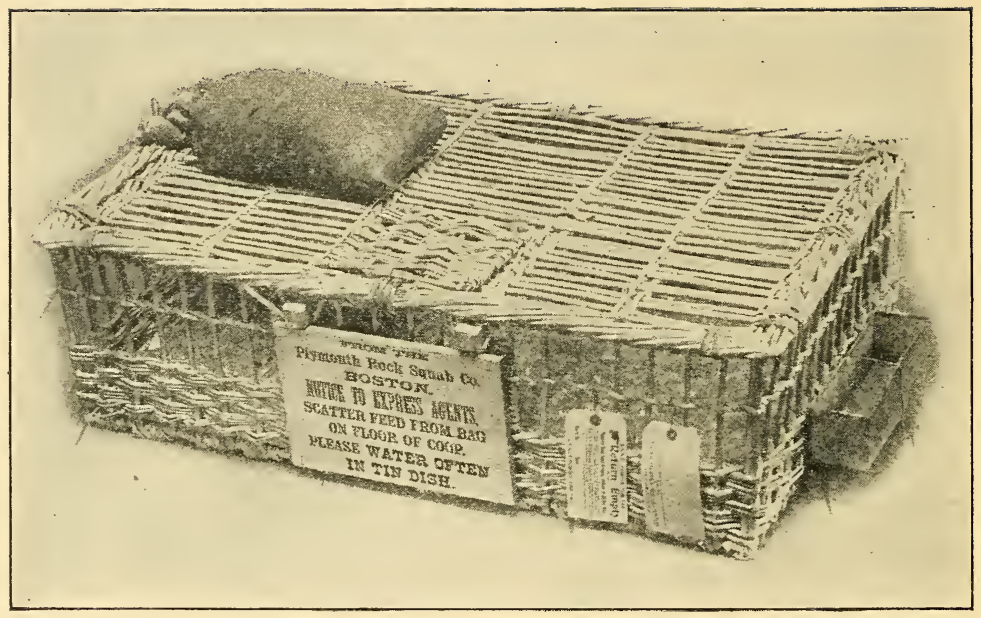

\section{HOW WE SIIP PIGEONS.}

Care and skill exercised in shipping live pigeons are large factors in satisfying customers. It is not a pleasant experience to send money away for pigeons and have them reach you in a home-made box, generally of enormous weight, and bearing enormous express charges.

We originated the above style of shipping and have two thousand shipping baskets in use. They are expensive but by their use we are able to guarantee safe arrival. The customer receives his shipment in faultless condition.

The small bag of grain on top of the basket, tied to it, is for the use of the expressman in feeding the birds en route. The tin water dish is at the end of the basket, outside, where it ought to be, not inside.

These shipping baskets remain our property and are returned to us empty at our expense after the customer has released his birds. 
could ship a crate of pigeons to Chicago from Boston cheaper than we could to Buffalo. All the express companies doing business in the United States and Canada have the same rule, which is, that between points where the single or merchandise rate is two dollars or more per hundred pounds, live animals, boxed, crated or caged, are charged for transportation at the single or merchandise rate. Between points where the single or merchandise rate is less than two dollars per hundred pounds, live animals are charged the animal rate (which is double the merchandise rate). Poultry (not pigeons) are charged the one and one-half rate when the rate per one hundred pounds is less than two dollars.

In order to obtain the lowest rate of transportation, the value of each pigeon must be stated by the shipper at five dollars or less.

We have seen breeders who have been shipping live-stock for years and they never heard of the above rule of the express companies, and also we have seen scores of express agents who did not know of their own rule, but always charged the animal rate on animal shipments. But the rule is found in every graduated charge book of every express company and the experienced expressmen and experienced shippers know all about it. If the agent in your town is ignorant of the rule, ask him for his graduated charge book. Many express agents at local points seldom handle a pigeon shipment and do not know how to charge for it.

A live animal contract release, to be signed both by shipper and express agent, is needed in all cases where the value of each pigeon is more than five dollars. If pigeons which we ship are killed in a smash-up, we can recover from the company. We have no hesitation, therefore, in guaranteeing the safe delivery of our pigeons to. customers. Our responsibility does not end when we have given them to the expressman. Our guarantee follows them as long as they are in the hands of the express company. We will put them into your hands safe and sound.

Once in a while you will read of live-stock and breeding associations getting together and complaining about the " exorbitant rates" charged by the express companies. The trouble is not with the rates of the express companies, but lies wholly in the ignorance of the breeders who meet to complain. 
They simply do not know how to ship and how to talk to the express agents.

We never read the above advice as to shipping live-stock in any book or paper. It is the product of our own experience and the information cost us at least one hundred dollars in excess charges before we learned how to get the low rate. It is worth dollars to our customers, and that is why we have given it here in detail.

Killed squabs go to market at the rate charged for ordinary merchandise, no matter what the distance. Breeders having special customers who wish the squabs plucked should pack them in a clean white wood box (with ice in the summer) and nail the box up tight. Such shipments go through in splendid condition and if the breeder has a choice article, with his trade mark stamped on the box, he gets the fancy price. Squabs which reach the Boston market from jobbers in Philadelphia and New York are plucked and packed with ice in barrels. Breeders around Boston who reach the Boston market with undressed squabs send them in wicker hampers or baskets on the morning of the day after they are killed.

No express agent anywhere has a right to make any extra charges whatever on our pigeon shipments.

There is no duty on our pigeons to Canada, Cuba or Porto Rico, when we send with the pigeons and also to the customer, as we do, a certificate of purity of breed, declaring that the pigeons are for breeding, and not to be killed for market. 


\section{CHAPTER XII.}

\section{QUESTIONS AND ANSWERS.}

Women and Squab Breeding - Attentions of the Male to the Female Pigeon - Equal Number of Males and Females - Birds Flying Wild-Sale of Birds for FlyersVariation in Size of Nest Boxes - How Squabs are Artificially Fattened - Shipping to England-Training Flyers - A Remarkable Service for Messages between Islands.

Question. I am a woman who knows absolutely nothing of squab raising. Do you think I can make a success of it? Answer. Our books are written and printed for the purpose of telling an absolutely ignorant person just how to proceed. If you will study this Manual, until you get the general plan and method of procedure in your mind, there is no reason why you cannot make a success of it. A woman is quick enough to puzzle out a new pattern of embroidery or a blind cooking recipe the terms of which are expressed in language utterly incomprehensible to a man. We find that our women customers are just as quick to comprehend pigeons as soon as they get started. It is necessary to have confidence, first, that the birds can make money, and second, that you are able to handle them right. Women succeed with hens quite as well as men. They "take" to animals fully as well as men. The fact that you, our customer, are a woman, ought to encourage rather than depress you, in the squab business.

Question. I have an old poultry house fifteen by twenty - feet in size, ten feet high. How many pairs of pigeons can I accommodate? Answer. We have this question asked us many times, and our reply to all is the same. Sometimes the customer varies it by asking, How large a house do I need to accommodate one hundred pairs of breeders? Sometimes they say they propose remodeling a barn loft which is thirty by twenty feet in size. The dimensions of the building vary with the customer. You can always accommodate in theory as many pairs of breeders as you can make room for pairs of nest boxes. Fix up your building to suit yourself, and put in 
as many nest boxes as you wish. Then count your nest boxes and you will know how many birds you can accommodate. You must have two nest boxes for every pair of birds. Always allow more nest boxes than there are pigeons, and do not crowd the birds, as we have explained on page 29 .

Question. How does the male bird impregnate the female bird? They do not seem to me to act as roosters and hens do. Answer. The human eye is not sharp and quick enough to follow the actions of the male bird. He mounts the female in a manner which is called "treading." A female occasionally will "tread" the male bird, exactly as a female animal when in excessive heat sometimes will mount the male, or another female. Customers who had what they thought was a doubtful pair sometimes have written us saying that each would tread the other, and that of course both were males. After a while the same customer would write and say that the pair fooled him and that he had two eggs from them. The actions are in nine cases out of ten, of course, a positive guide, but there are exceptions to every rule.

Question. (1) The legs of the pigeon you sent me are red; are they inflamed?. (2) The droppings are soft and mushy; I am afraid they have diarrhœa. What shall I do? (3) Most of my pigeons have a warty-like substance on their bills, varying in size with the pigeon; how shall I get rid of it? Answer. (1) The red color which you see is perfectly natural. The legs of all Homer pigeons are red. (2) The natural droppings of the pigeon are soft and somewhat loose. When they have diarrhoa the droppings are extremely watery and the tail feathers are soiled. Your pigeons are all right and have no diarrhoa. (3) The growth of which you speak is perfectly natural. It varies in size with the pigeon, sometimes covering the base of the bill, in other cases clinging closely to it.

Question. Can I figure with certainty that of each pair of squabs which my birds hatch, one is a male and the other a female? Answer. Not with absolute certainty, but as a rule. It is Nature's way to provide for an equal number of males and females, for that is the way the species mates and is reproduced.

Question. Enclosed find ten dollars, for which please send me settings of pigeon eggs to that value, and send me the balance due, if any. Answer. We do not sell pigeon eggs. 
It is impossible to use an incubator and raise pigeons successfully, because there is no way of feeding the young squabs when they are hatched. The life of squabs is nourished and prolonged from day to day by the parent birds, which feed them. To raise squabs, you must start by buying the adult breeders. You cannot start with the eggs.

Question. It seems to me that if each pair of squabs hatched consists of male and female, that this couple is likely to pair when grown, being well acquainted with each other. This would be inbreeding and would weaken my flock. What shall I do? Answer. It is not the plan of the species to mate and inbreed like this. If brother and sister mated as you describe, the species would be extinct after a while. They will look for new mates as soon as they get out of the nest and are of breeding age.

Question. When are the young pigeons old enough to mate? Answer. At from four to six months.

Question. My birds do not know enough to go in from the roof of the squab house when it rains. How shall I get them in? Answer. Let them stay on the roof in the rain if they wish. The rain will do them no harm.

Question. Must I heat the squab house in the winter time? Answer. No. The heat from a flock of pigeons in a wellbuilt house is considerable. You will get more squabs from your pigeons in the winter time if you do heat your house slightly, not enough to cause much expense, but just enough to take the chill off. Do not let your birds out of the squab house on bitter cold days.

Question. I live in Texas and I think in this climate your squab house would be too warm and stuffy. Answer. You are right. Adapt the construction to your locality. The poultry houses in Texas as compared to those in the North are much less expensive and more open to the air, and your squab house should be built on the same principle.

Question. Suppose I cool the squabs as you direct and pack them into a box for shipment, shall I use ice? Is there any danger that the meat will be discolored when they arrive at market? Answer. Ice is not necessary in the fall, winter and spring. In the summer time you should use ice, although if the shipment is for a short distance, ice may not be necessary. In hot weather the squabs should not be killed until the night 
before shipping. In the cool months you may keep them at home longer. If the squabs are cooled by hanging them from studding as we describe, there is no danger that the meat will be discolored. The object of hanging them from studding is to cool the carcasses properly so that the meat will not be discolored by contact.

Question. How shall I pack the killed squabs when I send them to market? Answer. Lay them in the box layer on layer, in an orderly fashion. Do not throw them in helter skelter.

Question. Can I hang the squabs to cool from studding suspended in the barn, in the summer time? Answer. It is better to use the cellar of the house, or the coolest room in the house.

Question. I do not like your idea of keeping the birds wired in. They are free by nature and it strikes me that they should have a chance to get exercise by long flights. Answer. You must keep them wired in, or they may leave you. Remember that the Homer is attached to the place where it is bred, that is the Homer instinct. If you buy birds of us and on opening the crate let them fly anywhere they choose, trusting to luck to have them come back to you, you may be disappointed and lose some of the birds. You must keep them wired in all the time.

Question. You say your Homers are fine flyers. What is the use of my buying them of you to fly in races or to sell again as flyers, if they may desert me when I let them out into the open air? Answer. The squabs which you breed from our birds will know no home but yours, and they will not fly away from you. You can send them away, when they are old enough, and time their flight back to your house, their home. When you sell these trained flyers to others, you do not expect that they will try to fly them, but that they will use them for breeders.

Question. How large are the mating coops? Answer. A convenient size is two feet long, two feet wide and two feet high.

Question. My birds seem timid and I am afraid to catch them. How shall I go about it? Answer. Do not be afraid of hurting them. Take a broom and drive one where you will, finally pinning it against the side of the squab house, or 
in a corner. Grasp it and hold its wings firmly and it will not struggle. Or you may make a net on the end of a pole, like an ordinary fish landing net, and scoop the bird into it as it flies through the air.

Question. Suppose I have several squab houses, as you describe, but let all the birds together in one large flying pen, where they can bathe from one large fountain. Answer. This is all right if you do not wish to keep close track of your birds. If the birds can roam from one house to another, there is nothing to prevent a pair from building one nest on one house and then going to another house to build the second nest.

Question. I believe I will put a strip of wire or piece of wood across the front of each nest box so as to keep each pair more secluded, and to keep the nests from dropping out. Answer. Don't do it. Don't worry about the nests falling out. Build the pigeon-holes perfectly plain.

Question. How many squabs shall I pack in one box when sending to market? Answer. Having picked out the size of the box you wish, fill it up close with squabs, so they will not "shuck." As to the size of the box, make it as big or little as you please, but do not make it any bigger than one expressman can handle easily. A good size is two feet square and one foot deep.

Question. Send me two males and ten females. Answer. You must buy your birds in pairs. They pair off in this way, namely, one male to one female. One male does not have two or three females. We have heard pigeon breeders talk of having one cock which would attend two hens, but never had a case in our experience.

Question. After plucking the squab, and before sending it to market, do you remove the entrails? Answer. No.

Question. In order to avoid the trouble of using the mating coop, may I put an equal number of cocks and hens in the same pen? Answer. Yes.

Question. Can I discover the male and female organs by examination of the birds with a magnifying glass? Answer. No. You can discover them by dissecting the dead bird.

Question. Suppose I build the nest boxes larger, so as to give a shelf on which the birds can alight? Answer. Don't do it. The bird will fly directly into the nest, or onto the nest 
box in front of the nest. You do not need an alighting place.

Question. Seems to me that if I start with forty-eight pairs of birds, I ought to have ninety-six perches. Answer. The birds do not all perch at the same time. While some are perching, others are on the nests, or walking on the floor, or are outside in the flying pen, or on the roof. Put up a few perches where you have room and let it go at that.

Question. I live in England; can you ship me twenty-four pairs of your breeders? Answer. Yes; the transportation charges will be four dollars. In addition you will have to pay the butcher or steward of the boat ten shillings for feeding and watering the birds. Send us six dollars and fifty cents in addition to the regular price of the birds and we will ship to you all charges prepaid. In shipping to $\mathrm{Cuba}$ and remote points in the United States and Canada, we do not have to pay anything extra for the feeding and watering of the birds; the express charges include the feeding and watering.

Question. What is a Runt pigeon? Please quote prices on a dozen pairs of Runts. Answer. A Runt pigeon is a special breed of pigeon, remarkable for its large size. They come all colors, as a Homer does. The white Runts are an exceptionally beautiful bird and command large prices, as high as six dollars to fifteen dollars a pair. The squabs which Runts breed weigh from eighteen ounces to one and one-half pounds at four weeks. If Runts bred as fast as Homers, they would be just the bird for squab breeders, but they are fatally slow in breeding, as a rule. The Homers raise two pairs of squabs to the Runts' one. Therefore it is of course more profitable to raise Homers. We do not sell Runts and do not advocate their use either as a separate breed, or crossed up with Homers. The large, plump, thoroughbred Homer is the best.

Question. What is the difference between the Homer and Antwerp breeds of pigeons? Answer. No difference. The name is used interchangeably to apply to the same breed of pigeon. In New England we speak of them mostly as Homers. In some places they are called more often Antwerps.

Question. Can I feed some of my squabs by hand if necessary? Answer. Yes. Mix up a mushy, soft handful of grain, hold the squab in the left hand, close to your body, and with the thumb and first finger of your right hand force the 
mixture into the bill. The squab will swallow and fill its crop. A backward squab may be forced in this manner.

Question. Can you sell me twelve pairs of young Homers, about eight weeks old? Answer. No. It is impossible to tell the sex of pigeons of that age. Any breeder who undertakes to furnish squabs several weeks old in equal males and females cannot do so and is imposing on you.

Question. Please give recipes for cooking squabs. Answer. See the cook books. Squabs are generally served broiled. They should be drawn, singed and washed. Cut off the heads, split into two parts, season, put on a lump of butter and broil over a hot fire. Place close to the fire at first so as to brown the outside and retain the juices, then hold further away from the fire to complete the cooking. If roasted, leave them in a hot oven for thirty minutes. For roasting, squabs may be stuffed with cranberries or currants. Baste every ten minutes with spoonfuls of hot water and butter.

Question. How shall I train the young birds raised from your Homers to fly? Answer. There is a large business in flying Homers and if you have a pen or two of trained birds you can sell them at fancy prices. There are homing clubs all over the country which have contests and it is worth while for a breeder to work for a reputation of breeding and selling fast flyers. The young Homers when five months old are strong enough to be trained to fly. Take them in a basket (having omitted to feed them) a mile or two away, and liberate them one by one. They will circle in the air, then choose the correct course. You should have left grain for them as a reward for their safe arrival home, and an inducement for their next experience in flying. Two or three days later take or send them away five miles and repeat. Next try ten miles, and so work on by easy stages up to seventyfive or one hundred miles. If you have a friend in another city, you may send your birds in a basket to him with instructions to liberate certain ones at certain hours, or you may send the basket by train to any express agent, along with a letter telling him to liberate the birds at a certain hour and send the basket back to you. If you wish to have the birds carry a message, write it on a piece of cigarette paper (or any sirong tissue), wrap the paper around the leg of the bird and 


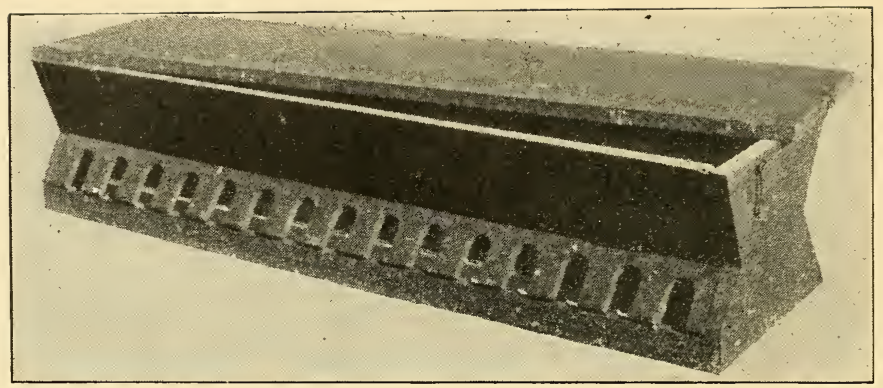

\section{SELF-FEEDER FOR GRAIN.}

This trough gives excellent satisfaction with us. We do not sell it, but will tell you how to have it made. It is four feet long. At the bottom of this page you will see a sectional view of it. The grain is put into the hopper, $H$. It drops in the direction indicated by the arrows into the spaces, AA, where it is eaten by the birds. As fast as they eat, more drops down. The strip through which they stick their heads is three inches wide and the slots are cut one and one-half inches wide. The $\mathrm{V}$ at the bottom of the trough is made from a solid piece of four by four. It is solid so that rats cannot get inside of it and hide and pilfer the grain. The inch-square pieces at the front of the bottom prevent the birds from pecking the grain out upon the floor. One-inch lumber is used in the construction for every part except the slot-boards, BB, which are three-eighths inch thick. The top and bottom are of twelve-inch boards, the sides of ten-inch boards. The top is held in place by a hook and eye at each end as pictured. The trough will hold from three days' to two weeks' supply of grain, depending on the size of the flock. Put the trough not in the flying pen, but inside the squab house. Or, you may build a half-trough (slot-board down one side only) and set it in the passageway, and it will fill the space between the lower tier of nest boxes and the floor. Here it may be filled from the passageway, and you will not have to enter the unit pen. We have tried all kinds of self-feeders and recommend this pattern as the best of all. If you adopt it in connection with the dowel system (illustrated on previous page) your dowels will be used only behind the drinker, this trough taking up four feet of the rest of the space. Make it either longer or shorter than four feet, to suit the size of your flock, if you wish.

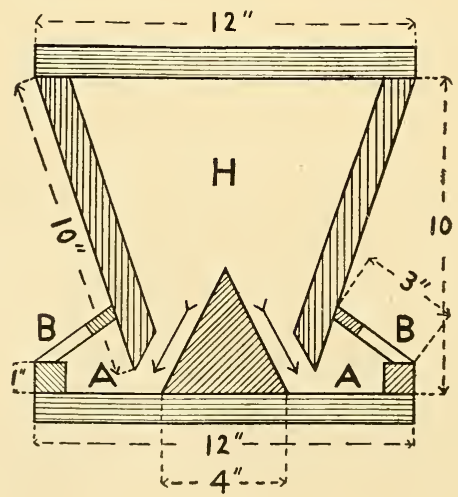


tie with thread, or fasten with glue or a stamp; or, you may tie the tissue around one of the tail feathers. A thin aluminum tube containing the message may be fastened to a leg, or to a tail feather. A trap window should be constructed to time the arrival home of birds. This is an aperture about six inches square closed by wires hanging from a piece of wood at the top of the aperture and swinging inward, but held close to the aperture by its own weight. The pigeon cannot fly out but on its return home (if you have sprinkled grain on the inside of the house, next the wires) the bird will push the wire door and go in. It takes only a day or two for the pigeon to become accustomed to the trap. If you connect the trap with a simple make-and-break electric circuit, the pigeon on its arrival home from its flight will ring a bell in any part of your house or barn. When you have a record of the flyers, you will have a guide for mating. The majority of fanciers recommend a medium-sized Homer. A large hen should be mated to a small cock, or a large cock to a small hen. What is perhaps the best pigeon service in the world has been in use for several years between Newton Roads, Auckland, New Zealand, and the Great Barrier and Maro Tiro Islands, some seventy-five miles distant. A boy of sixteen years worked up the service and makes a large income from it. About twenty messages an hour are carried back and forth by the Homers. A year ago the government declared its intention of laying a cable from Auckland to Great Barrier. The project was abandoned, however, as the residents of the little island decided that they were well pleased with the pigeons, and that a cable would not be patronized. The government offered to buy the whole pigeon outfit from the boy owner, but he refused. There are from four hundred to five hundred pairs of pigeons in the service.

Question. In the case of young birds mated up for the first time at five or six months of age, is it best to destroy the first eggs, or let them go ahead and hatch in the regular way? Answer. Let them go ahead and hatch and learn to feed their young. It will improve them for the next hatch.

Question. Please describe the self-feeder more fully and explain its operation. Answer. The hopper of the feeder is $\mathrm{V}$-shaped so that the grain will fall by its own weight to the centre at the bottom, which is cut away as shown in the 
illustration so that as the birds peck up the grain, more falls from the hopper. The slit where the birds eat should be about an inch and a half in width, just enough to prevent the grain from running out faster than it is eaten. If the grain is pulled out on the floor, tack a strip of wood, like a lath, so as partly to block the holes.

Question. Should I cover the yard of the flying pen with your grit? Answer. No. Provide a box and keep our grit in the box. When the pigeons want grit, they will go to the box and get it.

Question. Are the carrier (flying) pigeons the same breed as your Homers? Answer. Yes. A flying or carrier Homer is a Homer that has been trained to fly a long distance.

Question. What are artificially fattened squabs? Answer. An artificially fattened squab is a squab which has been stuffed by hand. Take a syringe and fill it with fattening mixture of gruel-like consistency, open the mouth of the squab and force the contents of the syringe into the crop of the squab. Very few breeders take this trouble to bring their squabs to an extraordinary size.

Question. I wish you had shipped my breeders in one large crate, then the express charges would not have been so much as for the two crates which you used. Answer. You are mistaken. An express shipment goes by weight and not by number of packages. The express clerks put all the crates going to one customer on the scales together and weigh them all at once and on the total weight the charge is based. They prefer to handle a large shipment in small packages, rather than in one large package.

Question. Can I use the upper part of my henhouse for pigeons, and if so will the pigeons interfere in the flying pen with the hens? Answer. You may use the upper part of your henhouse and the pigeons will not be harmed by the hens, nor the hens by the pigeons. It is best to build the flying pen in two stories so that the pigeons cannot fly into the henhouse to try to nest.

Question. To save room, I would like to build my pigeon house in two stories. Answer. That is all right. Build the top flying pen out over and extending beyond the bottom flying pen if you wish to separate the flocks on the ground floor from the flocks upstairs. 
Question. What are the bands for pigeons' legs and how are they applied? Answer. The seamless band is a ring of aluminum three-eighths of an inch in diameter and from three-sixteenths to one-quarter of an inch in width. You cannot apply it to an old pigeon. It is put on either leg of a squab when the squab is four or five days old, by squeezing the toes of the squab through the band. As the leg of the squab grows, it becomes impossible to remove the band except by cutting it off On the band, before putting it on the leg of the squab, you may stamp year of birth and your initials, or anything you choose. We sell an outfit consisting of aluminum tubing, dies, etc., by which the squab breeder may make his own bands at a cost of two or three for a cent.

Question. Since I bought twelve pairs of you, I have kept a careful account of the feed, and find as you state that five cents a month for a pair of breeders is right. Grain has been much higher than usual this summer and it strikes me that under normal conditions of the grain market the cost of a pair of squab breeders would be less than five cents a month, or sixty cents a year. Answer. Our figures of cost were ascertained not by "skimping" the birds, but feeding them liberally, and an estimate of five cents a month for a pair is based on a low cost of grain, and on selling the manure.

Question. What pattern of trowel do you recommend for cleaning the nest bowls and nest boxes? Answer. The common trowel such as bricklayers use is too pointed. The best pattern has a square point and a stout blade with strong handle. With such a trowel you can clean out the nest bowls and nest boxes very effectively.

Question. Can pigeons be raised on the sea-coast as well as inland? Answer. Yes; the Homer pigeon is descended from a variety of pigeon which first bred among the cliffs bordering the sea-shore.

Question. Do the squabs fly out of the nest before they are four weeks old? Answer. No; they look old enough to fly at four weeks, and their wings seem all ready for use, but they stay in the nest and are fed by the parent birds, and when you wish to kill them you find both in the nest ready for you.

Question. Your book states that pigeons sometimes lay their eggs on the floor. But it does not say anything about taking the eggs and putting them in a nest bowl. Would the 
birds follow their eggs and accept change of nest from floor to nest bowl? Answer. No; you must leave the eggs where they lay them. You can handle a nest and change eggs from one nest bowl to another, if you wish, but you cannot move eggs from one place in the squab house to another and expect the birds to find them and go on with their laying.

Question. Do all squab breeders heat their houses in the winter time; I mean those who do a large business like yourself. Answer. No; some breeders of many years' experience believe that a warm house is detrimental to the health of the birds, on account of the sudden change of temperature from a warm house to a cold flying pen. The object should be merely to take the damp winter chill off the air. If you have a warm, tight squab house which you will close when night comes, you will need no heat.

Question. In the case of a long house, say four units long, should there be wire netting partitions between the units, so as to separate the birds into four flocks? Answer. Such an arrangement is more practical than one long house. It is better to keep track of four small flocks than one large flock. You can keep account of the birds both on paper, and with your eyes, with more precision.

Question. How would a cement floor for the squab house do? Answer. Do not use cement. See page 43 again.

Question. How is salt cat made? Answer. Take sixteen quarts of sand, eight quarts of slaked lime, four quarts of ground oyster shells, one pint of salt, one pint of caraway seeds and mix with water into a stiff mud. Form into bricks and set away to dry. The water with which you mix should have a tablespoonful of sulphate of iron and a tablespoonful of sulphuric acid for tonic and disinfectant. The birds peck at this mixture and it is believed to have a tonic and strengthening effect on them.

Question. Shall I crowd one of the units with nest boxes, or would it be better to have a smaller number of nest boxes and build another unit to accommodate the new birds which I am going to buy? Answer. Better enlarge your squab house. In case of doubt, you will be on the safer side if you do not crowd the birds.

(See following pages for points which may occur to you and which are not covered in these questions and answers.) 


\title{
NATIONAL STANDARD SQUAB BOOK.
}

\author{
By Elmer C. Rice.
}

Every year shows a healthy growth in the squab industry and in our business, which has become the largest in the world in the pigeon or poultry line, and is expanding steadily, requiring every little while new buildings, larger business offices, more help-and the growth is going steadily on, with every prospect of a like increase the coming year.

On April 1, 1904, to get more room for the Boston office, we were obliged to move from No. 9 Friend street, and are now located at 287 Atlantic avenue, Boston, where in a new modern building and with our quarters fitted with every modern convenience for the rapid and accurate handling of business, we have the largest space in New England devoted to the pigeon or poultry, or kindred trade.

Our Manual, the National Standard Squab Book, is the best-selling work on breeding or farm-life ever published in any country, and has been carried in the mails to every part of the civilized world.

We do not speak of these matters in a boastful spirit to magnify what we have done, but because they are an assurance to new customers that we are entitled to their confidence and patronage.

We are most humbly grateful to the men and women who have favored us so bountifully with their trade and intend to merit further confidence.

Our business is too much a matter of pride with us, too large, and too successful, to permit of a single patron being dissatisfied. We have spent over $\$ 100,000$ to put our trade on a firm and successful footing and we cannot afford to run the risk of disnleasing a customer. If resources, skill and experience count for anything, and we think they do. we intend to keep on furnishing the best Homer pigeons nossible, and patron: can rest assured that they are getting for their money the greatest possible value. Moreover, we have one price to all; the customer in California can buy of us as cheaply as our next door neighbors. Our farm is always open to inspection and customers may make their own selection of breeding stock, if they desire.

Our general advertising in the highclass magazines and other periodicals not only induces the breeding of squabs but also leads people to eat squabs. For everyone who sees our advertising and writes for particulars and starts breeding, there are a score of men and women who enquire of their butchers or marketmen for squabs in order to eat them. Squab dealers in every section of the United States and Canada are reporting an increased demand with which the supply cannot begin to keep pace.

We take some pride in the squab industry. We were the pioneers in it and we put it on a commercial basis. We have fostered it on correct lines and according to sound business principles, and the growth has not been a "boom," as some other things in the past have been boomed, but has been steady and sure and successful. We paint no extravagant picture as to the profits of squab raising, and we show proofs every step of the way -stories of success of our customers wh: started green and are making money.

That there are occasional failures is to be expected. We give no recipe and sell no machinery for transforming an incompetent person who fails at many tasks into a success. But the history of this industry and of our business demonstrates with a power that cannot be denied that squab raising is RIGHT.

No business climbs up the hill of profit steadily for any length of time unless it is absolutely fair, advertised by true statements, and giving a true money's worth. When we began to tell the country about squabs, peonle would come to our offics and say, "Well, it reads pretty good, but is it true?" We did not have much evidence ready then, but we have now. Our answer is the present condition of the squab industry, forging ahead with giant strides to its place alongside of eggs and poultry, millions of dollars in value, and the unsolicited letters from our customers which we print, showing the most remarkable and convincing progres of this breeding.

We have already printed a great many of these letters in years past, and we print more in this supplement. We have room here to show only a small part of such testimony. For every letter printed here we have scores just as convincing. These communications have come to us unsolicited, day by day, as the business brought them, and more are coming every day, and they are our answer to doubters. They are the proof that what we say, about the business and what we teach in the Manual, is true, and is being worked out successfully. We do not print the names and addresses of the 
writers of these letters because many of them are regular buyers of our birds, and moreover, we cannot advertise other breeders free of charge. These letiers and the testimony they give are valueless if they are not genuine. Each and everyone is genuine, and moreover, Wf guarantee their genuineness, and will produce the originals at any time to satisfy anybody. In these days when many "testimonials", are unblushingly "worked up" without a shadow of foundation, there are skeptics, and to such who cannot come to Boston and see us, we recommend that they seni one of the commercial agency men to make the inquiry and handle the evidence. Tie have nevar yet had the genuineness of our letters from customers questioned, for they "ring true" and are in the simple language of facts which cannot be counterfeited, but we are ready at any time for any doubter.

Thhat others have done and are doing with our birds, you can do.

KILLING MACHINE.-To kill squabs with extreme rapidity we have made a machine with which the operator can work with much ease and satisfaction. The method of tweaking the necks which we describe and illusirate in the Manual is slow when compared with the work of this machine, and is repugnant to many, especially women.

The illustration shows the construction clearly. The neck of the squab is placed between the morable arm (or lever) and the lower arm, and the lever is brought down unon the neck, breaking the bones, crushing the spinal cord and killing the squab instantly. The operation produces no blood, nor does it break the flesh. The two edges of the upper and lower arms, where they come together against the neck of the squab should not be sharp so as to cut the flesh, but should be rounding, and slightly flat at the points of contact.

The base-board is made of three-quarters, or one-inch lumber, twenty inches long and seven inches wide. The upper

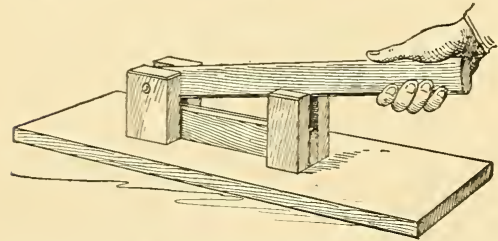

arm (or lever) is of half-inch stock, one and three-quarters inches wide and fifteen inches long. The lower arm is of half-inch stock one and three-quarters inches wide and eight and one-half inches long. The two upright pieces in front, nearest the hand of the operator, are each of seven-eighths or inch stock, one and three-quarters inches wide and three and three-cuarters inches high. The two upright pieces in back, furthest from the hand of the operator, are each of seveneighths or inch stock, two and one-half inches wide and three and three-quarters inches high.

The pin at the back of the machine on which the lever turns is of one-quarter inch brass or iron rod two and one-quarter inches long.

The upper arm (or lever) is beveled or cut off at an angle on lower corner (behind the uprights, and consequently invisible in the picture) so that the lever can be raised to an angle of forty-five degrees, thus permitting the neck of the squab to be inserted between the arms at a point just back of the farther uprights. When the upper lever is at rest upon the lower arm, there should be no space between the two; they should butt flush together.

The whole machine is built of wood witl the exception of the metal pirot and the screws which hold the parts together. It is not necessary to mortise the uprights into the base-board. The screws which fasten the uprights are started underneath from the back side of the base-board and go through the base-board. Nails may be used instead of screws to hold the parts together, but the job will not be so strong. The base-board should be nailed or serewed to a bench or table so as to give firmness and solidity in operation. Carry the squabs in a basket to the machine and kill them there; do not take the machine into the pens and kill the. squabs in sight of the other birds.

We do not sell this squab killer. It should be built by you or your carpenter.

Customers with large plants have told us that this tool is a handy article, and we have found it indispensable. The squabs can be killed as fast as you can work the lever. The pressure is considerable and the cords are crushed at once. The squab is not strangled but is paralyzed, and made lifeless at once.

After killing in this manner, the squab may be bled, if desired, by inserting a long, sharp knife in throat and cutting it inside, out of sight. It is easier to do this after the squab is dead than when it is alive.

TTEANING THE IOTNG BIRDS.-If you are starting with a small flock with the expectation of raising your oiwn breeders, do not take the young birds away from their parents out of the breeding pen until they are weaned. They are not thoroughly weaned until they are six to seven weeks old. It is true that many of them hop or fly or are pushed out of the nests when they are from four to five weeks old, but they continue to ery for food when they are hungry, and the old cock bird of the pair which hatched them will be seen feeding them on the floor. The youngsters at this time are feeding themselves, but to keep them strong and rugged they 
need the crumbs of parental food which they get as described, and for which they cry, or squeak. Thase crumbs have been moistened by the parent bird and consequently digest quicker and better.

When the youngsters are weaned, take them out of the breeding pen and put them in the rearing pen. You can tell by their looks when they are old enough to remove, even if you have not kept track of their age. The substance at the base of the bill of an old pigeon which is white will be a dark brown on a squab or young bird. A squab in the nest is so fat as often to be bigger than either of his parents, but after he has got out of the nest and hustled around on the floor he trains off that fat and becomes thin and rangy and can generally be told from an old bird, if in no other way, because he is smaller.

A poor beginner will sometimes be heard to say: "Many of my young birds are dying." When he says that, you may be sure that the trouble, every time, is with him, and not with his birds, provided, of course, his parent stock is rugged and handsome. It may be deduced, without asking any further questions, that he is taking his young birds away from the breeding pen before they have the strength to support themselves. The precarious period of all animal life is the weaning age. Some beginners who have had no difficulty in raising squabs to market age have had losses because they supposed that a full-fledged youngster was able to take care of itself, but we never knew a case of this which we could not straighten out simply by recommending the breeder to keep his young birds longer in the breeding pen.

NEED OF HEALTH GRIT.-It has been our experience in dealing not only with many thousands of beginners in the squab business, but also with a great many breeders of considerable experience, that comparatively few have a proper appreciation of the value of grit. Pigeons have no teeth and must have grit to take the place of teeth, otherwise they cannot prepare their food for their stomachs properly, and will not do well. We have had customers take the most extraordinary care with regard to the grain, but supply absolutely no grit, and then they complained because their birds were not breeding properly, and that the squabs were not plump.

Grit is not oyster shell, nor is oyster shell grit. You must have both. The grit is needed, as stated. to grind the grain, while the ovster shell is needed to supply the constituents out of which the female pigeon forms the egg.

The yard of the flying pen must be gravelled, not grassed, and out of this gravel the birds get considerable grit. If you watch them, you will see them pecking at this gravel in the flying pen constantly. Beach sand, or sand of any kind, may be used in the flying pen instead of gravel. The flying pen yard should be renewed with fresh sand or gravel every six weeks, for although it may look the same to you, you must remember that it does not look the same to the birds, for they have been going over it constantly picking out the particles which they liked. In the winter time when the flying pen may be covered with snow, it is well to keep a protected box filled with gravel or sand in the squab-house. By a protected box, we mean a box which the birds cannot foul, but which allows the grit to fall down as fast as eaten.

In a protected box in the squab-house there should also be fed the Health Grit which ve sell. We have used all kinds of rrits, and the grit we are now using and selling to the exclusion of everything else, is the only grit which pigeons will eat greedily (thus showing that it is good for them). It contains salt, and no salt need be provided in lump fcrm if this grit is supplied. The grits commonly manufactured and sold for poultry, made out of granite, etc., are useless for pigeons, and it is a waste of money to buy them, for common gravel or sand would be fully as good, and cost nothing.

A flock of pigeons under any conditions and in any part of the country will do better when our Health Grit is fed. The squabs will be ready for market a few days earlier, they will be plumper, and both they and the old birds will be in rugged health, and will keep so. We keep this grit before our own pigeons constantly, and consume and sell more tons of it every year than of any grit in the market. It is used by practically every large squab breeder of our acquaintance. We recommend it in the highest terms, knowing in our own experience that it pays for itself many times over.

We charge two dollars per 100 pounds for this grit. We do not sell less than fifty pounds. Price of fifty pounds, one dollar. We ship it in bags and it goes at a low freight rate. A $100-1 b$. bag will last a small flock for months. It is as good for hens as for pigeons. This grit should be kept in and fed from a wood box. Do not put it in a tin or galvanized iron box.

OYSTER SHFILL.-A great deal of oyster shell on the market is unfit for pigeons, not being ground fine enough. It is quite difficult in some sections of the west and south to get oyster shell, which has to be transported from the seaboard The ovster shell which we supply our trade is put up in one-hundrod pound baga. Price $\mathbf{7 5}$ cents per ino pounis. No orior filled for less than fifty pounds; price of fifty pounds, forty cents. It is ground fine and is just right for pigeons. It should be fed to the birds from a protected box in the squabhouse.

INSECT SPRAYER.-PIgeons have a long feather louse which is not harmful. 


\section{NATIONAL STANDARD SQUAB BOOK}

The mite which causes the only trouble is small, about the size of a pin-head, called the red mite, because after it has sucked the blood of the pigeon it is colored red. We have gone a whole season without seeing any of these mites in our breeding houses. If lice of this kind, or any kind, are discovered, the insect sprayer which we illustrate here will be found useful. The barrel is filled with kerosene (or water in which squab-fe-nol has been poured) and a fine spray driven against the nest-boxes and nest-bowls, or even against the birds.

These insect sprayers are well made of heavy tin. We sell them for fifty cents each. They cannot be mailed, but should

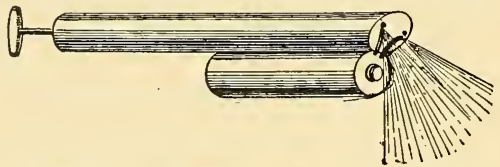

be sent by express, or with other goods by freight.

Birds which are lousy may be dusted under the feathers, next the skin, with any good lice powder. The best time for such treatment is at night, when the birds may be readily caught and handled. It is also a good idea to throw a pinch of lice powder in the nest, on and around the squabs, about once a month during the summer.

Lice are the terror of chicken raisers, but we never knew a squab raiser, if intelligent, to be troubled very much or very long with lice. Once free of lice, the birds almost invariably keep themselves clean. It is only the loft where cleaning is badly neglected which is troubled with lice.

There is a light-colored grub which sometimes forms in the manure on the bottom of the nest-box, but no trouble comes from it and it does not get on the bird.

RED AND WHITE WHEAT.-It is impossible for us to tell what is the difference between red and white wheat. We do not know the chemical constituents which color one kernel red and another variety white. This question is asked us by inquirers who have never leard of red wheat, yet it is a common and staple variety of wheat quoted daily in the Chicago and other grain markets. If you cannot get red wheat where you live, feed white wheat, which is fed regularly by nine-tenths of our customers. As we say in the Manual, we feed red wheat instead of white wheat because it is not so much of a laxative. When we cannot get red wheat, which happens at some periods of some years, we feed white wheat.

The effect of wheat is to keep the bowels of the birds open and regular. There is not much fattening substance in wheat.
That function is performed by corn

Birds fed on wheat and nothing else get so weak that they do no breeding. We have found this out by the experience of customers. Now and then a customer buys birds without thinking that they must eat to live. After he has got them he suddenly recalls that they must be fed and starts out to find something. We recall vividly one Kansas customer of this kin'] who was induced by some grain man to buy a lot of wheat and nothing else. After feeding his birds nothing but wheat for two weeks, he wrote us that they were dumpy and showing no inclination to build nests. "They are all the time on the floor," he wrote, "and cannot fly." He had got them so weak by feeding the wheat that they could not fly to their nes:boxes, to say nothing of building nests.

USE OF LEG BAND OUTFIT.-The aluminum which we sell with our leg band outfit is seamless tubing and by the use of the outfit you produce a band which is seamless and which can be applied only to a squab, because, of course, the feet of an old pigeon are too large to be squeezed through the band as a squab's can be squeezed. To make an open band (which can be applied to the leg of a fullgrown pigeon) out of the closed band, you simply make a saw-cut lengthwise the band, then open the band with your fingers, put it around the leg of the pigeon, then close the band again. If anyone has old pigeons which he wishes to band, he will find this band outfit quite as serviceable as if used only for banding squabs. We have sold thousands of these band outfits, and customers like them first rate. We can furnish open bands (to be applied to the legs of full grown pigeons) made of aluminum, V-shaped joint, each band numbered, a first-class band in every way, for two cents each, or two dollars for one hundred, postage paid.

MANAGEMENT OF BATH PANS.The sixteen-inch bath pan which we recommend and sell is better than a larger size, no matter what the capacity of your plant. It is easier emptied of water, there is less strain on the arms, and it is kept clean easier.

There should be one bath pan for ever twelve pairs of birds. If you have about 48 pairs of birds in each unit, you should have four bath pans in that unit, outside in the flying pen. You can get along very well with one drinking fountain to a unit with that number of birds, or a less num ber of birds, but if you do not have bath pans enough the bathing water will get dirtier than it should and the birds should not be given an opportunity to drink this dirty water.

In the winter, when the birds are shut up in the squab-house frequently for days at a time, it is not necessary to bathe them every day. Bathe them say once a week, taking the bath pans into the 
squab-house and letting the pans stand before them for about an hour. If you let the water stand in the bath pans in the squab-house in the winter time all day, they will splash too much out onto the floor, and the house will get damp.

We fill and empty the bath pans three times a day in the summer time. If your plant is a small one, it is not necessary to do that. The best way for you to manage is this: At evening (sunset, sometimes before) your birds will all leave the flying pen for their nests and perches inside. Then fill the bath pans with water. When the following day dawns, and before you are up, the pigeons will fly out and take a bath. When you get up, go to your pigeons and empty the bath pans, turning them bottomside up and leaving them that way all day.

The price of these sixteen-inch bath pans is forty cents, erated ready for shipment.

KILLING WITH A KNIFE.-Some dealers in squabs wish them to be killed with a knife as this gets out the blood and makes the flesh somewhat whiter. Find out whether or not the man to whom you are going to sell the squabs wants them bled. The way to kill them with a knife is to insert the knife inside the bill and cut the jugular vein. Then hang up the squab bill downward and lat the blood drain out. By using the knife on the inside of the throat you do not make a wound which is visible to the eye of the consumer. Use a knife with a long, narrow, sharp blade.

CONCERNING NEST-BOXES. - Many customers who do not use egg-crates or orange boxes, but build their nest-boxes of half-inch or five-eighths lumber, have written us that they have used the construction which we illustrate herewith, and which is good, because cleaning can be better done.

The bottoms of the nest-boxes are removable and rest on cleats, as the picture shows. The cleats are seven-eightlis or one inch square and are nailed to the uprights.

When this construction is employed, it is not necessary that you have a block or base serewed to our nappy or nest-bowl. The nappy or nest-bowl may be screwed directly onto this removable nest-box bottom.

It is not necessary, and not advisable, to nail a strip of wood across the fronts of the nest-boxes, to prevent the squabs from falling out. The plain nest-box construction is better in every way. Beginners who tack strips of wood across the fronts or who make a closed, dark nestbox, invariably abandon such construction after a few months' use of it.

The squabs stay in the nest until they are ready to leave it, and it is very rare to find one on the floor. It will be noticed that in the cities, the street pigeons' nests in many cases will be found on the open cornices of high buildings, and if squabs

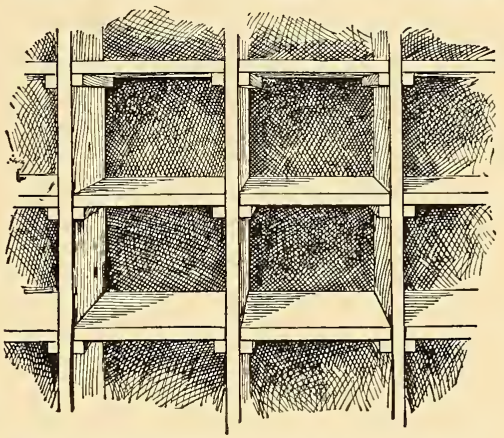

stay in such nests until they are able to fly, the beginner with squabs ought not to be worried about his birds' nests which are only a few feet from the floor.

SQUABS IN CHICAGO.-The following article is taken from the Chicago American:

SQUAB FARMING IS A NEW CHICAGO INDUSTRY.

LITTLE CAPITAL IS REQUIRED AND PERSONS OF GOOD JUDGMENT

AND CARE CAN REALIZE GOOD PROFITS FROM PIGEON CULTURE.

If all the birds in all the pies were suddenly to lift their voices in song like those in the nursery rhyme, the chorus would be loud and long, for raising of squabs for food is a constantly growins and luerative industry, and withal very fascinating.

A number of farms each sheltering several hundred birds are being conducted within easy reach of the Chicago market.

Such clubs as the Union League and Athletic are always ready buyers. Plump birds are readily sold for a dollar apiece for breeding purposes, and their squabs at $\$ 4$ a dozen for food. As in any field of labor the best results come from studied and carefully planned effort. Utmost cleanliness in food and in the little compartments to which each bird comes with unerring instinet to nest enters largely in success.

Eggs of clear black or white birds are difficult to hatch because the birds of those colors are very restless and nervous, not caring for their eggs; sometimes only one in a dozen being matured.

In four weeks the young bird is ready for the market. Many of the squab farms are side issues of those employed at other vocations during the day, and bid fair to attract the attention of those seeking quick returns from a small outlay.

Attention to recognized habits of the birds, sanitary conditions and good breeds 


\section{NATIONAL STANDARD SQUAB BOOK}

for parent birds are all that is necessary to success.

ACTUAL TESTS CONVINCED THEM.In Appendix A in our Manual, we tell of a sale of our Homers which we made in February, 1903, to a ship captain, who intended to sail from Boston around Cape Horn to the Pacific coast, with stops, the whole voyage to be made in about a year, the pigeons to furnish fresh squab meat for the long journey. The ship went to Florida, from Boston, thence to Rio de Janeiro, Brazil, safely, and sailed from there October 1, 1903 . Under date of June 22 , 1904, the Captain wrote us as follows from New York City: "The birds proved all you claim for them, and even more. I put them in a small house I built, four by eight, and four by four flying pen on March 7, 1903. ('This was on the deck of the ship.) They all hatched before April 6 , and up to June 5, 1904, every bird had hatched twelve times, and one pair thirteen times. I savad one pair of the first hatches, that was born about April 6, and in October they hatched their first pair, and up to June 5 had six hatehings, which I think was pretty good. I am satisfied that if the birds are taken care of there is big money in them, and just as soon as I can get a location in New Jersey near New York City, I will send to you for two or three hundred pairs. I have an option on a place now and will know tomorrow. I am pretty sure I shall get it and by next Monday I am in hopes to begin my houses. As soon as I get them ready, I will send you a draft for what birds I want. As my houses are built I will order and fill them and I hope you will try and give me a good lot of birds. I shall build for one thousand pairs this summer and increase next year if the birds are as good as those you gave me. In two weeks you may expect to get an order for two hundred pairs, so you can begin to get them paired off. Any suggestion you can give me about the houses will be very acceptable, as I am going to begin to build at once."

Since the above was written, he has built his first house and we have shipped him the first large lot of birds. His experience is certainly convincing. Anyone who has doubts can start with a small purchase of birds and find out the facts for himself. just as this customer did.

We are continually filling large orders for customers who started with a small purchase and did well. Why don't you start with two dozen or so pairs and have the experience of this Michigan eustomer whose order we received this summer: "A short time ago I received twenty-five pairs of your Homers. They are all doing finely, every bird being lively and full of vim. They are almost all at work now nest-building, and I am more than satisfied with results thus far obtained. I am about to build two houses, each house to accommodate two hundred and fitfy pairs, divided into five flocks of fifty pairs.
Enclosed find New York draft to pay for four hundred and fifty pairs Extra Homers."

Under date of July 1, 1904, a customer writes us from an Ohio town: "The Homers I purchased of you two years ago this month have been doing very well, in short, their increase has been marvelous, averaging nine and one-half $(91 / 2)$ pairs per year for the two years I have had them. I now have quite a flock, bred exclusivaly from the three pairs of mated birds purchased from you, but think it is about time to get some new blood in the flock, therefore will you kindly quote me your prices for birds from one to three or four months old, equal parts cocks and hens, so that I may turn them in with my young birds to prevent as much inbreeding as possible in that way. I want to say that I at first had some doubts as to the profits of the business, but must confess that they are even more than you have ever claimed."

Some of our most successful customers are women. One writes us this summer as follows: "Enclosed find post-office money order for $\$ 7,08$ payment for the following order: three dozen wood nappies, three bath pans, four galvanized iron drinkers. Ship by freight or express as is cheaper. Something over a year ago I bought twelve pairs of pigeons of you. Imperative duties have prevented my giving them as much attention as I would wish but they have increased and prospered with but trifling loss. There are now more than forty pairs nesting, and altogether a flock of something over one hundred and fifty. I have sold none, not having had time even to sort them out and send them to market. I hope soon to get into the lofts and put things in first-class shape and weed out all the culls. I am very well satisfied with my experiment.'

A customer in New York writes: "There have been two pigeon fanciers here this week who say they have no such fine stock as ours, nor have they seen anything like them."

BOSTON PRICES.-The squab market is improving every year, and breeders everywhere are getting better prices, even right here in Boston, the centre of the section where our business is done, and where the interest in squabs is very great. The following quotations from the Boston Daily Globe cover a period of nearly four years, and, as will be seen, prices are firmly maintained. New York prices are better than these:

Mar. 28, $1903 . \ldots \ldots \ldots . \$ 4.00$ and $\$ 5.00$ a dozen Apr. 25, $1903 \ldots \ldots \ldots \ldots .3 .50$ and 4.00 a dozen May 23, $1903 \ldots \ldots \ldots \ldots, 4.00$ and 4.50 a dozen June $27,1903 \ldots \ldots \ldots \ldots .3 .50$ and 4.00 a dozen July 11, $1903 \ldots \ldots \ldots \ldots \ldots \ldots \ldots .3 .50$ a dozen

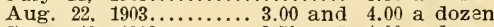
Sept. $19,1903 \ldots \ldots \ldots .3 .50$ and 4.00 a dozen Oct. $24,1903 \ldots \ldots \ldots \ldots .4 .00$ and $4.50 \mathrm{a}$ dozen Nov. $14,1903 \ldots \ldots \ldots . .3 .50$ and 4.00 a dozen Dec. $5,1903 \ldots \ldots \ldots \ldots .4 .50$ and 5.00 a dozen 
Jan. 30, 1904........ 5.00 and 6.00 a dozen Feb. 20, 1904.................. 4.50 a dozen Mar. $12,1904 \ldots \ldots \ldots \ldots .5 .00$ and 5.50 a dozen Apr. $30,1904 \ldots \ldots \ldots, 4.00$ and $4.50 \mathrm{a}$ dozen May 28, 1904.......... 3.00 and 4.00 a dozen June 11, 1904............ 3.00 and 4.00 a dozen July 23, $1904 \ldots \ldots \ldots \ldots .50$ and 4.00 a dozen Aug. 13, $1904 \ldots \ldots \ldots \ldots . .50$ and 4.00 a dozen Aug. 20, $1904 \ldots \ldots \ldots \ldots . .50$ and 4.00 a dozen Sept. 10, 1904........ 3.50 and 4.00 a dozen Oct. $8,1904 \ldots \ldots \ldots \ldots . . . .60$ and 4.00 a dozen Nov. $5,1904 \ldots \ldots .3 .00,3.50$ and 4.00 a dozen Dec. $31,1904 \ldots \ldots \ldots \ldots 4.50$ and 5.00 a dozen Jan. $7,1905 \ldots \ldots \ldots \ldots, 4.50$ and 5.00 a dozen Mar. 25, 1905........ 4.50 and 5.00 a dozen Apr. 1, $1905 \ldots \ldots \ldots \ldots, 4.00$ and 4.50 a dozen May $27,1905 \ldots \ldots \ldots \ldots 3.50$ and 4.00 a dozen June $3,1905 \ldots \ldots \ldots \ldots .3 .50$ and 4.00 a dozen July $8,1905 \ldots \ldots \ldots \ldots .3 .00$ and 3.50 a dozen

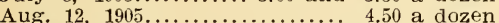
Sept. 23, $1905 \ldots \ldots \ldots .3 .00$ and 3.50 a dozen Oct. $21,1905 \ldots \ldots \ldots \ldots .3 .00$ and 4.00 a dozen Dec. $16,1905 \ldots \ldots \ldots \ldots 3.00$ and 4.00 a dozen Jan. $20,1906 \ldots \ldots \ldots \ldots \ldots \ldots \ldots . . . . .4 .00$ a dozen Mar. 31, 1906........ 4.25 and 4.75 a dozen Apr. $7,1906 \ldots \ldots \ldots \ldots .4 .00$ and 5.00 a dozen

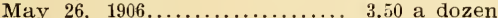
June 16, $1906 \ldots \ldots \ldots \ldots .50$ and 4.00 a dozen July $28, \quad 1906 \ldots \ldots \ldots \ldots \ldots \ldots \ldots . . . \ldots . . .50$ a dozen

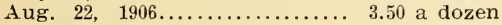

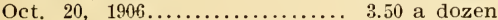
Jan. $5,1907 \ldots \ldots \ldots \ldots \ldots \ldots \ldots \ldots$. 5.00 a dozen It will be noticed, in the above table of prices, that although the supply of squabs has greatly increased during the past five years, the demand for squabs created by our advertising has more than kept pace with it. Prices at this writing (Jan. 15, 1907) are as high or higher than we have ever known them.

BUSINESS MANAGEMENT. - Not a few breeders raise squabs by the hundred and are successful in every detail of the management of their plant except selling the product. Some beginners seem to think they will be perfectly helpless without the co-operation of some dealer.

It is a shame to raise fine squabs and then sell them to some commission man or other dealer who immediately resells them, in most cases for double what he pay you for them. It is the steady practice of the dealers in Chicago, for instance, to pay from $\$ 2$ to $\$ 3$ per dozen and resell them for $\$ 3$ to $\$ 6$ per dozen. If you don't believe this is true, drop your role of a squab seller and go into these markets to buy and you will see how much profit is being made off your goods.

The squab dealers and commission men do not advertise for customers. The squabs are just as salable in your hands as in theirs. Many people. would prefer to buy of the producer, being surer of a fresher and more satisfactory product.

If you are producing squabs, by all means sell them to the consumer and get the price which the middleman is getting. It is essential, however, if you are going to do this, that you make it known in some way that you have got squabs to sell. Think of the rich people, the wellto-do people, the good diners around you or nearest you, and figure out for yourself a way of getting to them the information that you are selling something which they want and will buy steadily. Perhaps a neatly printed circular sent by mail will do it. Or an advertisement in the newspaper in your territory which will produce results. Or you might pick out two or three likely families and make them a present of a squab or two to get them started.

The products of the plants of hundreds of our small customers are spoken for ahead of capacity all the time by a neighborhood trade, and this is what you you should aim at. This is the way the finest butter and eggs and poultry are sold, and also squabs, and the plants of our customers who are selling squabs direct to the consumer are paying better than the plants of other customers whose product is marketed with poor judgment.

Don't be too fast to sell to a hotel. Some farmers and breeders get the idea that if only they can find a hotel to take all their goods, their fortune is made. In every city there are one or more firstclass hotels which want the best of everything and pay accordingly. On the other hand, there are many hotels which do not care for the best. For example, few hotels care for the best ducks, because a single dinner order is half a duck, and half of the big first-class, expensive ducks is more than a diner wants, so the hotel keeper of course prevents waste by buying a small duck. Same with squabs. The hotel buyers are sharp bargainers, and if they think that their trade will be satisfied with a seven or eight-pound squab, they will take such a bird rather than pay more for a ten or twelve-pound squab. The average squab breeder, like the average farmer and gardener, is content to sell to the middleman, and if you make the acquaintance of a good one, of course you avoid some bother, yet it has been our experience that it is just as easy to sell squabs to the consumer as to anybody else, in fact, after you have got started with him he will come after you and pay yon a great deal more than anybody else, still he is paying just what he always has paid, and he is better satisfied. Squabs are phenomenal sellers and it is well to take advantage of this condition, which is not always true of poultry.

MR. McGREW CALLS.-The following is from the pen of $\mathrm{Mr}$. T. F. McGrew, associate editor of the Feather, poultry editor of the Country Gentleman, also a widely-quoted writer for the government's bureau of animal industry, and a lecturer for the New York State Board of Agriculture. He is one of the best known judges of poultry and pigeons in the United States. The visit to our our farm of 
which he speaks was made in November, 1903; since then our stock of Homers has been increased.

"It was our pleasure within the last two weeks to visit the home plant of the Plymouth Rock Squab Co., at Melrose Máss. We were beautifully entertained by Mr. Elmer C. Rice and his family. The buildings at the home plant are by far the best that we have ever seen for squab growing. Each building is constructed for the best possible light, air, and sanitary conditions. Those who may be interested in squab growing will find it to their profit to communicate with Mr. Rice at Boston for the printed matter which gives a full description of his plant and methods of doing business.

"We saw at this plant 12,000 full-grown, well-matured Homing Pigeons ready for distribution for growing squabs. In all our experience we have never seen a better lot than these. They are large, vigorous, full-breasted, broad-shoulderel specimens such as one would select for producing squabs of the best character. There are Blues, Blue Checks, Silvers, Reds, and mixed colors such as would naturally be produced through the cross mating of any of these varieties. While we were there Mr. Rice shipped from the plant between five and six hundred birds, all of which are sent out in large roomy baskets, the baskets returnable at the shipper's expense. So far as we can calculate, we are under the impression that Mr. Rice is doing a very large business. In addition to this we carefully perused a number of letters received by Mr. Rice from localities as far West as San Francisco, as far South as Florida, all of these communications speaking in the highest terms of the shipments made to them by Mr. Rice."

RUNTS NOT DESIRABLE.-From the Farm Journal.- "Our remarks in the October issue respecting the relative merits of large and small birds were put in a way to be easily misunderstood.

"By large birds we meant runts and that class, usually found only in the hands of fanciers and experts in pigeon breeding. They are not at all desirable for squab breeding.

"Common pigeons are not hardy and prolific in proportion to their smallness. The largest of these should be selected for breeding always.

"There is a great difference in the size and quality of what are called common birds. Where they are chosen as the basis of a squab breeder's business a careful selection should be made.

"Of all the pure-bred types, we know of nothing superior or equal to the Homers for breeding squabs. They are hardy and prolific and rear large, meaty squabs. There is also room for selection in Homers, some being much larger than others.

"When a breeder already has a flock of common pigeons he can greatly improve it by the infusion of Homer blood,"

USEFUL MESSENGERS.-We have quite a call for our birds from physicians having a country practice. They leave two or three birds at a patient's house to be let loose when the doctor's services are needed. In cases of expected confinement at a distance of several miles from the doctor's home, our birds are extremely useful. We earnestly advise country physicians with a wide territory to cover to look into this matter and communicate with us. It will be money in their pockets.

DEMAND IN COLORADO.-We have had the same experience with the Western trade as the following writer in the Western Poultry World, of course excepting California, which is one of the best squab markets in the country. What he says is conservative and sensible and bears out what we have always maintained, that wherever there are men and women who are good eaters, there squabs will be eaten. If you live in a town where a squab never was seen, but where there are people who set a good table, to them you certainly can sell squabs:

"Having been asked by your editor to write an article on pigeons or squab raising, and also having said I would, I commence by stating a few facts which I have gained from both practical experience and inquiries from Eastern breeders. In the first place, I want to say that little is known of this industry in the West, and in fact it has not been known in the East until about ten years ago, when they began to take it up about the same as the Western people are doing now. Many got discouraged at finding it was not a get-rich-quick scheme.

"I am constantly having letters from different parts of the country asking me if squab raising pays, and saying that from inquiries they have made at meat markets and commission merchants, they are told that there is no demand for them. Of course there is not at the present time, for if there was they could not get them. No man can sell what he has not got. I once went to a gentleman and told him my plan of starting a squab farm, and he in turn went to his meat market and asked him what he thought of it, and he said I was either lazy or crazy. Now this man knew absolutely nothing of squabs, and never had any in his store, and, consequently, never had any calls for them. I dare say that if one were to go to every market in the city they would tell you the same thing, and nine out of every ten people would tell you they had never eaten a squab in their lives; still I have people-come right to my door-who come a good distance out of their way and want to buy 
squabs of me. The reason hotels and restaurants do not continually have them on their bill of fare is because they cannot be supplied at all times. Today they can get perhaps a dozen, and tomorrow, if they wish any, they cannot get them, and even then they are obliged to take common squabs and not Homers. As to the demand, I want to say right here, that I know one concern that will contract to take 400 dozen a week at good, fair prices. Two parties that I know of right here in this city are constantly in receipt of letters from hotels and clubs in Denver wanting to buy squabs. In the East, where there are ten squab farms to one in the West, the prices are higher than here. It is because of the demand.'

ELEGANT PROFIT.-The following is from Vick's Magazine, an article on squab raising by a practical breeder:

"Of recent years the demand for the toothsome squab has been so great that the supply does not come up to the demand. Where years ago they were used only for invalids, now they are on the bill of fare in almost all restaurants and hotels. They command good prices at all seasons and an elegant profit is derived from them by the raisers. It used to be that pigeons could not thrive when housed up, but now the former obstacles have been overcome and better success is made where they are confined than wnere they have their freedom.

"The squab business if conducted properly will bring in a large percentage of profit considering the first capital invested. Only a few hundred dollars are required to start where such a sum would be nothing to commence in such a business as stock keeping, etc., and yet with a few hundred pairs of pigeons anyone with a little judgment can make a living for himself and family. Many farmers' sons could make nice yearly incomes by stocking a part of their barn (not used for anything else) with pigeons. The risks are not so great as with chickens, but the birds must be atended to and not neglected.

"With chickens one must not only feed the old, but must also give the little ones their meals, but not so with pigeon breeding. You feed the old birds, and they feed their young. One person can feer a thousand pairs of birds in about a qualter hour, the rest is left for the old ones to do. The little birds are fed from pre-digested food from the crops of their parents, who by a sort of pumping force the food into the squabs' mouths. It takes no longer time for a person to feed a lot of birds with young than it does without young.

"After the squabs are four to five weeks old they are ready for market. It costs but one and one-half cents per pair for feeding birds a week and their young also, so with the prices received for the squabs, which is forty cents per pair in summer to eighty cents per pair in the winter, one can imagine the percentage of profit.

"Squabs of the largest size demand the highest market prices, so it pays to commence right by buying only good large stock. The amount of labor required is almost nothing, in fact unless very large numbers are kept, one will have only a few hours' work daily. The writer has nearly 2,000 , and it takes only fifteen minutes to feed and half an hour to give fresh water. Of course it takes a day or two a week for killing young ones, and a day or two each month for cleaning buildings, then the work is about done. One person can attend 1,000 pairs nicely and have ample time to do other work around a place. The writer finds it a snap to other ocupations and one is his own boss and can go or come when he pleases. It is the business for a young man; he can advance as he saves money. There are some who commenced on a few dollars and by careful saving now operate plants of thousands of pairs of birds.

"The larger the pigeon, the larger the squab, the higher the price. The breeding houses need not be heated artificially in winter as the birds can withstand any temperature and in cold weather sit upon their young until they are feathered sufficiently to stand the cold."

ENLARGED HIS PLANT WITH PROFITS.-Experience of a Breeder Who Made it Pay From the Beginning.In Country Life, a monthly magazine, one of the handsomest and highest-toned publications, the experience of a gentleman in squab raising gives the following facts: "Six years ago I did not have a bird, but I invested fifty dollars in purchasing twenty-five pairs of extra-choice Homer pigeons, remodelling a poultry house for their accommodation. I had kept pigeons for pleasure for five years, previously, and fielt that I knew a little about them. In these six years I have not invested another dollar excepting the dollars the birds have earned, and my present establishment of five houses and fifteen hundred pigeons, which has cost me two thousand dollars, is all paid for. In addition, for the last three years, I have paid out from five to seven dollars each week for the wages of a helper, to dress the squabs and clean the houses, for my regular business would not permit me to attend to these duties myself.

"The concensus of opinion of all experienced squab breeders stamps the Homer as the best pigeon for this purpose. This variety is strong and vigorous; a hearty feeder and good worker; bright-eyed, alert and active; stocky, symmetrical and full-breasted, which counts so much in squabs. They are also prolific, and their squabs are full-feathered and fit for market in four wceks.

"I was very fortunate in getting my 
first twenty-five pairs of birds. These were Homers, full-blooded, and had established records for flying, having taken first honors in several contests.

"They not only averaged me seven and one-half pairs of squabs a year, but stamped their vitality on the birds I have selected from their young.

"As my profits accrued I purchased straight Homer stock, picking from the best near-by breeders, as well as those of established reputation at a distance.

"I always put a lot of new birds in a clean coop by themselves, give generous supply of feed and water, and have plenty of nesting materials in the coop, and if they have come from a distance put a good poultry powder in their feed for the first meal, and let them alone for a few days. If they are strong, healthy birds they ought soon to begin to carry materials and build nests. When nest building is fully under way I transfer each mated pair to permanent breeding quarters. When I find a pair of birds mated, I call my assistant and tell him which bird to keep his eyes on, and not to lose sight of it a single instant. At the same time I note the other bird and catch it. I pass the caught bird to the assistant. He points out the other bird and it is soon eaught. I band all purchases as well as those I raise.

"My weekly expense for feeding my flock of fifteen hundred pigeons during the month of December, 1903, was eighteen dollars and thirty cents for the following: Three hundred pounds of cracked corn, three bushels each of wheat, peas and kaffir corn, one and one-half bushels of millet, one bushel of hemp and half a bushel of cracked rice. The rice I do not feed regularly, but give when the birds' bowels are loose, for which condition it is an excellent corrective. Feed is now much higher than last year.

"Pigeon-keeping for squabs may filly be termed a twentieth-century industry, for only during the last five years has it by its rapid development attained to the dignity of a special business. The business will surely still more increase during the first decade of this century. The price of squabs has been strongly maintained during the five years just passed, notwithstanding the marvelous increase in the business. The business furnishes a way by which either men or women (for many of the latter have successfuliy taken up squab raising) can embark in an enterprise which does not call for severe bodily exertion and which if intelligently managed will yield good dividends."

SQUAB-RAISING ON THE FARM.Pigeons Kept in the Upper Part of Duck and Poultry Houses.-The following is from an article in the Country Gentleman, entitled "A Combination Plant, Fruit, Bees, Fowls and Squabs":

"For growing squabs some have separate houses, some use the lofts of old barns, and many are so constructing their poultry buildings as to have quarters for growing squabs in the second story of the poultry houses. This is gained by laying a flat roof on top of the pouitry house, on top of this a double thickness of tar paper well coated with hot tar, with a board floor laid over it. This provides the floor for the pigeon house, the roof for the poultry house, and makes it absolutely vermin proof both ways. A large duck grower of our acquaintance has squab houses of this character built over his duck brooder houses and his poultry houses. Several thousand pairs of breeding pigeons are kept in this way, with a hanging outdoor flying aviary for the pigeons. When it has been successful on so large a scale, smaller growers need not hesitate in adopting such a plan.

"Of course cleanliness, care and sanitary conditions about the plant are imperative. The most successful squab growers do not scatter sand or dirt of any kind on the floor or in nest boxes. Neither do they use anything but straw for the birds to build their nests. Tle droppings are all thoroughly scraped up from the board floor, from the nest boxes and under the perches once or twice a week with a hoe, and stored away in bags and sold at 50 to 60 cents per bushel. They are used by tanners in making tne very best grades of leather. These droppings are of no value when mixed with tobacco stems, shavings, sawdust or sand. Grain or feed of any kind if mixed in with them will not injure their value, nor will some little straw or feathers count much against their value. Buy a good sharp hoe; floors constructed in this way can be thoroughly cleaned by scraping up once or twice a week, and in this way the sanitary conditions will be of the very best.

"Those who do not care to dispose of the droppings in this way in some instances spread from six to eight inches of soil from their land over the floor of the squab house. This is allowed to remain from three to six months. Usually at the end of the moulting season all the nest boxes and the whole house is thoroughly cleaned out and the entire contents of same dumped on the floor, scraped and hauled away and scattered over the land. This makes an excellent fertilizer. We know of one instance where a large number of squabs are kept in this way, and the house is cleaned but twice a year. In the spring all the cleanings from the house are hauled out and spread over the land for the growing of summer crops. After the fall moult, the place is thoroughly cleaned up for winter, the cleanings of the house are stored away in a dry place and retained until spring. Many persons would call this a filthy, unhealthful way to keep a squab house, but some of the most successful breeders follow this plan. The 
presence of the five or six inches of dry soil on the floor keeps it in good condition throughout the season. The cloud of dust that is raised at times by the pigeons' flapping their wings and flying about is almost a certain guarantee against insect attack. However, we do not advise this method. We simply give the facts as we have seen them.

"The only limit to the extent of such a plant is the ability of those who possess it properly to care for and manage all its branches at a profit. Where there is a family of boys and girls it might be well to engage the attention of all in growing these several kinds of products, and to lend encouragement to each by giving him a share of the profits. Scattered all over the country are thousands of families in country places continually worrying and wondering why they cannot keep their children at home. The real reason so many of the young people leave the farm is that they are compelled to work continually and never receive any portion of the income for their labor. If the parents would allow their growing families to make an equal sum of money or in proportion to what they can make by leaving home, there would be far less complaint on this score. All children wish to have the privilege of earning a few dollars that they may call their own."

The following paragraph is from the same paper in its report of the New York pigeon show, January, 1904:

"There seems to be a depression in the sale of high-class pigeons. Well-favored specimens of the liighest character still sell at top prices, but the absence of any commercial value for a large number of pigeons that are grown detracts from the numerous sales that their producers might have. If producers of the hundreds of varieties of beautiful pigeons would turn into the market as squabs the greater part of all their product that was not valuable for the exhibition room, greater returns would come for those which were saved for exhibition purposes. There is a grand stride forward in growing squabs. The combination of poultrygrowing with squab-growing works well. and is being adopted by so many small farmers as to create an unusual demand for all grades of pigeons that are good for this purpose.

"It is well for those who go into the squab business to remember that the price is graded by size and quality. During winter squabs that would average $s$ or 9 pounds to the dozen have sold at retail in the New York market at from 35 to 40 cents each, while those which averaged two or three pounds less to the dozen sold at from $121-2$ to 20 cents. It takes quite as much time and as much care and food to produce the small specimens that bring the lower vrices as it does to produce the higher grades which bring the better prices. People are be- ginning to find this out, and taking advantage of the knowledge, are looking about for the best quality of pigeons to produce the best market squabs."

SQUAB PIN-MONEY.-The following paragraph appeared in the January, 1901, issue of the Designer, a monthly magazine for women published by the Butterick Publishing Company of New Yorlc City:

"A young woman of my acquaintance has kept herself supplied with hats, boots and gloves during the past year by seliing the squabs of six pairs of Homer pigeons. They require very little care, and the young are ready for market when four weeks old. My friend is so well pleased with her success that she has added seven pairs to her stock, and confidently expects to dress herself completely on the sum derived from the sale of her squabs. -M. P."

THEY FLEW HOME.-A dispatch from Paris, printed by the Baltimore Sun, says: "A man named Maraud complained to M. Brunet, Police Commissary for one of the districts on the south side of the Seine, that he had been robbed of six valuable carrier pigeons and said that one of his friends had seen them at the house of another man.

"The magistrate went to the place indicated and there saw some birds. 'How did you come by them?' he asked of the man. 'Oh, I bought them months ago,' was the reply.

“' 'Well, bring them to my office,' said M. Brunet. There he had a wax seal attached to each bird's leg and the birds liberated.

"They flew back to Meraud's house and an hour later the thief was on his way to the police depot in the black maria.'

SQUAB INDUSTRY'S GREAT GROWTH. -Address Delivered Before the New Jer sey State Board of Agriculture-Years ago when poultry and egg production was being first advocated extensively, there were many fears expressect that the business would be overdone, that chickens and eggs would come to be common and low priced, and the fear that there would be no money in the business no doubt kept many out of it. Nevertheless, more and more have gone into poultry and eggs year after year, and millions of dollars' worth of both are marketed yearly. Whole communities, like Petaluma, California, are given up to poultry and eggs. Eggs got as high as sixty cents a dozen in the large cities the past winter (1904).

Some people not informed as to squabs think that if many go into squab raising the prices are going to drop until there is no profit in the business. On the contrary, prices for squabs have been in creasing every year here in the East. and they are going to increase in the West in the years to come. Consumers who have 
read our advertising all over the country are eating squabs who never ate them before, and the effect of our advertising on the general squab market everywhere has been to boost prices. Well-to-do people who are led to get into the habit of having squabs on their tables keep on ordering them, and tell others, and thus the market grows.

If all the Homer breeders we have sold during the years we have been in business were concentrated in one plant, we could sell the entire squab output of that one plant to any one of a hundred commission men in one of the large cities.

New Jersey is doing well with squabs. other states, notably California, Iowa, Wisconsin, Michigan and Masachusetts are producing a great many. Just what is being accomplished in New Jersey comes as a surprise to people who look upon this business as something new and untried. At the annual meeting of the New Jersey State Board of Agriculture in January, 1904, an address was given by Mr. G. L. Gillingham on squab raising, in the course of which he said:

"The production of squabs for the markets of our large cities is an industry that is reaching considerable proportions in this state. And, although it is growing yearly, yet the prices seem to be advancing; showing that there is an unlimited demand.

"The great scarcity of game all over our country compels the keepers of firstclass hotels and restaurants to look for something to take its place, and at the same time be sure of a supply at all seasons of the year. Therefore they have hit upon the squab to fill this void, and now when one calls for quail on toast, or order of a similar nature, it will very often be found that the quail was raised in a pigeon loft, and is much younger, more tender and juicy than the quail would have been, could it have been secured.

"This is a business that can be carried on in connection with poultry raising, and is one that may be conducted upon village lots by women and young persons, if need be, and by those whose other business takes their attention during the middle portions of the day, as the labor connected with it is not heavy. It is particularly adapted to women who wish to add something to their income. In fact, women are more apt to succeed in it than most men, as it requires close attention to the little things, as it is the many little things that go to make up the final profits at the end; as women are generally more patient and thorough with small details they will be more successful.

"The extent to which this business is conducted in some parts of our state may be shown by stating that in one town in Burlington County of about 3,000 inhabitants, the purchase of one dealer the past year was 56,582 squabs, for which he paid $\$ 16,400$; while another dealer bought perhaps a little over half as many more, bringing the aggregate to 86,000 squabs, for which the people of that town received nearly $\$ 25,000$; while another single grower in the same country shipped from his own lofts between 13,000 and 14,000 birds.

"The cost of feed and care for a working loft of pigeons is about $\$ 1$ per pair per year (manure not sold). Some put it much lower, but at the present prices of feed, if proper care is given, we should not figure not much lower than $\$ 1$. A good pair of birds will produce from seven to ten pair of squabs per year; generally an average of not over eight pair. The prices have ranged the past year from 25 cents for the poorest, to as high as 75 , 80 and 90 cents for the best, putting the number raised at the lowest (seven pairs) and the average price at 40 cents, we have $\$ 2.80$ for the $\$ 1$ invested yearly after the first cost of investment for buildings, etc., which need not be expensive, according to the taste and means of the builders and the amount of capital he wishes to put into it. The houses should always be placed where the drainage is good, preferably upon a dry knoll, facing the south or southeast. Some paying lofts have been made by fitting up unused wagon house or wood house lofts, or over hen houses. Other houses have been constructed for poultry on the ground floor and the story above for pigeons. In this case great care must be exercised to have the floor well laid with planed and grooved flooring, to keep vermin from passing up from the poultry.

"Very large flocks should not be kept in one room. From 50 to 100 pair is enough to keep together for the best results, preferably the former. A room $10 \times 12$ is ample for 50 pair of working birds. A house may be built of any desired length, 12 feet wide and divided into apartments of the above size by wire partitions with doors hung on spring hinges, to facilitate passing through in feeding.

"These houses should have windows on the south, of sufficient size to afford ample light in all parts of the house and no more, as too much glass makes the house too cold on the winter nights.

"As each pair require two nests, as they are generally sitting in one while raising young in the other, there should be twice as many nests as pair of birds, with eighteen to twenty to spare, that they may take their choice.

The period of incubation is eighteen days, the hen bird sitting on the eggs, excepting about four hours each day, when the male takes her place, while she is feeding and resting.

"During incubation a substance forms in the crop of both birds, known as pigeon milk or curd, on which the young are fed for the first five or six days, until they are old enough to digest the grain, 
which is carried to them in the crop of the old birds, and ejected from their mouths to the mouth of the young bird by the same process as the pigeon milk is fed in the first place. Hence it is important that the proper feed be given, which should consist of a variety of grain and seeds, the larger the variety, the better. These should consist of eracked corn, rather coarse (preferably about three or four pieces, from a single kernel), with the tine sifted out. This should be kept before them in troughs or hoppers, so constructed that they cannot throw it out and waste it, which they will frequently do in search of other grains of which they are more fond. The other seeds should consist of whole corn, Canada peas, Kaffir corn, hulled oats, millet and hempseed. These should be fed on the floor twice daily, just what they will clean up quickly, feeding the hempseed but twice or three times per week, except in the moulting season, when a small quantity may be fed each day, as hempseed is very fattening, and when fed in excess bad results may follow. Do not feed wheat too liberally. and always mixed with other seeds, using the hard, red wheat and never new wheat, as it has a tendency to loosen the bowels of the young birds with sometimes fatal results. In connection with the feeds, the birds should be furnished with ground oyster shell for grit, also a liberal supply of salt and small bits of charcoal and gravel. The salt is necessary to keep them in good health. These substances may be kept in small boxes around the house where the birds can have free access to them.

"A generous supply of pure water should be kept before them at all times near the feeding trough, and should be supplied each morning before feeding, that the old birds may have access to it immediately after feeding, before taking the feed to their young.

"In stocking the houses, always avoid using common breeders, as the results will be disappointing. They are not prolific and are more liable to produce dark squabs, which always bring the lowest price in market, and do not feed the young as well as the full bloods. The best all-round bird for squab raising is the straight Homer, as they are the most active, good workers, quiet disposition, and the best of feeders.

"The Runt is the largest of pigeons. but a very slow worker, seldom producing more than four pairs of squabs per year. They make a good cross with Homer and Dragoon, but even then will not produce as many birds as either of the others alone.

"The squabs are dressed for market once a week, on regular shipping days. They are dressed just before they are large enough to leave the nests, and when they are full-feathered, and should wolgh at this time eight pounds per dozen, this size commanding the highest price, the prices falling off very fast, as the size arops from this weight. The squabs should be dressed with empty crops. They may be caught in the early morning before feeding, and dressed, or caught the evening betore, after the old biras have fed them for the night, and kept in hampers until morning, when their crops will be just in the right condition.

"After the young birds are two or three weeks old, the old birds build another nest and begin to sit again, the male bird taking most of the care of the young until they are ready to dress; hence the importance of supplying two nests for each pair. Thus a good pair of working birds have a pair of young and a pair of eggs a large portion of the time.

"During the summer months the birds should be furnished with a shallow tub of water in which to take a bath, two or three times per week, which will help them to keep free of vermin. These tubs should be emptied after they have bathed, as they should not be allowed to drink the water in which they have bathed.

"With good care, properly constructed houses, wholesome food, never sour or tainted, very little disease should be encountered. Prevention is better and more easily administered than cure. Some of these are dry houses, pure water, regularity in feeding and cleanliness. The water buckets should be washed out frequently with creoline water, made by adding a teaspoonful of creoline to one quart of water. This will kill any disease germs that may be present, and is a good disinfectant.

"Give good care, not neglecting the small things, as it is the multitude of these wherein the profit lies.

"The demand for squabs is constantly increasing and any one entering into this business and willing to give it the attention it requires will always find a profit on the right side of the ledger. But remember this profit will be according to the care and intelligence put into the business.'

NEW YORK MARKET.-The following is taken from the New York World, an article on squabs, published in August, 1904:

Squab-Raising as a Fine Art.-Game Laws Make Propagation of this Small Bird a Remunerative Business,-Palates Demand Substitute for Quail and Other Morsels that Statutes Forbid,-Few persons, even among the devotees of late suppers in New York's high-priced restaurants, in looking over their elaborate menus and selecting, say, a squab on toast, realize what a tremendous industry the Broadway taste for a large cold bottle and a small hot bird has developed in the United States in recent years.

The industry may, indeed, be considered in itself in a squab state, but such has become the after-theatre demand for the 
tasty little birds that many business men have turned from less lucrative pursuits to devote their energies to their raising.

It would be impossible to state precisely how many squabs are annually bred in the United States, but it is est1mated that hundreds of thousands reach the tables and tickle the palates of luxury-loving and extravagant people.

The best of judgment in regard to quality and quantity of feed is essential, cracked corn and red wheat being the staple food. Kaffir corn, Canada peas, buckwheat and millet comprises about 20 per cent. of the food in winter, and in the summer less corn but more wheat. Grit and salt are before the birds always.

At the age of four weeks the squabs are ready for market and are deliciously tender, as they have never learned to fly, and their muscles have not had the hardening influence of ехегеise. The killer's now get busy. With a slip noose around the feet, and wings locked on the back, the squabs are suspended from a rack. A killing knife is inserted well into the mouth and a quick, deep slash made at the back of the throat, allowing the bird to bleed freely.

An expert can kill and rough pick about four birds before they get cold. The squabs are next dropped into a galvanized iron tub, through which a constant stream of water flows, which cools the birds. Then a small hose nozzle is inserted in the mouth and water allowed to fill the crop, after which it is withdrawn and a quick pressure forces everything out. A second use of the hose thoroughly cleanses the crop. Two more immersions in iced water make the birds ready for local shipment.

In the Lenten season commission houses buy and ice thousands of dozens of squabs for winter trade. That is also the time squab raisers select and save the best stock for breeders.

Many of the live birds, especially the Homers and red Carneaux, cost from $\$ 2.50$ to $\$ 6$ per pair.

Prices for squab in New York City run from \$4 per dozen in the early season to $\$ 5.50$ and $\$ 6$ in the winter.

TWO YEARS' EXPERIENCE WITH OUR BIRDS.-"Will you kindly. send us price-list and such other printed matter as you have issued within the past year? You will remember we bought six pairs of you one year ago last July. We have about 124 now and are disposing of all the squabs we can raise at three dollars per dozen. All of our birds are not laying yet but will soon mature. The have lost sereral when they were young birds, then we had some stolen (one of which came bacts). One bird had a peculiar substance form around the outside under the bill. Till you tell us if this was canker? We disnosed of the bird at once. We did not try to treat it at all. The people here know very little about fine squab, but I believe the market is growing better right along. Feed is much higher here than in the East. We have to pay $\$ 1.75$ per 100 for cracked corn, $\$ 2.15$ for red wheat, $\$ 1.75$ for Kaffir corn and about \$5 for hempseed, so that $\$ 3$ per dozen does not bring in a very large profit. Would you advise our raising the price? We hope to send you another order shortly. We have not tried to use the manure at all. We have had no trouble with our birds as to vermin. They seem to keep entirely free from it."-Mrs. H. D., State of Washington.

TO MONTANA IN GOOD ORDER.-"I receired the crate of pigeons yesterday. They were all alive and in good health." J. F., Montana.

FINDS OUR BIRDS FAST BREEDERS. - "On sept. 16, 1902, I or lered six pair's Extra from you and now (Aug. 30, 1904) have about two hundred old pigeons and squabs together, and will want to begin shipping a few before long. Wish you would please give me the names of a lot of desirable squab buyers in New York and other nearby cities. Do you think prices will be better later on in the fall, and which is the best way to ship them, dead or alive? Can I get shipping crates already made? If so, where, and at what price? Thanking you in advance for this information." -W. E. H., North Carolina.

HAD NO TROCBLE RAISING THEM."Last spring, in April, I think, we bought twelre pairs Extra for thirty dollars of you. At present we have eight-five in all, or about sixty young birds that we have raised ourselves. We would not think of selling them as we have had very good success and are much interested in the business, but through sickness I lost my former position in this viliage and have now secured a permanent one in Chicagc, and expect to move there in a few weeks. Expect to locate right in the city and consequently will have no facilities for keeping the pigeons, and so are anxious to sell. The birds are as healthy as wh॰n we received them, as we have followed rery carefully the rules laid down, in caring for them, and have never seen any signs if disease among them. Have lost only comparatively few, and those were small ones which were neglected by mother hirds, or by some accident. Quite a large number of our young birds have mated and have bred the latter part of the winter." - R. F. G., Michigan.

GETTING SIX DOLLARS A DOZEN."Two of the six nairs have now hatched out three squabs, two on February 4th and one on February 7 th (the other egg evidently was chilled by the extreme cold weather). The market price in Newark is six dollars a dozen, and we have contracted to sell these three squabs at that 
price. They are fat and very satisfactory. We are very much encouraged and wish to increase our flock."-F. C., New Jersey.

THE TRUTH ABOUT THE MARKETS. - "I received your Manual and have read it through very carefully. I have found that it tells the very truth. I was in Washington Market and there they told me just the same, they will take all the squabs I can give them. I think I will give you an order next month for 48 pairs Homers and one gross nappies." -H. T., New York.

ATTRACT ADMIRATION IN CALIFORNIA.- "Birds arrived on the 11 th safe anil in first class condition for the length of their trip. I am well satisfied with the birds and expect to give you an order for more before iong. Everyone that has seen them thinks they are fine."-E. J., California.

OUR METHODS IN SOUTH AFRICA."Enclosed find fifty cents for which please send me a copy of National Standard Squab Book. Perhaps it may interest you to know that this is to assist in the raising of squabs in South Africa."-L. E. D. Pennsylvania.

YOUNGSTERS ARE BEAUTIES.-"I have fifty or more pure Homers from the original old birds purchased from your concern. These youngsters are beauties between the ages of six months and one year."-B. R. D., Long Island.

IN PERFECT CONDITION.- "My mother bought one dozen pairs of your birds a year ago and now has about sixty in flock. They have been well cared for and are in perfect condition." - T. A. B., Kentucky.

A NEWS-AGENT'S SIDE LINE.-"I have been doing a little business that I did not have time to tell you about in my last letter. I have boys in several of the towns around here to get squabs for me and I have made arrangements with the above firm to deliver those that I don't sell niyself, on commission. The hotel has an order for 150 per week. Besides this order I sell to several restaurants and let the market deliver to the houses. I am the only one liere who buys squabs to any extent, and averase 200 to 300 per week. I make from $\$ 5$ to $\$ 7.50$ each week this way, besidcs what I make on the train. How is that for a news agent running a train every day from 11 P. M. to 1.15 A. M. ?"B. D., Texas.

HAS OVERSOLD HIS SQUAB CAPACITY.- "Could you supply me with two dozen first-class squabs for shipment from Wooster on or about December 22? I have an order for that amount, and while the birds I purchased from you are doing fine,
I will not have enough. Have orders for breeders and squabs enough to keep the flock working overtime until spring, at which time I expect to enlarge my plant to at least 500 pairs. I could of course fill this small order from nearby markets, but Homers are Homers, and I don't care to depreciate the value of my flock by shipping inferior squabs."-C. L. Z., Ohio.

THE MAN HE WORKS FOR IS MAIING MONEY WITH OUR BIRDS.- "I see in the Poultry Keeper that you offer a squab book free, so I would like to have one, for I have squabs myself and I would like to learn how to raise them. I am only a boy and I am working for Mr. Fairbanks on his farm. He told me that I could write to you and ask you for a book. I know the chicken busiless very well, but not the squab business. Mr. Fairbanks bought pigeons from you last year (eighty pairs Extra shipped August 4, 1902), and he is doing fine with them, so good-bye and don't forget the address. That penny is for a stamp, and the other stamp is for the letter."-W. H., Missouri.

A LONG SHIPMENT IN GOOD ORDER. _. "Your two letters dated January 27th were received yesterday, February 1st. I went to the express office early this morning and found the pigeons had arrived ill the night. The birds are all alive and in fine condition but two, one of which was bruised and I fear its wing is broken. I thank you for the extra two pairs and for the crates. I have a fine new squab house built according to your plans, only the flying pen runs up to the top of the roof, which I think a better plan for this damp climate. I may send for one or two dozen pairs more by spring."-Mrs. E. N., State of Washington.

A PERFEC'T SHIPMENT OF HOMERS TO FRANCE._"The pigeons arrived this day in perfect condition, but I am sorry to say I have neither the nappies nor the bases. I duly received your letter of $\mathrm{De}-$ cember 16th which I answered at once. I have this day written to Puritan Line of steamship asking for information concerning the non-arrival of the nappies."-G. D., France (Europe).

DOING WELL.-"The pigeons purchased of you last fall are doing well. Am in immediate need of more wooden nappies." F. C. J., Massachusetts.

GOT ONLY TEN CENTS EACH FOR SQUABS BUT MADE MONEY.-"I built two rustic seats for a neighbor for three pairs of Homer pigeons, and put them in a pen eight by eight feet. They increased at about a pair of squabs a month. We turned the young ones out as soon as they were able to fly. We soon had a flock of pigeons of about fifty or seventy-flve. Suddenly we found that we could sell the 
young ones for ten cents apiece and the butcher took them off the nest for us. We killed the three original pairs as we dia not want any in coops. I built a pigeoll house sixteen feet high and ten feet square on tle ground, two stories. The birds come in at the top and nest where they please. I took up a homestead seventy miles north. On this my whole family lived for most of the time. While we werc away from this place, the butcher came regularly and took away the squabs and left the money or his account with a neighkor. We never kept any account of the profit of these splendid birds except last year, when the profit was $\$ 34.50$, and the feed would not amount to a dollar, as they fly out and rustle their own feer. My wife feeds them a little to make them friendly. I have a large wagon shed and they used to nest in this. I shot some of them and they have never bothered me there now for two years. They are wise and I think thy can talk. As a comparison of profit between chickens and squabs, we had a coop of chickens that required constant care. After deducting $\$ 19$ for chicken feed, the profit on them was $\$ 33$. The chicken coop and corral is quite a distance from the pigeon house and the pigeons never feed with them." -W. S. M. California.

NEVER LOST A BIRD BY SICKNESS. - "In June, 1902, I got twenty-four pairs of you, paying sixty dollars for them. I have never lost a bird by sickness. I killed one. $\mathrm{He}$ was ailing and did not look well, so I killed him. This was three or four months after I got the birds. Right off after I got them I raised twenty-five pairs, then I began to kill squabs, as I had no room. I sold the first lot of squabs in February, 1903 , and got 25 cents apiece at first (this was much too low), then I sold for 30 cents apiece until May, 1903. I should say I sold in all 150 squabs up to May 1 . From that time on the marketman to whom I was selling refused to give me more than 18 cents apiece, so I rigged up a new place and put forty pairs in there, then I sold a few more. Since then to now (November. 1903) have sold about 60 to 75 squabs. I have sold only squabs, but the other day I sold six pairs of breeders for two dollars a pair. All the 24 original pairs I got of you have kent working. I have three or four pairs which have made a nest almost every month since I have had them. They had eleven nests, others four or five nests a pair. I have eighty-eight pairs of breeders now. I have got confinence now to go ahead and am going to start a large plant in the country and will buy some more birds of you."-H. C., Massachusetts.

A YOUNG ' WOMAN'S SUCCESS.- "A year ago last July I received from you one-half dozen pairs and paid you $\$ 15$. I have tried to take good care of them and they have increased till now I have some one hundred young birds. I did not try to sell any of them as I wanted to let the flock grow. I took good care of the young birds mating and so there are not any of them that are related to each other now that are breeding. I had built for them a gond warm house according to your directions and they have done very well. Som few died during this winter, but I think they were crowded and so the older ones would push tlie little fellows out of the nest and they froze during the night." Miss E. M. C., Kansas.

A GOOD HEALTHY FLOCK.- "I bought 24 pairs Extra of you a little over a year ago. I now have besides the 24 pairs about 40 pairs of mated birds, all leg banded. Also I have about one hundred young birds and all but about thirty of these will be old ellough to mate by the first of April. All of these are leg banded and are good healthy birds in first-class condition."-E. A. H., Iowa.

GOING TO MAKE AN EXHIBIT.-"My birds that I received of you in July and August are doing fine, and as there is a poultry show here in this city next montli. I thought perhaps I would show a few of them. Could you give me any pointers on putting them on exhibition?"-E. G., Michigan.

EXPEIRIENCE DEARLY BOUGHT."You may possibly think I am doing considerable correspondence without doins much trading, but I wish to get your advice in regard to a little matter. Last April I purchased seventeen pigeons of a friend of mine for $\$ 5.95$. I knew nothing except what your Manual taught me about the business. I purchased in the fall of a westerner what were supposed to be twenty pairs of A1 Homers, but they proved to be a poor mess. The westerner also proved to be a dead beat. The next man I tackled was in your state, who shipped me twentyfour pairs Homers for $\$ 36$. Well, at present I have fifty-three to fifty-five pairs of birds and about thirty-five to forty head of young stock. Now I see where I am lame, and where I made a big mistake in not buying your best breeders, if I had only purchased one-half the number. I wish to get rid of what I have. I have a large house and wish to fill it with the best stock obtainable."-M. D., New York.

NEW JERSEY SEES WHAT REALLY PLUMP SQUABS ARE.-"The 400 pairs of pigeons I got from you are hale and hearty. By actual count I have ninetyeight pairs of eggs and squabs, besides the squabs ready to kill, which number is, however, very small. Taking the lateness of the season when I got the birds and the extreme cold we have here, I think the outlook all right. What do you say? Everybody is stuck on the plumpness of the squabs when dead and their bright and fine appearance when alive." -J. B., New Jersey. 
OUR PROMISES MEAN SOMETHING."Thank you for prompt, kind and satisfactory way of settlement, in answer to our letter to you. If all dealers would as satisfactorily adjust claims similar to ours as you have done, there would be a much easier feeling among purchasers. This action on your part shows that your guarantee is just what it says. Again thanking you for your business-like settlement of our claim."-R. B. M., Pennsylvania.

BOUGHT BIRDS THAT NO ONE ELSE WANTED AND FOUND THEM INDEED CHEAP._About four years ago, my son, now 16 years old, got the pigeon fever, and I must admit I caught it myself. He first put up a dry goods box and bought a few birds. He showed so much interest in them I thought it would be a good pastime and bought him more birds, and eracted a house as per enclosed sketch. Like most beginners, we wanted a variety and we were foolish enough to buy them anywhere, and presume we got what no one else wanted. We spent quite a few dollars and our last purchase was from a fellow in Pennsylvania, who had 'more than he wanted,' and we bought them because they. Were cheap, and they were cheap, or I had better say they were mighty dear. The pigeons never had a nicer home or better feed. I try to do right what I undertake, everyone of our friends said we would succeed, but we made a miserable failure indeed. My wife saw your advertisement, sent for some literature, we then sent for your squab book, which we just received, and read it with considerable interest. The fever has slightly returned, not as hard as at first, but I honestly believe that had I your stock in the first place, we could now tell a different tale. After my wife read your book, she said, 'I believe I can do all right with that kind of stock myself,' so I have encouraged her, as she feels that it would be pastime for our two boys, and I was certainly fond of the birds when we had them. Send along the nappies and just as soon as we can get rid of the truck we have, and straighten house up, we will ba ready for the Extra Homers. I believe there is a great opportunity offered in squab raising, and we are going to try it." -E. G.. New Jersey.

READ OUR RULES TO THE EXPRESS AGENT AND GOT A REBATE OF ONE-HAIF.- "The pigeons came to me Monday afternoon and seem to be none the worse for the long journey. They are beauties and I find it almost impossible to keep away from their pen, but I suppose the novelty will wear away. I should have written yasterday, but the express agent had overcharged me and I wanted to settle the matter, if possible, without bothering you. I am glad to say I was able to persuade him he was in the wrong, and after reading your card he refunded half my money. Thank you for the very prompt attention you gave my order."-Mrs. R. B., Florida.

STRAIGHT BUSINESS METHODS."Birds arrived (this order was the second order from this customer, six months after the first order) in good condition, and are now housed. The birds look fine. I thank you very much for the extra pair, something that I did not expect you to do under the circumstances, as it was no fault of yours of those birds going light. I also thank you for the information and will try and save the bird by your method. To get even with you I shall show my birds to all and mention E. C. Rice. Thanking you again for prompt shipment and straight business methods." $-W$. D., Ohio.

AN OLD CUSTOMER HEARD FROM."I am still raising squabs and like my pigeons better than ever (this customer has been with us going on three years). Am having good success raising them all through this awful cold weather, and they seem healthier than when it is warmer. I enclose check for which please send me wooden nappies. If you have anything new in the way of literature kindly send me some, as I want to keep in touch with you. Have you supplied birds to anyone around here lately? Our visit to your squab plant last summer is pleasantly remembered by wife and I." -F. I. B., New Jersey.

NICE BIRDS.- "The pigeons arrived in fine condition and seem to like their new home very much. Thank you for selecting me such nice birds. Hope the baskets reached you safe."-Mirs. J. P. A., Virginia.

BEAUTIFUL BIRDS GOT TO HIM QUICK.-"Birds received yesterday noon, all in fine condition. Put them in their house last night. All took a good bath this morning. I thank you for your promptness and for sending me such beautiful birds. I had not expected birds so soon, but was ready." - P. M. R., Kansas.

SQUABS SUPERIOR TO POULTRY."I am an old pigeon and squab and poultry man. I have made money with squabs, and I think they are superior to poultry.' -H. S., Massachusetts.

FLORIDA PLRCHASER DELIGHTED. -"Pigeons arrived O. K. Saturday night. I am delighted with them, and as I have followed your instructions as to building house, pen and other articles, the birds seem to be at home."-M. F. B., Florida.

THEY ARE BEAUTIES.-"'Received pigeoss all $O$. $K$. They are beauties and 
have begun to nest,"'-F. M., Ohio. A TEXAS CUSTOMER'S APPRECIATION.-"Your second shipment of Homer pigeons was received yesterday and like the first, in excellent condition, and I am more than pleased with them. Although my dealings with you, when compared to some of your large customers, are rather insignificant, I can't allow this opportunity to pass without expressing to you my thanks and appreciation for your filling of my orders. For square dealings, conducted solely along sound business lines, you are without a peer in the pigeon world today. I most heartily recommend you to all." -S. A. F., Texas. (The writer of this letter is a well-known Texas business man, connected with one of the largest corporations in that state.)

WON SUCCESS ALSO BY DOING AS WE DO; NEVER HAD A SICK BIRD."Some time ago I bought a dozen pairs of Homer pigeons from you and paid $\$ 20$ for them, and I want to gat about four or five dozen more pair, and would like to know the price you ask for them at present, so I can send the money at once. I find your book on the pigeon industry covers the pigeon business in good shape. I have always found when you start to make a new pie or cake, follow the directions of the people that have made a success. Consequently, I have not had a sick pigeon since I received them some eight or nine months ago. The only difference I made was in the house, and in that the only difference was not to make it quite as tight as they are made in your locality. Hoping to hear from you soon." -James $\mathrm{W}$. C., California.

ANOTHER WOMAN PLEASED.-"The birds came on the afternoon of the 6th. They are all very handsome. Some of them are beautiful. You will be surprised to learn that in less than 24 hours two pairs were nesting. They have been very busy all day."-Mrs. R. L. U., New York.

INCREASING FAST.-" "Enclosed find $\$ 1.70$ for leg band outfit. I am receiving excellent results from the birds and they are increasing so fast that I find it necessary to band them."-H. C. K., Maryland.

OUR HOMERS ADVERTISE THEMSELVES.- "For the enclosed $\$ 15$ ship by National Express six pairs Homers, equally as fine birds as you sent on August 3 last year, ten months ago, to Ben Barber of this place," - J. B. H., New York.

MANUAL WORTH FIVE DOLLARS."I $a m$ in receipt of your Standard Squab Book and am very much interested in the work. I find that every time I pick it up something new seems to appear. In fact, the whole subject is covered, so far as I am able to judge, and I consider the work well worth five dollars instead of your dinky price of only fifty cents. There is a squab plant between here and San Francisco. four thousand birds. Their output of squabs, twenty dozen per week, all go to the Palace Hotel, San Francisco. I think prices for squabs are lower here than in the East. still I believe there is money in it." $-J$. L. S., California.

ONE YEAR'S SELECTION.- "The number of breeders have increased to about fifty pairs from those I purchased from you about a year ago (fifteen pairs), and all are good breeders, as I have been particular to raise those from the best breeders only."-H. W. C., Michigan.

BREEDING THROUGH THE TINTER. - "Several months ago I purchased from you a number of your best Homers. They have been doing fine, breeding right along through this severe weather; in fact, my flock has more than doubled." - I. Z. Ohio.

OUR MANUAL OF GREAT HELP TO HIM. - "Some little time ago I sent for youi National Squab Book and afterwards for six dozen of your wood nappies. Since then I have been keeping my pigeons according to your instructions and with great success. I had some fine, pure-bred Homers and have been getting squabs at four weeks averaging twelve ounces. I have had them up to $131 / 2$ ounces. You strongly urge the adoption of all methods that will reduce the time necessary to look after the birds, and I heartily agree with you." -C. C. C., California.

FROM A NEW JERSEY CUSTOMER."Anything new in the pigeon line? If so, send it to me. I am raising lots of squabs." -F. L. B., New Jersey.

SQUAB BUSINESS A SUCCESS.-"My father is in the squab business in a town in this state. His business is a success, but I would like to have him give your birds a trial and so have decided to make him a present of a dozen." -H. L. T., Iowa.

GOOD WORDS FROM A COMPETITOR.-"We have associated your splendid achievements and capacity with our dogged determination to remain in to the death, and by elimination have differentiated both of our establishments from the pretentious and ephemeral plants that come and go. We are a long way from feeling otherwise than modest, and yet we realize that in about eight months we have got a good plant, a good stock, a good name and a good trade, and do not owe a dollar. All the same, this has been regretfully on our sole, unaided inexperience, and your skill has been a loadstar of hope, suggesting that perhaps 
same day we might hit upon the course which you have taken and follow it. If this business shall ever be trustified, we shall wish to be near you, and in any event we have nothing but desire for your continued brilliant success, and that we shall be worthy compeers."-C. F., New York.

WONDERFUL FECUNDITY.- "Here is $\$ 3.84$, for which please send me four dozen wood nappies by Barstow's express. My pigeons bought of you a year ago are doing fine. I bought six pairs of you a year ago and have now (July 5 , 1904) 175 birds. I had 100 stolen. But for this misfortune I would now have 275. I have 400 or 500 hens as well as the pigeons." -N. J. G., Massachusetts.

RAISED A HUNDRED.- "Will you send me your prices on grain of all kinds? My birds are doing fine now. I have about one hundred birds raised from the ones I bought of you (twelve pairs). As soon as I get started in good shape I shall buy more breeders from you. I have not sold any yet as I have been raising them." -H. A. H., Massachusetts.

OTHER HOMERS NOT LIKE OURS."I enclose my check for $\$ 1.50$ to pay for leg band outfit, and 20 cents additional for postage. $\mathrm{My}$ birds are continuing to do fine, and I am more pleased than ever with them. I was out last night calling on a man who claimed to have Homers. They looked more like eommon street pigeons than my Homars. All these things tend to encourage me, when people can hreed such birds profitably. I know mine will show up much better. Please give me a few names of New York dealers in squabs,"-W. M. G., New York.

PERFECTLY SATISFIED._-"Pard'n me for not writing before, but I have been away from home since the birds came, until within a few days. I am perfectly well satisfied with the Homers you sent me. They are as fine a lot of birds as I could wish to see. Half of them are nesting now and I think that they want to work as quickly as could be expected. We have taken great pains to make their house warm, clean and convenient. I intended to order more birds before this time but have been unable owing to sickness in my family. However, as soon as I get straightened round again I intend to order more breeding stock and work my flock up to 150 pairs as soon as possible.'--L. A. C., New Jersey.

ENCOURAGED TO GO ON AFTER EIGHT MONTHS" TRIAL.- "Kindly quote me price on leg band outfit. I have lost circular which you sent me. The birds I got from you last fall (eight months ago) are doing fine, one pair especially, breeding regularly four weeks. I hope to have larger quarters and will then place order for more birds."-F. J. G., New York.

A PLEASURE TO DO BUSINESS IVITH US.- "The two dozen pairs of Extra birds ordered Thursday night arrived Saturday morning. It certainly is a pleasure to do business with you. I am delighted with the prompt service you have rendered, for which I beg to thank you. The birds are a fine lot, and they arrived all in the best condition. I am convinced that you make a special thing of each order sent you. Will return the baskets tomorrow.',-E. S. F., New York.

NEVER SEEN BETTER PIGEONS."Several men who have seen my birds have said that they have never seen a healthier or finer lot of pigeons anywhere. The reason they are in such healthy condition is simply this, that I have followed your method to the very letter, and henca the result." -E. W., New York.

SEVEN MONTHS OF STEADY INCREASE.- "In May last I bought of you a dozen pairs of Homer pigeons which proved a great sucecss, as I now have thirty or forty young birds flying at large. What I want to know is, can I let out my old ones? I have a fine large flying pen for them, but if you think they will stay with me if I give them their freedom, I would like to do so. They have now been in their present quarters nearly seven months." - W. L. J., Maine.

THANKS FOR EXTRA HEN.-"Th's is to advise you that our second order of breeders was received on the morning of the 24th in prime condition. We wish to thank you both for your promptness in filling our order, and also for the extra hen sent to replace the sick one of our first lot."-W. E. M., Pensylvania.

NEVER SEEN IAARGER, FINER OR MORE VIGOROUS BIRDS.-"The Homer pigeons ordered from you on Saturday last arrived today, Tuesday, about noon, apparently in excellent condition, and I believe I have never seen larger, finer or more vigorous looking birds. Please accept thanks for your careful consideration and quick shipment. For promptness you are certainly a wonder."-J. H. B., Delaware.

SHIPPED IN EXTRA FINE SHAPE."I received from you last evening at 7 o'clock 208 birds, all alive and so far as I call see in good condition. This morning one is choked and stupid, but I think will come out all right later. I am very grateful for the extra fine shape in which you crated, labelled and fitted them for their journey. I will send back your baskets this date all in fine shape. I have received evedything else ordared, all in fine condition." -J. C., Long Island, New York. 
SENT HIS FRIEND TO US.-"Please send me a pass to visit your plant at Malrose February $27 \mathrm{th}$, and one for $\mathrm{Mr}$. Burrows. Mr. B. intends buying birds soon. Mine purchased last April are doing nicely."-E. L. S., Boston.

HE IS RECOMMENDING OUR BIRDS. - "Enclosed you will find a money order for which please send me wooden nappies. I would like to have them as soon as possible for my birds are beginning to lay. I was over to your pigeon plant in Melrose and bought a few pairs and I think that they are the real stuff. They are doing fine. Please send me a pass for two, as I would like to visit your plant again, and $\mathrm{I}$ am recommending your birds."-A. L. R., Massachusetts.

STARTED SMALL AND IS NOW CONVINCED.- "Please give me your best price on 100 pairs, giving an estimate of the weight and express charges on same. My birds are doing finely. All young birds are larger than the parent birds and workers."-G. C. D., Michigan.

THF CHILDREN ARE BETTER THAN THEIR PARENTS.- "I have forty-eight birds raised from three pairs I bought of you, far ahead in looks and activity than those you sent me."-Mrs. C. L. P., Connecticut.

HAS RAISED SQUABS TEN YEARS."I have received your Manual and it is beyond my expectations. I have raised squabs for about ten years from common pigeons."-J. H. M., Pennsylvania.

EXPERIMENT A SUCCESS.-"My husband is going into the business. $\mathrm{He}$ bought some Homers of you last summer and intends buying more."-Mrs. G. W. P., Massachusetts.

THEY GROW UP IN INDIANA ALI RIGHT.- "I now (Dacember 1, 1903) have over eighty Homers from the eight pairs I purchased from you last spring. They are all in the very best of condition." R. T. M., Indiana.

IN FINE SHAPE ALL THE WAY TO OREGON.-"I write you to acknowledge the receipt of the birds. Th arrived on the morning of November 10 and were turned into their new quarters on the 19 th, and I guess they were very glad to get out of the baskets and stretch their wings which they did in great shape and a number of them took a bath as soon as it was presented to them. They all seem to be in fine condition after their long journey."-H. J. T., Oregon.

GOOD RESULTS IN SIX WEEKS."By actual count I find we have the following results today, six weeks after the arrival of the pigeons: Forty-two pairs of squabs and sixty-seven pairs of eggs in the process of being hatched." - I. B., New Jersey.

VERIFIED STATEMENTS AS TO COST OF FEED.- "My little experiment justifies the statement of your book as to cost of feed. If you will answer my query as to capacity of my house I shall greatly appreciate the courtesy." -F. B. S., Oregon.

COMMON PIGEONS DO NOT PAY FOR KEEP.- "I have studied squabs for two years and have had good luck with them. I have read your book and think it is good. If I had a price list I would get some Homers. I have always had good luck, but common pigeons do not pay for the keeping." $-\mathrm{H}$. K., Michigan.

AN ALABAMA BOY PLEASED.-"The birds arrived safely on the 24 th and in good condition. We think they are a very nice lot of birds. As I am a boy of only fifteen years, I expect to follow your adrice given in your magazines, and would appreciate any further advice you could offer me. As I have a little more money on hand, I may order some more birds soon. Thank you for your prompt delivery.'- II. L., Alabama.

THREE HUNDRED BIRDS RAISED IN LESS THAN ONE YEAR FROM THIRTY-SIX PAIRS.- "Our birds shipped by you Feb. 12, 1903 (thirty-six pairs), have done very well. We have now (January 12, 1904), over three hundred anò they are laying and hatching all the time. We are going to buy some more before very long and move our plant out onto our thirty-acre farm. I think we will do some more business with you. Please give us the name and address of the people who buy pigeon manure. We have some to sell." -S. M. M., Indiana.

FIVE DOLLARS A DOZEN FOR THE SQUABS PROVE THE QUALITY OF OUR HOMERS. - "I wrote you the first of the week for price of fifty pairs of Homers reary for hatching. Not receiving any answer, I think you did not get the latter. Please give me figures by return mail, and if you can ship at once. The Horners J bought from you two years ago are doing finely, also those I hatched from them. They are very large and hand. some. Shipped some dressed squabs last week to New York and they returned five dollars per dozen, which proves the quality of the goods. Hoping to hear from you soon." -A. C., Connecticut.

OUR STOCK THE BEST TO BE HAD. - "I find I will not be in the market for more birds as expecter, as my flock is in good shape, but have recommended your company to several prospective purchasers. Do not know, however, what result this will bring. I am glad to say that I 
have every confidence in your dealings, as I am nuch pleased with every article I have purchased from you from time to time and will not hesitate a moment to buy stock from you if in market for same, as I believe your stock to be the best that can be had." $-O$. C. S., Michigan.

IN FINE CONDITION, PERFECT BEAUTIES. - "Please excuse delay in acknowledging receipt of birds. They were delivered to me in fine condition and certainly are perfect beauties. They seem to enjoy their new quarters. I must congratulate you on your promptness in shipping orders. With me it was the quickest move I have ever seen, considering the distance. The same day I ordered poultry from a breeder in Jamesbury, New Jersey. Both letters were posted late Friday afternoon. The pigeons arrived Monday morning early, while the pouitry did not arrive until the following Thursday. I was much surprised at the differance." J. IH. B., New Jersey.

KINDNESS TO A BEGINNER.-"We thank you for the kindness you have shown us in our inexperience."-E. H. W.. New Hampshire.

PLEASED WITH HER INVESTMENT. - "Last April I purchased of you some Homers. I have had good success with them as far as the laying and hatching are concerned, and am very much pleas ad with my investment."-Mrs. L. G. S.. Ohio.

STOCK TO BE RELIED ON.-"In talking with my friend, Mr. C. F. Peters, about going into the poultry business, he advised me to write you about the squab business, saying he krew you would do as well if not better by me than anybody. and I could rely on your stock and what you might wish to tell me about the business. I have read your works and think you have the right idea about the business."-C. A. G., Illinois.

THREE WEEKS OLD AND WEIGHED OVER A POUND.- "We weighed one of the first pair of squabs from the birds bought of you when it was just three weeks old, and it held the scales at just seventeen (17) ounces. Pretty good, was it not?'-Mrs. E. K., State of Washington.

A FINE LOT OF BIRDS.-" "The last lot of pigeons which I ordered from you were received Monday morning in splendid condition after their long journey, and are a fine lot of birds. I will send you in a few days another remittance, in addition to the one already sent."-J. L., Louisiana.

SEES THE IMPORTANCE OF KNOWLEDGE AND GOOD STOCK.-"Just read your book and saw how foolish we were.
We haḋ seren dozen mixed birds, some commion and some Fantails, and some Runts and Homers. We were ignorant about the kind, and only had about eight or ten squabs in six months, so we sold them to the first person that came. Now I would like to start fresh again and get about a dozen pairs of your Homers. What would the express be to Alameda? Kindly let me hear from you immediately, as I would like to have some pigeons," Mrs. M., California.

DOING BETTER AS HE GETS EXPERIENCE.- "Enclosed find postoffice money order for which please send me leg band outfit and extra tubing. From the twelve pairs of Homer pigeons I bought from you about May 1, 1903, nine months ago, I have seventy-two birds all told, old and young, and ten pairs setting. According to this rate $I$ ought to have, I think, at least sixty pairs by May 1. That will be an increase of five to one. I have lost so far four young birds and four settings of eggs, but I hope to lessen this this year."-E. B. G., North Carolina.

PREFERS OUR HOMERS.-" "I am very proud of $\mathrm{my}$ birds, they are so tame and pretty. I can get Homers around here, but I would rather have them all from your place. Please send at your earliest convenience."-Miss B. D., New Jersey.

NO MORE CHEAP BIRDS FOR HIM."Herewith I enclose fifty cents worth of stamps, baing in payment for one of your Manuals. In May last I started in the squab raising business and never owned a pigeon before. I naturally have made some few mistakes, both in building a house and selecting birds. I am going to sell out if possible, if not incurring too much loss, which, being a poor man, I cannot afford to do, and if successful I shall buy land and build, and also buy the best birds I can find, even though it be only a few pairs. I now have 150 pairs all mated, working nicely, stove in house, eight-pound squabs, seventy-five cents per pair Philadelphia market. As I said before, I am poor, but not a cheap man. I want the best. which of course after giving proper food and attention I should be rewarded both in stock of squabs and prices."'-S. B., Pennsylvania.

A FRIEND'S FLOCK DOING WELL."Enclosed find express money order. I am sure you will send the best birds. I find the Manual very instructive. Mr. Connellev's flock which he obtained of you is doing fine." -C. L., South Carolina.

STOCK THE FINEST HE HAS SEEN. - "My home is in Buffalo, N. Y. I am stopning in this city (Atlanta, Ga.), temporarily. It is my intention to establish 


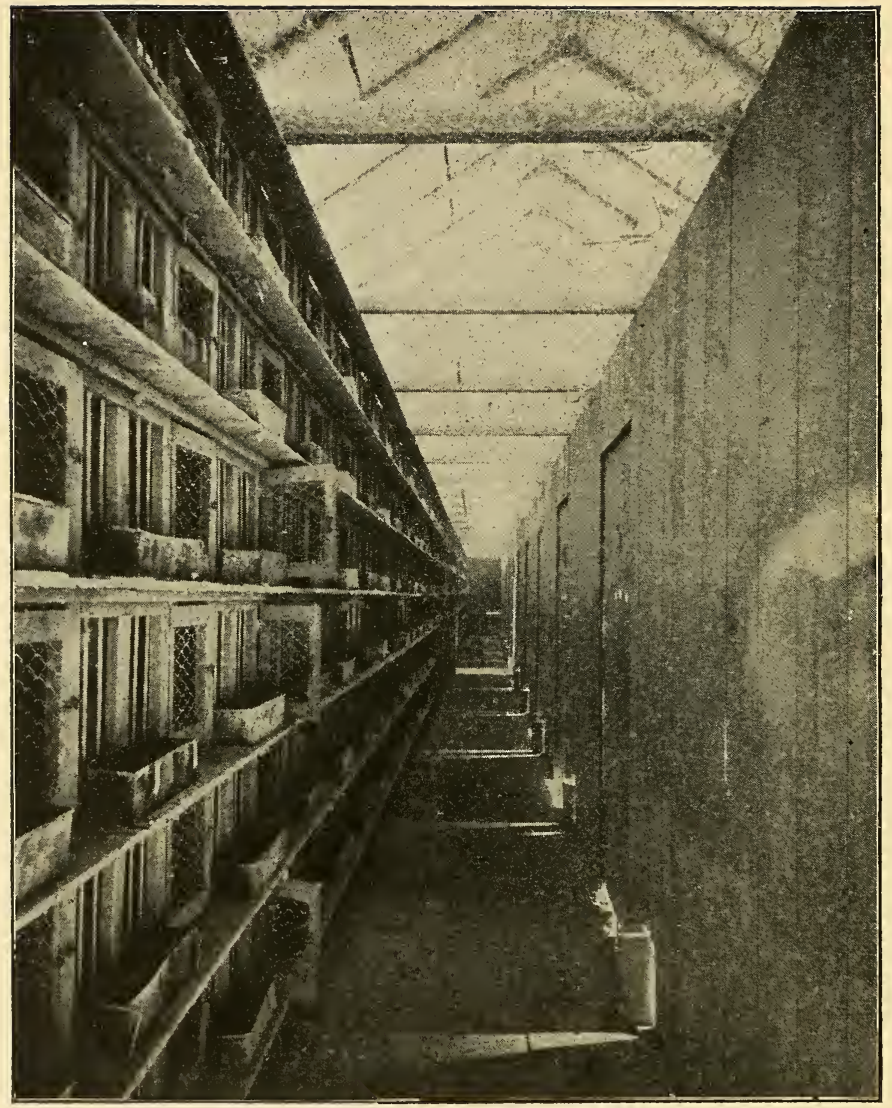

MATING COOPS IN MATING HOUSE.

We have a thousand mating coops in our plant. This illustration shows how they are arranged in a house, several tiers high. 
a squab plant in the vicinity of Buffalo. I have been to look over Mr. - 's plant, which is very fine, and the stock is the finest I have seen. $\mathrm{He}$ informed me that you furnished the stock (five hundred pairs), an entire equipment. My present intention is to start with not less than 300 pairs.' -P. H., Georgia.

IN FIRST-CLASS CONDITION.- "The birds arrived yesterday in first-class condition, all alive. Thanks for the extras." -R. W. B., State of Washington.

A NOVA SCOTIA CUSTOMER.-"The Homers arrived safely today, and I am very much pleased with them. They are a fine lot of birds." -J. H., Nova Scotia.

KIND AND CORDIAL METHODS."Many thanks for your kind and cordial methods of doing business, and if $I$ find that the conditions here are suitable to squab raising, I shall be wanting some more stock before long. So far I am very well pleased, and the birds you sent are certainly well worth the prices you quote." -D. T. S., Kentucky.

CHICKEN INDUSTRY NEEDS A MANUAL LIKE OURS.-The Manual sent me is the most complete and concise work on the subject of squab raising I have ever read. I doubt whether there is a book written on any subject of its kind so complete in all its detail. I would be willing to give most anything for a like account of how to succeed with chickens. If you know of any such work I would consider it a personal favor if you would kindly send me the title and where to get it. I am glad to have in my possession such a book as the Manual, it is a pleasure to read it. Of course it's business, but I think it wonderful that you should give such valuable information to the public."-J. H. J., Pennsylvania.

“SAME AS YOU SENT BEFORE." "Enclosed you will find $\$ 15$ for six pairs of your best breeding Homers that breed white squabs, the same as you sent before." $-\mathrm{F}$. P., Virginia.

FROM FIFTY DOLLARS TO FIFTY CENTS.-"Please send to us as soon as possible 48 nappies. We shall want 48 of your Extra Homers as soon as these nappies reach us, and if conditions prove favorable. hope to buy a thousand birds. I think there must be money in this business. 1 wrote a squab raiser in Iowa, asking if he would show me through his farm, and he replied that he would for fifty dollars. I enclose fifty cents for a National Standard Squab Book, which kindly send me."-A. D., Minnesota.

MAKING MORE MONEY WITH SQUABS.- "The nappies have not yet come. I have quit the railroad and gone into the squab business. We are going to send for some of your Homers soon and let what we have raise with a few additions ocasionally until the Homer trade gets rooted. I am now making more with pigeons than while working for the company, or rather, I am making a good living and putting in a large stock of pigeons." -S. D., Texas.

OUR CLAIMS PROVEN TO HIS SATISFACTIUN.- "Last February, 1903, I bought a small lot of adult Homers fronı your company and am satisfied they are all you claim for them. Being desirous of getting along faster in the business, I have advertised for additional capital in a New York City paper, and have had nearly two dozen inquiries about the industry." - A. D., New Jersey.

A HUSBAND WAITS FOR THIS YOUNG WOMAN.-“November, 1902, I bought twelve pairs of your Homers, now I'm sorry to say I must give up the idea of the squab business, and wish to know if you care to buy them and what you will pay. I have ninety birds, and sold some last summer. I think your birds have done very well. I would not have anything but your Plymouth Rock Homers," -Miss E. J. D., New York

A TEXAS WOMAN FINDS THEM EASY TO RAISE. - "I have now (January 7 , 1904), raised one hundred from those I bought of you (six pairs Extra sold December 11, 1902.)"'-Mrs. R. M. H., Texas.

ONE HUNDRED PAIRS IN MONTANA'S COLD WEATHER.-"The squab breeders arrived here all safe and well in spite of the cold snap Monday noon. Wa are much pleased with the flock. Number is correct, 208 birds (only two casualties). They certainly are having a fine initiation to Montana weather. The mercury stood thirty-two degrees below zero last night and has been below since their arrival." -T. H., Montana.

DEAI,ERS ADVISE HIM TO BUY OF US.- "About a year ago I bought your Manual and plans for squab houses. I have been studying the book thoroughly and find it very complete in every detail and 'out of sight' as compared with others I have seen. I am compelled to move to Southern California and will try squab raising. What discount do you give on 300 pairs of your best birds? I have been somewhat used to stock raising, including poultry. I am advised by dealers in Los Angeles to get my stock from Boston, even at the expense necessary. While no names were mentioned, I presume they referred to you."-W. W. D., Minnesota. (Correct. We have shipped to California within the past few years thousands of pairs of Homers and at all the places in California where squabs are sold and eaten, the product of our Homers is 
wanted because they are the best in the market there.)

USES THE HEALTH GRIT.-"Please send me by American express one hundred pounds Health Grit, for which find \$2 enclosed. My pigeons are doing finely and I now have 75 in addition to my original lot, and the young ones are hatching out squabs." -W. L. J., Maine.

HE IS PLEASED WITH US AND OUR BIRDS.-." I am so much pleased with the birds I got from you and the bright prospects of the squab industry, that I feel interested in getting some of my friends started in squab raising. The last shipment of squab breeders reached me in splendid condition and are very fine birds. I am very much pleased with the selection and your good judgment. All your stock, birds, supplies and dealings with me in the past have been so satisfactory that you may expect more orders from me and my friends in the future. I have raised and sold pigeons and pet stock for years, so of course am capable of judging good stock when I see it, and I consider your squab breeding Homers the best that can be bred for successful market squab breeding. Trusting that you may continue to have much success in this worthy business."--L. E., Tirginia.

THEY EAT OUT OF HER HAND.- "I enclose money order for more nappies. I like my pigeons better every day. They are so tame now they will eat out of my hand."-Miss L. V. P., New York.

THREE MONTHS' WORK.-“We are going to move this week to California. The six pairs I bought of you in March, three months ago, have all nested and done fille, and $\mathrm{I}$ have raised 24 young birds from them."-Mrs. H. B. S., Massachusetts.

ALL THE WAY TO VANCOUVER.-"I received my birds on June 8 and all of them were in fine condition except one hen, which seems to be a little stupid. My express charges were all right. Thank you for the free birds. Hoping that I will be able to send for a few more soon." G. A. L.. Vancouver.

HAS SEEN HOW OUR BIRDS WORK IN HIS TOWN.- "I am sending you herewith money order for $\$ 31.50$, for which please send me 12 pairs of your Extra Plymouth Rock Homers, and two of your drinkers, same as you sent me before. I have seen two different lots of your Homers in this city, and although I have some good ones that are rapid breeders and raise large squabs, I am so much impressed with the work that Mr. Barrett's Homers (purchased of you) are doing, that I have gone to work and fitted up two more breeding pens to accommo- date some of your stock." -W. H. M., Massachusetts.

ALL AT WORK IN SIX WEEKS.-"Whoever took the pair of pigeons from the basket must have been an expert in determining the sex and mates, as every one of them, that is, twelve females, have eggs and are setting. Don't you think this is strong evidence that two pigeons never were taken from the basket during transit? I will make no claim against the express company. I feel very positive they are not at fault. The shipment reached me six weeks ago."-C. S., Ohio.

INCREASING HIS FLOCK.-"The twelve pairs of breeders that I bought from you last fall are beginning to lay very nicely and I am very much pleased with them. Please send me six more pairs, in payment for which you will find money order enclosed." $-\mathrm{H}$. W., New York.

A LARGE SHIPMENT TO CALI FORNIA.- "I received all the birds (312 pairs) without one being dead, and the lot seems to be in splendid condition, on the whole, after such a long journey. It seems wonderful to me that none was dead with all the rough handling they must have received on such a long journey. The birds are beauties and attract a great deal of attention." $-P$. W., California.

QUICK WORK HATCHING.-"The Homers I got of you are doing finely; received May 1, five weelss ago, and I have a dozen or more squabs from the dozen pairs."-J. F., New Jersey.

FINEST HE EVER SAW.- "The Extra Homers arrived today in first-class shape, and are the finest $I$ ever saw." - L. C. Y., Maryland.

UNABLE TO FILL ORDERS FOR HOMERS.- "The writer has been engaged in selling Homer pigeons for squab breeders for the past several months, but my stock is now almost completely exhausted and I am unable to fill my orders. Have just received an order from Hot Springs, Arkansas, but as I make it a rule not to attempt to fill orders for birds which I do not have in my own lofts, have declined the order and referred the customer to your company. He wants fifty pairs, and would suggest that you get into correspondence with him. Trusting that you may be able to get the business." -G. C. S., Ohio.

OUR PIGEONS AT THIS LARGE SHOW IN 1906 MADE A CLEAN SITEEP OF THE PRIZES.-Plymouth Rock Squab Co. Boston, Mass. Gentlemen:-Pardon the delay in not answering about the safe arrival of the birds. The show was a big 
success and over nine hundred entries were regiscered. I had a nice coop fixed up and brought the entire flock of fourteen birds. They behaved fine and did not mind the close confinement after the first day. One of the pairs laid two eggs. My flock took first, second, third and fourth prizes, also one for the largest flock of one exhibitor (which was \$3), and the white birds took first prize over three other pairs. The judge was high in praise of the birds and their markings. I understand you have sold some birds to Mr. Marsh, who has heard about my success and is to start with one hundred pairs. The pigeons sold several months ago to a doctor of Warren were through my recommendation. Thanking you again for past favors, I remain, etc.-Mrs. R. C., Pennsylvania. (The pigeon exhibition to which she refers was held in February, 1906.)

OFFERED FIVE DOLLARS A PAIR FOR THE BIRDS.-"Pigeons arrived August 29th in good condition and I thank you. I am well pleased with the birds; they are the finest flock I have ever seen. The teamster who brought them out from Seattle informs me a man on the way offered him five dollars a pair for the birds. Had I been with him, I surely would have taken him up, and made nearly $\$ 100$ by the bargain. You may expect another order from me in a month or six weeks for one hundred pairs, and then I shall have enough breeders to commence with."-C. C., State of Washington.

We have had quite a number of letters similar to this one, and from other information which we have in regard to the Western market for breeders, we know it to be a remarkable one. Anyone who buys our fine birds can find a purchaser who is willing to pay in many cases much more than the difference in express charges. We receive numerous requests from wholesalers who wish to sell our birds in their territory, but we sell all the birds we wish to at retail, to the extent of our capacity, at one price to all, and do not supply such dealers. We are shipping at least one order a day the year round to California or the State of Washington.

OUR HOMERS ARE PRIZED BY FANCIERS AS WELL AS SQUABBREEDERS.-Our Homers sell on their merits as squab breeders, but they are first-class flyers, able to win in any company. $\Lambda$ t the New York and Chicago Na.. tional Pigeon shows in January, 1904, in competition with the whole country, Homers sold by us and exhibited by our customers were the best birds there. In awarding the first prize, New York show, class of Blue Homer Cocks, the judge said: "Grand one; the best bird in the ring today to my way of thinking. $\mathrm{He}$ is a larte, fine-colored Homer with almost perfect head, broad shoulders and wedgeshaped body, nice eye and fine dark cere. This cock also won the cup for best Homer shown, and this honor was not new to him, as he did the same trick at Lawrence earlier in the season.'

The class of Blue Checker Cocks at the New York show was the largest. "A finer class of Blue Checker Homers we have never seen," said the judge. The first prize in this large class was awarded a Homer from our coops exhibited by one of our customers with the following comment by the judge: "Grand-bodied, upstanding bird, elegant head and eye with the most perfect checkering I ever saw on a Homer, but for being a trifle light (in color) on rump he would be hard to find fault with.'

In awarding the first prize in the New York show, class of Blue Hens, to a hen sold by us and exhibited by one of our customers, the judge said: "This class outside of the winner was not bang-up. Good blue hens are scarce, but the first bird is an exception, and probably one of the best hens going. She is extra large for a hen, almost over the limit in this respect, but she is built on the correct lines, very good color and smooth type of head. She would maka a great mate for the first Cock."

In the fall of 1903, one of our customers, with a Homer Cock bought of us, won first prize every time exhibited, also special prize for best Homer in the show. every time exhibited, at the pigeon and poultry shows at Taunton, Brockton and Hartford.

THIS COMMISSION FIRM IN NEIV YORK CITY WANTS ONE THOU SAND DOZEN SQUABS DAILY, PAY ING FROM \$4 TO $\$ 6^{\circ}$ A DOZEN FOR SQUABS BRED FROM OUR BIRDS.

The large commission houses handle squabs by hundreds of dozens daily and firms which are known to furnish squabs of first-class size and weight, such as our birds breea, get more orders than they can fill. We received the following letter in January, 1904, from a well-known commission firm in New York City (whose name and address we give to customers who buy breeding stock of us):

Plymouth Rock Squab Co., Boston, Mass.:

Gentlemen: I am receiving quite a few letters from time to time from the different customers of yours, that are starting in the squab trade. I wish if you see or write them, that you would advise them as I have done, to put themselves in a position to ship from 5 to 10 dozen squabs at a time, and if they intend to make a business of it, they might as well buy enough breeders in the start, so as to be able to ship a quantity at a time, as these little shipments of one or two dozen hardly pays one to handle, the expense eating up the commission. I have stated 
to them before, and you can also tell them, that the squab trade is in its infancy, and will certainly increase from time to time, and we are in a position to handle daily any part of 1,000 dozen squals, as we have a big outlet to place them promptly at top prices, with check to balarce same day goods are received and sold. For the present, and until further notice, we quote you market as follows: Squabs weighing ten pounds to the dozen, \$2.50 per dozen; nine pounds, \$5.25 per dozen; eight pounds, \$5 per dozen; seven pounds, $\$ 4$ per dozen; six and onehalf pounds, $\$ 2.75$ per dozen; dark, $\$ 2.10$ per dozen. Would like to have all the squabs you can get. In case you have any good customers that are starting in, I wish you would send me a complete list of that trade, so that I can write to them occasionally, and post them on the condition of the market.

To our answer we received the following letter from the above firm:

Plymouth Rock Squab Co., Boston, Mass.: Gentlemen: Your letter of the 1st duly received, and I am glad to hear from you so promptly. I have received quite a number of letters from small shippers who, judging by the way they write, must be beginners, and know but very little of the business. I have tried to make things as plain as possible to them, and encouraged them all to start in and increase the size of their purchases from you to such an extent that it will pay them to ship. of course we are obliged to take these small shipments, and encourage them along as much as possible, but very often after we have got a man started, he would have made a pretty fair shipper, but someone gets hold of him in the meantime and makes him believe that they can do better than we can, which is one reason that I object to helping these small shippers along. As above stated, as soon as they get started they begin switching around, and the man who starts them has very little for his trouble and pains of putting him in the way of making money.
I wish if you have any shippers' addresses in the West or in Wisconsin (which seems to be quite a squab country) and also in either Illinois or Minnesota, that you would send them to me. They seem to be doing pretty well in that section, and are satisfied with the fair prices they get from our market, on account of the poor prices they get in Chicago, or elsewhere nearer home.

At the present time, squabs are very scarce and very high. We are even returning more money than the last quotations I sent you, in order to gat enough birds to supply our trade. So if you can put me in the way of increasing our squab supply, I would greatly appreciate it, and try in some way to reciprocate for same. Thank you for the information you have given me thus far in regard to shippers.

Under date of January 30, 1904, we have the following letter from a commission firm in St. Louis, showing that the demand in that section is becoming extraordinary:

Plymouth Rock Squab Co., Boston, Mass.: Gentlemen: We are in the market for squabs and if you have any eustomers in this vicinity who are seeking a market for their squabs, we would be glad to be placed in correspondence with them. We will pay the highest market price for them, and feel confident that the service we will render your patrons will prove advantageous to you, to them and ourselves. Please let us hear from you.

We do not give the addresses of these firms, and other good squab buyers, until we have sold breeding stock to the customer. Commission men in all the cities are getting letters from curiosity seekers who are merely "looking up" squabs, and to such letters the commission men pay scant attention, for lack of time, and as there is no money in it for them. Anyone who doubts the genuineness of the letters we print should come or send a friend to our Boston office to see the originals.

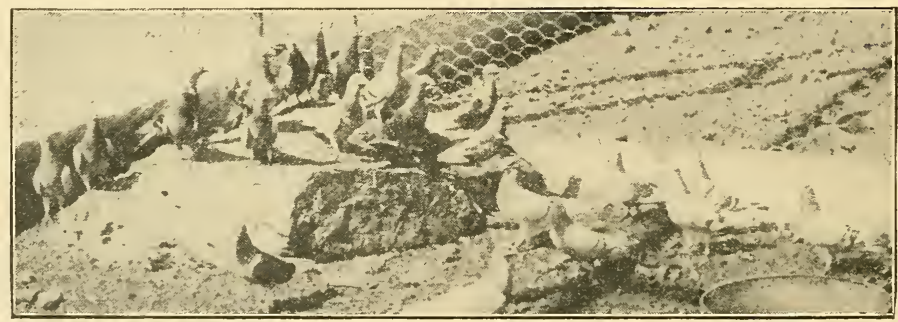




\title{
APPENDIX A. \\ NATIONAL STANDARD SQUAB BOOK.
}

\author{
By Elmer C. Rice.
}

CALIFORNIA MARKET.-The California you do not care to deal with commission market for squabs is excellent, especially at men. the invalid resorts. In San Francisco it is BRANCHING OUT.-We have put some of not so good as at the Southern Coast places our best birds, in largest orders, for 300 to frequented by rich travelers. We print the 1,000 pairs, right into the heart of the squab following letter:

Poultrymen's Union of California, 413 Front ideas and our birds are all right. On Feb. street, San Francisco (Jan. 28, 1903): "Your 9. 1903, we received the following letter from valued favor just received and in reply would Heacock \& Hokanson, architects, of Philasay that usually the quotations in the papers delphia:

'are close to being correct, but if you desire to call and see us at any time, we will give you exact quotations. There is always a good market here for large, fat squabs. They are readily selling today at $\$ 3$ per dozen."

SUMMER RESORT MARKETS.-The pleasure and vacation resorts all over the country are good squab markets. Maine squab breeders ship to Boston in the winter but in the summer they get better prices at Bar Harbor and elsewhere along the coast. The White Mountain resorts in New Hampshire are a fine summer market, also the resorts along the eastern coast of Massachusetts. Newport, in Rhode Island, is a good summer squab market. Two or three of our customers in the vicinity of Lenox, Mass., and in North Carolina, and Florida, are quite enthusiastic over the splendid market at their doors. Wherever the good eaters go, winter or summer, there is the demand for squal,s.

HOSPITAL TRADE.-A woman in the state of Washington wrote us that two big hospitals in a city near her had offered to take all the squabs she could supply. She moved out, bought a farm and in January, 1903, we shipped her four baskets. Under date of Feb. 7 she replied: "Please pardon my delay in acknowledging the receipt of the shipment of fifty pairs extra nuated Homers I ordered from you. I have been so busy with them that I have not really had time to write. Out of the whole lot there was only one dead one, which surprised us." (As we had shipped two pairs more than the order called for, or 52 pairs altogether, the customer had no complaint.) "The birds are perfect beauties and we are greatly pleasef with them. They seem to like their new home. Thanking you for your kindness and with best wishes."

The hospital trade in squabs is worth catering to, for they are such a delicacy that eager one, and the dealers are imploring they are greatly esteemed by physicians. squab raisers to sell, saying they will take There may be a suggestion in this for you if all offered. We advise our customers in the 
Middle West to sell their squabs to the trade direct over the heads of the Chicago commis sion men until the latter advance prices. We print herewith some letters from Chicago commission houses, showing that they want them both with the feathers on and off, depending on the dealer:

C. B. Hayden, Jr., \& Co., 214 and 216 South Water street, Chicago, Illinois (Jan. 26, 1903): "Your favor of the 24th inst. at hand and in reply will say, fat dressed squabs bring $\$ 2$ to $\$ 2.25$ per dozen. We hąndle them in any quantities."

Gallagher Bros., 191 South Water street, Chicago, Ill. (Jan. 26, 1903): "We have your favor of the 24th to hand and noted. In regard to handling squabs will say, we are in a position to handle any quantity to good advantage. We are now getting fancy squabs from Wisconsin, which are selling at $\$ 2.50$ per dozen, about seven pounds to the dozen."

C. H. Weaver \& Co., 129 South Water street, Chicago, Ill. (Jan. 29, 1903): "Your favor of the 27 th received. The market on squabs is $\$ 2.25$ per dozen for the weights you speak of. We can handle all that you will be able to ship us, but would advise making a small shipment at first, so that we will get an idea of your stock and dressing."

Theo. C. H. Wegeforth Co., 133 South Water street, Chicago, Ill. (Jan. 28, 1903): "In reply to your favor requesting us to quote you prices on squabs will say that there is a very good demand for them on this market at present and when fine they will bring from $\$ 2$ to $\$ 2.25$ per dozen but in order to bring these prices, the squabs must be fat and weigh on an everage about three-quarters of a pound each, and for such there is a ready sale. If you have any, or receiving, you can safely ship all you can get."

H. R. Waszko, 213 South Water street, Chicago, Ill. (Jan. 29th, 1903): "In reply to your letter of Jan. 27th, we wish to say that we can handle your squabs, in fact we can place any amount at the extreme top market price, for we are heavy receivers of dressed squabs, especially from South Dakota and Wisconsin. Squabs should weigh not less than six or seven pounds per dozen. Should be dry-picked as the trade that can pay fancy prices want them No. 1 , and we quote thein firm at $\$ 2.50$ per dozen, but they must be fancy. We think we can get you still higher prices but we can tell from your first shipment to us just where we can place them and what we can do. See that they are well cooled off before shipping. Trusting that you will favor us with a good shipment as soon as possible and also give us an idea of how many you can ship us daily or weekly.",

Peter Britten \& Sons, 2 and 4 Fulton street, Chicago, Ill. (Jan. 30, 1903): "There is no limit to the amount of squabs we can handle, as we have inquiries for the same at all times. We assure you, and you can rely on us to obtain the highest possible price for your stock at all times."

Cougle Brothers, 178 South Water street, Chicago, Ill. (Jan. 29, 1903): "Replying to your favor of Jan. 27th will say that good fat squabs are worth from $\$ 2$ to $\$ 2.50$ per dozen. We can handle all of that kind you can get. The best way to ship them is just to pinch their necks, cool thoroughly and pack in a box. Do not bleed them nor take the feathers off. We hope you can ship us some of this kind of squabs as we need them."

F. W. Melges \& Co., 100 South Water street, Chicago, Ill. (Jan. 28, 1903): "Replying to your favor of the 27 th in regard to squabs we beg to say that there is a wide range of prices according to quality. If they are fine fat birds vie can handle advantageously all you can ship us. We shall do all in our power to obtain the very top price for same at all times."

A. Booth \& Co., 63-65 Lake street, Chicago, Ill. (Jan. 25, 1903): "If squabs are well dressed and weigh eight to nine pounds to the dozen, we can use them at $\$ 2.25$ per dozen F. O. B. Chicago.",

H. G. Lane, buyer for the Wellington Hotel, Wabash avenue and Jackson boulevard, Chricago, Ill. (Feb. 2, 1903): "In reply to yours of Jan. 26th about squabs would say that we are buying the large white squab you speak of. We have them shipped with the feathers on and market price for the best squab is $\$ 2.75$ to $\$ 3.00$ per dozen."

William H. Taylor Co., 156 and 158 South Water street, Chicago, Ill. (Feb. 4, 1903) : "Your letter at hand in regard to squabs. Would say we could use all your squabs you can ship. We would just as soon have them with the feathers on as off. We can offer you $\$ 2.50$ now for good stock. Should at any time market do better, we should certainly give it to you. Please let us know how soon you can ship and how many each week. We have the trade for them and can do as well as any one for you."'

Herman Weber Co., Inc., Union Hotel and Restaurant, 111-117 Randolph street, Chicago, Ill. (Fcb. 3, 1903): "Your favor of the 1st to hand. I am buying squabs fresh in the market all the time and am paying \$3 per dozen for same. You can bring in two dozen of your squabs and if satisfactory will buy same of you right along."

The letter last quoted above, that from Herman Weber, is an indication of what the consumer in Chicago is paying for inferior squabs. It rests with you whether you will be satisfied with breeding a product which commands a price of $\$ 2$ to $\$ 3$ a dozen, or $\$ 3$ to $\$ 6$. If you put squabs weighing ten prunds a dozen and over into the Chicago market, you can get from $\$ 3$ to $\$ 6$ a dozen.

NEW YORK MARKET. - In the first part of 
January, 1903, we received the following letter from the manager of the squab department of a commission house in Washington market, New York city:

"Your name and address as raisers of fancy squabs was given me by Mr. Howes of Detroit, Michigan, who was over to your place a few days ago. As I have heard of your plant before and have tried to get your address so as to write to you for squabs, I hope this letter will mean some business for us both. If you have any squabs to ship, I would like to get your output, and can use all you can ship at full market, and make you prompt returns day received and sold. This week I am returning the following prices: Squabs weighing ten pounds to dozen and up, \$4.50 per dozen; eight pounds and up, seven pounds and up, $\$ 3.50 ;$ six and one-half pounds and up, $\$ 2.60$; dark, $\$ 1.80$ per dozen. If you will prepay charges, account of sales will be sent you same day goods are received, less five per cent. commission."

Letters like the above come to us from all parts of the country, and squab breeders whom we have supplied get similar communications. The poultry and game dealers in all sections are after squabs all the time and could sell a great many more than they are now able to get hold of. The above letter is written notwithstanding the fact that in New Jersey and Eastern Pennsylvania alone are today four or five thousand squab breeders, many of them with large flocks of over one thousand pairs of birds each. In the town of Moorestown, New Jersey, to take only one case, are from 200 to 300 squab breeders. As we say in our Manual, people in these sections keep hens for their own use, but not for market, for they know that squabs pay better than hens. Poultrymen in other sections of the United States are fast finding this out and are putting in squabs along with poultry, or giving up poultry altogether. In spite of the large output of squabs from the 4,000 to 5,000 breeders in New Jersey and Eastern Pennsylvania, which go into the Philadelphia and New York and Boston markets (for the squab raisers in New England supply only about one-tenth of the Boston demand), there is all the time a scarcity of squabs, as the above letter proves. This letter comes to us because we have the reputation for dealing in a fancy product. There are breeders of squabs who send to market an inferior product from small and cheap Homers, and such squabs are not the kind which commission dealers are anxious to get. Be sure you are able to breed a fancy squab by getting your breeding stock of us. Some beginners are anxious as to express rates, not comprehending that they can ship squabs long distances at a trifling cost. The express rate from Boston to New York is $\$ 1$ per 100 pounds. This means that an express team will call at our door, get a box of squabs weighing 100 pounds, transport it to New York, and in that city deliver it by team to the commission dealer for $\$ 1$. In the case of a box of our squabs weighing twelve pounds to the dozen, about eight dozen and the box would weigh 100 pounds. If we delivered them in New York at the price quoted, $\$ 4.50$ per dozen (or $\$ 36$ gross), we would net, deducting his five per cent. commission and the $\$ 1$ express charges, $\$ 33.20$. The commission man would resell the squabs to his trade for $\$ 5$ to $\$ 8$ per dozen. By a dozen squabs we mean in this case and in all cases where prices are quoted, twelve squabs. We do not mean one dozen pairs of squabs. We mean six pairs of squabs. Squabs are always quoted at so much per dozen, not so much per dozen pairs.

On January 8, 1903, the New York squab buyer above quoted offered the following prices for squabs: For squabs weighing ten pounds to the dozen and up, $\$ 4.75$; eight pounds and up, $\$ 4.50$; seven pounds and up, $\$ 3.60$; six and one-half pounds, $\$ 2.75$; dark and No. 2 squabs, $\$ 2$

On January 25th, 1903, he offered the following prices: Ten pounds and up, $\$ 5.50$ per dozen; eight pounds and up, $\$ 5.00$ per dozen; seven pounds and up, $\$ 4 ;$ six and one-half pounds, $\$ 3$; dark and No. squabs, $\$ 2.10$.

On February 6, 1903, he offered us the same prices as last quoted, adding that he would pay $\$ 3$ to $\$ 3.75$ per dozen for squabs of average weight and grade. In this letter he said: "As I have been getting quite a few letters from some of your squab customers of late, I want to thank you for same, and hope to get some of their birds and prove to their satisfaction by the prices large fine birds will sell at, that squab raising if properly carried on is a very profitable and paying industry. The demand for squabs in on the increase and will be from now on, as the game laws of all the states are such as to prevent much small game from reaching the several markets, where there has been a big supply of such at low prices that squabs will now take their place, so that new beginners have nothing to fear from a glut by over production of good-sized squabs. This we have proven to our own satisfaction when we introduced the large or royal squab to our best hotel and cafe trade in this market, during the past season, and it now looks as though our demand will be greater this coming season. The buyers of these large birds see they are worth the difference in price, that they have a better call for them once they introduce them to the sonsumer. Encourage all your buyers to invest in birds that produce large, plump squabs. It will pay them best in the end and make a hetter demand for their grade of birds."

On Feb. 16th, 1903, he offered us the fonowing prices: Squabs weighing ten pounds to the dozen and up, $\$ 6$ per dozen; nine pounds, 


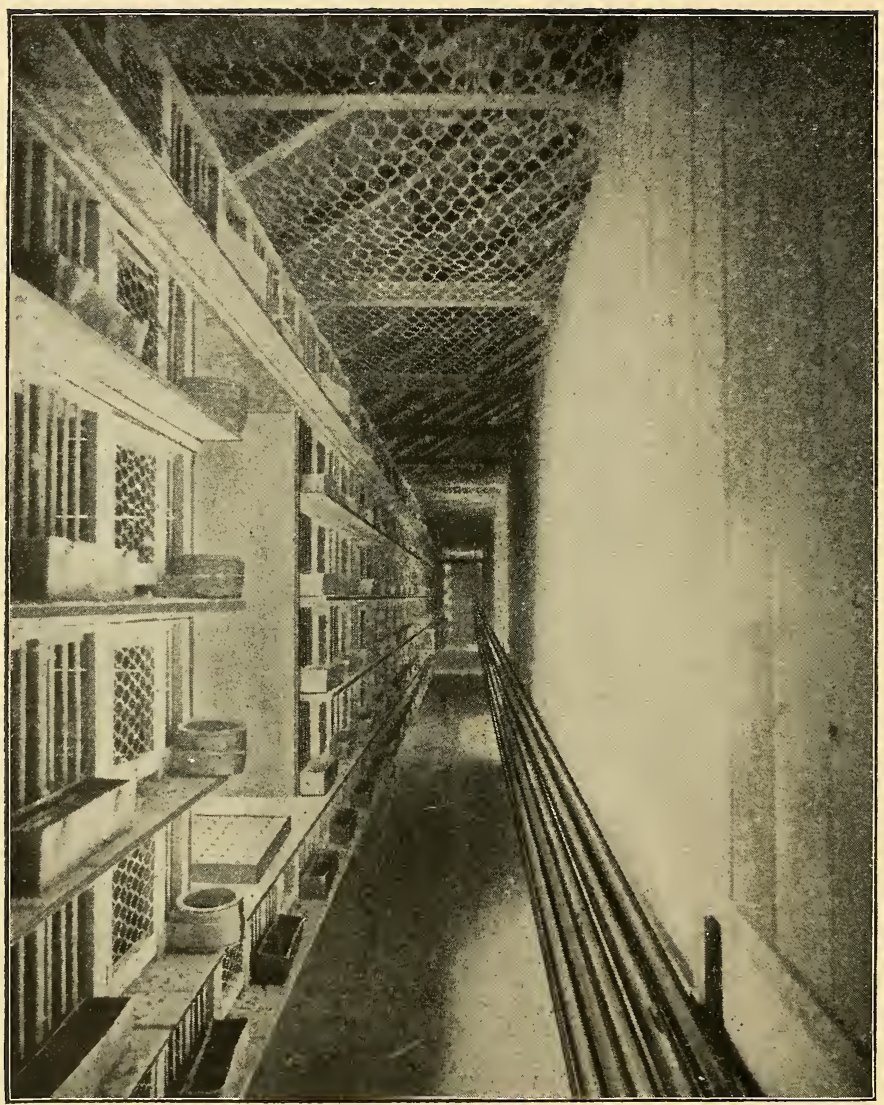

INTERIOR OF MATING HOUSE.

This shows mating coops in use in one of our mating houses. This house is heated by hot water. 
$\$ 5.50$ per dozen; eight pounds, \$5 per dozen; seven pounds, $\$ 4$ per dozen; six and one-half pounds, $\$ 3$ per dozen; dark, $\$ 2.10$ per dozen.

The above quotations are a good indication of what the New York market for squabs is. One of the practical ways we have of helping our customers is to refer them to such first-class buyers of squabs as the firm above quoted. We will give the address of the above New York firm to you when you buy breeding stock of us.

SCRANTON MARIKET.-The following letter is from Chandler and Short, commission merchants, 15 Lackawanna avenue, Scranton, Penn., dated Feb. 15, 1903: "We have yours in regard to squabs. They are worth from $\$ 2.75$ to $\$ 3$ per dozen, dressed, on our market. Whatever you ship, we will endeavor to get the very highest market prices for. All you have to do is to have the feathers picked off.",

CLEVELAND MARKET.-The steward's department of the Union Club, 158 Euclid avenue, Cleveland, Ohio, sends the following letter under date of Feb. 13th, 1903: "I am in receipt of your letter of yesterday and beg to say regarding your questions about squabs, that they are worth to us from $\$ 3$ to $\$ 3.50$ per dozen for the best and largest squabs either dressed or in the feather.",

W. H. Bennett, proprietor of Oyster Ocean Cafe, 368 Superior street, Cleveland, Ohio (Feb. 12, 1903): "I use about one and onehalf dozen squabs a week. Price averages $\$ 3$ per dozen the year through.",

W. H. Seager, Sheriff street market, Cleveland, Ohio (Feb. 12, 1903): "I purchase squabs when offered in this market and have sent to California for them on special occasions. The market price varies from $\$ 2.40$ to $\$ 4$ per dozen."

Gibson Pinkett Company, Fulton market, 21-25 Prospect street, Cleveland, Ohio (Feb. 12, 1903): "We buy squabs and pay what they are worth. Price runs from $\$ 2.50$ to $\$ 4$ per dozen. We could use fifty dozen or more today."

KANSAS CITY MARKET.-The market for squabs here is steadily improving. Here are some letters bearing on the subject:

From James R. Peden \& Co., 404 Walnut street, Kansas City, Mo. (Jan. 26, 1903): "Send your squabs to me. I have good, steady demand for them and will take all you can offer. Top prices paid, or handled in commission." (Mr. Peden ships squabs .) New York city and other points east.)

W. M. Woods, produce company, stalls $、 12$ and 13 west side, City Market, Kansas City, Mo. (Jan. 26, 1903): “The market for squabs is good. Prices range from $\$ 1$ to $\$ 1.50$ for common stock and from $\$ 1.80$ to $\$ 2$ and $\$ 2.25$ for fancy. I am sure you will find a market for your squabs and if they come up to the mark you have set for them, will command 2 much better price. Kansas City market for squabs is growing. I will take your squabs at market price day received.",

C. T. Wiggins, East entrance City market, Kansas City, Mo. (Jan. 26, 1903): "It is only a question of how many you can supply. I can handle all the squabs you will offer and will pay you good prices for them. The demand is strong and increasing. Hope you will soon make a start with me.",

George O. Relf, steward, Midland Hotel, Kansas City, Mo. (Jan. 27, 1903): "We can use squabs almost any time at $\$ 2.75$ per dozen. If you have some now we will take one or two dozen and if $\mathrm{O}$. K. will very likely use them right along."

Ewins-Dean Hotel Co., proprietors Hotel Metropole (St. Joseph, Mo.) and Hotel Baltimore (Kansas City, Mo.) (Jan. 30, 1903): "Irindly quote me prices on squabs by the dozen. I have been using about two hundred per month and expect to use more. If your prices are right you will hear from me in a few days." (Signed) E. G. Venable, steward.

E. Klidey, the New Coates House, Kansas City, Mo. (Jan. 29, 1903): "We are using a few squabs which we buy from the commission men here at $\$ 2.50$ per dozen. Let me know what price you want for yours and we may be able to use eight or ten dozen a week."

D. P. Ritchie, steward Hotel Baltimore, Kansas City, Mo. (Feb. 6, 1903): "Your favor of Jan. 27 received. We pay $\$ 2.75$ per dozen for fancy squabs delivered, with feathers on.",

OUR PIGEONS GOING AROUND CAPE HORN.-We have sent our breeding stock ahout everywhere, but one of the most curious orders we ever had is from Captain Lane of the ship Kennebec, which arrived in Boston in November, 1902, from Seattle, with 2 cargo of lumber. At this writing (Feb. 18, 1903), Capt. Lane is making arrangements with us to supply him with a breeding outfit of our Homers, which he will instal on his ship so that on his long return voyage to San Francisco (or Seattle) he will have fresh squab meat regularly. Capt. Lane is part owner of his big ship and is accom. panied by his wife and young son. He has visited our place and knows about our birds and our methods.

SQUABS IN NEW MEXICO.-Here in the east we would not look upon New Mexico as a fancy market for squabs, but here is 2 letter from a customer in Albemarle, New Mexico, which proves that he is getting interested (Jan. 29, 1903): "The pigeons you sent me on the 20th were received yesterday in excellent condition, and am well pleased with them. Please find enclosed a money order for thirty dollars, for which send me twelve more pairs of your extra mated thoroughbred adult pigeons. Ship as hefore by Wells Fargo express." 
SOUTHERN MARKET.-Our breeding stock has gone to every state in the South. If you live in any part of the South, you can market squabs as readily as poultry is marketed. One of our Southern customers, who lives in Citronelle, Alabama, has been to Boston to see us. Under date of January 30,1903 , he writes: "I have received Homers from two others, but they do not compare with yours. I will build my second house very soon as the first one is filling up fast."

LONG DISTANCE SHIPMENTS.-To all inquirers we wish to state again emphatically that we certainly do guarantee the safe arrival of every bird, no matter in what part of the world you live. We are learning all the time how to handle the long distance shipments best and experience has taught us little wrinkles about the baskets and the arrangements of the feed and water dishes which are valuable. The express messengers get their instructions not from guesswork or from written notices or tags, but from a board a foot square on which is printed in bold type the necessary directions. This winter (1903) we have shipped every week to California, One order of 200 pairs for Santa Ana, California, filled seventeen baskets. Of the 400 birds, only one turned up dead, but as we had sent along four more pairs than the order called for, we were seven birds ahead on the count. Another large shipment to San Rafael, California, in January, 1903 , brought back by return mail the following letter, which we print exactly as we got it, word for word, and altogether it is one of the best recommendations for us to people who live at a distance that we ever received:

"Yesterday, A. M. (Jan. 20th) at 8.30 we received your letter advising us of the shipment of 100 pairs of Extra Mated Homers, on Jan. 14th; advising also that the pigeons would reach us before the letter. Well, they did not arrive until 4.30 today, Jan. 21 (7) seven days on the road. We notice that seven days is also required to get your shipments to Los Angeles; and when you assume that they will reach here at or before the receipt of notice of shipment we think you are mistaken. Nevertheless, be this as it may, the birds reached us tonight at 5.30 , every bird in first-class shape-every individual one being in first-class shape; giving evidence of being shipped in perfect condition and having plenty of feed and water en route. Your feed ran short, as evidenced by charges of 40 cents made by express company for feed provided by them, which we are only too. glad to pay, and at same time shows care and attention of express company messengers-a good fault. Every bird in the lot is bright and active, and they come into a first-class home, a fine house and flying pen, plenty of feed and a galvanized iron pan 6 inches deep with water 4 inches deep running constantly. Dimensions of pan, 4 feet 6 inches by 2 feet 10 inches, guaranteeing plenty of bathing facilities. They were liberated after dark, but the early morning will afford all the bathing facilities they will need, and we prophesy they will embrace the opportunities afforded at first opportunity. We wish to compliment you on your prompt methods of doing business, and on the superiority of the birds shipped us. They were indeed high class birds, in fact, Mr. Rice, they are better stock than we expected to receive. Your sending us 4 extra pairs above order was a graceful act on your part, one which we fully appreciate, and thank you right here for it. Your shipment was nearly a week before we expected it, but by extra exertion we got all ready in time and they have a fine home. Express charges at $\$ 14$ per hundred Boston to San Rafael, 270 lbs. weight of shipment, amounted to $\$ 37.80$ plus 40 cents for feed, $\$ 38.20$ total, at merchandise rate. Still at rate given in your circular $\$ 4$ for 24 birds (12 pairs), this is too much by a margin. \$4 rate to San Francisco per 12 pairs is not just correct, still we are not kicking, for the difference is not very much. Note this, 201 birds came out of those baskets, now we are sure, absolutely sure of the count; two people kept count as each bird was liberated and 201 birds came out of the crates. If 100 pairs are mated, what will we do for that poor lone bird? We await for suggestions; pretty tough on that lone bird, 3,500 miles from home, but he or she is here sure. In conclusion we thank you for your promptness, your honesty and your fair, square deailing and will keep you posted as to our progress as per your suggestion. We thank you for the crates; they are fine. We wrote you yesterday and look for reply in accordance with your usual promptness.",

We sent the above letter to Mr. R. H. Dwight, agent for the Wells-Fargo Express Company in Boston, and he was quite as pleased as we were. Through Mr. Dwight's co-operation our through western shipments by the Wells-Fargo have been a remarkable success. The only difficulty we have ever had on account of long distance trade came when we were shipping in crates, not baskets. We sent a large order into San Francisco and on the way four of the crates were broken into by rough handling and fortytwo birds got away. The Wells-Fargo Express Company settled with us for the loss of those birds and we made good to the customer, sending the missing birds on, and the customer was out not a cent for further express charges, for the Wells-Fargo people carried the birds deadhead.

The baskets in which we now ship cannot be broken open except with the aid of an axe and they can be thrown ten feet across a depot platform without being injured. 
There is a minor criticism in the above know of his experience. His letters are at letter in the matter of express charges. Ac- our Buston office, where they may be seen. cording to the figures which we give in the We will not give his name by mail because circular headed "Express Rates," the cus- he is a customer, but if you think the above tomer should have been asked to pay about letters are made up by us, you write to the $\$ 33$, instead of $\$ 37$, as he did pay. We be- Boston office of Dun's or Bradstreet's comlieve the figures which we give to be correct mercial agencies and ask for one of their - in every case-the slight variation which men to be sent to our office to investigate. may come as it came in this case is due to PIGEON MANURE.-Our advice in the the fact that no two persons will weigh up Manual as to pigeon manure has interestod the same lot of goods exactly the same, and that, of course, the birds vary in weight. The weight when the shipment starts is less than when it finishes, because at the end the bottoms of the baskets are covered with manure. (The grain which we send for feed is not weighed in and charged for transportation.) If the waybill is lost or delayed, and the agent at destination weighs the shipment, he will get a greater weight, and consequently a higher rate, than the express employee who weighed the shipment here in Boston.

We wish to say further that if you think we have figured the express rates to you too low, send us money which we claim to be correct and we will prepay all charges, thus putting on ourselves and not on you the difference, if there is any.

COMMON PIGEONS AGAIN.-We have had some of the old-time raisers of squabs from common pigeons on the ranches in the Middle West write us for more proofs that Homers are ahead of common pigeons.

In reply we will print here the letter which we received in January, 1903, from, a customer as follows:

"I have for sale between four and five hundred pen fed common pigeons. Can you use them, and at what price? Should you not be in a position to use them yourself probably you could refer me to some one that is in the market for some fine pen fed birds. The Homers which I purchased of you some time last summer are doing very nicely, and have to make more room for them is the reason of wanting to dispose of $m y$ common birds. Thanking you in advance for favor asked."

We asked him to tell us if he had not found our Homers more profitable than common pigeons. He replied as follows:

"In reply to yours will say that your statement of the Homers being more profitable than the common birds is true, as the fact has been demonstrated to me in the past five or six months, by my experience of having the two lots side by side in separate pens. My common birds referred to are fine birds and will soll them F. O. B. at $\$ 2.50$ per dozen, which, taking the plumpness of the bird in consideration, is very reasonable."

The above breeder lives in Missouri and we expect to sell a good many of our Homers to him and to those in his state who pigeon breeders all over the country, nearly all of whom say that they never have taken pains to save it, and when it got too thick they have scraped it up as best they coul and used it for fertilizer. They want to know how we keep it pure, and all about the market, etc.

The pigeon breeder who does not make provision for the purity of the manure and the steady sale of it is just throwing bank bills straight into the fire. We have erected a special building at our place for just the manure, and take every precaution to keep the manure free from straw, sawdust, sand, etc. The building stands at the back of one of the long houses, and about halfway in the whole plant, so that we can reach it easily with a wheelbarrow from the houses. There is a slide cut in the north wall of what we call No. 2 squab house, and through this slide the manure is shovelled from the wheelbarrow (standing in the passageway) directly into the manure house, where it stays until there is from $\$ 50$ to $\$ 100$ worth of it, when we bag it up and send it off. First we take the wheelbarrow empty down a passageway and stop at a unit pen, then go into the unit pen with a bushel basket and scrapers. We use a trowel to clean off the nest-pans, a tree-scraper to clean out the nest-boxes and a hoe or a floor chisel (same as is used to clean off snow and ice from city sidewalks), six inches wide at the blade and with a long handle so that it can be used easily while the operator is standing. In scraping the floor, the manure rolls up with little exertion off the blade of the chisel. It is shovelled into the bushel basket and the basket taken out into the passageway and dumped into the wheelbarrow. It takes one man not over thirty minutes to clean a pen thoroughly and the product of each pen is between two and three busnels, or from $\$ 1.20$ to $\$ 1.80$ for half an hour's work, which is pretty good pay. (We have been getting in the winter of 1903 sixty cents a bushel from the American Hide and Leather Company of Lowell, Mass.) We ship the manure by freight in bags. We buy these bags when we can from farmers who have large herds of cows and who use considerable grain, and they let the bags go for one and two cents apiece. Second-hand bags in the Boston junk shops cost from four to nine cents apiece. The leather people let 


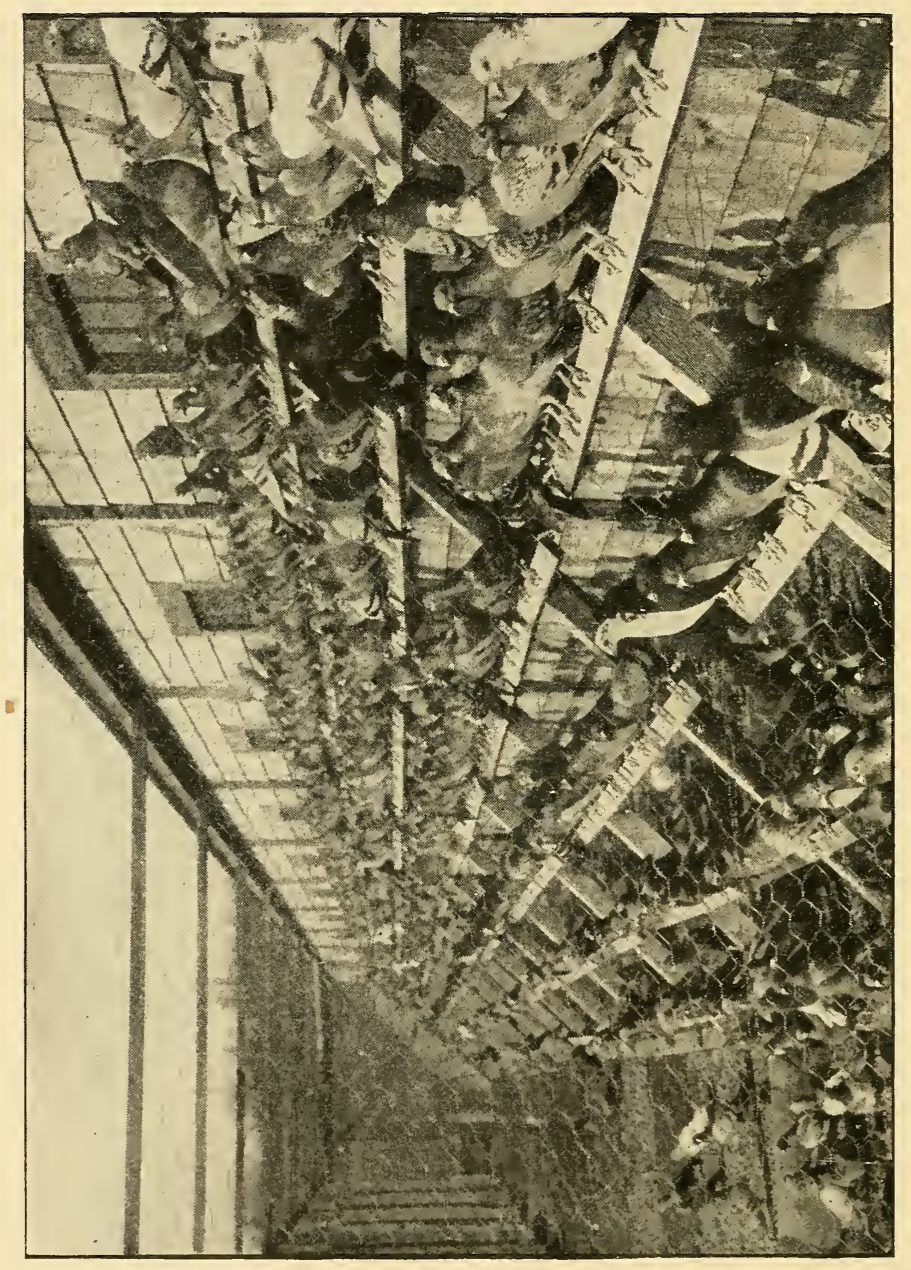

氮

$\approx$

छ

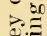

产咅

옹

웅

㱐

$\dot{\sim 0} \Xi$

T.

으릉

$\Xi \cong$

䋑

$0 . \Xi$

동.

0 폻

纹

O

동

0.5

的跣

证产

$=9$

E

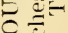

U.

0

(5

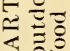

¿อ

ธ요

包

อ

돌

등

过

些

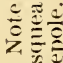

$\stackrel{x}{\underline{y}}$ 
the bags pile up and then send them back tomers to ship to Lowell. We have always to us in a bunch. We are particular to save found the leather people square in measuring not only the manure in the unit pens, but the manure, in fact they have given us credit in the sorting and mating cages and coops. on two or three occasions for more than we We cover the floors of these cages with bur- thought we. had. They pay after you have lap, not tacking the burlap down, but sent your bill of lading and the report of stretching it over three finish nails tacked the measurer has gone to the New York at the backs of the cages and two nails office. You need not be afraid of swamping tacked at the front of the cages. The the leather trust with pigeon manure. They manure cakes and dries on the burlap as it will take all you can scrape up. They use it would on the floor. When there is a layer about half an inch thick, all tramped hard, dry and odorless by the constant hammering of the feet of the birds, we take the burlap off the nails and stretch it outside, bottom up, then sprinkle water on the back and the manure drops off in large cakes. The burlap then is dried and replaced. This method saves an immense amount of time which otherwise would be consumed in scraping the floors of the cages. We have 108 of these cages at the farm and in our Boston shipping room, each capable of holding from 12 to 20 pairs of birds, and we have burlap carpets on all of them. We use a large amount of burlap not only for this purpose but for small grain bags to go with orders for breeders to distant points, and also for the floors of our shipping baskets. We buy this burlap in large rolls weighing 150 pounds and containing from 300 to 320 square yards. We do not hem it or sew it in any way for the cages, simply cut it and in stretching it over the nails fold the raw edges under.

Having read the Manual, you know that we do not use sand or sawdust in our squab houses, so we are able to deliver manure which is absolutely pure. The tanneries do not like to get lots of impure manure and of course pay more for the unadulterated article. It is just as easy and more businesslike to keep this by-product pure.

The manure in the houses has no odor, but when we have got it scraped up and banked in the manure house, it gives forth a pungent, ammonia-like smell. As the manure house is entirely cut off from the squab houses by the slide in the passageway, this pungency does not trouble anyone. It is not a nasty smell, anyway.

We have had customers from as far off as Illinois write that they were quite charmed with our story about the manure, and that they were saving up bags of it to ship by freight to the American Hide and Leather Company at Lowell, Mass. This tannery is a branch of the Leather Trust, which has other tanneries, so use your wits and find out which tannery is nearest you, and ship to that one. If you can find a tannery not in the trust, sell to that, if you wish to. If you sell to a trust tannery, the check which pays you will come from the New York office of the trust, same as ours do. We recommend our New England custo take the hair off the raw hides, and it is said to be the only substance which will do this job thoroughly without injuring the hide. Chemicals which are used as substitutes when pigeon manure cannot be had are said to be injurious to the hide.

We write the above to help you sell the manure from your squab houses. Do not ask us to advise you further on this point, for we cannot. If you cannot find a tannery within shipping distance, try the florists. We are informed that the florists' exchange in New York city is a good place to sell pigeon manure, and customers near that city have told us that they are selling there. SQUABS IN THE POULTRY PRESS.-The magazines devoted to poultry are beginning to take up squabs on account of the increasing interest shown by poultrymen in the subject. In the Poultry Keeper for Nov. 15th, 1902, appeared a contribution by A. P. Spiller. After giving the general arrangements for caring for the birds, he says: "At about four weeks of age the squabs are ready for market. Some markets require them dressed, others only killed. Good breeding pigeons will hatch and rear from six to eleven pair of young a year. The cost to keep a pair of breeders, including the raising of the young, at the present time is about eighty cents a year, this, of course, varying some with location and cost of feeding stuff. Wild game birds are becoming more scarce each year. The properly raised squab pigeon comes nearer taking the place of these wild birds than anything else. That they make fine eating, those who have eaten them can not deny. There is always a ready sale for good plump squabs at hotels, restaurants, markets and private families, prices ranging from $\$ 2.50$ to $\$ 4.50$ per dozen, depending upon quality and season. When one begins to raise pigeons it is better to try to secure strains from some reliable breeder who has stock bred along profitable lines. There is a difference in regard to breeding and feeding qualities and results obtained which warrants the paying of a little more at the start in obtaining more profitable stock. The writer is in favor of the straight Homer, carefully selected as to size, shape, breeding and feeding qualities, as it is well known that the Homer pigeon is one of the best feeders and breeders of any variety, and the numbers they will produce in a year more than balance any slight 
advantage that may be obtained in size. The breeding of pigeons is fascinating to most people. It is true there are some losses, but with care and some experience in management the few losses that occur to the beginner may be reduced to a very small percentage. The work is light and not as exacting as in some other lines, affording a lucrative employment almost from the start to those who are not strong, as well as to the most robust. A flock once mated will give but little concern to their owner, as they remain constant for life regardless of the numbers contained in the flock, and for years will amply repay in profit and pleasure for the feed and care given them."

We wish to call the special attention of our readers to that portion of the above article by Mr. Spiller where he says that the cost of a pair of breeders is eighty cents a year. We say the cost is sixty cents a year. In his article, Mr. Spiller says nothing about keeping the pigeon manure free from dirt and selling it to tanneries. This must be done in order to hold the feed bill down to its lowest notch. We say that the manure will pay one-third of the grain bill, and taking Mr. Spiller's figure of eighty cents, and deducting one-third from it, we have as the net cost fifty-three cents.

We asked one of our friends living in West Newton, Mass., to ask Mr. Spiller if his estimate of cost was made when he was saving the manure and selling it to tanneries. Mr. Spiller replied by letter as follows under date of Feb. 16th, 1903: "No, the manure was not taken into consideration at all. I do not know what the tanneries pay for it."

The owners of large flocks of common pigeons in the West who are breeding squabs for market do not sell the manure and for this reason they lose an important source of revenue. It is remarkable to us that pigeons pay with them at all. Certainly the manure is a very important by-product, and you should figure on selling it just as ynu figure on selling the squabs.

NEWSPAPER MARKET QUOTATIONS.Only a few of the daily newspapers of the country are in the habit of printing regularly market quotations on squabs. The Boston Globe has an article about once a week for the information of the household and in this article squabs are regularly quoted. At Thanksgiving time, 1902, the Globe quoted squabs at from $\$ 4$ to $\$ 5$ per dozen. In the Globe of Feb. 14th, 1903, squabs were quoted at $\$ 4.50$ and $\$ 5$ per dozen. If our New England eustomers will buy a copy of the Friday or Saturday Globe each week, they will probably find this household article containing the quotations for squabs on one of those days.

Our customers sometimes cut from the newspapers quotations for squabs and send them to us. In the winter of 1902 we received a clipping from the New York Evening Sun of Feb. 28, 1902, in which white squabs were quoted at $\$ 5$ a dozen and dark squabs at $\$ 3.50$ a dozen. We are told that the New York Evening Sun prints every Friday evening a household market column giving quotations on squabs.

The Rural New Yorker, an old-established and progressive farmers' weekly, printed the following quotations for squabs as wholesale prices ruling Feb. 6, 1903: "Squabs prime large white, per dozen, $\$ 3.75$; mixed, $\$ 2.75$ and $\$ 3 ;$ dark, $\$ 2$ and $\$ 2.50 . "$

The Albany (New York) Express, on Feb. 9, 1903, printed the following quotations: "Squabs, native, \$5; Philadelphia squabs, \$5 per dozen; pigeons, $\$ 1.50$ per dozen."

The Chicago Tribune, on March 10, 1902, printed the following quotations: "Squabs, prime, large, white, per dozen, \$3."

The St. Louis Republic, on Dec. 2, 1902, printed the following quotations: "Squabs, white, choice, dozen, $\$ 2.75$ and $\$ 3$; mixed, $\$ 2.25$ and $\$ 2.50$; prime dark, $\$ 1.87$ and $\$ 2 . "$

The San Francisco Chronicle, on April 3, 1902, printed the following quotations: "Pigeons, young, $\$ 2.50$ and $\$ 2.75$; ditto, old, $\$ 1.50$ and $\$ 1.75$."

SQUABS IN THE STATE OF WASHINGTON.-The squab raisers in New Jersey, New York and Pennsylvania are very well satisfied with the New York and Philadelphia markets for squabs, and we have lone considerable talking about the New York market ourselves, but let us tell you that the market for squabs on the Pacific Coast is a fine one, too. Here in the East we think Seattle is a long way from home and you may find some city chaps around us who think that city is but just on the edge of the tall timber. If you live out in Michigan, Illinois, Minnesota, Indiana, Ohio, Kentucky, or any state in that section, you ought to feel pretty sure that the markets for squabs around you are good, after you have read what we are going to tell you here about the market for squabs in Seattle and its vicinity.

These letters were obtained for us by a customer who lives near Seattle:

Fulton Market, corner Second avenue and Columbia street, Seattle, Wash. (Feb. 11, 1903): "Yours at hand and will say that if your birds are as you say, we can use on an average of twenty dozen per week at $\$ 2.50$ per dozen, feathers on."

A. D. Blowers \& Co., 817-819 Western avenue, Seattle, Wash. (Feb. 12, 1903): "Your valued favor to hand regarding squabs. In reply will say that most of the squabs used in this city are brought from the east and held in cold storage, so that native birds will no doubt sell much better than thia article. We have made some inquiry about them and find that it will be no trouble in selling four to six dozen a week, and no 
doubt many more, as the trade would open up. We do not think there is anyone in this part of the country who raises them for sale, and think if you can produce a good article that you will have no trouble whatever in selling them here. The price for eastern squabs is $\$ 2.25$ to $\$ 2.50$ per dozen. Some of the customers prefer to have them plucked, others alive. We think it would be better, perhaps, in the first shipment to send them alive until a regular trade was established. Our commission for selling them will be ten per cent. of the gross sales. If you have any nice ones, it would be well for you to send two to four dozen along and see what we can do with them for you."

(It is better to ship squabs killed and properly cooled. Do not send them alive to your market. Few butchers in the commission men's employ understand how to kill and cool a squab right. Do your own killing and cooling and packing as we have given you precise directions and you will know (not guess) that your product is reaching the consumer in perfect condition.)

Palace Market Co., Second avenue, Seattle, Wash. (Feb. 11, 1903): "Squabs such as you speak of would be worth 20 to 25 cents each. Would prefer the feathers on. We can use all you have."

California Commission Company, 923 Western avenue, Seattle, Wash. (Feb. 11, 1903): "Your favor to hand and contents noted. In reply we heg to state that squabs are selling from $\$ 2.50$ to $\$ 3.50$ per dozen, according to the quality of the birds. We want them with the feathers on and not drawn. You may ship us two or three dozen for a trial and then we will be better able to tell what we can do for you and see how many we can handle at a time. Our commission is ten per cent. on all goods. We are certain that we can give you entire satisfaction and know that our business methods will please you. We make prompt returns and keep shippers well posted on the market conditions. Trusting to be favored with your further valued orders."

C. W. Chamberlain \& Co., 905-907 Western avenue, Seattle, Wash. (Feb. 13, 1903): "Yours of the 9 th at hand and contents fully noted. Squabs, such as you mentioned, would sell here for about $\$ 3$ per dozen. Our selling charge is ten per cent. Twelve to fifteen dozen per week could be disposed of from present information at hand. They should be shipped alive."

J. F. Gayton, steward Ranier Club (this club is composed of the richest men of Seattle), Seattle, Wash. (Feb. 13, 1903): "I am in receipt of your letter with regard to squabs. Yes, I want some squabs at any time. Will be glad to have them. I will take a dozen at 25 cents each, either dressed or undressed, three dollars per dozen. After I see the first birds I can tell whether I can take them regularly.'
Williams Bros., Gilt Edge Cafe, Everett, Wash. (Feb. 12, 1903): "In reply to yours will say, I cannot say at present how many squabs I can use, but will start with two dozen a week, picked, at $\$ 2.50$ per dozen. Ship as soon as you please and will look the market up for you in the meantime."

Gordon \& Co., commission merchants, 811 Western avenue, Seattle, Wash. (Feb. 13, 1903): "Replying to your letter will say that we have telephoned to several of the hotels and restaurants here that would be apt to use squabs and we find that there are some places that make a specialty of using them and we do not believe we would have any trouble in disposing of them nicely. We would suggest that you send down a small box of them and let us show the customers just what they are and find out just what they will be willing to pay for them. They have been selling recently for 25 cents each. If you care to make this shipment, we will be glad to get it."

Seattle Market, Cor. First avenue south and Washington street, Seattle, Wash. (Feb. 10, 1903): "In reply to yours would say, it would be a good idea for you to ship us in two or three dozen squabs for sample, I could get the hotel and restaurant people's opinion on price and quality and be able to talk to you on quantity. Eastern frozen squabs are selling on this market for $\$ 2$ to $\$ 2.25$ per dozen. If your stock is as you say, I think it would be a better seller than frozen goods."

Maison Barberis, restaurant and dining parlors, 204-210 James street, Seattle, Wash. (Feb. 11, 1903): "We will take thirty dozen squabs every month; have them plucked, and will pay you $\$ 3$ per dozen. Please answer and say about what day of the month you will send them in."

E. C. Irlyce \& Co., commission merchants, 906 Western avenue, Seattle, Wash. (Feb. 13, 1903): "Yours regarding squabs to hand. We have investigated the market here and find a good many of the first-class hotels and cafes will take them at very fair figures. There seems to be a variance of opinion as to what they will pay, but we presume that the supply has been very limited, and they would pay just about whatever the seller would ask in order to get them. We think the aver ge price would be about $\$ 2.50$ to $\$ 2.75$ per dozen. of course there would be some bidding among the different buyers in case they were scarce, and we might get more for them. We have immediate access by 'phone and salesmen with all our customers who serve squabs for short orders or otherwise. By this means you would be in close touch with the people most in need of them and would always try to get you top notch prices. We believe this is a good investment for you to grow them for this market. Of course you would have to start in and graduate up to find how large the volume of trade will be 


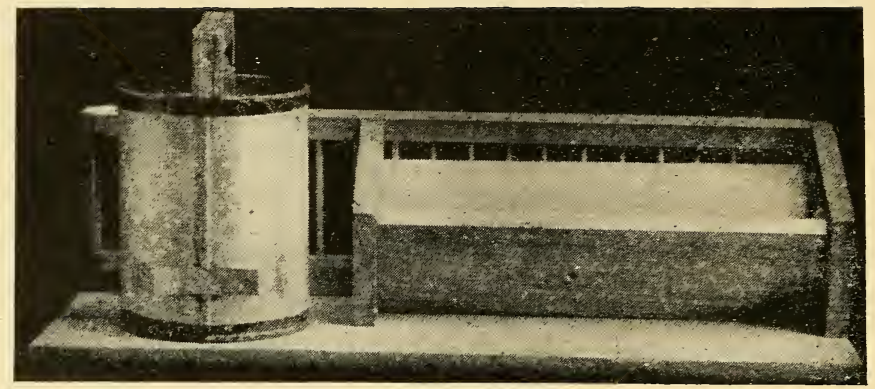

VIEW FROM PASSAGEWAY.

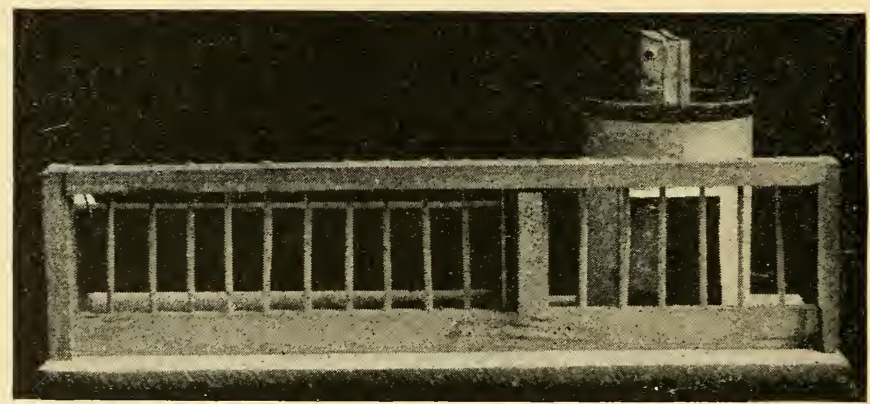

VIEW FROM INTERIOR OF SQUAB HOUSE.

Above are two views of a model made to illustrate what we call the dowel system of feeding and watering. It is a great time-saver in a long house. Between the floor of squab house and the lowest tier of nest boxes is one foot space. Fill this space with three-eighths inch doweling set one and one-half inches apart, as pictured. (This doweling comes in any length from a carpenter and is very cheap.) Set galvanized drinker and feed trough as shown. The trough has a three-quarter inch slot in its bottom so that the grains will fall into position ready for eating on the back side of the bottom strip into which the dowels are driven. The birds stick their heads through the dowels to eat and drink, and cannot foul either grain or water. Push a wheelbarrow with grain along the passageway and a house one hundred feet long can be attended to in fifteen minutes. Without this arrangement, if you go into each unit pen to feed and water, you will use up at least an hour, and it will be harder work. By this method you need enter the breeding pens only when killing or cleaning times come. 
that we can command you on them. Anything in the way of game, fowls or meats are staple sellers at good prices."

Hamm \& Schmitz, Hotel Butler, Seattle, Wash. (Feb. 12, 1903): "In reply to yours, will say that we could use three dozen a week of the squabs and will pay three dollars per dozen for plucked birds, laid down here.",

The above letters indicate to us that people in the state of Washington who eat squabs have to pay from $\$ 3$ to $\$ 4$ a dozen for the cold storage, frozen kind. Poor as these are (they are the lightweight squabs of common pigeons) they are in active demand. Of course the consumers would pay as much, and no doubt more, for fresh-killed squabs bred from our fine Homers. The commission men are certainly eager to get squabs. They are willing to pay from $\$ 2$ to $\$ 3.50$ per dozen. They resell them at a profit.

The above letter from E. C. Klyce \& Co. is sensible and could well be written by any commission firm in any state in the Union, or by any commission firm anywhere that sells poultry, eggs and butter. Wherever there is a sale for hens and chickens, dressed or with feathers on, there is a sale for squabs at higher prices not only because they are a greater delicacy, but also because good eaters everywhere know they are a greater delicacy, and expect to pay, and do pay, more for squabs, pound for pound, than they pay for hens and chickens, geese and turkeys.

We ship to Seattle by the fastest express trains. The birds go from Boston to St. Paul (Minnesota) by the Wells-Fargo Express Company. At St. Paul the birds are taken by the Northern Pacific Express Company, which has charge of them to destination. Every express messenger in the employ of these two companies on this long route has handled our shipments and made a fine record, and is trained to the work of feeding and watering all sizes of shipments. Our Seattle trade can be sure that their shipments will be treated right and will reach them in perfect condition. That is what we guarantee.

MORE LETTERS.-Here are more letters from squab buyers, unclassified, as they came to us in the first part of February, 1903:

Allyn House, Hartford, Conn. (February, 1903): "In answer to yours will say we are continually using squabs. We buy them plucked in all cases. We pay all prices, according to size, age, and condition when received. They run from $\$ 2.25$ to $\$ 3.25$ per dozen. Sometimes the market is a little higher."

Russell House, Detroit, Michigan. (February, 1903): "In reply to your letter would say that we use quite a few squabs here. Am paying at present $\$ 2.50$ per dozen for splendid stock. If you care to send me any at that, you to pay the express, I should be glad to have same."

Duquesne Club, Pittsburg, Penn. (Feb. 11, 1903): "Wish to know, if you have squabs of first quality, should you have about three dozen on hand, I would pay you per dozen, squabs plucked and delivered, from $\$ 3.50$ to $\$ 3.75$ per dozen. If price suits you please let me know." Signed by $\mathrm{E}$. Max Heinrich, superintendent.

Lincoln Hotel, Lincoln, Nebraska. (Feb. 16, 1903): "Replying to your letter. We can use about two dozen squabs per week in our cafe at present. Will pay $\$ 2.50$ per dozen delivered here, feathers on."

Hoted Victoria, Pittsburg, Penn. (Feb. 18, 1903): "In regard to your letter, will say, we use about one dozen or one and one-half dozen per week, just depends on the business, and will pay $\$ 3.50$ per dozen delivered here at the hotel."

Fred Harvey, general office, Union Depot Annex, Kansas City, Missouri, Chicago office Cor. 17th street and Wentworth avenue. (F'eb. 14, 1903): We can use 15 to 20 dozen squabs per week if the birds are very nice and the price reasonable. Can use them with feathers on. Do not know what we can afford to pay, it depends entirely on the birds. If you will please send three dozen squabs by Santa Fe baggage car to Kansas City, charging them at such a price that you can afford to furnish them, I will use them as a sample. If the birds are not of the right quality and the price is too high, we will not need any more, but if the birds and price are right, we can use quantity given above. I enclose baggage car shipping bill; be careful to fill it out correctly. This bill is made in duplicate: you hold one copy as your receipt and the other goes with the birds. Please put the squabs in a small box with a little ice."

Hotel Savoy, Ewins-Childs Hotel Co., proprietors, Kansas City Missouri. (Feb. 16 1903): "What is your lowest price on best squabs in five dozen lots? We are not in the habit of scnding out of town for our supplies, but if you have something better than we can get here, it is possible that we can do business with you." (Signed by George Thompson, steward).

Frank E. Miller, superintendent Dining Service Missouri, Kansas \& Texas Railway system, No. 707 Chestnut street, St. Louis, Missouri. (Feb. 16, 1903): "I have your favor relative to squabs. It is proper for you to state the price per dozen. We occupy eight or ten large dining stations and requir a large number."

Hollenden Hotel, Cleveland, Ohio. (Feb. 19, 1903): "In reply to your letter making inquiry regarding squabs I will state that we are paying $\$ 3.00$ per dozen for nice dressed squabs. We do not buy any unless they are fully dressed, no feathers on." 
Louis A. Fisher, Manager Century Club, Cleveland, Ohio. (Feb. 17, 1903): "We buy all our squabs in New York as the prices of three and four dollars per dozen prevailing in this city are too high-that is, we buy cheaper in New York than here."

A. S. Barnett, steward Morton House, Grand Rapids, Michigan. (Feb. 11, 1903): "In reply to your inquiry in regard to what we would pay for squabs such as you have, we are paying $\$ 2.25$ per dozen. Should you consider our price an object, would be pleased to learn how many you could furnish a week."'

Hotel Schenlen, Pittsburg, Penn. (Feb. 10, 1903): "Your squabs must be according to the weight and you should find a ready market for such stock. Nice white squabs are bringing $\$ 3.50$ today.,"

Hotel Rider, Cambridge Springs, Penn. (Feb. 11, 1903): "We can pay you $\$ 2.25$ per dozen for genuine squabs (no pigeons) delivered here. Can use six or eight dozen at a time, but we do not want anything but young birds."

E. A. Goodrich \& Co., commission merchants, 103 South Water street, Chicago, Illinois. (Feb. 13, 1903): "Your favor at hand. If you mean fat young pigeons that have left the nest and can fly, they are worth 75 cents to $\$ 1$ per dozen, and the trade wants them alive. (This is the way the trade in Boston wants them, but they pay more). If you mean nestlings, or very young pigeons which have not left the nest and are unable to fly, we can get you $\$ 2$ to $\$ 2.25$ per dozen, dressed neatly. Either kind is good sale at prices named and can handle for you any quantity from five dozen to one hundred dozen. If nestling tie in one-half dozen bunches packed in ice and ship by express."

A FINAL WORD.-Our object in printing the letters from marketmen and other squab buyers, in this appendix, is to convince any Intelligent man or woman that there is a market for him, provided he goes to raising squabs, no matter where he lives. We have hundreds of similar letters on hand, but we have not room to print all, and we think we have printed enoligh. If you are not convinced by what we have printed that there is a paying market for squabs within five hundred miles of you, do not write to us and ask us to tell you the names and addresses of squab buyers in your town or city, or vour county, for that we may not be able to do, but sit down at your writing desk, or go out in person, and find out for yourself.

It is unnecessary to argue the squab market within anyone of common sense who lives east of the Mississippl and Missouri rivers, and on the Pacific coast, and within shipping distance of Denver. If you live in a harren territory or a foreign country, and wish to take up this subject with us, we will reply to the best of our ability, but remember that you are on the ground, and can find out such facts for yourself better than we can tell you.

This Manual is intended to ke a book of facts, krcked up by evidence. If anybody has any additional facts as to squabs which will improve this Manual, we will be glad to consider same, and will pay for them if accepted.

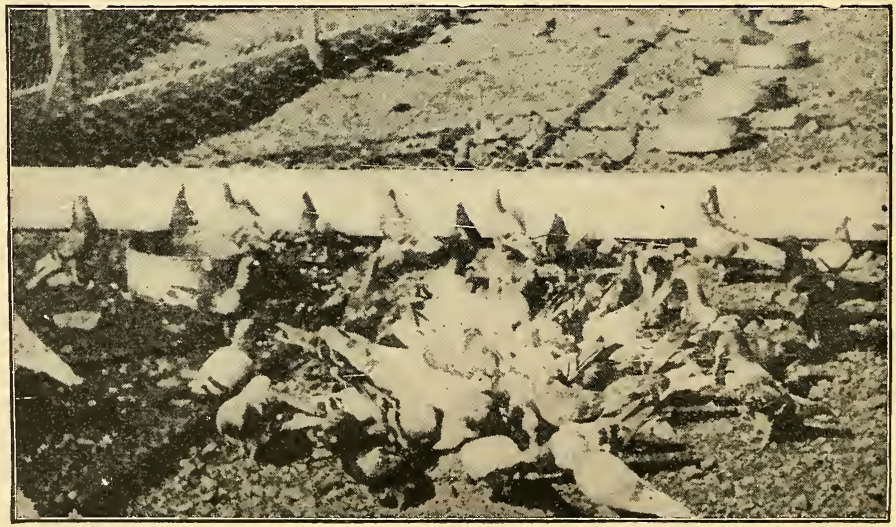




\section{APPENDIX B}

(Copyrighl, 1906, by Elmer C. Rice)

In $\mathbf{1 9 0 7}$, we expect our trade to be even greater. In 1906, we sold more birds and supplies than in any previous year. That our trade is larger than that of all others combined is not an idle boast, but is very much of a fact, due to this, namely, that we sell Homers which are larger, more prolific, and which breed larger squabs, than any others. This supremacy we intend to maintain.

We offer additional proof in the following pages. For every letter which we print here, we have a dozen just as good, or better. The following letters, only a part of many received in nine months of 1906, are not from customers merely pleased by the fine appearance of the birds on arrival, but are accounts of breeding which has won success.

There are some very strong letters here. All are worth reading for the practical information and news they give of the squab industry up to date. We do not print the names and addresses of these customers. Many are regular buyers of our birds. We guarantee the genuineness of the letters, and will prove it in any way desired. The originals are at our Boston office and may be seen there.

We ask your trade for 1907 by deserving it. If anybody tries to make a sale to you by "running down" competitors, insist that he or them demonstrate the worth of claims by furnishing proof in volume and character, concerning birds, matings and management, equal to the letters we print here and in our other publications.

OUR LARGEST 1906 ORDER. In looking back over our year of business, 1906, we recall first an order from a customer whom we started in 1905 , with 120 pairs Extra, for which he paid $\$ 300$. We sent him 125 pairs, five pairs free. A year later we received the following telegram from him:

"Wire bottom prices for one thousand pairs Extra, including two thousand nappies and date you ship."

We quoted him our regular price for Extras, the same to all, namely $\$ 1.70$ per pair in large lots of 300 pairs and over. Our customer was a man of few words and knew what he wanted. Three days after sending us the above telegram he sent us the following letter: "Enclosed find draft for $\$ 2111.25$ as payment in full for 1150 pairs Extra and supplies. I trust you will exert every care in interest of shipment. You will please hold the birds until May 10, as it will crowd me to get my quarters ready before that time."

We shipped 1200 pairs, giving the customer 50 pairs free. He lives in the West and the birds had a long trip to reach him. We expect to sell him more yet, judging from his last letter. We will be pleased to show the correspondence at our Boston office. The point we wish to make is, that we are the only firm anywhere actually filling orders this size, or able to fill them, and that we earned the confidence of this customer by giving him his first lot of birds so good that he kept on trading with us. More 1906 experiences follow.

STARTED WITH SIX PAIRS EXTRA AND IN TWO YEARS RAISED SIX HUNDRED AND THIRTY-SIX SQUABS. Nearly two years ago (in October, 1904), I purchased of your firm six pairs of your best Extra Homer pigeons, from which I have been breeding since, and it may be of interest to you to have some particulars as to results. I should premise by saying that I was, at the time, a novice pure and simple - as a matter of fact a lawyer by profession-and knew absolutely nothing of the care or culture of pigeons, 
However, study of your squab book, close and constant observation of the birds, their habits, etc., with the resultant experience, enable me to get along pretty well.

My pigeon house was not originally intended or constructed for that particular purpose, but had, hitherto, been used for a hen house. It is about 40 feet by 12 feet, with five windows. Along the whole of the west front and extending across the south end I built a fly 10 feet wide, 12 feet high and about 70 feet long. My flock has hatched, up to th? time of writing this, six hundred and thirty. six squabs (636), without those consumed at my own table, but I contemplate marketing the squabs this fall as the overcrowding stage is rapidly approaching.

If you can find time I shall be glad to hear whether or no, in your expert opinion and in the above circumstances, you think that I have been fairly successful. Although I feel reasonably satisfied with my progress, were I to start again, $a b$ initio, I think that I should do so with a complete flock of fully matured birds rather than waste the time consumed raising stock, by breeding, to a business basis. Wishing you continued success.-W. C., Massachusetts.

DOING GREAT WORK. The Homers which you sold me two years ago are doing great work. I am perfectly satisfied with them.-F. S., New York.

TOOK FRIEND'S ADVICE. Enclosed find an order for birds and supplies with remittance. A friend here was much pleased with our birds from your lofts and decided to go into the business. We prevailed on him to order from you because we felt your birds were the best. He could have bought here in Illinois at a much cheaper rate but he took our advice. So we trust you will do well by him and trust you will send us another order blank like the one enclosed.-Mrs. K., Illinois.

MULTIPLIED SIX-FOLD. About two years ago next June, I bought of you 60 pairs of your Extra selected Homers and they were a very fine lot of birds, and I have raised a very fine lot of birds from them. I have about 400 birds now, and they are straight ba1 wing and mottle ith the exception of about eight chocolate.-A. C., New Jersey.

GETTING THREE DOLLARS A DOZEN. Please send me your new literature on squabs. I bought 18 pairs of you in 1903 and now have a flock of 190 birds and am getting $\$ 3.00$ for my squabs in St. Louis. If any one in this section writes to you for squabs you may refer them to me.-F. L., Missouri.
NEIGHBOR PLEASED. Your favor of the 21st to hand, also price list of $\$ 1.70$ for Extra Homers in 300-pair lots. Mr. J. A. Westendorf, of this city, purchased of you on a trial order five pairs of Extra. Why cannot you make me the $\$ 1.70$ rate for 50,100 or 200 -pair lots? In going over my buildings I find that I cannot accommodate 300 pairs so would not like to order that number for fear of being too crowded.

$\mathrm{Mr}$. Westendorf is pleased with his birds and if the birds you should send would be the equal of those I would be more than satisfied. -A. S., Missouri.

ENTIRELY SATISFACTORY. Please send me the feeding slip that you have published as your daily feeding ration. The birds we got from you are entirely satisfactory.-J. D., Pennsylvania.

RECOMMENDED BY ANOTHER. Will you kindly let me know how I can expect to receive birds ordered from you to be sent to the above address? I have been recommended to try your birds by Mr. R. Warner, of $9 \mathrm{DuBois}$ Avenue, and if you can guarantee safe shipment I will place an order with you as soon as I hear to this effect. And if they are as you represent them, I shall be a regular customer of yours. If you will give me the desired information, you will greatly oblige.G. S., New York.

THIS SHOWS WHAT A CUSTOMER DID WITH TWELVE PAIRS OF OUR BIRDS. My Extra Plymouth Rock Homers have done finely. I sent to Boston $\$ 30$ for 12 pairs. The birds arrived before I expected them and they all looked fine. I got my first egg March 21,1905 . I raised all of my young to increase the flock for one year and found at the end of the year that I had 271 young birds, all seamless banded, and as fine a lot as I ever have seen. This year I am selling squabs and mated pairs, raising my best young, and have already sold squabs and mated pairs which have to date netted me $\$ 60$. I have sold my squabs for $\$ 3$ a dozen, and mated pairs for $\$ 2.50$ a pair.

I now (September 10, 1906), have 400 birds that I have raised. A good lot of them are worthy to be put in the show pen, and if they were they would be among the winners.

When I went into the pigeon business I bought what I thought was the best stock to be obtained, namely, Extra Plymouth Rock Homers, and my flock shows that I did not go wrong, for every one that has seen my birds pronounces them the best lot they have ever seen together.

My birds now are in the midst of moult, but most of them are breeding right along.

These are strong letters. Read them over. You want some assurance, when you buy pigeons, that you will be treated right, as these customers were. 
I now have 95 mated pairs at work and as soon as the moult is over I snall begin mating again. By November I expect to have 50 pairs more mated and at work.

I feed the best of grain, using cracked corn, kaifir corn, red wheat, buckwheat, a little hemp, and during the moult sunflower in the head, letting the birds pick off the seed as they like.

I use the self feeder Mr. Rice describes in his Manual and I find with it the feed is always clean. I never feed on floor. I use automatic water fountains and scald them out every two or three days. I give the birds a good clean bath every day.

I have trays to feed any dainty which I have, removing trays when seeds are eaten.

One thing that is essential with pigeons is cleanliness. I clean loft every Saturday, cleaning out nests that have young, putting in new straw, and spraying over lofts with liquid disinfectant.

I have followed the instructions of $\mathrm{Mr}$. Rice's Manual and found it to be good solid advice.

In the past 18 months I have been in a good many pigeon lofts and have seen exhibits at New York State Fair and Rochester, N. Y., Pigeon Shows, and never have seen any better birds tha? I have raised from the Extra Plymouth Rock Homers.

I an perfectly satisfied with what my birds have done and when I buy more they will surely be Extra Plymouth Rocks.

The feed bill will not exceed eighty-five cents a year per breeding pair. I use tobacco stems for nesting material and like them. I shall always try and speak a good word for the Plymouth Rock Squab Company, for I have found them always ready to assist at any time.-W. R. R., New York.

THEY HAVE NOT LOST A BIRD. I wrote to you some time ago in regard to the squabs we got from you in the month of May, or rather pigeons, 50 pairs, and have yet to lose sur first bird, which not only speaks well for your birds but it looks as if we are giving them the right attention.

There is one thing we wrote to you about, those not working-but they are doing fine and, counting your birds, we have 100 pairs, besides we have sold some which were greatly admired.

The hotel we take them! to in Washington gives seventy-five cents a pair all the year round dressed, the commission merchants never higher than 60 cents a pair.-M. B., Maryland.

MANUAL INDISPENSABLE TO SUCCESS. In regard to the National Squab Book which you publish, would ask if you ever revise it.
The one I purchased of you in May, 1904, is all right and I could never have raised the number and quality of squabs I do without its guidance. Of course you are learning new points about your business and if you have a later edition than mine please let me know.

The Homers have started in on their annual spring campaign and from all appearances they are going to outdo their former productions. With best wishes for your continued success.-A. T., Ohio.

HIGHLY RECOMMENDED TO HIM BY OTHER CUSTOMERS. Some time ago I wrote your company for their free book on squab raising. Later I sent for your National Standard Squab Book. I have read each one from start to finish and am well pleased with them. I have made up my mind to give the squab business a trial as I am quite sure that there is money in it, if properly conducted.

I realize that to make a success of any business one must thoroughly understand it. As I have had no experience in this line I wish to start in with a small number and increase them as I grow to understand the business.

My plan is to buy 12 pairs of the very best breeders that I can obtain and keep only the best of their increase for breeders till I get my flock to the desired size. Now, from reading your books and having you highly recommenided to me by other parties, I have made up my mind that you can give me what $I$ want in this line.-H. B., Illinois.

\section{FROM FOUR PAIRS TO THIRTY PAIRS} IN NINE MONTHS. Nine months ago I bought of you four pairs of Extra Homers. I had to move them twice to make room. I have now 60 first-class Homers. I have had several chances to sell some of the squabs but I think too much of them. By studying your manual carefully I have not lost a bird. From a friend of your Homers.-W. M., New York.

NO DISEASE. You no doubt have $m y$ name on your books as a purchaser of 10 pairs Extra, which I purchased of you last winter. I am still enthusiastic over the industry. I have all the original 11 pairs you sent me and 33 young, all the offspring of your birds, 55 birds in all. They are every one in finest condition, disease has never touched my flock. -J. P., Virginia.

FIVE MONTHS IN CALIFORNIA. When I received those birds from you in March I turned them into a pen and have been so taken up with other work that they have been left to themselves until now. At present I am taking all the working birds out and banding, and when they have young squabs I have

Beware of anybody who tries to make a sale to you by running down the Plymouth Rock Squab Co. Insist that he show you letters like these in proof of his claims. 

THE PLYMOUTH ROCK SQUAB COMPANY OF BOSTON IN NINE MONTHS OF 1906.

moved them also, putting them in a corresponding section in the other pen, the arrangement of the pens being the same. I find that the old birds find their young and go right on keeping house just the same as before they were moved. At present I have 100 young birds, the oldest being less tban five months and already at work. The squabs are fully developed and out of the nest at three weeks. I expect to have about 80 or 90 pair of birds at work about the first of November. Then I shall begin to ship.-E. R. C., California.

GETTING ALONG IN VIRGINIA. Please ship by freight to us six drinking fountains and six bath pans. We got some birds of you last year. They have done very well. Thank you for the advice-P. N., Virginia.

\section{GENEROUS TREATMENT OF CUSTOM-}

ERS. Your letter of May 21 was most satisfactory and certainly very generous. I hope I made it very plain to you that you were not at all to blame for the loss of one of my pigeons. Your offer to replace it free of charge was quite in keeping with my impression as to your very generous treatment of your customers. I have at last found that the lost pigeon was a female and if you think a white pigeon would be well received by my colony of three checkered, I would like to have a white female Extra Homer pigeon. My pigeons are in fine order and doing well.Mrs. H. C., Georgia.

LOST ONLY ONE SQUAB IN FIVE MONTHS. Five months since, come the $12 \mathrm{th}$, I received of you, by express, 13 pairs of your Plymouth Rock Homers. Up to date I have lost but one squab (and I think he was killed by a dislocation of the neck), possibly 10 eggs, several by frost. I have 54 squabs, most of them able to take care of themselves, and seven pairs of eggs. Three pairs of young ones have hatched and begun to build their nests. Now I wish to ask you if you think they are doing well. I do, and I am proud of my intelligent birds. I am now preparing to remove all young ones from the pen except those that are mated and then as fast as the others mate, to do as you say, put them into the breeding pen. I shall also build on another unit to my breeding pen in a short time, as I figure on 110 birds in my present house.

I wish I was financially able to put in a good plant as these birds have demonstrated their fecundity. I notice you say that there is little liability of nest-makers mating. I have not discovered any with the few I have. I have just gone through the nest boxes with whitewash containing a good per cent of carbolic acid and vitriol solution. I clean out houses often and so far have not had a sick bird. Occasionally I put ginger in the drinking fount and I firmly believe it is by following your plain and definite instruction that they keep as well.

I hope I am not trespassing on your valuable time but cannot resist telling you how I am getting on with your stock.-W. G. P., Wisconsin.

CONVINCED AFTER TRIAL. I have delayed in writing you as I wanted to see how the birds were going to turn out. Can say now, I am more than pleased with the birds. I have now 18 squabs and five pairs of eggs. Three squabs died and six eggs went to waste. That is all over with now. Don't expect that to happen again. As far as I can see squab raising looks to be very simple and profitable. I have a nice clean house and running water so the time spent is nothing. Enclosed you will find my check for 12 pair Extra more.J. S., Washington.

GETTING FOUR DOLLARS A DOZEN FOR SQUABS. Please send me as speedily as possible 25 pairs of Extra Blue Homer Pigeons. I have now about 125 pairs of birds bred from the original 20 pairs I bought from you about 18 months ago and am selling squabs at $\$ 4.00$ a dozen. I am building a coop 48 feet by 14 feet which will accommodate about 600 birds and if successful will enlarge my plant shortly.

Will you kindly supply me with the name of the large Commission house in New York mentioned in your circular? The original birds were bought from you in November 1904 and shipped to my partner in the business.-H. B., New Jersey.

QUICK TIME. I have read a large number of your testimonials, none like this however. Now I wiil make an affidavit that I received the 38 pairs Saturday morning, put them in the pen by ten a.m. I gave them a ferw tobacco stems from a crock on the floor in the corner. Atl five p.m. a hen laid an egg. She laid her second egg to-day, Monday, and is now setting. Can any of your customers beat this?-S. H., Illinois.

THINKS WE ARE TRUE BLUE. I am giving $\mathrm{my}$ pigeons occasionally lettuce or some raw cabbage, which they most heartily enjoy. Is this conduct prudent? The last batch of birds you sent me "Extra selected" were magnificent. You people (The Plymouth Rock Squab Company) seem to be "true blue." I like to deal with your kind; don't find them all the time. Please answer

Is there anybody in your town who has failed at squab raising? Some play at pigeons as they would with a new toy, then they give them up. If they bought of us, the trouble is with them and not with the pigeons. 


\section{STORIES OF SUCCESS ON THIS PAGE ARE NEW. THEY WERE RECEIVED BY THE PLYMOUTH ROCK SQUAB COMPANY OF BOSTON IN NINE MONTHS OF 1906.}

the above and return to me. Yours well satisfied with your treatment.-O. J., Illinois.

SUCCESS IN TEXAS. In October 1905 I purchased from you 25 pairs of birds and since that time I have had fair success in raising squabs. I have about 175 young birds on hand at present. They are all strong and healthy, having had the best of care, and a great many of them are mating now.-W. B., Texas.

THANK YOU FOR YOUR LETTER. I received the birds all O.K. The last ones were every one all right, as were the first. A thousand thanks for your kind, courteous, and prompt treatment in all our business dealings and you will be sure to hear from us again. If our letter will help you any, you are perfectly welcome to use it. Thank you again.-J. C. H., Michigan.

SELLING MANURE. Some time ago I bought 24 pairs Homer Pigeons from you. I have had fairly good luck with them, having increased my flock to about 200 pairs. I want to write you in regard the manure. You state in your National Standard Squab Book, that the Leather Trust used it for tanning purposes. Now I have considerable on hand and I wrote them. They said in reply, that they did not use it at all, which was a surprise to me as I have been careful in saving it.-W. H. H., Pennsylvania.

Answer. The trust doès use pigeon manure or did, the last we knew. We shipped to one of the Lowell plants of the American Hide and Leather Co. for three years. Perhaps your letter was directed to one of the plants of the trust which does not use pigeon manure. We have printed so long the fact that pigeon manure is salable to tanneries of the trust that the New York office of the trust has been bombarded with pigeon manure letters for the last five years to such an extent that they are sick of the topic there and give an inquirer poor satisfaction. For some time we have been selling our pigeon manure to leather men whose factories are within ten miles of our Melrose plant. Their teams call for it and take it away with very little trouble to us. We get sixty cents a bushel for it, same as usual. If any customer of ours wishes to ship manure to New Jersey or New York, we will help him to find a buyer there, as we have letters from tanneries in both States on file asking us to sell them "pigeon pure."

HIS FLOCK GROWING. About a year ago I bought some birds from you, some $\$ 2.00$ per pair and some $\$ 2.50$. My flock is growing and seems to be getting along pretty good, having now 180 birds-will soon have 200 birds. I thought I would try and sell some now. They are all good birds. I want to try and sell what I raise now and if possible make a business of the squabs if there is enough in it to warrant putting up more buildings and getting more stock.

It costs me about $\$ 1.90$ per week for feed for this amount. Am I feeding enough?M. N., Massachusetts.

BUILT NEW HOUSE. I have built a new house for my pigeons. Have increased my flock from the original six pairs to 50 , besides selling 30 pairs of squabs. Could I have done any better than that?

Have been having some trouble by a few going light and have followed your advice and think have got the better of the difficulty. I lay the trouble to the poor quality of wheat they have been furnishing me. It seems to be all shrunk up and they don't eat half of it. -A. D. V., Pennsylvania.

Answer. More pigeon troubles are caused by wheat, or too much of it, than almost anything else. Squabs which are thin and dark are caused by too much wheat in the ration. Pigeons fed on too much wheat get thin, with sharp breastbones, and will not lay as they ought to. A good ration of Canada peas and hempseed is necessary to bring eggs and keep the flock in condition. A pigeon will not thrive if not kept in condition by nourishing food. The results of too much wheat are loose droppings, stupid and non-productive birds. Pigeons should be active and eager.

IN FINE CONDITION. My birds I bought a little over a year ago (12 pairs) are still doing fine; have sold several small lots of squabs. I have been following your manual's instructions as close as possible. I have about sixty pairs. They are in fine condition and have lots of eggs and youngsters.-C. W. H., North Carolina.

SQUABS WEIGHING NEARLY A POUND APIECE WHEN ONLY THREE WEEKS OLD. Please send me your price list on birds and supplies as I intend to get about ten more pairs of Extra Homers and want to get them of you. The birds I have now, which I got from you, are doing fine and I have doubled my flock. I could sell all the squabs I have but want them for breeders.

Would you kindly advise me if oats are good for breeding pigeons if fed moderately. Also do you think it wise to sell my squabs when they are from two and one half to three weeks old, as some of them will weigh about fourteen ounces at that age.-A. P., Ohio.

Look up the standing and character of the concern with which you contemplate dealing. Your bank will find out the facts for you. Avoid advertisers whom you find out by investigation are worthless. Have their ratings looked up for you. 

THE PLYMOUTH ROCK SQUAB COMPANY OF BOSTON IN NINE MONTHS OF 1906.

Answer. Pigeons do not care much for oats. Pigeons in the street eat them, as they eat peanuts or bread. Of course if you have oats handy and cheap, you can feed some, but pigeons will eat almost every other grain in preference. When squabs weigh 14 ounces they can be killed, no matter what their age.

MOVE THEM AS YOU PROPOSE. I have pigeon breeders in unit numbers one and three. Squabs in unit number two, from one to three months old. I wish to put number three with number one. Number three is breeding right along. Will it hurt to move nest, pigeons and squabs out of number three into unit number one? Will it damage eggs and squabs to do so? If rot I can move them through unit number two, as I can let number two in flying pen while I am moving number three.

I shall want more pigeons by fall. I got 13 pairs from you last year, and I have 100 pairs in all now, so you see $I$ have done well with them. I wish you would answer as soon as possible as I do not wish to molest them before I hear from you.-J. P. M., Michigan.

Answer. Move them as you propose, putting the nests in the same relative positions in the new nest-boxes. You will lose few, if any.

INCREASED STOCK. In May, 1903, you sent C. I. Bruce forty (40) pairs of your pigeons at $\$ 2.50$ a pair, and in 1904 , twelve (12) females. We have sold and increased stock since then by breeding, until, at present, we have about three hundred (300) birds. Miss H. J., Connecticut.

BEST HOMERS HE EVER SAW. You favor of the 12th June, answering my inquir of the 9 th June, was duly received. Thank for the information. I had fully intended $t$, visit your plant, but, just as $\mathrm{I}$ am ready to start, my wife, who was to accompany me on a two weeks visit to the New England coast is taken sick. I have seen the birds which you sent to my neighbor, Mr. P. C. Evans, and they appear to be all you claim for them t.je best specimens of Homers I have yet had the pleasure of seeing.

If you can let me have a small lot of onehalf dozen pairs, at same price as paid by Mr. Evans, you may enter my order for same, with dozen bowls, for early delivery.-G. W. G., Pennsylvania.

FLOCK WENT TO WORK OUICKLY. Out of the seven pairs of Extra Homers you shipped me June 2, 1906, I have already (August 10) got twelve squabs. I am very much pleased over having such good success, but I have no way of marking them. You will please send me an outfit for marking them by mail. Send about what you think a beginner ought to have. As the business grows, will send you a larger order.-L. L., Nebraska.

A WOMAN'S WORK. I have 90 pigeons on hand, bred from the 26 my husband bought of you a year ago last April.-Mrs. H. C., Illinois.

STRICTLY ALL RIGHT. A friend of mine of this city recommended you to me as being strictly all right. I will thank you to send me your literature explaining the cost of starting a squab farm of about 250 pairs, raising and marketing same, as I contemplate going in that business. Thank you in advance for any information that you may give me.-W. M. A., Alabama.

RESULTS TELL THE STORY. As all of my birds secured from you in May this year have their second pairs of young ones and I think will continue to multiply as fast, will you kindly forward me a list of commission men as stated in your letter of recent date. $\mathrm{Am}$ perfectly satisfied with the results obtained from your birds. If you have any inquiries for birds in this locality I will be glad to attend to them for you.-J. L. T., Indiana.

SIZE OF SQUABS A REVELATION. We are pleased to advise you that we ate our first squab from the lot of birds you shipped in May last Sunday and wish to state that the size of these squabs is a revelation to us, being almost twice as large as any we have ever been able to secure.

The enclosed list will give you an idea as to their productiveness. I also would like to have you answer the questions contained therein.-H. B. R. Illinois.

OUR BIRDS BETTER THAN WE CLAIM. My birds reached me in good order and was glad to see them when I got home from work safe and sound. I think the American Express Co. is about the best there is. Everybody that sees your birds say they are the finest they ever saw. I think when anybody is looking for good birds they don't need to look any further than your place and I know they will go ahead of any birds in this town for looks and flying. I think we will stay here till we get a good flock of birds then we will move outside of town. The next time I send for birds I will try and send you a bigger order.

Your birds are better than you claim for them. Some of them have eggs before their young ones are two weeks old. They get so

We were the first. Our birds and methods revolutionized the squab industry and are widely imitated. But imitators who copy or find fault with our printed matter cannot give you our birds. We have no agents. 
big they just about can't sit in the nest. I think if you would put an advertisement in some of the evening papers you would ge $t$ some more trade. I am advertising your birds to everybody I know.-J. S., Wisconsin.

COMPLIMENTED BY AN EXPERIENCED JUDGE. One of my hens made her nest and I thought she was ready to lay but she sat all one day and part of the next and did not, but had her mouth open panting and seemed very sick. I telephoned to Mr. M. to come and tell me what to do. When he came he held her in warm water for 15 minutes and then fastened her in her nest. In ten minutes she laid her egg and got all right.

Mr. M. holds the world's record for three hundred miles and has some of the most valuable birds in Chicago, and he said my birds were very fine, in fact he said he could have hardly told them from his own, they resembled them so much.

When so good a judge will compliment them so highly I feel very proud of them.A. B., Illinois.

SQUABS WEIGHING ONE POUND AT TWO WEEKS. I thought you might like to hear from the birds you sent us a year ago. They have been working overtime since. We have 54 birds now with several nesting. Every one is a solid color the same as the old ones.

The squabs we have weighed have averaged a pound at three weeks old. One weighed a pound at two weeks.

There is a party here getting birds of all kinds and colors and claims they are better than what we got for Extras on account of the bands.- J. W., South Dakota.

Answer. It is quite common for parties selling poor Homers to put bands on their legs, some of them quite ornamental, in an endeavor to enhance their value, same as putting a gaudy label on cheap goods. It is the pigeons that count, not the bands. Bands are useful to number the birds, that is all.

NO. 1 PLYMOUTH ROCKS ARE GOOD HOMERS. It will probably be fall before I get my house built and give you an order for more birds. If money is not too scarce the order will be for your best birds, for the No. 1 Plymouth Rocks are doing even better than the Manual claims them to. Your Extra birds must be wonderful.-W. H. W., Massachusetts.

WE " SHOW THEM" OUT IN MISSOURI. I received the grits and oyster shell all $\mathrm{O}$. $\mathrm{K}$. My birds jump on to the grits and hemp seed in a hurry. They are doing well. I will have about sixty squabs this month and quite a number mating this week. I had an order for 100 squabs this morning. It made me sick to think I could not fill it, but my time came after a while. I will build another house soon and I want 100 more of your birds. Mr. Hall's birds look well. They came through nice. He is well pleased and I think he will order more. There are two more people talking of going into the squab business. I will try to get an order for you.-J. W. H., Missouri.

HAS NEVER SOLD ANY SOUABS LESS THAN NINE POUNDS TO THE DOZEN. About three years ago I purchased of you six pair of Homer pigeons for which I paid $\$ 2.50$ per pair. My flock are all from the stock I bought of you and I have some nice birds. I have never sold any squabs under nine pounds to the dozen at four weeks old. I never sell my birds after they have left the nest for squabs. Will you send me your price list for grains, that is, Kaffir corn and red wheat. I would like the address of Boston dealers.C. E. W., Rhode Island.

LETTING BIRDS FLY. I would like to have your opinion and advice on a matter that is very important to me. I have a beautiful start with your birds, have followed your book exactly and the result has been very gratifying. Now what I want to do is to buy about three hundred more old birds from you and pen them. Will the young birds be as prolific, mate and hatch as well if properly fed, watered etc., exactly as my pens are, if I allow them to run loose on my farm? There is no danger of them being shot and I would much prefer allowing them the run of the farm. I have the buildings that I could convert into comfortable houses at once, and I will appreciate your thoughtful opinion and advice in the matter for I know you are headquarters.T. W., Tennessee.

Answer. Birds which you raise you can let fly because they know no home but yours, but Homers which you buy you cannot let fly safely because they know another home (their old home) and their instinct and desire to go home may lead them to leave you.

NEW JERSEY NEIGHBORS ALL AGREED. The six pairs of birds received from you the first day of May are still doing fine $\left(J_{t 1} l y\right)$. One pair has her third pair of young at this writing-less than three months. The rest will hatch this week. Mr. Tevis (the neighbor I spoke to you about in a former leter) came over after me to see the birds that he had just received from you. They are fine birds and he is very much pleased with them and sorry that he did not take my advice and send

The squab industry is growing every year. More squabs were bred in 1906 than ever before. Prices were better and they are going to be as good or better in 1907. The habit of squab eating is growing in every section. 
to you in the first place, but he bought about 60 pairs from a New Jersey dealer. He showed him a letter that was supposed to have come from a man that bought birds of you, saying that he didn't want any more of them. But now he sees the difference when he has them side by side. Mr. Webster, my next door neighbor, is so well pleased with the way mine are doing that he is going to send for a few pairs this fall. I would if I could, and had the room.

I now have 16 pairs of the Plymouth Rock birds. My pen is open to any one that wants to see the birds before they send to you for breeders. I thank you for the fine birds you sent to Mr. Tevis. It shows that I didn't exaggerate your ability, to send six pairs or 100 pairs of fine birds. - D. C. T., New Jersey.

FINEST FLOCK HE HAD EVER SEEN. A year ago to-day we received eighteen pairs of your Homers. Our flock now numbers nearly 100 pairs and all are doing fine. We have sold a few pairs at $\$ 1.25$ per pair, and have had any amount of inquiries after squabs. We have had a number of fanciers up to look at the flock, and all seem to think they are an exceptionally fine lot of birds. One gentleman who keeps an excellent lot of imported birds said they were the finest flock he had ever seen, which speaks well for your birds.-B. B., Michigan.

BEST BIRDS IN HIS CITY. Find enclosed $\$ 16.34$ for which to send me a dozen of your Homers, a dozen of nest bowls, and two feet of aluminum tubing. Would have liked to send an order sooner but had no place to keep them. My birds are doing fine. We have moved into a larger place where $I$ can let my birds out in a wire cage. Your birds are the best I ever saw and the only ones I ever intend to keep. I have sold off all my young stock so I have more room for the others.-J. B. T., Wisconsin.

SPLENDID WORK WITH SPLENDID BIRDS. I wish to advise you now (August, 1906) of the splendid luck I have had with the six pairs of birds purchased from you last May and which were received at my home on May 17.

These birds, within a week after arrival, commenced to construct their nests and, out of the six pairs, five began hatching within two weeks and every egg produced a squab. Two squabs weighed at the age of four weeks and two days, 16 ounces, after plucking, and the remainder weighed from eight to 12 ounces. The two squabs, weighing 16 ounces, were the largest I ever saw and I tnought you would be interested in knowing the weights.

On account of not having room for any more birds, I am killing the squabs as they mature but would have liked to have mated the two large squabs, as I believe that their offspring would have averaged 16 ounces each.-S. P. N., New Jersey.

DOUBLED IN THREE MONTHS. Enclosed find money order for $\$ 1.70$ for which please send leg band outfit. The birds I bought of you in April are doing fine. They have doubled themselves.-W. A., Missouri.

DOING WELL IN CANADA. Saw your advertisement in R. P. Journal, "Squab book free." Anything new in it? I have your book of 1904 with two dozen your Homers. They are doing fine. What would you seli me one dozen more?-P. I. B., Quebec.

ORDERS FOR A FRIEND. I enclose you herewith a check for $\$ 30$. Please ship to enclosed address 12 pairs of your Extra Plymouth Rock Homers. Be sure to send him some nice ones.

Those we bought of you some time back are doing nicely and if these show up as weil I think that I will be able to send you some more orders soon.-S. W. T., Georgia.

HAS DEALT WITH THE FAKIRS. The pigeons that you shipped to us have arrived in fine condition and the best of health. We are shipping back to you, via American Express the wicker basket in which you sent our pigeons. Also our many thanks for the trouble you took in selecting the different colored pairs.

I wish to say that the pigeons are beautifully mated, because one pair have started in business already, the hen having laid two eggs, and all the others have showed promising signs of mating.

After having dealt with poultry fakirs and receiving their treatment, I fully appreciate your kind treatment which is so unlike that of these fakirs, but your endeavors are not in vain, as I soon expect to order some more pairs. Your treatment has encouraged me. I have provided an excellent house and pen for them. Thank you for your interest shown in this matter.-L. J. H., Illinois.

IN THE BLUE GRASS STATE. Could you kindly tell me where I could get some white Homers? The Plymouth Rock Homers

New laws passed a year ago by the legislatures of Massachusetts and New York forbid the sale of quail except in the months of November and December. The penalty is a heavy fine for every quail found in the hands of any marketman or restaurant keeper. Quail are no longer found on bills of fare in these two states except around Thanksgiving and Christmas. Squabs are on the bills of fare all the year everywhere. Other states, it is said by sportsmen, will follow Massachusetts and New York with a similar game law. 
I got from you are doing fine.-R. L. J., Kentucky.

HIS SECOND ORDER. Enclosed please find express money order for five dollars for which please send me three pairs of your No. 1 Plymouth Rocks at your earliest convenience. A previous order which I received from you has been doing fine.-J. E. D., Pennsylvania.

PROLIFIC BIRDS. I purchased 12 pairs Homers of you about 18 months ago and they have done fine work for me. I have 50 pairs mated birds, saved the best ones and sold the second class.-J. A. D., Pennsylvania.

SENT SISTER GOOD BIRDS. I enclose a money order for $\$ 17.88$ for which please send three dozen nappies and six pairs blue checkers. You sent my sister such fine birds that I would like the order duplicated.-H. S. B., New York.

RECOMNENDS OUR BIRDS TO EVERYBODY. The birds arrived in good order and I am pleased with them. I have 14 fine birds from the first ones I bought of you and I think the last four pairs will go to work soon. I recommend your birds to everybody.-J. M. M., Philadelphia.

HE KNOWS OUR TEACHINGS ARE RIGHT. I have read your Manual carefully, studied every point as I went, because I wanted to impress it on my mind. I have found in my own experience that pigeons do just as your Manual says. Your book is worth two or three dollars instead of 50 cents.

I want to thank you for the favor you did at finding the weight and charges of some things for me. Would you kindly tell me what would be the cost of freight charges on one hundred, two hundred and three hundred pounds of grain?-G. A. S., Georgia.

FIVE DOLLARS A PAIR WOULD NOT BUY HIS. Birds came Friday at noon, and accept many thanks for the fine birds you sent to me. My friend says $\$ 5.00$ per pair would not buy his.- J. P. B., Georgia.

PLEASANT BUSINESS FOR A WOMAN. You will possibly remember that a year ago last April I bought from you twenty-five pairs of your Extra Homers.

I now have some eighty pairs in my house and have used something like two hundred squabs. My birds have done well and I have lost only one of my original stock.

I am thoroughly convinced that there is money raising squabs and it is a very pleasant business for a woman, requiring only a little time each day to attend to them and one soon becomes very much attached to them-Mrs. M. L., Kentucky.

GENEROUS TREATMENT. The pigeon that I wrote you about a few days ago has died. I think it must have been injured in shipping. It was a female. I think your promise to send another a very generous one, and I would appreciate it very much. In about two or three months I expect to order more birds of you. The others are doing excellently.-A. H. B., Massachusetts.

TRADE BEGETS TRADE. I have been instrumental in making some sales of pigeons for you. At least I have recommended you to several people who said they would buy of you. Did a doctor of Fairhope buy a lot of pigeons of you? He came over here to see me about what I thought of the business and I recommended you to him strongly. I just sold 30 pair of my pigeons to Dr. O. F. Cawthon and E. J. Buck and I recommended them to buy 10 or 12 pairs of you. I will continue to advertise you all I can. Later on I want to rearrange my house and build up a big place and I will send to you for what I need. -M. O., Alabama.

GOOD INCREASE IN SIX MONTHS. Yesterday I wrote you for the Manual or National Standard Squab Book, but I forgot to tell you of some of your birds I have seen. Last August or September a doctor friend of mine in Brunswick bought of you six pairs of Homers. In two or three weeks they began to lay and hatch. He sold four or five pairs at $\$ 1.00$ to $\$ 2.00$ a pair. He has now betwcen seventy and eighty total. They are beauties and if mine are as pretty and do as well I don't think I will be disappointed. Please send Manual as quick as possible.-G. S., Georgia.

GOOD RECORD FOR FIRST MONTH. I deem it will be gratifying if you know how the 13 pair of Homers I received from you on May $3 \mathrm{~d}$ are doing.

There has not been a sick one in the lot and they are very much admired by all who see them, and are pronounced first-class Extra stock.

They are contented and very busy all the time. Eight pairs are breeding now, with three nests each having a pair of nice healthy squabs. I think this a splendid record for the first month in a new home.-S. H. W., Pennsylvania.

LOST HIS TEXT BOOK. Please find enclosed 50 cents, and send me another National Standard Squab Book. I have mis-

Remember, these are stories told in 1906 , by customers who are really raising squabs with our birds and not merely talking about what they are going to do. They are getting satisfactory results day after day. 
placed my other one and can't find it. My birds are doing well. I have had 15 pairs of young birds since I had them. I sold one pair of old white birds for three dollars to a bird store.-H. K., Missouri.

ATTRACTING ATTENTION. Please to send some literature to address of gentleman enclosed, descriptive of the squab business, and give him prices on same. I have been talking with him in regard to the business and as he has a couple of farms over in Michigan, I have no doubt but what he will make an investment.

The pigeons that I purchased of you last spring are doing very nicely. Our pen is attracting considerable attention. We have about 75 in it now and we are about to build larger accommodations.-T. T., I1linois.

ENLARGING PLANT. Will you kindly advise the address of party who purchases pigeon manure?

My birds are getting along very nicely. Intend putting up a large house for them in the near future and will write you later regarding wire for flies.-B. T., New York.

SWAMPED WITH SQUAB ORDERS. It is impossible for me to fill the orders that I have for squabs. I am sending you an order. Please get them out as soon as possible. When I receive them, I will order another dozen Extras. I now have about 350 pair of breeders. They are doing fine.- H. S., Louisiana.

SATISFIED WITH ALL. I received the two baskets containing 36 birds on Thursđay. Pardon delay in not answering sooner, as I was out of town. I am perfectly satisfied with all the birds I bought of you and hope to be able in the future to secure more. Am shipping the two baskets this morning by National express, homeward bound.-J. W., New York.

GOOD REPORT. Please find enclosed a money order for which please ship me 12 pair pigeons as I saw some birds which you shipped to $\mathrm{Mr}$. Walter of this town. I received a booklet from your firm some time ago but did not order birds until I saw Mr. Walter report on his. I decided to give you an order if you can send me mixed colors. Ship via Adams express. Wishing you success.-L. D., Pennsylvania.

ONE YEAR'S GOOD TRIAL. Qucte me prices on your No. 1 Homers. Those I bought of you one year ago are doing nicely. -C. M. R., Pennsylvania.
THIS LETTER WAS WRITTEN BY ONE OF OUR CUSTOMERS TO HIS FRIEND IN A NEIGHBORING TOWN. I am pleased to know that you are getting along so nicely with your squab house. Wish you could see the last consignment of birds I received from the Plymouth Rock Squab Co. of Boston. They are beauties, and they commenced building their nests the second day after they arrived. I have no idea where you are going to purchase your birds but I certainly think you will make no mistake if you get them from Mr. Rice, for the ones he sent me are the finest I ever saw.

I am confident if you buy your birds of $\mathrm{Mr}$. Rice he will use you right for he has done the right thing by me.-F. B., New York.

WANTS 500 PAIRS IN THE SPRING. MY pigeons are doing very well but they are shedding a great many feathers. I want to make arrangements early in the spring for 500 pairs of your best stock, but before building my houses I want to take a trip to Melrose and look your plant over, in order to get all the ideas about construction, maintenance, etc. I enclose separate slip with a few questions that I would like to have you answer if it is not too much trouble.-J. W., North Carolina.

LOST ONLY ONE BIRD, AND THAT BY ACCIDENT. I recently bought a few pairs of birds that you sold to a gentleman in this city about March 1st. He was moving to St. Louis and had to dispose of the birds. With what I got from you and the seven pairs I bought from him I now have 65 birds. Have never lost but one bird and that was my own fault for I was experimenting on it and accidentally killed it. I have a market in St. Louis for all I can ship at $\$ 4.00$ per dozen. If not asking too much would you kindly give me the address of a couple of Chicago and New York commission men that handle squabs.-W. E. T., Missouri.

STARTED WELL. I write you in regard to the pigeons you will remember we bought of you (24 pairs) about two years ago this month. Our Homers have done very nicely. I have about 200 pairs. We sold 40 pairs last year. We have quite a nice little plant started.-A. C., Wisconsin.

DOING WELL, GOING TO BUILD. Please send me a plan for your multiple unit house. My pigeons are doing fine.-D. B., Illinois.

STARTED IN TO MAKE REFORMS. Please find enclosed check for nine dollars

Somebody handling the small, stunted Homers may tell you that eight pounds to the dozen is good weight for squabs and that squabs are not bred to weigh more from Homers. That is true, from his Homers. In these pages you will find that eight pounds is low for Plymouth Rock Homer squabs. 
tor which kindly send us one dozen drinking fountains. We would like you to get these off as soon as possible.

I was very much pleased with my visit to your plant at Melrose which I made yesterday, especially with your facilities for mating birds up. Got some new ideas along with a lot of good advice from your superintendent, and to-day have started in to make a few new reforms here.-T. H. D., Connecticut.

KNOWS PLYMOUTH ROCKS BY EXPERIENCE. I saw your advertisement of Homer Pigeons in a magazine. I would like very much for your company to send me one of your catalogues, and how much you charge for Homers a pair. I know from experience that a Plymouth Rock Homer is a good breeder. A friend of mine got some from your people a short time ago, but I did not inquire as to the price of them. In answer to letter from you, I will send for some, and if they are satisfactory, I will be glad to get more, as I am a great pigeon fancier.-W. A., Illinois.

ONE YEAR'S SATISFACTION. Send one bushel of Kaffir corn and one bushel of Canada peas to me. It mav interest you to know that the birds I bought from you a year ago are in every way satisfactory. I have doubled the number of workers in that time and have had all I wanted for my own table, and sold quite a number.-J. B. H., Massachusetts.

SOME WEIGH 14 OUNCES WHEN 15 DAYS OLD. I received your pigeons in May when I was in Longueuil. They have done well, as I have had some which weigh 14 ounces at 15 days old. What do you think of a mirror in my squab house? I will be very pleased to receive all your advertising booklets.-G. C., Canada.

SUNFLOWER SEEDS ARE GOOD. Your book doesn't say anything about feeding pigeons sunflower seeds. Will they eat them or isn't it good for them to have them? Please let me know. The pigeons I got from you are doing pretty well, I think. I may get more next year.-B. J., Vermont.

Answer. Sunflower seeds are a good pigeon food and are used by many of our customers. They are rich and oily and should not be fed in excess, but as a dainty. A good way to feed them is to throw the whole head in front of the birds and let them pick out the seeds themselves with their bills.

BREED WELL IN CALIFORNIA. Enclosed find money order for 40 cents for which kindly send me two feet of your aluminum tubing for bands. Also send one of your price lists, as mine has been mislaid. Twenty-four pairs of Homers purchased of you one year ago are doing fine. Flock now numbers 150.-W. J. M., California.

CONTINUOUS SATISFACTION. Enclosed find check which is to cover enclosed order. All the birds which you have sent me so far are very satisfactory.-G. S., New York.

FINEST BIRDS AROUND. Your birds I bought of you a year ago are going fine - the finest birds around, so my friends say.-Mrs. J. J. M., Massachusetts.

HOTEL KEEPER RAISING HIS TABLE SQUABS. Am very glad to know that you were pleased with our menus and will continue mailing them to you from time to time if you do not object. I hope that the temptation will be strong enough to cause you to come to our city and look over our squab farm. I have been quite successful and have a fine lot of birds. It is more than likely, however, that I shall want some additional birds in the very near future. I would like a few show Homers, Dragoons and Runts For squab raising purposes, I could not ask anything better than I now have. Will mail you an order for supplies in a few days.-W. S., Georgia.

BEAUTIFUL, HEALTHY BIRDS. Will you please quote me the price of your wicker shipping baskets, size for 12 pairs, or kindly forward me the address of the manufacturers of same. Also state in your letter if the droppings must be entirely free from straw and feathers, or reasonably so, to satisfy the purchasers at the tanneries. The six pairs I purchased of you two years ago have increased to 150 or 170 , besides what I have killed, and the stock has proven entirely satisfactory in every way. I have taken pains to follow your instructions to the letter so now I have the above number of beautiful, healthy birds.W. H. Y., New York.

Answer. It is impossible to get all straw and feathers entirely out of the manure. Sweep out what you can with a broom before cleaning the squab-house. The leather people do not care if some straw and feathers get in but they do not want gravel and tobacco stems. The latter discolor and stain when wet.

BIRDS THAT FLY AWAY. On about April 20,1905, we bought of you six Plymouth Rock Homer pigeons. Since then they have

For six years we have had a complete monopoly of the fine trade of the United States. We sell more Homers every year than all other firms and breeders combined. The reason for this is that our birds demonstrate their value and make friends wherever they go. This supremacy we intend to maintain. 
done exceedingly well, and we have got a pretty good start in pigeons now, but what I write you to-day for is this." This morning at 9 o'clock one of the birds we got of you got out of the flying pen. She flew into the air and started for Boston. This was a brown bird, and we thought she might arrive at her destination, so I wish you to keep a lookout for her and see if you can tell if she gets there. If she does arrive, would you mind letting me know? I am anxious to know if she gets there. This was a female bird and she left a young bird about a week old in the nest. R. H.. Iowa.

Answer. No Homer would fly that distance. We receive many letters like the above. Customers should watch the doors of squab-house and pens and not let their birds get away.

LARGE, HEAVY AND FULL-BREASTED. Enclosed find money order for one more dozen pairs of your Extra Plymouth Rock Homers.

I did not rush a letter down to you the same afternoon I received the other birds for the reason that I wanted to try them out first. The dozen pair of Plymouth Rocks, on their arrival weigned exactly 22 pounds, while a few days later I received another dozen pair from another company and they weighed only 17 pounds. They were not full-breasted like your birds.

I received first shipment on the 2 nd of March. They are now working like good fellows. Have three nests with eggs in.

You will hear from me occasionally with further orders.-A. P. S., Michigan.

WANTS TO BUY SOME GOOD ONES. Kindly send your catalogue and any other printed matter you have about pigeons. An acquaintance wants to buy some good birds and he is going to look at my lot that I received last Thursday. I feel sure I can land him as a customer for you.-H. D. C., Pennsvlvania.

GOING SLOWLY. Please send free book, "How to Make Money with Squabs." The birds bought of you are doing well now and some of their young are hatching. Have enough now to ship a dozen a month now.W. M., Maryland.

JUST THE BIRDS. I thought I would let you know how my birds are getting along. They arrived on Tuesday, May 1st, as I wrote you. Thursday of the same week one pair had commenced to build. At this writing four pairs have eggs. The others are building. That is what I call going right to work.
I am very much pleased with them. There was a party here this morning looking at them. He talks of putting in one hundred pair, and says they are just the birds that he wants. He is coming up to see your plant. Of course I showed him my birds and told him just what they were doing and where they came from so I think he will be a customer for you. I shall advertise the Plymouth Rock birds wherever I have a chance. Thankyou for your kindness.-J. C., Nerw Jersey.

SOUABS WEIGHING ONE POUND APIECE WHEN ONE MONTH OLD. I received my pigeons from you April 20, 1905. I have one pair that has hatched eleven (11) times up to the 22 nd day of April, 1906, so you can see that they have had fairly good care. I now have 110 birds and am getting them fast now and will commence shipping when I get 70 or 80 . pairs. I have weighed a number of birds four weeks old that weighed 16 ounces and I think that is very good.--L. F., Iowa.

QUICKLY AT WORK. Please pardon my delay in acknowledging the receipt (right side up) of the pigeons you shipped to me at Harpers Ferry, W. Va., which place I left before the shipment arrived. My wife informed me that they were all in good shape and the finest specimens she ever saw. Also thought they had returned the baskets to you. As soon as I go home, which will be in a few days, will send you another order. My wife's third letter tells me that 16 pairs out of the 18 have gone to setting. Dor't think you can beat that at home. We have everything good to feed them, peas, kaffir corn, wheat and millet, and we intend to make a success of the business.-W. S., Virginia.

SQUABS HAVE AVERAGED ONE POUND APIECE. Enclosed please find certified check for \$173.98 for which kindly send me birds and supplies as enclosed. Kindly send the shipment of birds as soon as possible as I would like to receive them before Tuesday. All my birds are doing nicely. My squabs, under your system of feeding, have averaged a pound apiece and I expect from the present outlook of things to make them average a good deal more.-E. H. M., Pennsylvania.

THIS WOMAN IN BRITISH COLUMBIA KNOWS WHAT A FINE HOMER IS. A week ago I wrote you complaining of nonacknowledgment of my remittance sent in with my order. As I was beginning to wonder if it had miscarried. I am pleased to be able to inform you that I received the best possib!e answer to my letter in arrival of the birds I ordered from you. They arrived

The equipment at our farm for mating birds cost $\$ 2000$ and no expense was spared to make it perfect. A thousand mating coops are in constant use. The principal mating house is heated by hot water so as to get the best and quickest results in the cold months. 
about the same time as your letter (May 1st). All of them are in first-class condition and $\dot{I}$ am very pleased with them, as I consider that they are a fine lot of birds, and I think I know what a fine Homer is when I see it, as my father and brothers have bred and sold trained flying Homers for years in Lancashire, England, some of them worth twenty-five dollars a pair. Although I never heard of squab raising before I came to Canada three years ago, when I first saw your book advertised in Munsey's I thought it was some kind of game bird reared in captivity. and sent for your book more out of curiosity than anything else. I think I shall like the business very much and shall probably be sending another order in a month or two when I see how I go on with the birds I have got. Thank you very much for the two pairs extra you sent, also nest bowls. They were a very agreeable surprise to me as I did not expect anything like that on such a small order. The express charges were six dollars, and 25 cents duty on nest bowls. If you would write me from time to time giving me your prices I shall be much obliged.-Mrs A. R., Canada.

SQUABS WEIGHING FROM 13 TO 16 OUNCES. Please send me at your earliest convenience the names of reliable merchants to whom I can ship squabs, in New York. The 80 pairs I bought of you last fall are doing well. I sold squabs that weighed from 13 ounces to almost one pound apiece. I have over 100 pairs of young ones that I am saving for stock.-H. J., Ohio.

WORTH THEIR PRICE. Sorne time ago I sent you an order for three pairs No. 1 and three pairs Extra Homers, stating that I wished to compare with Homers a friend of mine was ordering at a very much lower figure. In a word, after due comparison, I order six more pairs Extras. Please send me fine birds.-C. J., Illinois.

SQUABS WEIGHING 16 TO 17 OUNCES EACH. Please find enclosed remittance for which send me 12 pairs and supplies noted. The dozen pairs you sent me started in to do business last month, having been moulting up to that time. The first two pairs squabs hatched, at one month old, weighed one pound each, with one that was 17 ounces. That is very good, is it not? I am well pleased with them. Make this dozen as good and I shall be more pleased.-C. B. G., Connecticut.

HIS FOURTH ORDER. Enclosed you will please find money order for which you will please send me as soon as fossible one dozen pairs Extra bred Homers (fourth order.)-L C., Louisiana.

SUPERIOR IN LOOKS AND WORKS. The birds (60 pairs) arrived on the late train from St. Paul on Sunday night last, and remained in the depot here until early on the following morning when we took them home Outside of the injured ones mentioned, I will say that the birds arrived in perfect condition and are fully up to what we expected them to be. They are now " at home" and present a beautiful appearance. The birds which you sent me last November (nine months ago) are entirely satisfactory, and "out-class" any I received from the- or those which my friend here received from the same people. Mine are plump, his are " cranish," long-legged and long-necked. I would not keep that kind of birds. My friend has not accommodations for pigeons, and wanted to sell out. A doctor who for several years rented offices in my law office building here, looked them over with the view of purchasing the outfit, and I advised him to do so, to get a start in the business. He visited my lofts, and saw my birds, wanted to buy some from me, and after he saw mine, he would not buy of my friend. I gave him your address, but have not seen him since, and do not know whether he has made a purchase or not. I have none to sell at this time as we are trying to increase the flock to at least 1200 , for which we have ample accommodations, then we will begin to sell.

There is no mistake in saying that the birds which I received from you, out-class those which the- have sent here. If your $\mathrm{Mr}$. Rice should ever come to this country I would be pleased to have him stay with me and look over the "greatest" farming country on earth.

My elder boy (17 years of age) visited the great Minnesota State Fair. Saw Dan Patch break his record, reducing it to 1.55 flat. He looked the pigeons over as a matter of course, and he tells me that he could find no Homers there which compared with ours. He intends to exhibit some at the fair next fall.-H. M.; Minnesota.

MADE A SUCCESS AND GOING AHEAD ON A BIG PLANT. I have a party that wants to go into the squab business with me, and it is possible that I will call on you during November for 2000 breeders. I have done very well with the 800 I have, encouraging enough to put in quite an extensive plant. I would like to have your personal opinion as to whether 2000 birds will do as well in 20 units of 100 birds each with one fly $12 \times 48 \times 200$ as they would in 20 units with 20 flies $10 \times 12 \times 48$. On

Our whole time and energies are given to squabs. We handle trade as it ought to be handled-promptly, courteously and thoroughly, with every detail attended to. Letters are answered at once. It is a business with us, pushed steadily every day in the year except Sundays and holidays, and not a side issue or an amusement. 
account of labor I would prefer the one large fly, but I want no experiments and leave the matter with you. I can get $\$ 4.00$ per dozen for a large portion of my squabs, and would like to have an opinion as to what 5000 of your breeders would net us yearly when we raise our own feed on the farm.

WE SUPPLY HENS TO THOSE WHO NEED THEM. After recommending your firm to A. F. Kennelley of this city and he being a purchaser from you recently, I find that he is well pleased with treatment accorded him. Enclosed please find $\$ 5.00$ for five female birds to be used as breeders. I bought some birds from a friend of mine and he had five odd cocks which I want to mate up. You will forward these by first express to my address.-H. E. W., Ohio.,

BEST BIRDS HE EVER SAW. The Homers ordered from you reached me in due time and in excellent condition. They certainly are the finest birds I ever saw. I really believe they are a finer lot than the first consignment, if that be possible. The second day after their arrival they commenced building their nests, which I imagine is a pretity good record.

Some of my friends have secured birds from other parties and although I have not seen their birds, I am confident they can't tell me that they have a finer lot than mine.

If I have an opportunity of securing you any customers I shall be only too glad to do so.-B. Y., New York.

BEST HOMERS IN CALIFORNIA. Birds received in A1 condition. Your birds have stirred up quite some interest here and what I hear from people who know is that your birds are the best in the colony. As it is I am well pleased with the bunch. I have a house $12 \times 32$ feet divided into four pens $8 \times 9$ feet with. a three-foot passage running the length and everything up to date. That also has opened their eyes in the building and arrangements in an up-to-date squab house. I have had the birds less than a week and am pretty well advertised already. The market here is strong at $\$ 3.00$ to $\$ 3.50$ and the demand far exceeds the supply.-C. H., California.

SOLD YOUNGSTERS FOR \$2 A PAIR IN KANSAS. Enclosed find remittance for one leg band outnit. My pigeons have been doing fine, and are keeping busy all the time. Have sold off the young pigeons at eight weeks old for $\$ 2.00$ per pair. What is the difference in Canada peas and the peas we raisc here? Will the common peas do to feed to the pigeons?-G. W. S., Kansas.
LATEST NEWS FROM THE NEW YORK MARKET; HIGH PRICES WHICH ARE GOING HIGHER BECAUSE OF THE NEW LAW FORBIDDING ENTIRELY THE SALE OF QUAIL EXCEPT IN NOVEMBER AND

DECEMBER. I take the liberty of asking you for a little more advice for the birds I bought from you last November. Of sickness I have not seen any sign of it. I lost only two of them, one of apoplexy I think, because it fell like shot dead, the other one died of diarrhoea. Of the young squabs, the casualties have been a little higher, but out of 50 I did not lose more than six, or 12 per 100.

Now I wish you would give me your opinion how I have progressed, if I am on the regular average or if $\mathrm{I}$ am under it.

The prices for squabs on the New York market have been very high all winter-have reached as high as $\$ 6.50$ a dozen for squabs of over 10 pound a dozez, and $\$ 4.50$ for birds of near eight pound or so. Of course private trade is better and I have been able to sell squabs for 50 cents apiece easily.

I have a set of birds that give me three eggs and have hatched them successfully with three days late for the extra one. Does that happen often?-H. G., New York.

\section{WILL NOT BUY ANY HGMERS BUT} PLYMOUTH ROCKS. Last May I ordered from you twelve Plymouth Rock Homers. They arrived on the eighth of May and on the twelfth of the same month the first egg was laid. Five pairs of them went to work almost immediately and have been at work ever since. I raised the squabs during the summer. I have now 13 pairs of mature pigeons. Twelve pairs work constantly and I am. very much pleased with them and want to thank you for them and as you are so kind as to offer to answer questions and to help we people who do not know all about raising squabs I shall be so much obliged if you will give me a little help. My present ambition is to increase my plant. I want to buy some Extras from you as soon as I can raise the capital. I can buy Homers nearer home but yours have done so well for me that whatever new stock I get I would like to get from you. Yous say in 'your book that you will give your patrons the address of a good New York buyer. Will you please send me the address?-C. O., New Jersey.

BRANCHING OUT. Please quote me your best figures on the following: Homer pigeons in pairs ready to go to work in lots of 20,50 and 100 pair lots. Hempseed in bushel lots. Health grit in 100 pound lots. I have your prices of last year but presume there are some changes. I purchaser 12 pairs of Homers from you last spring and they raised me about

These are strong letters. Read them over. You want some assurance, when you buy pigeons, that you will be treated right, as these customers were. 
60 young ones by the first of November.R. W. H., Iowa.

BLOOD AND HIGH BREEDING COUNT. Enclosed find draft for which you will send by Pacific express, Extra Homers, as per memorandum. Several weeks ago I ordered 15 pairs of - - When the birds came I did not think they were much more than common birds. A friend in our town wanted sonie breeders and I got him to try your birds. They came last night. There is a big difference between the birds. My first birds do not show any white on bill to amount to anything and they are most all white or very light color. Yours show their high breeding. Blood tells, when you put them together. I sold mine at half price to-day to get shut of them. What I want is blooded stock or nothing. Please send me a good collection of assorted colors, blues, reds and checkers. I ordered one of your squab books some time ago and I think it the best I ever read on pigeons.-J. A., Missouri.

TRIFLING DEATH LOSSES. In January of this year I purchased 12 pairs of your Extras. They are now (April) in fine condition and have hatched out 24 young ones, 22 of which are living and doing fine.-W. J., Massachusetts.

SEVEN PAIRS WOR T H \$25, THIS ARKANSAS CUSTOMER THINKS. 'Writing you a few lines to let you know that I got the pigeons all O.K. They were all well. I got them two weeks to-day and out of the seven pairs, four pairs of them have built and are setting on eggs already. I would have written you sooner but wanted to see what they were going to do. I would not take $\$ 25$ for the seven pairs. Sending the basket back this evening with the letter. You can put this letter on your list. I think it is the only one from Arkansas.-C. W., Arkansas.

GOOD SHOWING AFTER THEIR 3000MILE JOURNEY. Enclosed please find Wells Fargo Express money order for $\$ 1.70$ for which please send me by mail post paid, one leg band outfit at your very earliest convenience. My birds received from you March 17 are doing fine. They got right to work and one month from the day I received them I had three pairs of squabs hatch. Since then one more pair has hatched and two more pairs are sutting and two pairs building. I think that is a pretty good showing in six weeks for 10 pairs after travelling 3000 miles. I lost one hen. She got sick and I could not find what was the trouble. She did not have diarrhoea, but just seemed to droop and die. The remainder of them are as fine as could be.
Will you please quote me prices on nine pair Extra Homers to be delivered in June or July. Cannot tell yet just when I will be ready for them, but either June or July sure. Best wishes for your continued success.-E. M., California.

ARKANSAS CUSTOMER IS PLEASED WITH SQUARENESS. I received your Manwal a day after I wrote that letter, and I received another one. I have sold both of them, and find enclosed $\$ 1.00$ to pay for your extra one and another one for myself. You people treated me so well I won't buy any Homers from anybody else. I was surprised at your squareness and have told every one about it and got them all a-going in the right direction. I was very, very much pleased with your Manual.-G. R., Arkansas.

HIS MONEY TALKS FOR HIM. Last August I purchased 124 pairs of your Extras and am now in the market for about 375 pairs more. I am also in need of some extra hens of the same quality. Can you supply same? Also let me know if you can furnish these birds in pairs in the following colors: blues, blue checkers and red checkers in any number I may desire. Please state your very lowest price on above number of pairs. Let me hear from you by return mail, as I am in a great rush for the birds. $-\mathrm{S}$. T., Indiana.

CANNOT SAY TOO MUCH IN PRAISE OF OUR HEALTH GRIT. Enclosed find $\$ 2.00$ for 100 pounds of health grit. I find this grit the best on the market for pigeons. I cannot say too much for it as it keeps the pigeons in fine health. Although the price is high I would never be without it. I have quite a few people that want to get this grit from me. Can you let me have it cheaper, so that I can make something out of it? Answer and let me know.-R. O., New Jersey.

\section{BIG SOUAB FARM WHOSE OWNER} BOUGHT HIS BREEDERS OF US. I visited a squab farm last Sunday and before I left found that the owner bought his breeders of your company, five hundred pairs. He has 1100 pairs at present and is making a fortune. After seeing this farm I was more than convinced that the Plymouth Rock Squab Co. is $\mathrm{O}$. K. If I get as good a lot of birds as he has I certainly will be pleased.

I am sorry that I did not figure on handling more birds than I did. Have built house to accommodate 100 birds. Enciosed find stamps for which please send plans and specifications for squab houses. No doubt you will receive a larger order from me in a short time. Will notify you in a few days when to ship birds.

Beware of anybody who tries to make a sale to you by running down the Plymouth Rock Squab Co. Insist that he show you letters like these in proof of his claims. 

THE PLYMOUTH ROCK SQUAB COMPANY OF BOSTON IN NINE MONTHS OF 1906.

I want to have everything complete before $\dot{I}$ have them shipped.-I. S., New York.

HAS TRIED THEM AND KNOWS. I am at present debating with myself and with some of my relations in regard to starting in the pigeon business. My folks are trying to persuade me that it is going to cost too much to start, and that I will not realize any great profits very soon. As I see, and at the best I can figure it out, it will take about $\$ 100$ to start in with fifty pairs of breeders and build a home to accommodate them, getting the price of building down as low as possible with lumber at its present price. What I want to know is, do you think it would pay me to start and about how long do you think it would take to get back the amount paid out if I relied entirely on the birds?

I think I could get it back in four months at the most, because I have three pairs I purchased of you in January, besides the young ones I have raised. I have watched and studied their ways and know something about them. I know how fast they breed, etc. Now am I right in my estimation as to the time it would take to regain my money and would you advise me to start if possible? My birds I have now are doing fine.-S. A., Massachusetts.

MANURE FOR SALE. Will you please give me the address of some firm to which I can sell my pigeon mallure? My pigeons are doing well this spring.-T. O., New York.

RHODE ISLAND SUCCESS. I am enclosing money order for which kindly send me enclosed supplies. If this money order does not cover cost do not delay the grain but send me bill for extra. My birds are all doing finely.-B. O., Rhode Island.

THIS IS THE KIND OF PLAIN TALK ONE LIKES TO HEAR. I am finding out for myself if there was money in squabs and I have found it to be true by other squab breeders. I was to a man's place this afternoon and he said he had no trouble in selling his squabs for a good price. I guess the only trouble is people are sleeping half the time. That's why they don't know much about squab breeding. If a fellow doesn't believe in squab breeding, all he has to do is to open his eyes and look around. I've been to a couple of bird shows and have seen nothing to go ahead of your birds yet. My friend was saying what nice birds they had at the show, and I thought I would go down with him. We had to pay 25 cents to get in. After we looked at the birds, he said that mine would get the first prize if I would take them down. Then I found out that I have some of the biggest birds in town. I would like to get some pictures taken and show you some of the birds I got from yours. I found your book to be a book anybody can read and knows what he is reading about. Everything is so plain-what a beginner wants to know about breeding birds. I was thinking of sending you my third order. If I do, it will be next week. Hoping you are doing a good business. My birds are doing fine. Your birds are the best breeders and I won't take any others.-S. C. H., Wisconsin.

NEST BOWLS ALL RIGHT. Please find a money order for one dozen more of your nest bowls. They are O. K. Put them in the house one evening and on going in the next found that a pair had already taken possession and started a nest. Have 11 pair setting on eggs and they are doing fine. I intend to purchase more from you later as I am going to build a unit to start this spring and enclose money for your plans for squab houses. Wishing you every success.-W. A., Massachusetts.

ENLARGING. Enclosed find check for which please send me seven pairs of your Extra Homers and one dozen fibre nests. Send by American express. This time I would like to have different colored birds. The birds and supplies you sent me in January came in good shape. I was well pleased with same. Am thinking some of putting in 50 or 100 pairs more this summer if I can arrange for another house.-H. B., Indiana.

BEST EVER SEEN IN OKLAHOMA. Enclosed please find money order for which send me your best Extra Homers as specified. Send all blue-speckled birds, as shown on right of special offer sheet. Your last shipment of birds are fine ones and every one that has seen them say they are the finest they ever saw. Trusting these will be the same or better and that I may receive them at your earliest convenience.-W. H., Oklahoma.

BUYING MORE AFTER ONE YEAR'S EXPERIENCE. A little over a year ago, I bought 24 pairs of your pigeons. Now I wish to buy 300 pairs of your Extra Plymoutl Rock Homers and am fixing a house for them and will be in shape to receive 75 pairs a month, say March 1, April 1, May 1 and June 1. I see that $\$ 1.70$ per pair is your price in lots of 300 pairs and upwards. I should want the best birds as I believe they are the cheapest. Now if this arrangement is all right, you can let me know and I will send you $\$ 127.50$ for the first 75 pairs. I want your best birds.-E. F., Ohio.

Is there anybody in your town who has failed at squab raising? Some play at pigeons as they would with a new toy, then give them up. If they bought of us the trouble is with them and not with the pigeons. 

FEB 11907 

